EUDES JOSÉ ARANTES

\title{
CARACTERIZAÇÃO DO ESCOAMENTO SOBRE VERTEDOUROS EM DEGRAUS VIA CFD
}

Tese apresentada à Escola de Engenharia de São Carlos da Universidade de São Paulo para obtenção do título de doutor em Engenharia Civil na Área de Hidráulica e Saneamento.

ORIENTADOR: Prof. Assoc. Rodrigo de Melo Porto.

São Carlos

2007 
AUTORIZO A REPRODUÇÃO E DIVULGAÇÃO TOTAL OU PARCIAL DESTE TRABALHO, POR QUALQUER MEIO CONVENCIONAL OU ELETRÔNICO, PARA FINS DE ESTUDO E PESQUISA, DESDE QUE CITADA A FONTE.

Ficha catalográfica preparada pela Seção de Tratamento da Informação do Serviço de Biblioteca - EESC/USP

Arantes, Eudes José
Caracterização do escoamento sobre vertedouros em
degraus via CFD / Eudes José Arantes ; orientador Rodrigo
de Melo Porto. -- São Carlos, 2007.
Dissertação (Mestrado) - Programa de Pós-Graduação e
Área de Concentração em Hidráulica e Saneamento -- Escola
de Engenharia de São Carlos da Universidade de São Paulo.
1. Engenharia Hidráulica. 2. Canais com degraus. 3.
Eluidinâmica computacional. 4. Escoamento aerado. 5.
Escoamentos turbulentos. 6. Cavitação. I. Título.


FOLHA DE JULGAMENTO

Candidato: Engenheiro EUDES JOSÉ ARANTES

Tese defendida e julgada em 20/04/2007 perante a Comissão Julgadora:

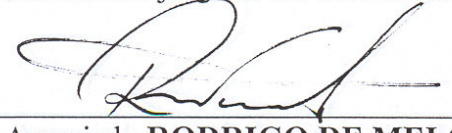

Prof. Associado RODRIGO DE MELO PORTO (Orientador)

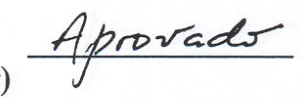

(Escola de Engenharia de São Carlos/USP)

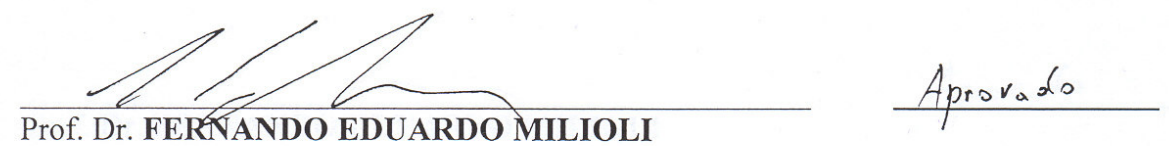

(Escola de Engenharia de São Carlos/USP)

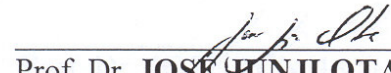

APROVAOO

(Universidade Federal do Paraná/UFPR)
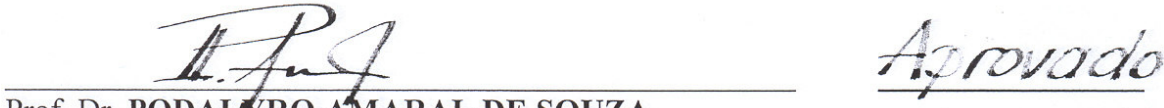

Prof. Dr. PODALKRO ÁMARAL DE SOUZA

(Escola Politécnica/USP)

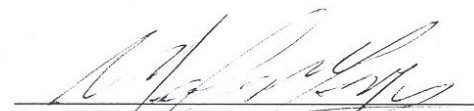

Prof. Dr. MARCELO GIULIAN MARQUES

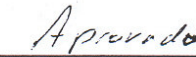

(Uniyersidade Federal do Rio Grande do Sul/UFRGS)

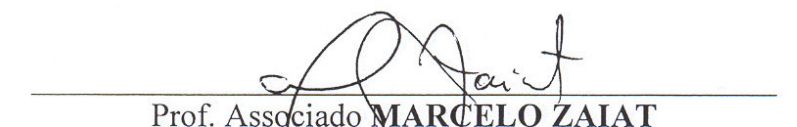

Prof. Associado MARCELO ZAIAT

Coordenador do Programa de Pós-Graduação em Engenharia (Hidráulica e Saneamento)

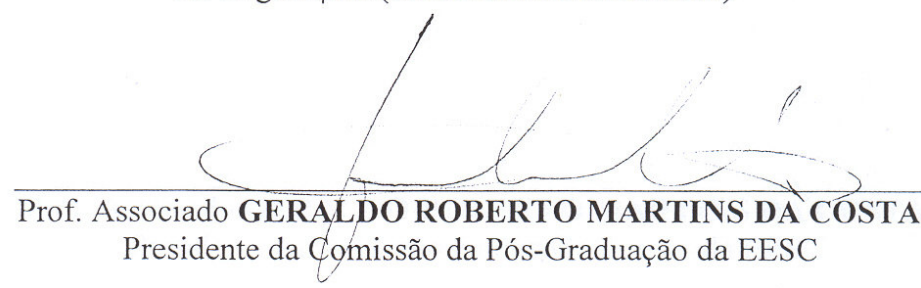


"Se tratti di acqua anteponi l'esperienza allá teoria." (Leonardo da Vinci) 


\section{DEDICÁTÓRIA}

À minha família, em especial à minha amada esposa, Elisângela, à minha querida filha, Caroline, que alegra nossas vidas e aos meus queridos pais, Mário e Bernadete. 


\section{AGRADECIMENTOS}

Ao Prof. Assoc. Rodrigo de Melo Porto, meu orientador, pelos ensinamentos, apoio, dedicação. Ao Prof. Tit. Fazal Hussain Chaudhry pelo início da orientação. Ao Prof. Tit. Harry Edmar Schulz pelas sugestões e contribuições. Ao Prof, Tit. José Cuminato pela disponibilização do Cluster e também contribuições na pesquisa. Ao Prof. Dr. Edson C. Wendland pela disponibilização do Laboratório de Hidráulica Computacional. Aos funcionários da USP: André, Roberto, Rose, Pavi, Sá, Sônia, entre outros. Aos meus amigos: Anderson, "Andréias", Ângelo, Antenor, Alexandre (Botari e Kleper), Carlos, Caruso, Cazuza, Christian, Fábio, Fernando, Francisco, Giovani(e), Gustavo, Keil, Klebber, Kid, Johannes, José Eduardo (Alamy e Quaresma), Leonardo, Lijalém, Lobão, Lute, Luiz, Marcos, Peter, Roberto, Ronan, Stênio, Tina, Velhinho, Zanqueta, Zozó e todos os que por ventura não tenha sido citados.

À Deus, que me dá saúde, a capacidade de me empenhar nas pesquisas e a felicidades de ter ao meu lado tantas pessoas amigas.

Além da dedicatória, agradeço minha esposa, minha filha e meus pais, por proporcionarem os melhores momentos de minha vida. Aos meus irmãos (Kátina e Marcel), minhas avós, minha sogra, meu sogro, meus cunhados, sobrinhos, tios e primos por fazerem parte de minha vida de forma especial.

À ESSS que por intermédio da equipe FORMULA SAE da EESC-USP disponibilizou a licença do CFX durante o primeiro semestre da pesquisa.

À Escola de Engenharia de São Carlos pela oportunidade de realização do curso de doutorado. À Fundação de Amparo à Pesquisa do Estado de São Paulo - FAPESP, pela concessão da bolsa de doutorado e pelo apoio financeiro para a realização desta pesquisa. 


\section{SUMÁRIO}

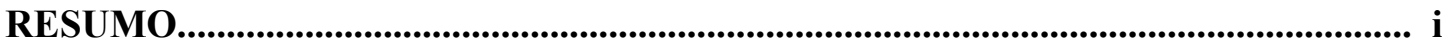

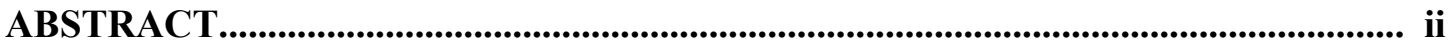

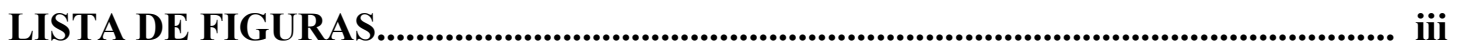

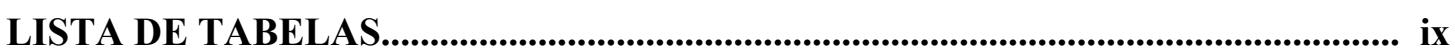

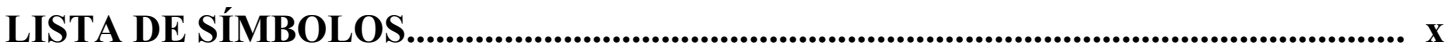

1. INTRODUÇÃ

1.1. Generalidades...................................................................................................................... 1

1.2. Objetivos do Trabalho..................................................................................................... 2

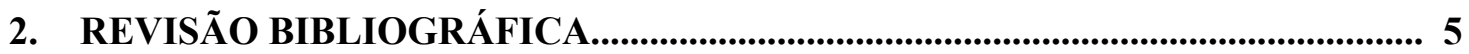

2.1. Considerações Gerais Sobre Vertedouros em Degraus.................................... 5

2.2. Regimes de Escoamentos em Vertedouros em Degraus....................................... 6

2.3. Análise do Escoamento Tipo Skimming (RAJARATNAM, 1990)................... 13

2.4. Características Hidráulicas no Escoamento Tipo Nappe..................................... 14

2.5. Perda de Energia em um Vertedouro em Degraus.......................................... 15

2.5.1. Regime de Escoamento Skimming - Dissipação de Energia................... 15

2.5.2. Regime de Escoamento Nappe - Dissipação de Energia......................... 21

2.5.3. Comparação entre os Regimes de Escoamento Nappe e Skimming...... 23

2.6. Aeração ao Longo de Vertedouros em Degraus................................................ 24

2.7. Distribuição de Velocidades.......................................................................... 31

2.8. Estudos Experimentais em Vertedores em Degraus no Brasil......................... 33

2.9. Estudos Numéricos do Escoamento em Vertedouros em Degraus.................. 36

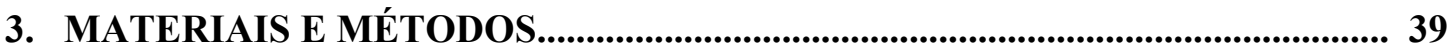

3.1. Modelagem Computacional.................................................................................... 39

3.2. Modelação numérica via "Computational Fluid Dynamic - CFD"................. 40

3.3. Escolha do Software............................................................................................................ 40

3.4. Equações Representativas dos Escoamentos.......................................................... 41

3.5. Equações da Média de Reynolds para Navier-Stokes. (RANS)...................... 42

3.6. Modelos de Turbulência..................................................................................... 43

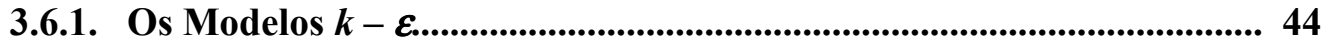

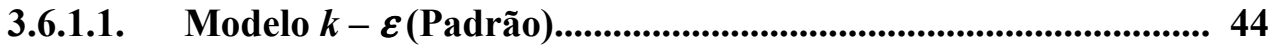

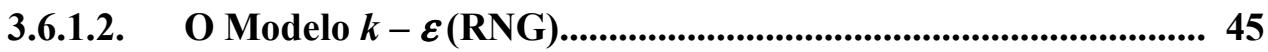

3.6.2. Modelos de Tensões de Reynolds.......................................................... 48 
3.6.3. Simulação de Grandes Escalas (Large Eddy Simulation - LES).......... 51

3.7. Modelos Multifásicos............................................................................................... 54

3.7.1. Modelo Não-homogêneo..................................................................... 55

3.7.2. Modelo Homogêneo................................................................................... 57

3.7.3. Transferência de Massa na Interface................................................... 58

3.7.4. Modelo de Mistura (Mixture Model)........................................................ 59

3.7.5. Modelo de Superfície Livre.......................................................................... 60

3.8. Discretização Numérica............................................................................................ 61

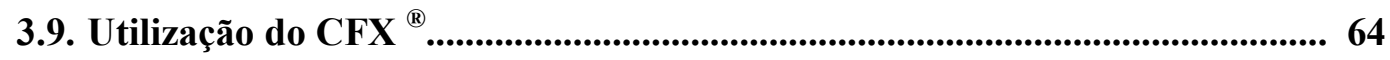

3.9.1. Geração da Geometria e da Malha............................................................... 64

3.9.2. Condições de Simulação.................................................................. 65

3.9.3. Acompanhamento da Resolução e Visualização dos Resultados......... 68

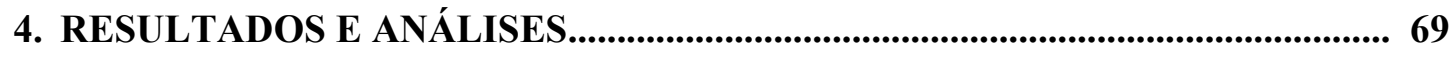

4.1. Considerações Gerais................................................................................................... 69

4.2. Estudo do Escoamento em Vertedouros em Degraus.................................... 70

4.2.1. Perfil de Pressão e de Velocidades................................................................ 70

4.2.2. Estudo da Perda de Energia em Vertedouros em Degraus.................. 76

4.2.3. Estudo Numérico da Caracterização do Escoamento em Vertedouros

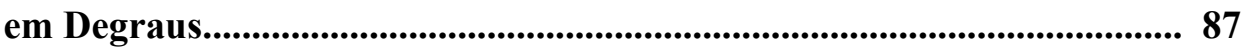

4.2.3.1. Distribuição das Velocidades do Escoamento............................... 90

4.2.3.2. Perda de Energia Específica ao Longo do Vertedouro.............. 93

4.2.3.3. Fator de Resistência do Escoamento............................................. 95

4.2.3.4. Posição de Início de Aeração do Escoamento.............................. 98

4.2.3.5. Estudo da Aeração do Escoamento................................................ 100

4.2.3.6. Estudo da Cavitação em Vertedouro em Degraus.................... 104

4.3. Estudo da Mudança de Escoamento do Regime Skimming Flow para Nappe

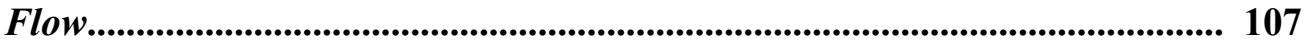

4.4. Aplicação de Ferramenta CFD em Escoamento em Canal com Forte Declividade............................................................................................................................... 108

4.5. Proposta de Aerador de Fundo no Início do Vertedouro.............................. 122

5. CONCLUSÕES E DISCUSSÕES............................................................... 131 
6. REFERÊNCIAS BIBLIOGRÁFICAS............................................................ 135

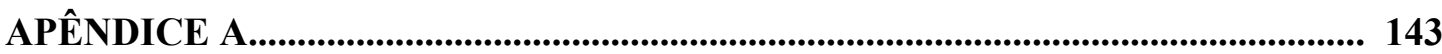

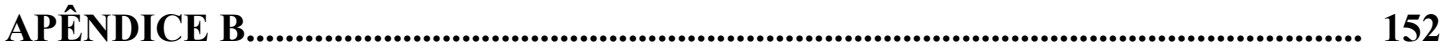

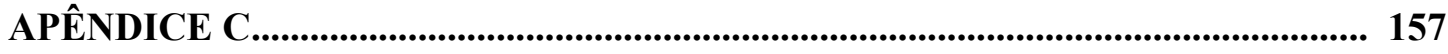

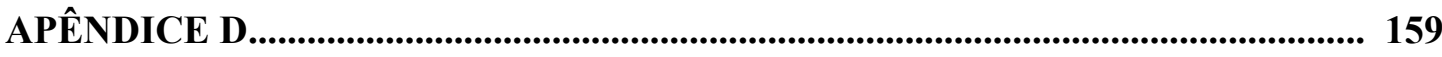

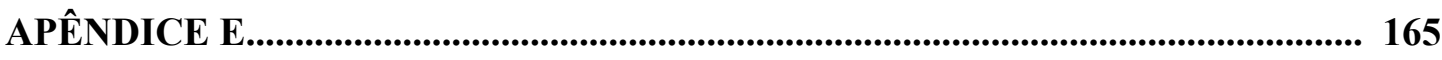

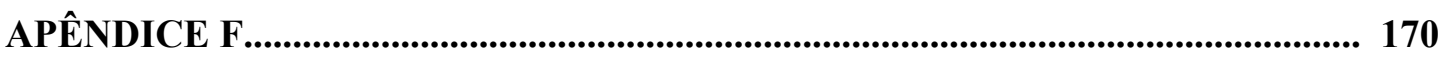

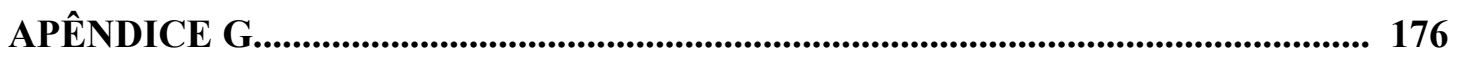





\section{RESUMO}

ARANTES, E. J. Caracterização do Escoamento sobre Vertedouros em Degraus Via CFD. 2007, 178 f. Tese (Doutorado) - Escola de Engenharia de São Carlos, Universidade de São Paulo, São Carlos, 2007.

Estudos do escoamento em vertedouros em degraus foram realizados experimentalmente por diversos autores, mas a utilização de ferramentas de computação numérica para a simulação destes casos ainda é muito escassa. Neste trabalho realizou-se um estudo da simulação numérica do escoamento sobre vertedores em degraus, utilizando-se um programa de fluidodinâmica computacional (CFD). As configurações geométricas e hidráulicas de alguns autores da literatura foram reproduzidas através das simulações em CFD. Com as simulações testaram-se as equações propostas experimentalmente ou compararam-se diretamente os resultados experimentais com os numéricos. As características dos escoamentos nos vertedouros em degraus que foram analisadas e comparadas são as seguintes: perda ou dissipação de energia, distribuição da velocidade, distribuição da concentração de ar, perfis de pressão do degrau, um estudo da resistência de atrito e um estudo da cavitação. Foram obtidas boas comparações entre os resultados experimentais e numéricos, desta forma, todas estas análises serviram, tanto para validar a utilização das ferramentas de fluidodinâmica computacional, como para caracterizar os escoamentos para uma possível proposta de melhora no desempenho desta estrutura hidráulica. Conhecendo-se o problema da cavitação, buscou-se uma solução para minimizar a ocorrência deste fenômeno no escoamento em vertedouro em degraus. Assim, foi realizado um estudo do escoamento em um aerador de fundo. Neste estudo do aerador de fundo foram caracterizados numericamente os perfis de concentração de ar, os perfis de pressão sob o salto do aerador, os perfis de velocidade e ainda foi realizado um estudo da vazão de ar que alimenta a aeração sob o jato do aerador. Após este estudo do aerador de fundo, uma nova de configuração geométrica foi proposta para o vertedouro em degrau, com a construção de um aerador de fundo no inicio do escoamento de forma a minimizar o risco de cavitação ou ainda aumentar as vazões máximas de serviço.

Palavras-chave: canais com degraus, fluidodinâmica computacional, escoamento aerado, escoamentos turbulentos, cavitação. 


\begin{abstract}
ARANTES, E. J. The stepped spillways flow characterization using a CFD tools. 2007, 178 p. Thesys (Doctoral) - Escola de Engenharia de São Carlos, Universidade de São Paulo, São Carlos, 2007.

Several experimental studies about stepped spillways flow were carried out by several authors, no ever the use of numeric computation tools is still very scarce. This work study numeric simulation in stepped spillways flow was carried out using a computation fluid dynamic (CFD) software. Several hydraulics conditions from the literature were reproduced through simulations by CFD tools. Those simulation results were compared with experimental results. The characteristics of the flow in stepped spillways were analyzed and compared focusing the following aspects: energy dissipation, velocity distribution, air concentration distribution, pressure profiles in the steps, friction resistance and cavitation. The numerical simulation results had a good approximation to the experimental results. All these analyses could be used to validate the use of the computational fluid dynamic tools, to characterize the flow for a possible improvement proposal of this hydraulic structure. The cavitation problem is the great challenge in thigh velocity flows. One solution to reduce the cavitation in the stepped spillways is the construction of a bottom aerator. A numerical study of a bottom aerator was carried out, focusing out of air concentrations, pressures under jet and velocity profiles. It was studied the discharge of air under the jet. As final result, this work proposes a new geometric configuration for stepped spillways with a bottom aerator. This bottom aerator was suggested to be set in the beginning of the spillway chute in order to reduce cavitation risk or to increase the maximum discharge in spillway.
\end{abstract}

Keywords: Channel in step, computational fluid dynamic, aeration flow, turbulent flow, cavitation. 


\section{LISTA DE FIGURAS}

Figura 2.1 - Esquema de nappe flow (a) e de skimming flow (b) 7

Figura 2.2 - Limite entre os regimes nappe flow e skimming flow para várias inclinações do piso dos degraus (Fonte: ESSERY e HORNER, 1978)..... 9

Figura 2.3 - Esquema para análise do início do escoamento tipo skimming flow..... 10 Figura 2.4 - Comparação de resultados experimentais com as posições teóricas para identificação do início do regime skimming flow (Fonte: CHAMANI e RAJARATNAM, 1999).

Figura 2.5 - Comparação dos regimes de escoamento em calhas com degraus (Fonte: OHTSU e YASUDA, 1999) 13

Figura 2.6 - Sub-regimes do escoamento tipo nappe: Escoamento nappe com ressalto hidráulico totalmente desenvolvido (sub-regime NA1); escoamento nappe com ressalto hidráulico parcialmente desenvolvido (sub-regime NA2) e escoamento nappe sem ressalto hidráulico (Fonte: Adaptado de CHANSON, 1994)...... 15

Figura 2.7 - Perfil Testado por Christodoulou (1992) - Dimensões em cm. 16

Figura 2.8 - Esquema de Notação. 17

Figura 2.9 - Variação de perda de carga relativa $\Delta H / H_{o}$ com $y_{c} / h$ e $N$ (Fonte: CHRISTODOULOU, 1993). 18

Figura 2.10 - Dependência de $\Delta H / H_{o}$ com $y_{c} / N h$ (Fonte: CHRISTODOULOU, 1993)........ 18

Figura 2.11 - Dissipação de Energia no escoamento tipo nappe. (Fonte: Adaptado de CHANSON, 1994). 22

Figura 2.12 - Comparação da dissipação de energia no escoamento tipo nappe e skimming (Fonte: Adaptado de CHANSON, 2002). 23

Figura 2.13 - Escoamento Ar-Água (Fonte: Adaptado de GONZALEZ e CHANSON, 2004)... 24

Figura 2.14 - Regiões do escoamento ao longo de um vertedouro em degrau com regime skimming (Fonte: Adaptado de MATOS e QUINTELA,1996). 25

Figura 2.15 - Distribuição da concentração de ar com a altura adimensionalisada: comparação com a equação 2.43 (Fonte: CHANSON et al 2002). 29

Figura 2.16 - Croqui para identificação das variáveis envolvidas na equação............................ 32

Figura 2.17 - Malhas gerada e utilizada na simulação (Fonte: CHEN et al, 2002).................... 36 Figura 2.18 - Superfície livre obtida pela simulação e experimental. (Fonte: CHEN et al, 2002). 36 
Figura 2.19 - Isolinhas de Pressão no vertedor em degrau (Fonte: CHEN et al, 2002).............. 37 Figura 2.20 - Vetores velocidade dos fluidos no vertedor em degrau e comparação entre numérico e experimental no Degrau №.7 (Fonte: CHEN et al, 2002). 37 Figura 2.21 - Vetores velocidade dos fluidos no vertedor em degrau (Fonte: CHENG et al, 2004). 38

Figura 2.22 - Concentração de ar em relação a altura adimensionalisada y/y90. (Fonte: CHENG

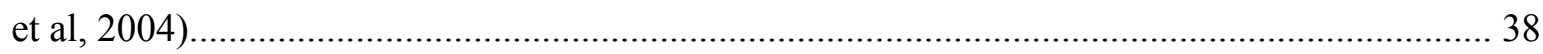

Figura 3.1 - Volume de controle para balanços de massa e de quantidade de movimento........... 41

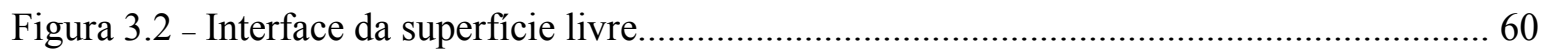

Figura 3.3 - Malha típica bidimensional (Fonte: Adaptado de CFX, 2004).............................. 62

Figura 3.4 - Elemento de malha isolado (Fonte: Adaptado de CFX, 2004)............................. 63

Figura 4.1 - Configuração geral do trecho do vertedouro simulado por Olinger (2000) - degraus

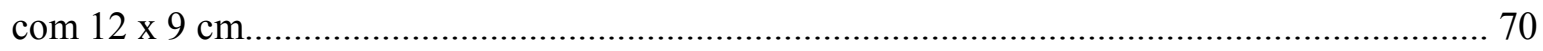

Figura 4.2 - Detalhe da Malha (Triangular-Refinada nas proximidades dos degraus)................ 71

Figura 4.3 - Detalhe da recirculação nos degraus (Tridimensional)........................................ 72

Figura 4.4 - Superfície Livre no escoamento sobre os degraus................................................ 72

Figura 4.5 - Perfis de velocidade sobre o degrau instrumentado (Ensaios 1, 23 e 4)................ 74

Figura 4.6 - Pressão nos degraus (Ensaios 1, 2, 3 e 4) ........................................................... 75

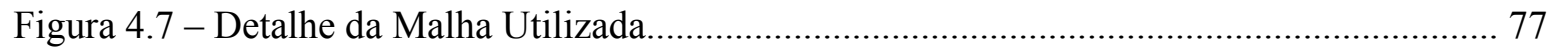

Figura 4.8 - Perfis da Superfície Livre Para: $y_{c} / h=1,377, y_{c} / h=2,186, y_{c} / h=2,864 \ldots \ldots \ldots \ldots \ldots .77$

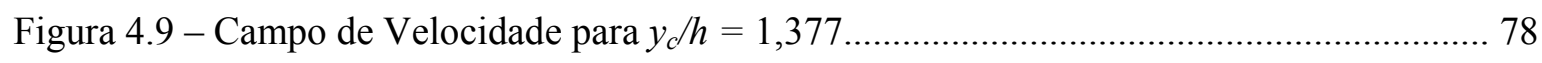

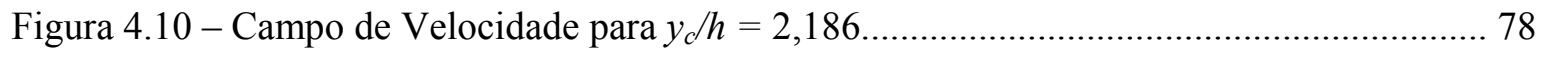

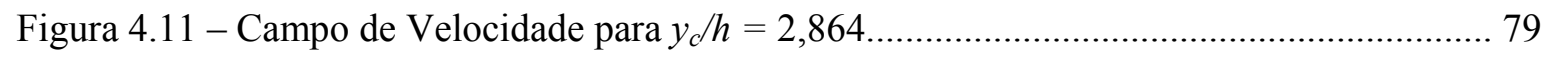

Figura 4.12 - Perfis de velocidade no degrau 10.................................................................. 79

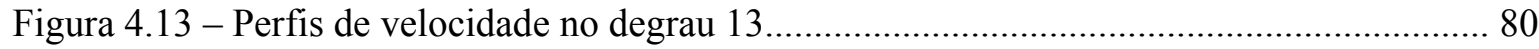

Figura 4.14 - Comparação da Variação da Perda de Carga Relativa $\Delta H / H_{o} \operatorname{com} y_{c} / h$ e $N \ldots 82$

Figura 4.15 - Comparação da Variação da Perda de Carga Relativa $\Delta H / H_{o} \operatorname{com} y_{c} / N h \ldots . . . .82$

Figura 4.16 - Efeito do Coeficiente de Coriolis na Perda de Energia Relativa............................ 84

Figura 4.17 - Efeito do Coeficiente de Coriolis na Perda de Energia Relativa............................ 85

Figura 4.18 - Efeito do Coeficiente de Coriolis na Perda de Energia Relativa............................ 86

Figura 4.19 - Dimensões principais do Vertedouro do Aproveitamento Hidroelétrico de Cubatão.

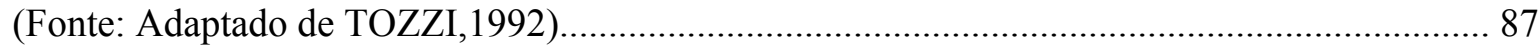


Figura 4.20 - Configuração/transições adotadas para os degraus do protótipo $(h=50 \mathrm{~cm})$ e do modelo reduzido $(h=3.33 \mathrm{~cm}, 5.00 \mathrm{~cm}$ e $10.0 \mathrm{~cm}$ ) (Fonte: Adaptado de TOZZI,1992). 88

Figura 4.21 - Comparação entre os perfis de velocidade experimental (TOZZI,1992) e numérico - Seção III $-k_{a}=2 \mathrm{~cm}$. 91

Figura 4.22 - Perfis de velocidades adimensionalisados para seção III $-k_{a}=2 \mathrm{~cm}$ 92

Figura 4.23 - Comparação entre a simulação numérica (a - CFD) e a velocimetria a LASER (PIV) (b - Fonte: AMADOR et al., 2004)

Figura 4.24 - Dissipação de energia adimensionazada para a condição de modelo reduzido e protótipo e comparação com a equação teórica $2.27 \mathrm{a}$ 95

Figura 4.25 - Esquema para a determinação da velocidade média do escoamento de água 96

Figura 4.26 - Relação entre $V / V *$ e $y_{o} / k_{a}$ - comparação entre resultados da simulação numérica e curva proposta por Tozzi (1992). 97

Figura 4.27 - Crescimento da camada limite e altura da superfície livre (início a aeração) para vazão de 120,5 1/s.m $\left(k_{a}=2 \mathrm{~cm}\right)$. 98

Figura 4.28 - Relação entre os adimensionais $L_{a} / k_{a}$ e $\delta / L_{a}$ 100 Figuras 4.29 - Perfil de aeração do escoamento na seção III $\left(68,8\right.$ 1/s/m e 86,1 1/s/m, $k_{a}=2$ $\mathrm{cm})$.. 101

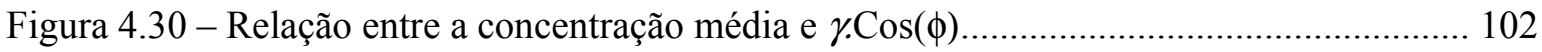

Figura 4.31 - Relação entre a concentração média e o parâmetro $\beta$.......................................... 103

Figura 4.32 - Relação entre a concentração média e o adimensional $H_{b a r r} / y_{c}$. 104

Figura 4.33 - Pressão nos degraus. (a) - Na região de transição dos degraus, (b) - Na região próxima ao fim do vertedouro. 106

Figure 4.34 - Pressão nos degraus - No início dos degraus. 107

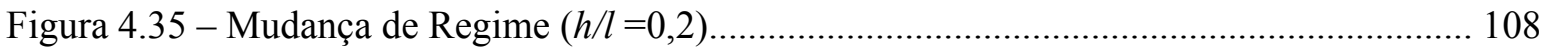

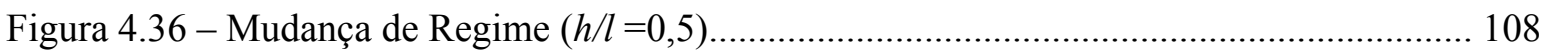

Figura 4.37 - Bancada experimental de Lima (2003)........................................................... 109

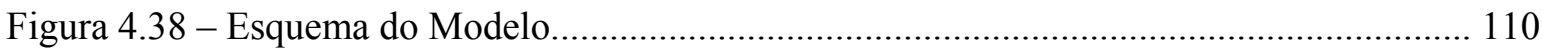

Figura 4.39 - Seções de interesse para o estudo......................................................................... 113

Figura 4.40 - Malha Inicial Usada na Simulação Numérica................................................... 113

Figura 4.41 - Malha na simulação numérica após o refinamento............................................. 114

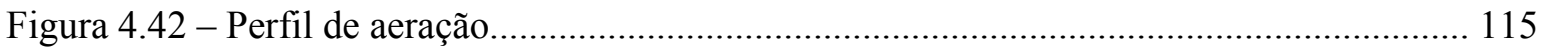

Figura 4.43 - Concentração de Ar para o Experimento 4 ........................................................ 117 
Figura 4.44 - Pressão Sob o Jato para o Experimento 9........................................................... 118

Figura 4.45 - Velocidade para abertura da comporta de $6 \mathrm{~cm}$ (Experimentos 3, 4 e 5)............ 119

Figura 4.46 - Velocidade para abertura da comporta de $9 \mathrm{~cm}$ (Experimentos 6 e 7)................ 119

Figura 4.47 - Velocidade para abertura da comporta de $11 \mathrm{~cm}$ (Experimentos 8 e 9).............. 120

Figura 4.48 - Comparação dos valores de vazão de ar............................................................ 121

Figura 4.49 - Vertedouro com Aerador de Fundo............................................................. 123

Figura 4.50 - Detalhes do Aerador de Fundo Proposto...................................................... 123

Figura 4.51 - Variação da concentração e ar no escoamento do vertedouro em degrau com

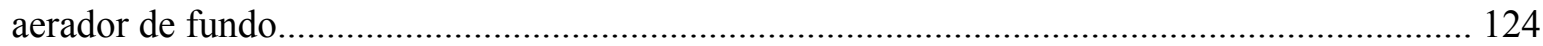

Figura 4.52 - Perfis de velocidades nas seções de estudo para os vertedores com e sem o aerador de fundo

125

Figura 4.53 - Variação da energia específica ao longo do escoamento, com referência ao pé da

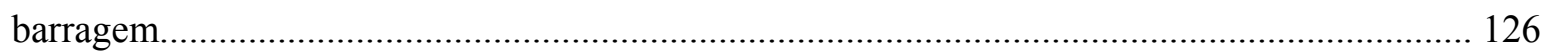

Figura 4.54 - Região com concentração de ar variando de 0 a 7\%......................................... 127

Figure 4.55 - Campo de Pressões no vertedouro em degraus com aerador de fundo. (a)-Na região do aerador de fundo, (b)-Na região próxima ao fim do vertedouro........................................ 128

Figura A.1 - Comparação entre os perfis de velocidade experimental (TOZZI,1992) e numérico Seção I $-k_{a}=2 \mathrm{~cm}$. 143

Figura A.2 - Comparação entre os perfis de velocidade experimental (TOZZI,1992) e numérico Seção II $-k_{a}=2 \mathrm{~cm}$. 144

Figura A.3 - Comparação entre os perfis de velocidade experimental (TOZZI,1992) e numérico Seção III $-k_{a}=2 \mathrm{~cm}$. 145

Figura A.4 - Comparação entre os perfis de velocidade experimental (TOZZI,1992) e numérico Seção I $-k_{a}=3 \mathrm{~cm}$. 146

Figura A.5 - Comparação entre os perfis de velocidade experimental (TOZZI,1992) e numérico Seção II $-\mathrm{ka}=3 \mathrm{~cm}$ 147

Figura A.6 - Comparação entre os perfis de velocidade experimental (TOZZI,1992) e numérico Seção III $-k_{a}=3 \mathrm{~cm}$...... 148

Figura A.7 - Comparação entre os perfis de velocidade experimental (TOZZI,1992) e numérico Seção I $-k_{a}=6 \mathrm{~cm}$.

Figura A.8 - Comparação entre os perfis de velocidade experimental (TOZZI,1992) e numérico Seção II $-k_{a}=6 \mathrm{~cm}$. 150 
Figura A.9 - Comparação entre os perfis de velocidade experimental (TOZZI,1992) e numérico Seção III $-k_{a}=6 \mathrm{~cm}$. 151

Figura B.1 - Perfis de velocidades adimensionalizados para seção I $-k_{a}=2 \mathrm{~cm}$. 152

Figura B. 2 - Perfis de velocidades adimensionalizados para seção II $-k_{a}=2 \mathrm{~cm}$. 152

Figura B.3 - Perfis de velocidades adimensionalizados para seção III $-k_{a}=2 \mathrm{~cm}$. 153

Figura B.4 - Perfis de velocidades adimensionalizados para seção I $-k_{a}=3 \mathrm{~cm}$. 153

Figura B.5 - Perfis de velocidades adimensionalizados para seção II $-k_{a}=3 \mathrm{~cm}$. 154

Figura B.6 - Perfis de velocidades adimensionalizados para seção III $-k_{a}=3 \mathrm{~cm}$ 154

Figura B.7 - Perfis de velocidades adimensionalizados para seção I $-k_{a}=6 \mathrm{~cm}$. 155

Figura B.8 - Perfis de velocidades adimensionalizados para seção II $-k_{a}=6 \mathrm{~cm}$. 155

Figura B.9 - Perfis de velocidades adimensionalizados para seção III $-k_{a}=6 \mathrm{~cm}$. 156

Figura D.1 - Crescimento da camada limite e altura da superfície livre (início a aeração) para vazão de $86,11 / \mathrm{s} . \mathrm{m}\left(k_{a}=2 \mathrm{~cm}\right)$.

Figura D.2 - Crescimento da camada limite e altura da superfície livre (início a aeração) para vazão de 120,5 1/s.m $\left(k_{a}=2 \mathrm{~cm}\right)$.

Figura D.3 - Crescimento da camada limite e altura da superfície livre (início a aeração) para vazão de 163,5 1/s.m $\left(k_{a}=2 \mathrm{~cm}\right)$ 160

Figura D.4 - Crescimento da camada limite e altura da superfície livre (início a aeração) para vazão de 201,4 1/s.m $\left(k_{a}=2 \mathrm{~cm}\right)$

Figura D.5 - Crescimento da camada limite e altura da superfície livre (início a aeração) para vazão de $86,11 / \mathrm{s} . \mathrm{m}\left(k_{a}=3 \mathrm{~cm}\right)$. 161

Figura D.6 - Crescimento da camada limite e altura da superfície livre (início a aeração) para vazão de 120,5 1/s.m $\left(k_{a}=3 \mathrm{~cm}\right)$. 161

Figura D.7 - Crescimento da camada limite e altura da superfície livre (início a aeração) para vazão de 163,5 1/s.m $\left(k_{a}=3 \mathrm{~cm}\right)$. 162 Figura D.8 - Crescimento da camada limite e altura da superfície livre (início a aeração) para vazão de 201,4 1/s.m $\left(k_{a}=3 \mathrm{~cm}\right)$

Figura D.9 - Crescimento da camada limite e altura da superfície livre (início a aeração) para vazão de $86,11 / \mathrm{s} . \mathrm{m}\left(k_{a}=6 \mathrm{~cm}\right)$.

Figura D.10 - Crescimento da camada limite e altura da superfície livre (início a aeração) para vazão de 120,5 1/s.m $\left(k_{a}=6 \mathrm{~cm}\right)$. 163 
Figura D.11 - Crescimento da camada limite e altura da superfície livre (início a aeração) para vazão de 163,5 1/s.m $\left(k_{a}=6 \mathrm{~cm}\right)$ 164

Figura D.12 - Crescimento da camada limite e altura da superfície livre (início a aeração) para vazão de 201,4 1/s.m $\left(k_{a}=6 \mathrm{~cm}\right)$. 164

Figura E.1 - Perfil de aeração do escoamento na seção III $(68,8$ 1/s/m)................................. 165

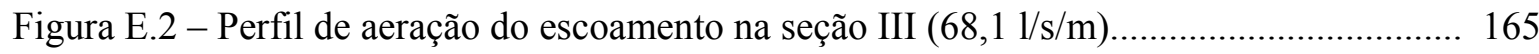

Figura E.3 - Perfil de aeração do escoamento na seção III $(120,5 \mathrm{l} / \mathrm{s} / \mathrm{m})$................................ 165

Figura E.4 - Perfil de aeração do escoamento na seção III $(163,5$ 1/s/m) ................................. 166

Figura E.5 - Perfil de aeração do escoamento na seção III $(201,4$ 1/s/m)................................. 166

Figura E.6 - Perfil de aeração do escoamento na seção III $(68,8$ 1/s/m) .................................... 166

Figura E.7 - Perfil de aeração do escoamento na seção III $(86,1 \mathrm{l} / \mathrm{s} / \mathrm{m})$.................................... 167

Figura E.8 - Perfil de aeração do escoamento na seção III (120,5 1/s/m)................................ 167

Figura E.9 - Perfil de aeração do escoamento na seção III $(163,5$ 1/s/m)................................. 167

Figura E.10 - Perfil de aeração do escoamento na seção III $(201,4$ 1/s/m)............................... 168

Figura E.11 - Perfil de aeração do escoamento na seção III $(68,8$ 1/s/m)................................ 168

Figura E.12 - Perfil de aeração do escoamento na seção III $(86,1 \mathrm{l} / \mathrm{s} / \mathrm{m})$.................................. 168

Figura E.13 - Perfil de aeração do escoamento na seção III (120,5 1/s/m).............................. 169

Figura E.14 - Perfil de aeração do escoamento na seção III $(163,5$ 1/s/m)............................... 169

Figura E.15 - Perfil de aeração do escoamento na seção III $(201,4$ 1/s/m)................................ 169

Figura F.1 - Concentração de Ar para o Experimento 4 ........................................................... 170

Figura F.2 - Concentração de Ar para o Experimento 5 ........................................................... 171

Figura F.3 - Concentração de Ar para o Experimento 6......................................................... 172

Figura F.4 - Concentração de Ar para o Experimento 7 ........................................................ 173

Figura F.5 - Concentração de Ar para o Experimento 8.......................................................... 174

Figura F.6 - Concentração de Ar para o Experimento 9.......................................................... 175

Figura G.1 - Pressão Sob o Jato para o Experimento 3 …....................................................... 176

Figura G.2 - Pressão Sob o Jato para o Experimento 4........................................................ 176

Figura G.3 - Pressão Sob o Jato para o Experimento 6.............................................................. 177

Figura G.4 - Pressão Sob o Jato para o Experimento 7 ............................................................ 177

Figura G.5 - Pressão Sob o Jato para o Experimento 8.............................................................. 178

Figura G.6 - Pressão Sob o Jato para o Experimento 9....................................................... 178 


\section{LISTA DE TABELAS}

Tabela 4.1 - Valores das alturas de água $\left(\mathrm{y}_{\mathrm{o}}\right)$ e das velocidades (V) na entrada nas quatro simulações realizadas. 71

Tabela 4.2 - Resultados da Simulação Numérica....................................................................... 81

Tabela 4.3 - Resutados da Simulação com o Coeficiente de Coriolis......................................... 84

Tabela 4.4 - Domínio, Características do Fluido e da Simulação................................................ 89

Tabela 4.5 - Resultados da Simulação Numérica (CFD) para rugosidade $k_{a}=2 \mathrm{~cm}$................. 94

Tabela 4.6 - Resultados da Simulação Numérica (CFD) para rugosidade $k_{a}=2 \mathrm{~cm}$................. 99

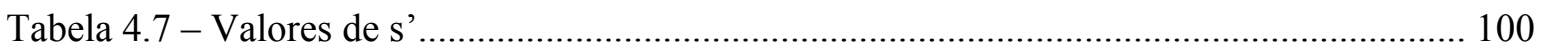

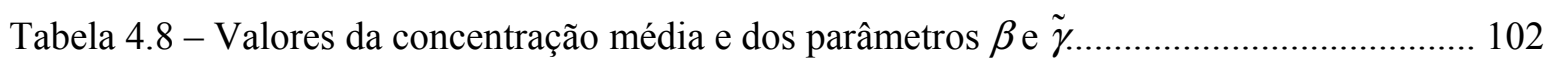

Tabela 4.9 - Relação de Pressão mínima entre da simulação do protótipo e do modelo............ 105

Tabela 4.10 - Grandezas Básicas e Comprimentos dos Jatos................................................... 114

Tabela 4.11 - Domínio, Características do Fluido e da Simulação............................................ 116

Tabela C.1 - Resultados da Simulação Numérica (CFD) para rugosidade $k_{a}=3 \mathrm{~cm} \ldots \ldots \ldots \ldots \ldots . . .157$

Tabela C. 2 - Resultados da Simulação Numérica (CFD) para rugosidade $k_{a}=6 \mathrm{~cm} \ldots \ldots \ldots \ldots \ldots . . . .158$ 


\section{LISTA DE SÍMBOLOS}

$\vec{a}$ - Aceleração (L.T $\left.{ }^{-2}\right)$.

A - Área da seção $\left(\mathrm{L}^{2}\right)$.

$a-$ Velocidade do som $\left(\mathrm{L} . \mathrm{T}^{-1}\right)$

$A_{\alpha \beta}$ - Área interfacial entre as duas fases $\left(\mathrm{L}^{2}\right)$.

$A_{w}$ - Área molhada do canal $\left(\mathrm{L}^{2}\right)$.

$B$ - Largura do canal (L).

$C$ - Concentração de ar ou fração de vazios.

$C_{\mu}$ - Constante para cálculo da viscosidade turbulenta.

$C_{1}$ e $C_{2}$-Constantes do modelo $k-\varepsilon$ RNG ou Constantes da modelagem do termo de efeito de pressão.

$C_{1 \varepsilon}, C_{2 \varepsilon}$ e $C_{3 \varepsilon}$ - Constantes do modelo $k-\varepsilon$.

$c_{f}$-Coeficiente de rugosidade efetivo para vertedouro em degrau.

$c_{f}{ }^{\prime}$ - Coeficiente de rugosidade efetivo para vertedouro liso.

$\mathrm{C}_{\mathrm{ij}}$ - Termo convectivo para equação de transporte da tensão de Reynolds $\left(\mathrm{M} \cdot \mathrm{L}^{-1} \mathrm{~T}^{-3}\right)$.

$C_{1}$-Constantes da modelagem do termo de efeito de pressão.

$C_{\text {média }}$ - Concentração de ar média para a profundidade $\mathrm{y}_{90}$.

$C_{s}$ - Constante de Smagorinsky

$C_{v}$ - Constante da modelação da viscosidade efetiva.

$d$ - Distância normal à parede (L).

$\mathrm{d}$ - Altura de água característica em um escoamento (L).

$\mathrm{D}$ - Difusividade para a densidade média $\left(\mathrm{L}^{2} \mathrm{~T}^{-1}\right)$.

$D^{\prime}$ - Difusividade turbulenta adimensional $\left(\mathrm{L}^{2} \mathrm{~T}^{-1}\right)$.

$d_{A}$ - Profundidade do escoamento no ponto de início da aeração (L).

$d_{\alpha \beta}$ Escala de comprimento na interface, entre a fase $\alpha$ e $\beta(\mathrm{L})$.

$D_{\alpha}^{(\phi)}$ - Difusividade cinemática do escalar na fase $\alpha$.

$D_{h}$ - Diâmetro hidráulico (L).

$\mathrm{D}_{\mathrm{L}, \mathrm{jj}}$ - Termo da difusão molecular da equação de transporte da tensão de Reynolds $\left(\mathrm{M} \cdot \mathrm{L}^{-1} \mathrm{~T}^{-3}\right)$.

$\mathrm{D}_{\mathrm{t}}$ - Difusividade turbulenta na direção normal ao escoamento $\left(\mathrm{L}^{2} \mathrm{~T}^{-1}\right)$.

$\mathrm{D}_{\mathrm{T}, \mathrm{j}}$ - Termo da difusão turbulenta para equação de transporte da tensão de Reynolds (M. $\mathrm{L}^{-1} \mathrm{~T}^{-3}$ ). 
$\mathrm{E}_{1}^{\text {liso }}-$ Energia especifica no pé do vertedouro liso (L).

$E_{1}^{\text {degrau}}$ - Energia especifica no pé do vertedouro em degraus (L).

EDR - Energia dissipada relativa.

$f$ - Fator de cisalhamento.

$F$ - Taxa de formação de bolha $\left(\mathrm{T}^{-1}\right)$ ou

$F_{*-}$ Número de Froude para a rugosidade.

$F_{\alpha \beta}-$ Força de tensão superficial (M.L.T ${ }^{-2}$ ).

$f_{\alpha \beta}-$ Força superficial contínua (M.T $\left.{ }^{-2}\right)$.

$f_{a r}$ - Fator de atrito associado à perda de carga distribuída no tubo aerador.

$F_{b}$ - Número de Froude sobre o degrau.

$f_{e}$ - Fator de resistência do escoamento aerado uniforme.

$\mathrm{F}_{\mathrm{ij}}$ - Termo de produção de tensão para equação de transporte da tensão de Reynolds $\left(\mathrm{M} \cdot \mathrm{L}^{-1} \mathrm{~T}^{-3}\right.$ ).

$F_{o}{ }^{\prime}$ - Número de Froude no pé do vertedouro de face lisa.

$g$ - Aceleração da gravidade $\left(\right.$ L.T $\left.{ }^{-2}\right)$.

$g^{\prime}$ - Aceleração da gravidade fictícia $\left(\mathrm{L} . \mathrm{T}^{-2}\right)$.

$G_{b}$ - Geração de energia cinética turbulenta pela flutuação da velocidade (M.L $\left.\mathrm{L}^{-1} \cdot \mathrm{T}^{-3}\right)$.

$g_{i}$ e $g_{j}$ - Componentes gravitacional na direção i e j(L.T $\left.{ }^{-2}\right)$.

$G_{i j}$ - Geração da turbulência devido à flutuação $\left(\mathrm{M} \cdot \mathrm{L}^{-1} \cdot \mathrm{T}^{-3}\right)$.

$G_{k}$ - Geração de energia cinética turbulenta pela velocidade média $\left(\mathrm{M} \cdot \mathrm{L}^{-1} \cdot \mathrm{T}^{-3}\right)$.

$h$ - Altura do degrau do vertedouro (L).

$H$ - Carga hidráulica sobre o degrau (L).

$H_{\text {barr }}$ - Altura da barragem (L).

$H_{o}$ - Carga hidráulica à montante do vertedouro $(\mathrm{L})$.

$h_{o}$ - Elevação da superfície do reservatório em relação à crista $(\mathrm{L})$.

$H_{\text {res }}$ - Energia residual $\left(H_{\text {res }}=1-\Delta H / H_{o}\right)$

ip - Sub-índice para um ponto de integração pertencente ao volume finito

$i p_{n}$ - Pontos de integração.

$k$ - Energia cinética turbulenta $\left(\mathrm{L}^{2} \cdot \mathrm{T}^{-2}\right)$.

$K$ - Somatório dos coeficientes de perdas de carga localizadas.

$K^{\prime}$ - Constante de integração.

$k_{a}$ - Altura da rugosidade; $k_{a}=h \cdot \cos \phi(\mathrm{L})$. 
$l$ - Comprimento (ou piso) do degrau do vertedouro (L).

$\mathrm{L}$ - Comprimento do salto do aerador (L).

$\mathrm{L}_{\mathrm{A}}$ - Distância, ao longo da calha do vertedouro, entre a posição de início do desenvolvimento camada limite e o inicio da aeração do escoamento (L).

$l_{p}$ - Comprimento do salto no degrau (L).

$L_{s}$ - Comprimento de mistura de sub-malha (L).

$m-\operatorname{massa}(\mathrm{M})$.

$\dot{m}_{\alpha \beta}$ - Taxa de massa de fluxo por unidade de área da fase $\beta$ para a fase $\alpha\left(\mathrm{M} \cdot \mathrm{L}^{-2} \mathrm{~T}^{-1}\right)$.

$\dot{m}_{i p}-$ Fluxo de massa sobre uma superfície do volume finito $\left(\mathrm{M} \cdot \mathrm{L}^{-2} \mathrm{~T}^{-1}\right)$.

$M_{\alpha}-$ Forca interfacial que age na fase $\alpha$ devido a presença da outra fase (M.L $\mathrm{L}^{-2} \cdot \mathrm{T}^{-2}$ ).

$M_{t}$ - Número de Mach turbulento.

$n_{\alpha \beta}-$ Vetor normal à interface do fluido primário para o secundário.

$\mathrm{N}$ - Expoente da distribuição de velocidade ou Número de degraus do vertedouro.

$N_{P}$ - Total de número fases

${ }^{o}$ - Super-índice referente ao tempo anterior.

$p_{\alpha}-$ Pressão da fase $\alpha\left(\mathrm{M} \cdot \mathrm{L}^{-1} \cdot \mathrm{T}^{-2}\right)$.

$p$ - Pressão $\left(\mathrm{M} \cdot \mathrm{L}^{-1} \cdot \mathrm{T}^{-2}\right)$.

$p_{a t m}$ - Pressão atmosférica $\left(\mathrm{M} \cdot \mathrm{L}^{-1} \cdot \mathrm{T}^{-2}\right)$.

$p_{\text {est }}$ - Pressão estática $\left(\mathrm{M} \cdot \mathrm{L}^{-1} \cdot \mathrm{T}^{-2}\right)$.

$p_{\text {tot }}-$ Pressão total $\left(\mathrm{M} \cdot \mathrm{L}^{-1} \cdot \mathrm{T}^{-2}\right)$.

$\mathrm{P}_{\mathrm{ij}}$ - Termo de produção pela rotação do sistema para equação de transporte da tensão de Reynol (M.L $\left.\mathrm{L}^{-1} \mathrm{~T}^{-3}\right)$.

$\mathrm{Pr}_{\mathrm{t}}$ - Número de Prandtl turbulento para a energia.

$P_{w}$ - Perímetro molhado do canal (L).

$Q$ - Vazão do vertedouro $\left(\mathrm{L}^{3} \cdot \mathrm{T}^{-1}\right)$.

$q$ - Vazão específica; Vazão por unidade de largura do vertedouro $\left(\mathrm{L}^{3} \cdot \mathrm{T}^{-1} \cdot \mathrm{L}^{-1}\right)$.

$Q_{\text {água }}$ - Vazão de água $\left(\mathrm{L}^{3} \cdot \mathrm{T}^{-1}\right)$.

$q_{a r}$ - Vazão de $\operatorname{ar}\left(\mathrm{L}^{3} \cdot \mathrm{T}^{-1}\right)$.

$r_{\alpha}$ e $r_{\beta}$ - Fração de volume da fase $\alpha$ e $\beta$.

$\mathrm{Rc}-$ Relação entre os coeficientes de atrito; $\mathrm{Rc}=\left(c_{f} / c_{f}\right)^{1 / 3}$

$R_{\mathcal{\varepsilon}}$ - Termo adicional da equação de $\varepsilon$ para o modelo $k-\varepsilon$ RNG. 
$S$ - Modulo do tensor médio da taxa de força $\left(\mathrm{T}^{-1}\right)$ ou Superfície de integração.

$S_{\alpha}^{(\phi)}-$ Termo fonte volumétrico externo na fase $\alpha$.

$S_{M \alpha}$ - Termo fonte de quantidade de movimento devido às forças externas no modelo multifásico $\left(\mathrm{M} \cdot \mathrm{L}^{-2} \cdot \mathrm{T}^{-2}\right)$.

$S_{M S \alpha}$ - Fonte de massa no modelo multifásico (M.L $\left.\mathrm{L}^{-3} \cdot \mathrm{T}^{-1}\right)$.

$S_{M}$ - Termo fonte da equação de momento $\left(\mathrm{M} \cdot \mathrm{L}^{-2} \cdot \mathrm{T}^{-2}\right)$.

$S_{o}$ - Declividade do vertedouro em degraus (L.L $\left.{ }^{-1}\right)$

$S_{\phi}-$ Termo fonte da equação de transporte genérica.

$\bar{S}_{i j}$ - Tensor de taxa de força $\left(\mathrm{T}^{-1}\right)$

$t$ - Tempo (T).

$T-$ Temperatura $(\theta)$.

$T_{\alpha}^{(\phi)}-$ Fonte total de $\phi_{\alpha}$ devido à transferência de um fase para outra.

$u_{\alpha}, v_{\alpha}$ e $w_{\alpha}-$ Velocidades da fase $\alpha\left({\left.\mathrm{L} . \mathrm{T}^{-1}\right)}^{-1}\right.$

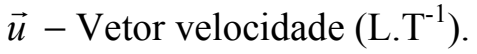

$u^{\prime}$ - Componente da velocidade variável no tempo ou da flutuação da velocidade (L.T $\left.{ }^{-1}\right)$.

$\bar{u}$ - Componente média da velocidade $\left(\mathrm{L} \cdot \mathrm{T}^{-1}\right)$.

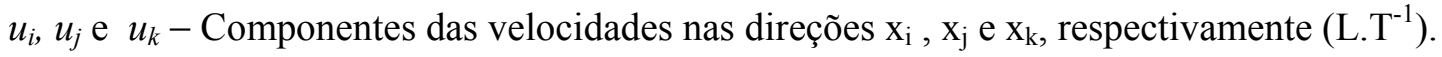

$u_{i}$, $u_{j}$, e $u_{k}$ - Flutuação das velocidades nas direções $x_{i}, x_{j}$ e $x_{k}$, respectivamente $\left(\right.$ L.T $\left.^{-1}\right)$.

$v$ - Velocidade local $\left(\mathrm{L} . \mathrm{T}^{-1}\right)$.

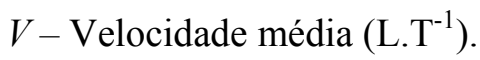

$V_{*}-$ Velocidade de atrito $\left(\right.$ L. $\left.\mathrm{T}^{-1}\right)$.

$V_{c}$ - Velocidade média crítica $\left(\right.$ L. $\left.\mathrm{T}^{-1}\right)$.

$V_{j}$ - Velocidade do jato $\left(\mathrm{L} . \mathrm{T}^{-1}\right)$.

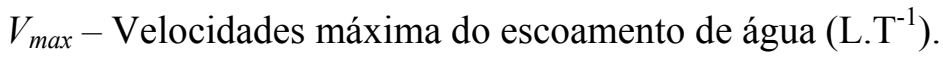

$V_{o}$ - Velocidade de aproximação do vertedouro $\left(\mathrm{L} \mathrm{T}^{-1}\right)$.

$V_{o l}$ - Volume ocupado pela fase $\alpha\left(\mathrm{L}^{3}\right)$.

Vol - Volume computacional da célula $\left(\mathrm{L}^{3}\right)$.

$v_{\mathrm{w}}-$ Velocidade da água (L. $\left.\mathrm{T}^{-1}\right)$.

$x$ - Abscissa do sistema Cartesiano (L).

$w^{\prime}-$ Flutuações transversais das velocidades $\left(\right.$ L.T $\left.^{-1}\right)$ 
$Y$ - Profundidade de aproximação no vertedouro (L).

$y$ - Distância medida perpendicularmente ao pseudo-fundo formado pelas extremidades dos degra ou Ordenada do sistema Cartesiano (L)

$y_{1}$ - Profundidade do escoamento supercrítico (L).

$y_{2}$ - Profundidade do escoamento subcrítico (L).

y90 - Altura em que a concentração de ar é de $90 \%$ (L).

$y_{c}$ - Profundidade crítica do escoamento (L).

$Y_{M}$ - Contribuição na taxa de dissipação total devido à variação volumétrica (compressível).

$y_{o}$ - Profundidade normal do escoamento (L).

$y_{p}$ - Profundidade alagada no espelho do degrau (L).

$\hat{v}$ - Relação entre a viscosidade efetiva e a viscosidade absoluta.

$\Delta \mathrm{x}$ e $\Delta \mathrm{y}-$ Tamanho da malha na direção x e y, respectivamente (L).

$\Delta E$ - Perda de energia relativa entre vertedouro em degrau e liso (L).

$\Delta H$ - Perda de energia total (L).

$\Delta h_{\text {estático }}$ - Pressão estática na cavidade do bocal (L).

$\Delta n j-$ Vetor de superfície discreto.

$\Delta t$-Passo de tempo $(\mathrm{T})$.

$\Delta z$ - Altura do fundo do reservatório, em relação a um referencial (L).

$\Delta \delta$ - Variação entre altura de aeração em duas seções (L).

$\Gamma_{\alpha \beta}$ - Taxa de fluxo de massa por unidade de volume da fase $\beta$ para a fase $\alpha\left(\mathrm{M} \cdot \mathrm{L}^{-3} \cdot \mathrm{T}^{-1}\right)$.

$\left(\Gamma_{\alpha \beta}^{+} u_{\beta}-\Gamma_{\beta \alpha}^{+} u_{\alpha}\right)$ - Termo que representa a transferência de quantidade de movimento induzida $\mathrm{p} \epsilon$ transferência de massa $\left(M \cdot L^{-2} \cdot T^{-2}\right)$.

$\Gamma_{\alpha}-$ Fonte de massa por unidade de volume na fase $\alpha$ ou a difusividade da fase $\alpha$

$\Gamma-$ Difusividade.

$\alpha$ - Ângulo de inclinação do jato.

$\alpha, \beta, \gamma, \ldots-$ Fases dos fluidos nos modelos multifásico.

$\alpha_{c}$ - Coeficiente de correção da energia cinética (coeficiente de Coriolis)

$\alpha_{k}$ e $\alpha_{\varepsilon}$-Inversos dos números de Prandtl turbulentos para $k$ e $\varepsilon$, respectivamente.

$\alpha_{o}$ - Constante para determinação do inverso do número de Prandtl turbulento

$\alpha$ - Condutividade térmica $\left(\mathrm{L}^{2} \cdot \mathrm{T} \cdot \theta^{-1}\right)$. 
$\beta$ - Variável em função da concentração média ou coeficiente de expansão térmica $\left(\theta^{-1}\right)$

$\delta$-Espessura da camada limite (L).

$\delta_{\alpha \beta}-$ Delta de interface (L).

$\delta_{i j}-$ Delta de Kronecker.

$\varepsilon_{\mathrm{ij}}$ - Termo da dissipação para equação de transporte da tensão de Reynolds (M.L $\mathrm{L}^{-1} \mathrm{~T}^{-3}$ ).

$\varepsilon$ - Taxa de dissipação da energia cinética turbulenta $\left(\mathrm{L}^{2} \cdot \mathrm{T}^{-3}\right)$.

$\phi$ - Ângulo de inclinação do canal com degrau.

$\phi_{\alpha}-$ Variável por unidade de massa na fase $\alpha$

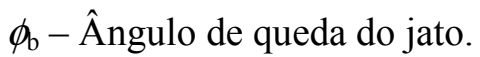

$\phi_{e}-$ Termo fonte da equação de energia $\left(\theta . T^{-1}\right)$.

$\phi_{i j, 1}$ - Termo de efeito lento da pressão (M.L $\mathrm{L}^{-1} \mathrm{~T}^{-3}$ ).

$\phi_{i j, 2}$ - Termo de efeito rápido da pressão $\left(\mathrm{M} \cdot \mathrm{L}^{-1} \mathrm{~T}^{-3}\right)$.

$\phi_{i j, w}$ - Termo de reflexão nas paredes $\left(\mathrm{M} \mathrm{L}^{-1} \mathrm{~T}^{-3}\right)$.

$\phi_{i j}$ - Termo do efeito de pressão para equação de transporte da tensão de Reynolds $\quad$ (M.L $\mathrm{L}^{-1} \mathrm{~T}^{-3}$ ).

$\phi_{t}$ - Variável transportada para a equação de transporte genérica.

$\Phi_{\alpha}-$ Variável por unidade de volume da fase $\alpha$,

$\gamma$ - Peso específico do fluido (M.L $\mathrm{L}^{-2} \cdot \mathrm{T}^{-2}$ ) ou Variável em função da concentração média.

$\eta$ - Taxa de pressão.

$\kappa$-Constante de Von Karman $(\kappa=0,4)$.

$\kappa_{\alpha \beta}-$ Curvatura da superfície $\left(\mathrm{L}^{-1}\right)$.

$\mu_{\alpha}-$ Viscosidade da fase $\alpha\left(M \cdot L^{-1} \cdot T^{-1}\right)$.

$\mu_{e f f}-$ Viscosidade efetiva, Soma da viscosidade molecular com a turbulenta $\left(M \cdot L^{-1} \cdot T^{-1}\right)$.

$\mu_{t}-$ Viscosidade turbulenta $\left(M \cdot L^{-1} \cdot T^{-1}\right)$.

$\mu$-Viscosidade dinâmica, absoluta ou molecular $\left(\mathrm{M} \cdot \mathrm{L}^{-1} \cdot \mathrm{T}^{-1}\right)$.

$v-$ Viscosidade cinemática do fluido $\left(\mathrm{L}^{2} \cdot \mathrm{T}^{-1}\right)$.

$\Phi-$ Variável do escoamento

$\bar{\Phi}$ - Parte da variável do escoamento referente à grande escala de turbulência.

$\Phi^{\prime}$-Parte da variável do escoamento referente à pequena escala de turbulência.

$\theta$ - Ângulo de inclinação do piso dos degraus. 
$\rho$ - Massa específica do fluido (M.L $\left.{ }^{-3}\right)$.

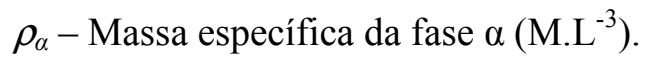

$\widetilde{\rho}_{\alpha}-$ Massa específica efetiva do fluido (M.L $\left.{ }^{-3}\right)$

$\rho_{a r}$ - Massa específica da ar (M.L $\left.{ }^{-3}\right)$.

$\rho \overline{u_{i}^{\prime} u_{i}^{\prime}}-$ Tensões de Reynolds $\left(\mathrm{M} \cdot \mathrm{L}^{-1} \cdot \mathrm{T}^{-2}\right)$.

$\sigma$ - Tensão superficial do fluido (M.T ${ }^{-2}$ ).

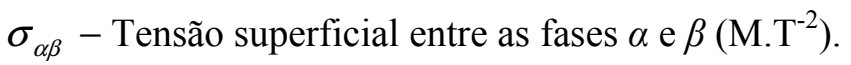

$\sigma_{k}$ e $\sigma_{\varepsilon}-$ Números de Prandtl turbulentos para $k$ e $\mathcal{E}$, respectivamente.

$\tau_{\mathrm{ij}}$ - Tensão de sub-malha (M.L $\left.\mathrm{L}^{-1} \cdot \mathrm{T}^{-2}\right)$.

$\tau$-Tensão de cisalhamento média ou tensão de tensões molecular $\left(\mathrm{M} \cdot \mathrm{L}^{-1} \cdot \mathrm{T}^{-2}\right)$.

$\tau_{\mathrm{s}}-$ Fator de segurança para critério de BULGARELLI.

$\nabla_{S}$ - Operador gradiente na interface $\left(\mathrm{L}^{-1}\right)$. 


\section{INTRODUÇÃO.}

\subsection{Generalidades}

Grandes barragens têm sido construídas nos últimos tempos para suprir as necessidades de armazenamento de água para os mais diversos objetivos. Na maioria dessas barragens, deve-se prever a construção de dispositivos que permitam a passagem de água para jusante. Dentre estes dispositivos, destacam-se os vertedouros, que se caracterizam por uma estrutura para a passagem da água excedente sobre a barragem, garantindo a integridade da obra durante a ocorrência de cheias. Se o vertedouro não for devidamente projetado, a barragem poderá ser galgada e a sua estabilidade ficará comprometida, podendo eventualmente verificar-se o seu colapso.

Nos projetos de vertedouros, em geral, utilizam-se cristas executadas em concreto alisado e definidas por formas consagradas, objetivando manter as pressões compatíveis com um desempenho da estrutura isento de problemas. A calha que segue à estrutura da crista é normalmente alisada para evitar riscos com cavitação, principalmente quando sujeita aos escoamentos de altas velocidades. Conseqüentemente, apenas pequenas parcelas de energia do escoamento são dissipadas ao longo da calha, tornando-se necessária a utilização de estruturas de dissipação de energia, que podem envolver custos elevados de construção. Portanto, o escoamento a jusante de soleira de vertedouros exige uma atenção especial com a dissipação de energia cinética, para que o escoamento na base do vertedouro não ponha em risco a segurança da barragem.

Uma das formas de dissipar parte da energia cinética é através da construção de degraus ao longo da calha do vertedouro, o que conduz a uma redução da energia específica residual na base do vertedouro. A dissipação de energia causada pelos degraus pode reduzir significativamente o tamanho e o custo da bacia de dissipação necessária na base do vertedouro, comparada com uma calha convencional (calha lisa).

Apesar do conceito do vertedouro em degraus não ser recente, o crescimento do interesse em sua construção foi favorecido pelo uso da tecnologia do concreto compactado a rolo (CCR) na construção das barragens. O CCR consiste no uso de concreto magro espalhado em camadas que podem variar de $0,1 \mathrm{~m}$ a $0,6 \mathrm{~m}$, que é compactado por meio de rolo compressor. A espessura depende do tipo de equipamento, da cancha de construção, etc. As 
extremidades das camadas formam degraus de modo natural, que posteriormente recebem um acabamento final. Existem projetos com degraus de até $1,8 \mathrm{~m}$ de altura, mas a melhor eficiência se dá com degraus com degraus em torno de 0,6 m (Laboratório de Goiânia de Furnas).

Estudos com modelos reduzidos de vertedouros em degraus foram realizados desde o inicio dos anos oitenta por muitos pesquisadores. Esses estudos se concentraram na caracterização do escoamento no vertedouro, na quantificação da perda de energia relativa, no estudo das configurações dos degraus e também no estudo da ocorrência de cavitação. Vultosos esforços envolvidos na realização de ensaios em modelos reduzidos coíbem maior número de combinações de relações geométricas, de configurações e de relações dinâmicas, necessárias à caracterização adequada dos escoamentos em obras hidráulicas.

Com o avanço da tecnologia computacional das últimas décadas, a resolução numérica das equações representativas dos escoamentos passou a ser viável para muitas condições. Nos dias de hoje é possível realizar uma simulação do escoamento tridimensional, multifásico, transiente, turbulento, etc, utilizando um computador pessoal, mas, dependendo do grau de detalhamento do resultado pretendido, esta simulação pode demorar horas, dias ou meses.

A fluidodinâmica computacional ou CFD (do inglês Computational Fluid Dynamic) constitui em uma ferramenta capaz de reproduzir numericamente os fenômenos de transportes em escoamentos em qualquer domínio e características diversas. Para isto existem softwares desenvolvidos para construção da geometria, geração de malha, pré-processamento, processamento e a visualização dos resultados.

As ferramentas de fluidodinâmica computacional ainda são pouco utilizadas em projetos de obras hidráulicas. Apesar do custo computacional ainda ser alto, dependendo das condições de escoamento, ele tende a diminuir com os avanços tecnológicos. Outra dificuldade na utilização desta ferramenta para projetos é o custo de licenciamento dos softwares, mas acredita-se que com a maior concorrência no mercado, o desenvolvimento de softwares ou, quem sabe, o aparecimento de bons softwares livres podem diminuir este custo, que atualmente pode ser da mesma ordem ou até maior que o computacional.

\subsection{Objetivos do Trabalho.}

Com o intuito de estudar os fenômenos envolvidos nos escoamentos em vertedouros em degraus, para este trabalho, foi utilizada uma ferramenta de fluidodinâmica computacional. Ensaios experimentais dessas estruturas dissipadoras de energia foram realizados por diversos autores em todo o mundo, mas estudos por meio de simuladores numéricos são escassos na 
literatura. A utilização dessas ferramentas computacionais pode tornar os processos de elaboração do projeto, diferenciados dos métodos até então utilizados, possibilitando um estudo inicial da configuração das geometrias das estruturas hidráulicas antes da construção de modelos reduzidos.

Este trabalho constitui no estudo do escoamento em vertedouros em degraus, através da simulação em um programa de fluido dinâmica computacional, caracterizando o escoamento sobre o vertedouro, verificando as equações estabelecidas na dissipação de energia e também o estudo da ocorrência de cavitação nos degraus e da aeração no escoamento.

A mudança de regime de escoamento que ocorre em vertedouros em degraus foi estudada por meio das simulações de diversas configurações geométricas e vazões de entrada. O estudo da aeração do escoamento também foi realizado comparando-se resultados experimentais com os simulados numéricos.

Para se avaliar os campos de escoamento sobre vertedouros em degraus com confiabilidade desejada e obter resultados de utilidade prática via CFD, foi essencial a escolha dos modelos representativos dos escoamentos que representam de forma adequada os fenômenos envolvidos, para comparação com testes experimentais disponíveis na literatura.

Para validação da aplicação da ferramenta CFD foram realizados os seguintes estudos:

- Estudo dos perfis de pressões no degrau e dos perfis de velocidades, comparação com resultados experimentais.

- Correção na dissipação de energia específica foi realizada através do cálculo do coeficiente de Coriolis, a partir da distribuição das velocidades obtidas com a simulação.

- Um equacionamento proposto por Chanson (1994) para a dissipação de energia foi comparado com os resultados numéricos.

- Estudo do ponto de início da aeração do escoamento, em função do crescimento da camada limite e da macro-rugosidade dos degraus.

- Duas equações, para a distribuição da concentração de ar, foram comparadas com os resultados da simulação numérica.

- Estudo adimensional de distribuição de velocidades com comparação com duas equações teóricas.

- Estudo comparativo entre simulações em condição de protótipo e de modelo reduzido para velocidades e pressões.

Os degraus do vertedouro, além de provocar uma intensa turbulência, em que se dissipa energia do escoamento, tendem a antecipar a aeração em relação às calhas lisas. Mas essa 
aeração muitas vezes é insuficiente para impedir que as pressões negativas nos degraus sejam capazes de provocar riscos de cavitação, o que limita, atualmente, o uso de vertedouros com degraus para vazões específicas da ordem de 11 a 15 m³.m. A construção de um aerador de fundo no início da calha poderia propiciar uma boa aeração, que deve ser mantida pela própria turbulência do escoamento. Esta é uma proposta deste trabalho.

Para a caracterização do escoamento em um aerador de fundo, decidiu-se estudar o escoamento aerado em canal de forte declividade utilizando os dados experimentais do trabalho desenvolvido por Lima (2003). Os resultados da simulação numérica para as características dos perfis de distribuição de concentração de ar, velocidade, pressão sob o jato foram comparados com os resultados experimentais de Lima (2003). Um estudo da vazão de ar sob o salto foi realizado comparando-se vários métodos teóricos, empíricos e experimentais com o resultado da simulação numérica.

Para finalizar este trabalho propôs-se uma nova configuração geométrica para vertedouros em degrau em conjunto com um aerador de fundo. O estudo das características do escoamento nesta nova configuração para o vertedouro pode servir como metodologia para uma etapa inicial de projetos através da utilização das ferramentas de fluidodinâmica computacional. 


\section{REVISÃO BIBLIOGRÁFICA.}

\subsection{Considerações Gerais Sobre Vertedouros em Degraus.}

Os vertedouros em degraus são estruturas usadas desde a Antiguidade, sendo a que primeira barragem com este tipo de estrutura foi construída por volta do ano 694 A.C. pelos assírios. Entretanto, segundo Chanson (1994), a sua primeira aplicação baseada no conceito de dissipação de energia, data do início do século 20, em que a primeira barragem nos Estados Unidos da América foi construída em New Croton em 1906.

Os estudos de Essery e Horner (1978), Sorensen (1985), Bayat (1991), Diez-Cascon et al. (1991), Bindo et al. (1993), Christodoulou (1993), Tozzi (1994), Sanagiotto (2003) foram executados em modelos físicos de canais em escadas, com declives que variaram de 1,2H:1V a $0,7 \mathrm{H}: 1 \mathrm{~V}$, com altura de modelos entre 0,36 a 3,80 m. Estes estudos mostraram que, em um escoamento do tipo skimming (ver definição, pg. 7 , Figura 2.1.b) em um vertedor em degrau, há uma região de água sem aeração próximo da crista, seguida por uma região de aeração em desenvolvimento e uma região de escoamento aerado já desenvolvido.

Sorensen (1985), Bayat (1991), Diez-Cascon et al. (1991), Bindo et al. (1993) e Christodoulou (1993), mediram a profundidade do escoamento no pé ou ao longo do comprimento dos vertedouros em degraus. A perda de energia relativa (ver eq. 2.1) sobre esse vertedouro em degrau foi calculada baseada nessas profundidades, resultando em torno de $50 \%$ a 97\%. Tozzi (1994) calculou a perda de energia relativa através da medição da velocidade na região aerada do escoamento e verificou uma variação de $47 \%$ a $74 \%$. Chistodoulou (1993) propôs um método aproximado e mais prático, para calcular a perda de energia em função do número de degraus. Rajaratnam (1990), com base na suposição de uma região completamente desenvolvida com uma tensão de cisalhamento entre o escoamento skimming e a região de recirculação nos degraus (ver definição, Figura 2.1.b), desenvolveu uma expressão para a perda de energia relativa sobre um vertedouro em degraus em termos de relação deste com um vertedouro liso e conclui também que uma perda de energia significativa pode ocorrer em um vertedouro em degraus.

Houston (1987) realizou estudos em modelos reduzidos de Upper Stillwater Dam, cujos modelos foram construídos em duas escalas diferentes, um deles com canal estreito, em escala 1:15 e outro com canal largo, na escala 1:50. Seus principais resultados foram semelhantes 
aos obtidos por Sorensen (1985), ou seja: para vazões pequenas, da ordem de até $3 \mathrm{~m}^{3} / \mathrm{s} / \mathrm{m}$, a energia dissipada ao longo da calha era da ordem de até $95 \%$ da energia total, decrescendo com a vazão, atingindo valores da ordem de $60 \%$ para vazões da ordem de $10 \mathrm{~m}^{3} / \mathrm{s} / \mathrm{m}$.

Em trabalho mais recente, Chamani e Rajaratnam (1999) estudaram as características do escoamento em vertedouro em degrau com duas inclinações, a distribuição da concentração de ar foi determinada ao longo do vertedouro através de uma sonda e também através de uma câmara digital de alta resolução. Eles concluíram que o escoamento desenvolvido em um vertedouro em degrau é completamente aerado e pode ser dividido em duas regiões, baixa e superior, semelhante aos escoamentos aerados em calhas. A concentração de ar nestas duas regiões estava de acordo com as equações desenvolvida por Straub e Anderson (1958) para escoamento em calhas inclinadas. Nas regiões mais baixas, os perfis de velocidade foram descritos pela equação de Karman-Prandtl para escoamento turbulento rugoso, onde foi usado um fundo rugoso equivalente. Na região superior, a velocidade do escoamento de ar-água decresce com a distancia do fundo. A perda de energia relativa no vertedouro em degraus foi da ordem de 48 a $63 \%$.

Pegram et al (1999) construiram e testaram dois modelos de vertedouro em degraus com declives de 1H:0,6V com diversas alturas de degraus e diversas vazões com vertedouro em regime de escoamento tipo skimming (ver definição, Figura 2.1.b). Os dados observados de energia foram analisados em termos da energia dissipada relativa, EDR, dada pela seguinte equação:

$$
\mathrm{EDR}=\left(\mathrm{E}_{1}^{\text {liso }}-\mathrm{E}_{1}^{\text {deg raus }}\right) / \mathrm{E}_{1}^{\text {liso }}
$$

sendo $E_{1}^{\text {liso }}$ a energia especifica no pé do vertedouro liso e $E_{1}^{\text {deg raus }}$ a energia especifica no pé do vertedouro em degraus.

Pegram et al (op. cit) concluíram que a EDR é independente da altura do degrau h; esta conclusão não é afetada se o escoamento no vertedouro em degraus estiver ou não totalmente desenvolvido. Eles também determinaram que os valores de EDR encontrados nos experimentos são menores que o valor estimado por Rajaratnam (1990).

\subsection{Regimes de Escoamentos em Vertedouros em Degraus.}

Um canal em degrau consiste em um canal aberto com uma série de quedas. Sorensen (1985) concluiu que ocorrem dois tipos distintos de escoamentos em função da vazão, o primeiro denominado de nappe flow (jato livre entre degraus - Figura 2.1.a), para vazões 
menores e skimming flow (deslizante, escoamento passando sobre os vórtices estáveis que se formam entre os degraus - Figura 2.1.b) para as vazões maiores.

No regime de escoamento tipo nappe, a queda total é dividida em inúmeras pequenas quedas livres. A água prossegue em uma série de mergulhos de um degrau a outro (Figura 2.1.a). O escoamento em cada degrau atinge o degrau abaixo com um jato em queda livre, seguido por um ressalto hidráulico em muitos casos. A energia dissipada ocorre pela dispersão do jato no ar, pela mistura do jato no degrau e com a formação ou desenvolvimento de um ressalto hidráulico no degrau (RAJANATNAM, 1990). Sobre pequenas barragens, uma grande taxa de dissipação de energia pode ser aplicada (ELLIS, 1989; PEYRAS et al., 1992). Para um regime de escoamento tipo nappe, os degraus precisam ser relativamente grandes. Esta situação não é sempre possível, mas pode ser aplicada em vertedores ou canais com pouca inclinação ou em pequenos riachos canalizados.

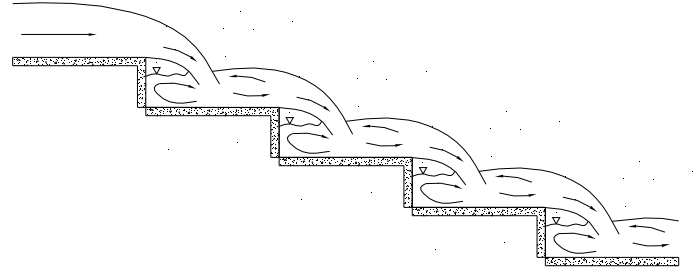

Regime tipo nappe

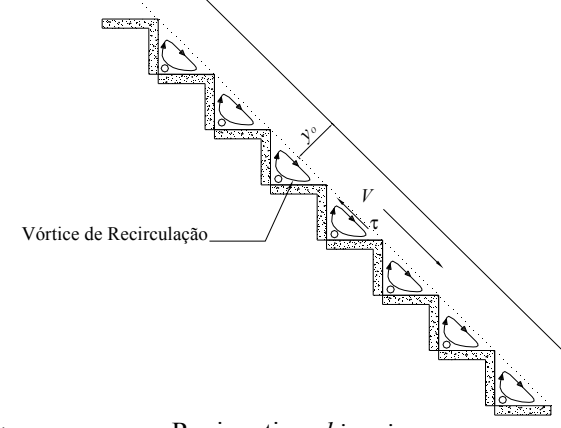

(a)
Regime tipo skimming (b)

Figura 2.1. Esquema de nappe flow (a) e de skimming flow (b)

No regime de escoamento skimming, o escoamento de um degrau ao outro se comporta de forma coerente, deslizando sobre os degraus, sendo amortecido por um fluido recirculante preso entre eles. (Figura 2.1.b). A linha externa ligando os vértices superiores dos degraus forma um pseudo-fundo sob o qual o escoamento desliza. Abaixo desta linha, um vórtice recirculatório desenvolve-se e é mantido pelo cisalhamento com a água que passa sobre os degraus. Nos primeiros degraus do vertedouro, o escoamento é liso e não ocorre o carreamento de ar. Em alguns degraus mais abaixo o escoamento é caracterizado pela existência do carreamento de ar e dos vórtices aprisionados. A dissipação de energia no escoamento parece ser aumentada pela transferência de momento para o escoamento recirculatório (RAJARATNAM, op. cit).

A passagem de um escoamento em regime nappe flow para o regime skimming flow é obtida por meio do aumento da vazão específica ou da declividade da calha. Chanson (1994), 
Diez-Cascon et al. (1991), Elviro e Mateos (1995), Essery e Horner (1978), Rajaratnam (1990), Chamani e Rajaratnam (1999) e Yasuda e Ohtsu (1999) estudaram a mudança do escoamento do regime nappe flow para escoamento com regime skimming flow em ensaios experimentais com modelos reduzidos.

Chanson (1994) definiu o início de regime skimming flow como sendo a situação em que desaparece a cavidade de ar abaixo da queda livre do jato e a água passa a escoar de forma quase homogênea.

Segundo Diez-Cascon et al. (1991) a transição entre o regime nappe flow é gradual e contínua, resultando que os dois tipos de regime aparecem simultaneamente em certa faixa de vazão.

Para Elviro e Mateos (1995) não é fácil determinar o limite entre os dois regimes de escoamento. Em testes realizados com uma calha em degraus com declividade $l / h$ igual a 0,77 os autores observaram a ocorrência do regime nappe flow para $y_{c} / h<0,51$ e o regime skimming flow para $y_{c} / h>0,72$, sendo $y_{c}$ a profundidade crítica do escoamento e $h$ e $l$, respectivamente, a altura e o comprimento dos degraus.

Alguns pesquisadores apresentaram formas para identificar as características do escoamento no início do regime skimming flow, com indicado na seqüência (OLINGER, 2001).

Essery e Horner (1978) realizaram testes em canais com declividade $h / l$ entre 0,2 e $0,842\left(11,3^{\circ}<\phi<40,1^{\circ}\right.$, onde $\phi$ é o ângulo formado entre a reta que tangencia os picos dos degraus e a horizontal) para determinar os valores de $y_{c} / h$ que passaria a identificar o limite entre os regimes nappe flow e skimming flow. A figura 2.2 apresenta os resultados obtidos pelos autores, relacionando $h / l$ em função de $y_{c} / l$, para inclinações $\theta$ do piso dos degraus com a horizontal iguais a $0^{\circ}$ (degraus horizontais), $5^{\circ}, 10^{\circ}, 15^{\circ}$, e $20^{\circ}$. 


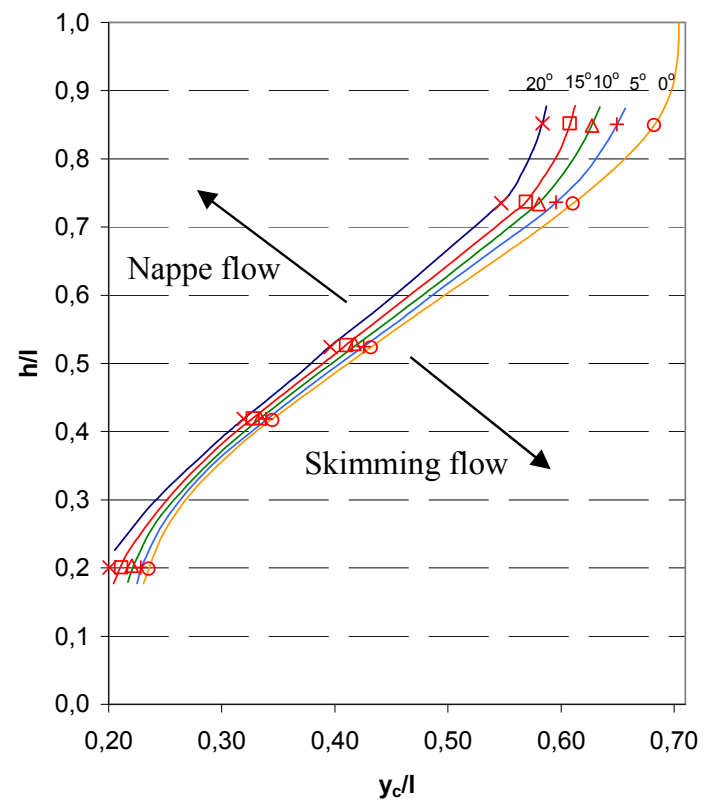

Figura 2.2. Limite entre os regimes nappe flow e skimming flow para várias inclinações do piso dos degraus (Fonte: ESSERY e HORNER, 1978).

Analisando os resultados obtidos por Essery e Horner (op. cit.) que identificam o início do regime skimming flow, Rajaratnam (1990) observou que os valores $y_{c} / h$ para a faixa de $h / l$ de 0,4 a 0,9 , resultaram aproximadamente constantes e iguais a 0,8 . Isto significa, segundo Rajaratnam (op. cit), que valores de $y_{c} / h$ maiores do que 0,8 conduzem à ocorrência do regime skimming flow.

As análises de resultados experimentais obtidos com calhas em degraus executada em concreto e gabião indicaram que o regime "skimmnig flow" ocorre para vazões maiores que um valor crítico. A vazão característica para o início do regime skimming flow foi definida em função da profundidade crítica mínima para a ocorrência deste tipo de regime, $y_{c, m i n}$, através da equação 2.2 (CHANSON, 1994):

$$
\frac{y_{c, \min }}{h}=1,057-0,465 \frac{h}{l}
$$

Chanson (1994) ressaltou que a equação 2.2 foi obtida para valores de $h / l$ compreendidos entre $1 \mathrm{H}: 5 \mathrm{~V}$ e $1 \mathrm{H}: 0,75 \mathrm{~V}\left(11^{\circ}<\phi<52^{\circ}\right)$.

Chanson (1996) assumiu que o regime skimming flow ocorre quando o ar aprisionado sob o jato desaparece, ou seja, quando a altura da superfície livre abaixo do jato $y_{p}$ é igual à altura do degrau $h$. Este critério dá origem à equação 2.3: 


$$
\frac{y_{c}}{h}=F_{b}^{2} \frac{\sqrt{1+\frac{1}{F_{b}^{2}}}}{\sqrt{1+2 F_{b}^{2}\left[1+\frac{1}{F_{b}^{2}}\right]^{3 / 2}\left[1-\frac{\cos \phi_{b}}{\sqrt{1+\frac{1}{F_{b}^{2}}}}\right]}}
$$

em que, $F_{b}$ é o número de Froude sobre o degrau, e $\phi_{b}$ é o ângulo de queda do jato que pode ser substituído pelo ângulo de inclinação do canal com degraus $\phi$. Na figura 2.4 , a equação 2.3 é apresentada para $F_{b}=1,66$ e $F_{b}=4,5$ - dois valores usados por Chanson (1996).

Chamani e Rajaratnam (1999) observaram que o início do escoamento tipo skimming flow, em um vertedouro em degrau, ocorre quando o jato torna-se paralelo à inclinação deste vertedouro, e o comprimento inferior do jato coincide com o à distância entre as arestas superiores dos degraus, como pode ser visualizado na figura 2.3 .

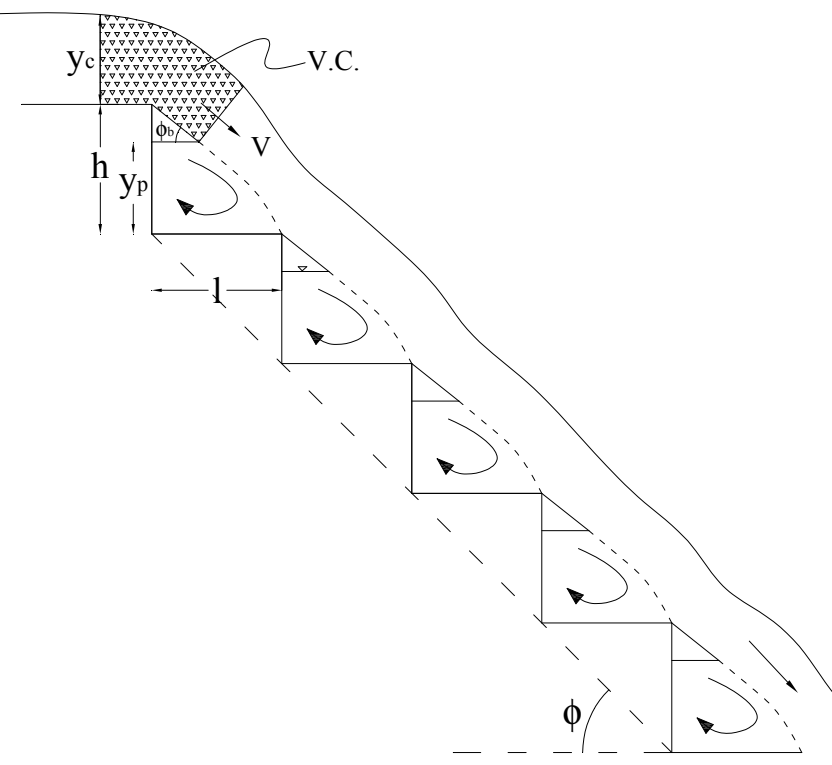

Figura 2.3. Esquema para análise do início do escoamento tipo skimming flow.

Se $V$ é a velocidade média na saída do jato com um ângulo de saída $\phi_{b}$, temos a seguinte equação para o volume de controle (equação de Bernoulli):

$$
\frac{V^{2}}{2 g}=1,5 y_{c}+h-y_{p}
$$

Para o mesmo volume de controle temos também (equação da quantidade de movimento): 


$$
\frac{1}{2} \mathscr{y}_{c}^{2}=\rho q\left(V \operatorname{Cos} \phi_{b}-V_{c}\right)
$$

onde $\gamma$ é o peso específico, $\rho$ é a massa específica, $q$ é vazão unitária e $V_{c}$ é velocidade média crítica. Combinando as equações 2.4 e 2.5 encontra-se a relação teórica para $\operatorname{Cos} \phi_{b}$ :

$$
\operatorname{Cos} \phi_{b}=\frac{1,5}{\sqrt{2\left[\frac{h}{y_{c}}-\frac{y_{p}}{y_{c}}+1,5\right]}}
$$

O comprimento de salto, $l_{p}$ é estimado usando a seguinte equação empírica, desenvolvida por Rajaratnam e Chamani (1995):

$$
\frac{l_{p}}{h}=2,47\left[\frac{y_{c}}{h}\right]^{0,62}
$$

Quando o comprimento do salto é igual à distância entre as arestas superiores dos degraus, tem-se.

$$
\frac{h}{l}=0,405\left[\frac{y_{c}}{h}\right]^{-0,62}
$$

Usando a equação a seguir, proposta por Rand (1955, apud CHANSON ,1994):

$$
\frac{y_{p}}{h}=\left[\frac{y_{c}}{h}\right]^{0,66}
$$

com as condições em que o jato é paralelo à inclinação do vertedouro em degrau uma equação para o início do regime skimming flow, a equação 2.6 pode ser transformada em:

$$
\frac{h}{l}=\sqrt{0,89\left[\left(\frac{y_{c}}{h}\right)^{-1}-\left(\frac{y_{c}}{h}\right)^{-0,34}+1,5\right]-1}
$$

Uma comparação entre as equações 2.2, 2.3, 2.8, 2.10 e os dados experimentais de Essery e Horner (1978), Peyras et al.(1992) e, Beitz e Lawless (1992) é apresentada na figura 2.4 . 


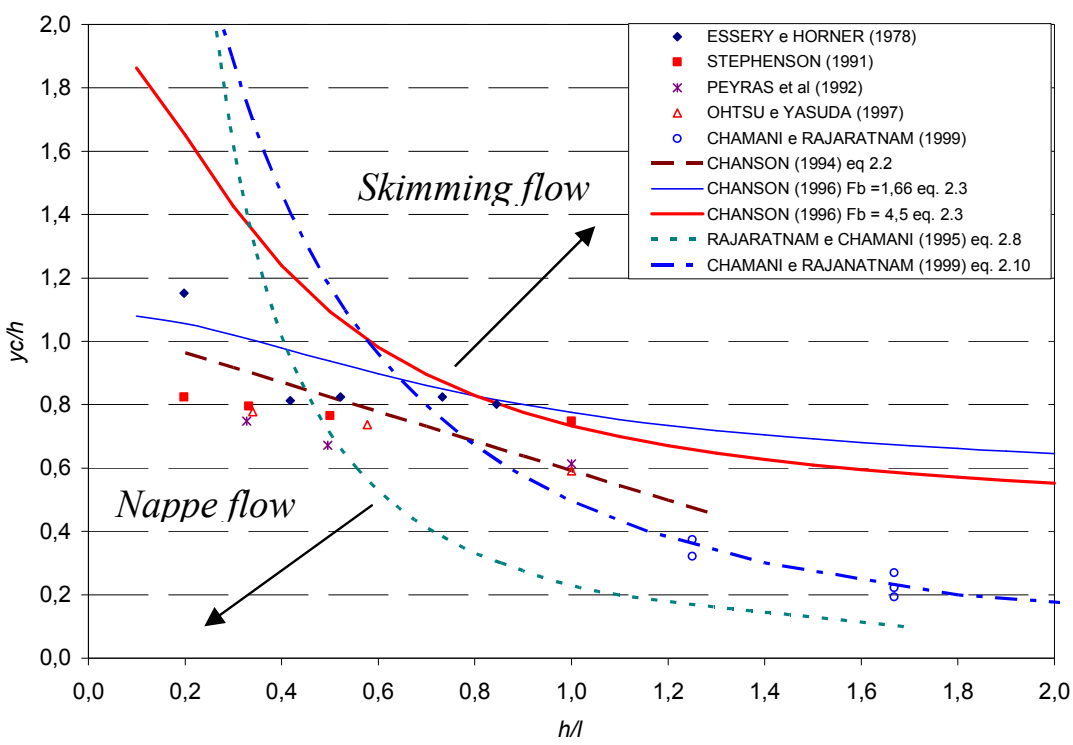

Figura 2.4. Comparação de resultados experimentais com as posições teóricas para identificação do início do regime skimming flow

(Fonte: CHAMANI e RAJARATNAM, 1999).

Considerando o regime skimming flow como a formação de vórtices nos degraus sem a observação da presença de ar, Yasuda e Ohtsu (1999) apresentaram uma expressão - equação 2.11 - que define o limite superior da altura do degrau para formação do regime skimming flow:

$$
\frac{h}{y_{c}}=1,16(\tan \phi)^{0,165}
$$

Apresentaram, também, a equação 2.12 para a definição da mínima altura do degrau para a formação de regime nappe flow, considerando a formação de uma bolsa de ar em cada degrau na região de escoamento totalmente aerado:

$$
\frac{h}{y_{c}}=0,57(\tan \phi)^{3}-1,3
$$




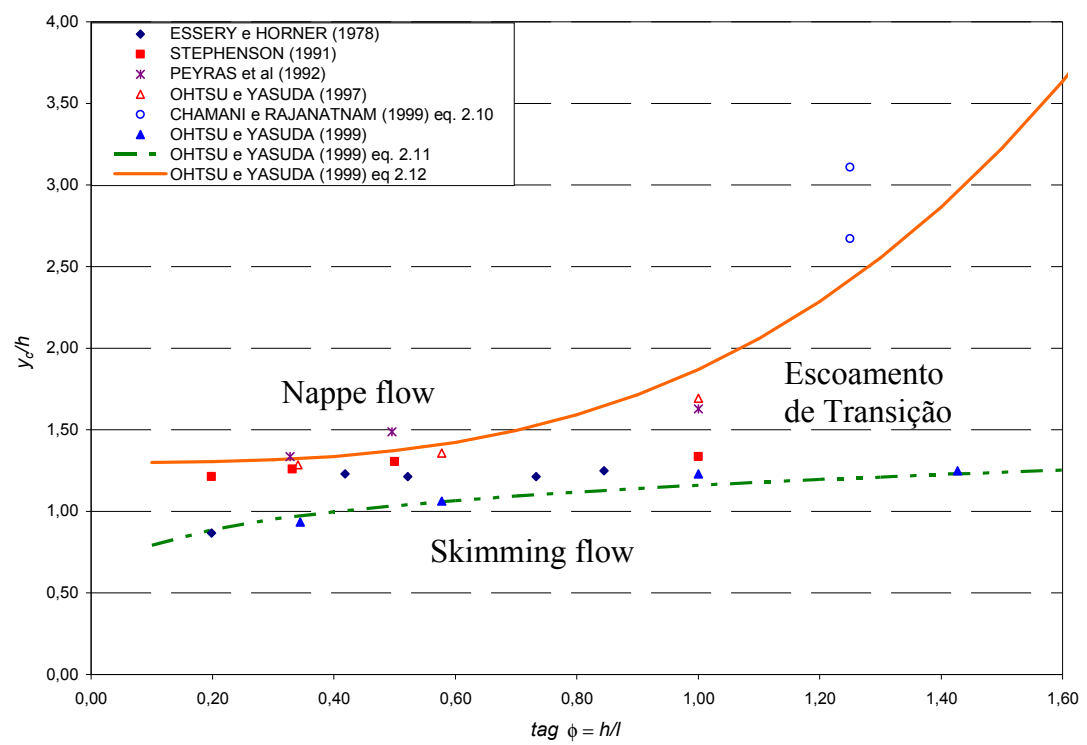

Figura 2.5. Comparação dos regimes de escoamento em calhas com degraus.

(Fonte: OHTSU e YASUDA, 1999).

\subsection{Análise do Escoamento Tipo Skimming (RAJARATNAM, 1990).}

Para um vertedouro em degraus de altura $h$ e espaçamento $l$, define-se a declividade $S_{o}=\operatorname{sen} \phi=h / \sqrt{l^{2}+h^{2}}$. Seguindo a formulação da tensão de cisalhamento nos escoamentos em canais, pode-se exprimir a tensão média, $\tau$, entre o escoamento tipo skimming e a parte inferior com recirculação como:

$$
\tau=y_{o} \gamma \operatorname{sen} \phi
$$

em que $\gamma$ é o peso específico do fluido e $y_{\mathrm{o}}$ representa a profundidade do escoamento.

Tendo em vista, a definição do coeficiente de cisalhamento $c_{f}$ :

$$
\tau=c_{f} \cdot \frac{\rho \cdot V^{2}}{2}
$$

onde $\rho$ é a massa especifica do fluido. A equação 2.13 pode ser reescrita:

$$
c_{f}=\frac{2 y_{o}^{3} g \operatorname{sen} \phi}{q^{2}}
$$

sendo $g$ a aceleração de gravidade e $q$ a vazão por unidade de largura do vertedouro.

Eq. (2.15) pode ser reescrita como:

$$
V=\sqrt{\frac{2}{c_{f}}} \cdot \sqrt{g \cdot y_{o} \cdot S_{o}}
$$


A vazão por unidade de largura $q$ pode ser expressa:

$$
q=\sqrt{\frac{2}{c_{f}}} y_{o}^{3 / 2} \sqrt{g S_{o}}
$$

\subsection{Características Hidráulicas no Escoamento Tipo Nappe.}

O regime de escoamento tipo nappe já foi definido como uma sucessão de jatos livres. O salto do escoamento de água para o degrau seguinte se dá como uma série de quedas livres pequenas.

Existem três tipos distintos de escoamentos em regime nappe (CHANSON, 1994): 1 Escoamento nappe com ressalto hidráulico totalmente desenvolvido (sub-regime NA1), 2 Escoamento nappe com ressalto hidráulico parcialmente desenvolvido (sub-regime NA2) e Escoamento nappe sem a formação de ressalto hidráulico (sub-regime NA3) (Figura 2.6).

O escoamento tipo nappe com degrau horizontal é caracterizado tipicamente pela presença do ressalto hidráulico. A ausência do ressalto hidráulico pode ocorrer para vazões altas, anteriores a aparição do escoamento tipo skimming.

Moore (1943, apud CHANSON, 1994) e Rand (1955, apud CHANSON, op. cit)

analisaram o escoamento de um jato em degrau simples. Para um degrau horizontal, a condição de escoamento próximo ao fim do degrau, muda de subcrítico para crítico em uma seção a uma pequena distância da extremidade.

MOORE, W. L. Energy loss at the base of a free overfall. Transaction, ASCE, v. 108, p 1343-1360. Discussion: v. 108, pp. 1361-1392, 1943 


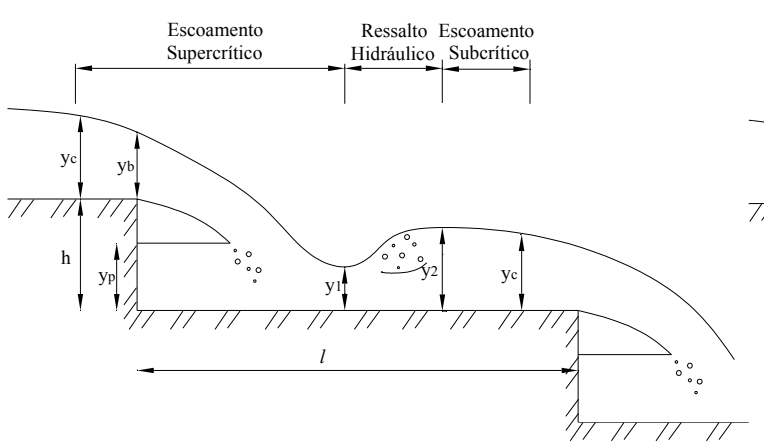

(Sub-regime NA1)

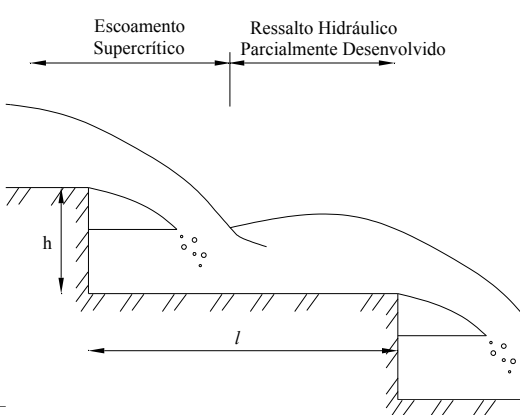

(Sub-regime NA2)

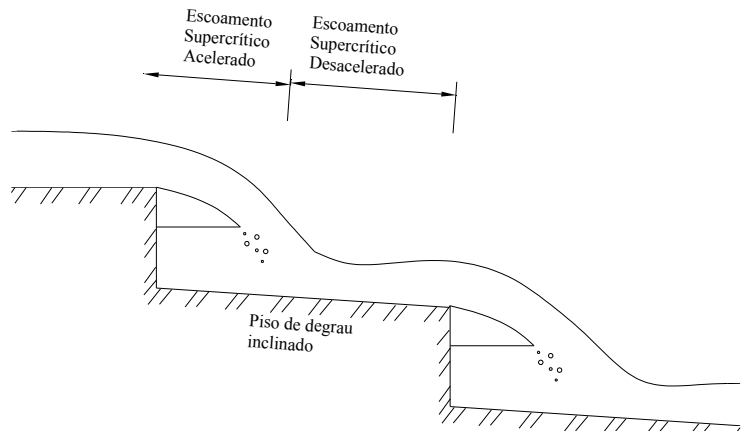

(Sub-regime NA3)

Figura 2.6. Sub-regimes do escoamento tipo nappe: Escoamento nappe com ressalto hidráulico totalmente desenvolvido (sub-regime NA1); escoamento nappe com ressalto hidráulico parcialmente desenvolvido (sub-regime NA2) e escoamento nappe sem ressalto hidráulico (Fonte: Adaptado de CHANSON, 1994).

\subsection{Perda de Energia em um Vertedouro em Degraus.}

\subsubsection{Regime de Escoamento Skimming - Dissipação de Energia.}

Sorensen (1985) e Christodoulou (1993) estudaram a perda de energia em modelos reduzidos e estabeleceram uma relação de dependência desta perda com o número de degraus para diversas vazões.

Sorensen (op. cit) apresenta resultados de ensaios em modelos Froudianos bidimensionais da Barragem de Monksville, construídas em três experimentos diferentes, sendo o primeiro em escala 1:10, representando a parte superior do vertedouro, para estudar a transição entre a crista e a região de degraus com dimensões constantes, o segundo, em escala 1:25 em calha lisa, para servir de base aos estudos do vertedouro em degraus e o terceiro também em escala 1:25 do vertedouro em degraus. O formato padrão que se desenvolve em degraus, recomendado pelo WES (Waterways Experiment Station, do U. S. Bureau of 
Reclamation), foi utilizado na Barragem de Monksville. A vazão deste projeto foi de 9,3 $\mathrm{m}^{3} / \mathrm{s} / \mathrm{m}$, com um desnível de $61 \mathrm{~m}$, possuindo uma declividade de $1 \mathrm{~V}: 0,78 \mathrm{H}$ e os degraus com 0,60 $\mathrm{m}$ de altura. Ele concluiu em seu trabalho que uma fração elevada de energia é dissipada ao longo da calha.

Christodoulou (1993) realizou experimentos no Laboratório de Hidráulica Aplicada da Universidade Técnica Nacional de Atenas e também utilizou o formato ogiva recomendada pelo WES. O vertedouro testado com escala de 1:25 tem a forma apresentada na Figura 2.7.

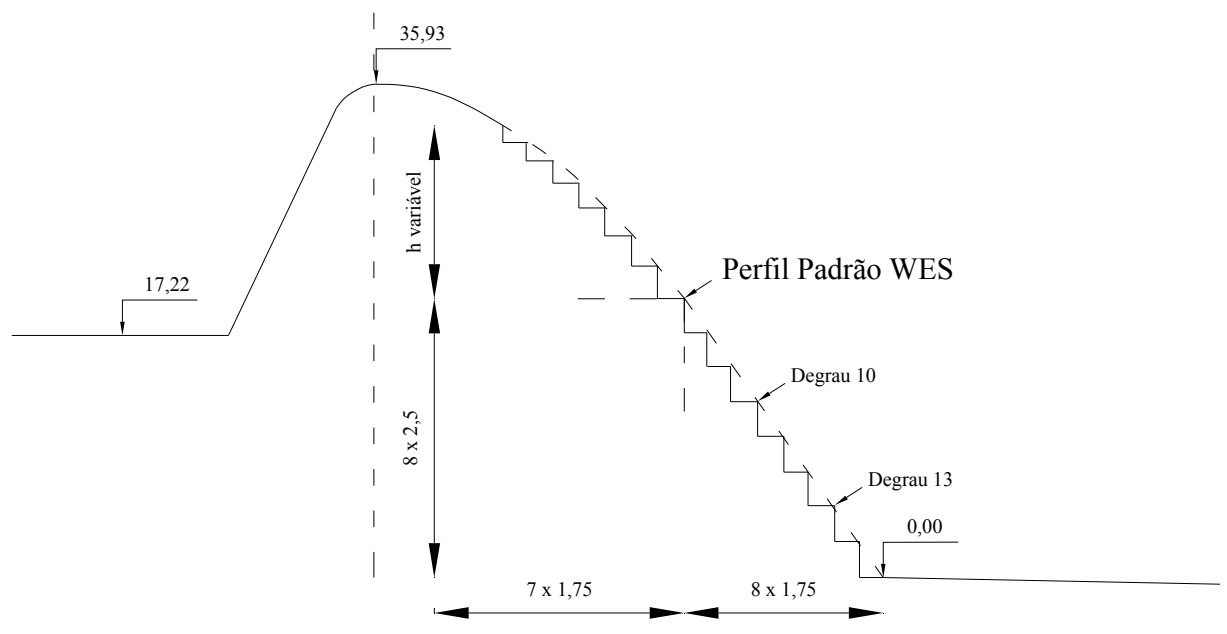

Figura 2.7. Perfil Testado por Christodoulou (1993) - Dimensões em cm.

Variando-se a vazão de entrada entre 10 1/s e 45 1/s as alturas das laminas d'água sobre os degraus de número 10 e 13 foram determinadas. A perda de energia total pode ser expressa como:

$$
\Delta H=H_{o}-H
$$

onde $H=y \cos \phi+\left(V^{2} / 2 g\right)$ é a carga hidráulica sobre o degrau considerado, $H_{o}=\Delta z+Y+\left(V_{o}^{2} / 2 g\right)$ é a carga hidráulica à montante do vertedouro, $V=Q /(y B)$, a velocidade média local, $V_{o}=Q /(Y B)$, a velocidade de aproximação e $B$, a largura do canal. 


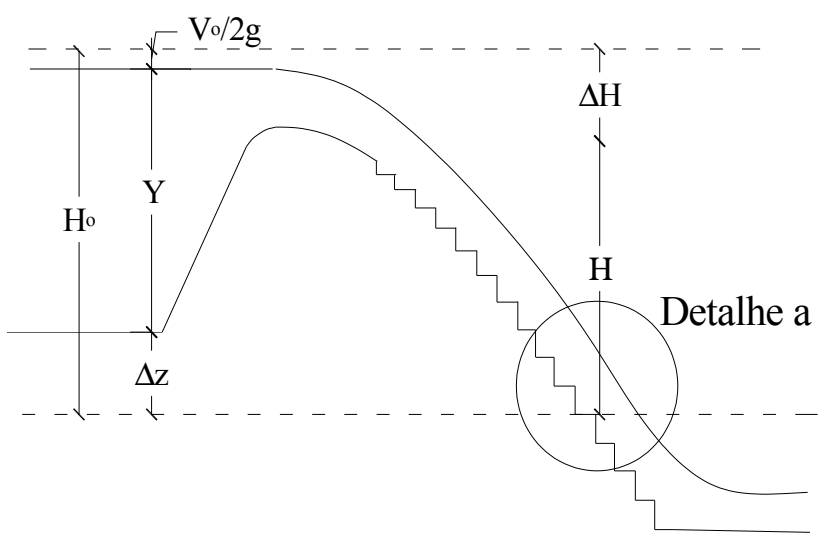

(a)

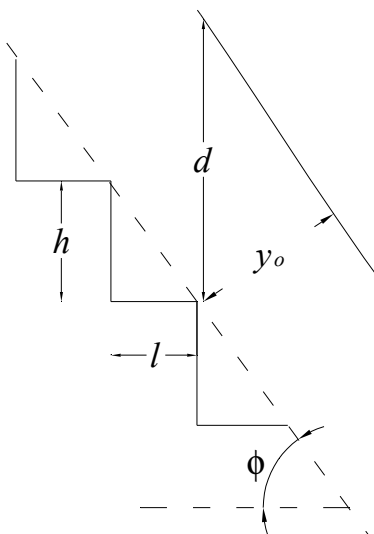

(b)

Figura 2.8. Esquema de Notação.

Sendo $B>>y_{o}$, a perda de carga hidráulica depende do número e da geometria dos degraus e da vazão $Q$, que por sua vez pode ser expressa em forma de altura crítica que ocorre em alguma seção na crista do vertedouro, em que $y_{c}=\sqrt[3]{(Q / B)^{2} / g}$. Uma análise dimensional simples leva à seguinte relação:

$$
\frac{\Delta H}{H_{o}}=f\left(N, \frac{y_{c}}{h}, \frac{l}{h}\right)
$$

Christodoulou (1993) utilizou $l / h$ de 0,7. Este valor é próximo ao 0,78 utilizado por Sorensen (1985); ao 0,60 a 0,62 de Hollingworth e Druyts (1986, apud CHANSON, 1994) e, ao 0,75 de Bouyge et al (1988, apud CHANSON,1994) e de TOZZI (1992).

CHRISTODOULOU (op. cit) apresenta os dados de $\Delta H / H_{o}$ versus $y_{c} / h$ (Figura 2.9). Em conjunto a este gráfico ele apresenta os dados de SORENSEN (op. cit). O efeito do número de degraus $N$ é evidente, para um valor específico de $y_{c} / h$ a perda de energia aumenta com o número de degraus.

HOLLINGWORTH, F.; DRUYTS, F. H. W. Rollcrete: Some applications to Dams in South Africa. Intl Water Power and Dam Constrution, v. 38, n. 1, p 13-16, Jan. 1986

BOUYGE, B; GARNIER, G.; JENSEN, A.; MARTIN, J.P., and STERENBERG, J. Construction et Controle d'un Barrage en Béton Compacté au Rouleau (BCR): un Travall d'Equipe. (Roller Compact Concrete Dam Construction and Works Supervision: a Team Job.’) Proc. 16 th ICOLD Congress, San Francisco, USA, Q. 62, R. 34. p 588-612, 1988 (em Francês) 


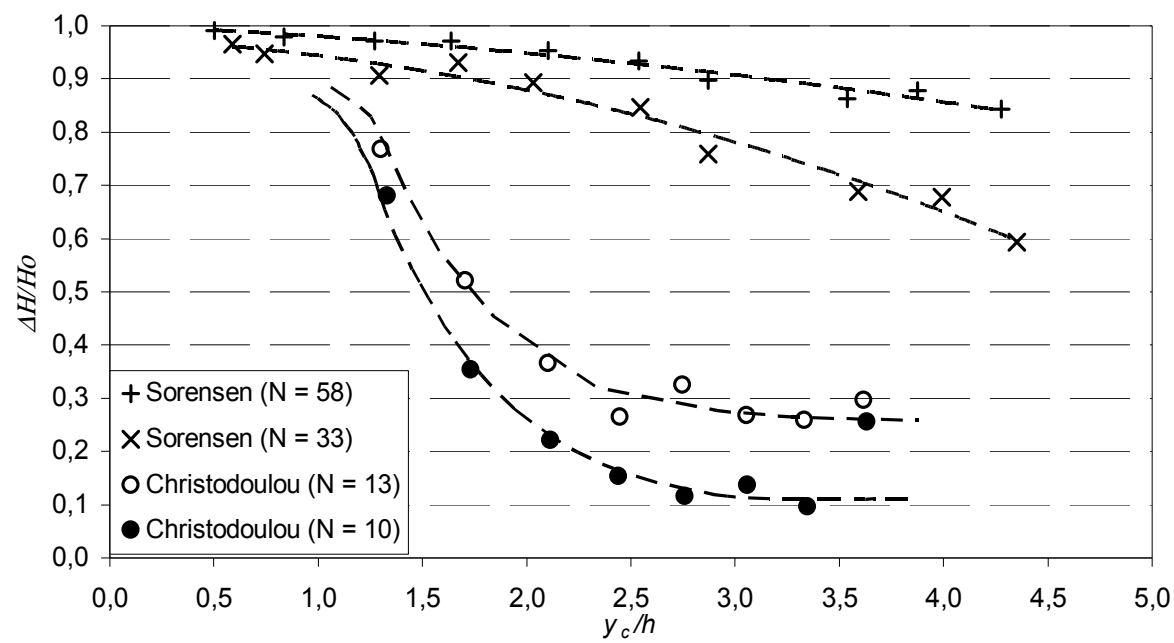

Figura 2.9. Variação de perda de carga relativa $\Delta H / H_{o} \operatorname{com} y_{c} / h$ e $N$

(Fonte: CHRISTODOULOU, 1993).

A Figura 2.10 ilustra a dependência de $\Delta H / H_{o}$ com o parâmetro $y_{c} / N h$. Christodoulou (1993) sugeriu uma curva unindo os dados experimentais dele com os de Sorensen (1985) e visualizou o maior efeito na perda de energia relativa no vertedouro em degrau quando $y_{c} / N h$ é menor ou quando a vazão é pequena. Essa admensionalização é contestada por alguns pesquisadores, pois um único degrau ou um vertedouro liso tem a mesma perda de carga. Sabe-se que há um aumento na dissipação de energia com o aumento da altura do degrau, $h$.

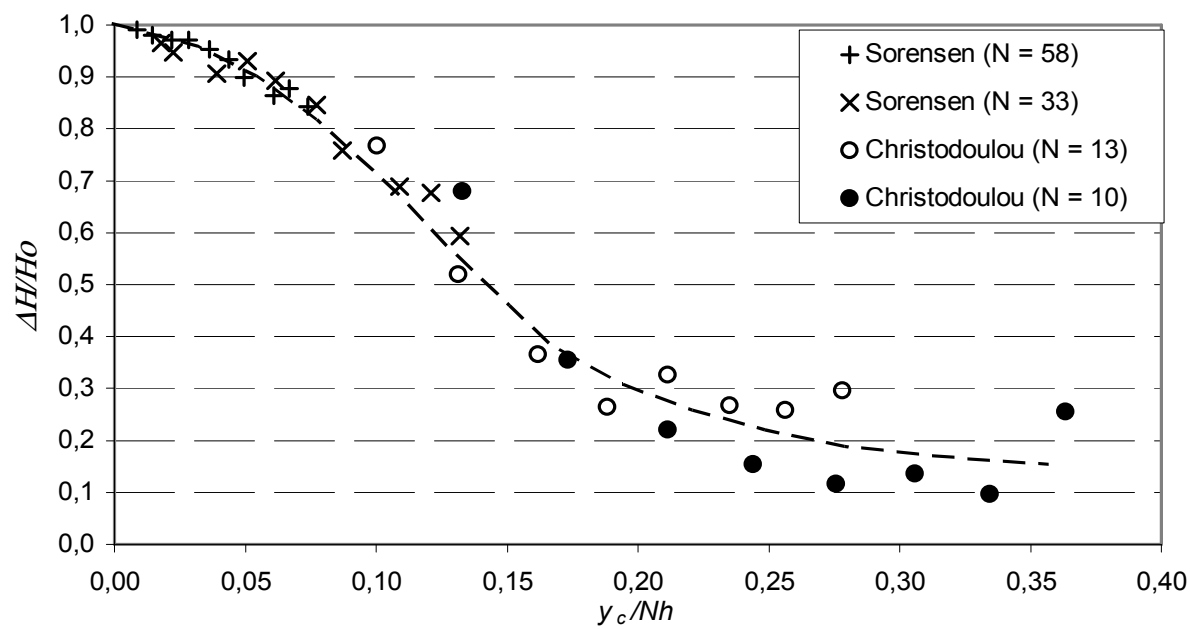

Figura 2.10. Dependência de $\Delta H / H_{o}$ com $y_{c} / N h$ (Fonte: CHRISTODOULOU, 1993).

Uma estimativa da perda de energia para o escoamento tipo skimming em um vertedouro em degraus é apresentada por Rajaratnam (1990) usando a análise já conhecida 
das seções prévias. Se $E_{l}{ }^{\text {degrau }}$ for a energia no escoamento ao pé do vertedouro em degraus, temos:

$$
\begin{aligned}
& E_{1}^{\operatorname{deg} r a u}=y_{o}+\frac{V^{2}}{2 g} \\
& E_{1}^{\operatorname{deg} r a u}=\left(\frac{c_{f} q^{2}}{2 g \operatorname{sen} \phi}\right)^{1 / 3}+\left(\frac{q \operatorname{sen} \phi}{c_{f} \sqrt{2 g}}\right)^{2 / 3}
\end{aligned}
$$

Seja:

$$
\Delta E=E_{1}^{l i s o}-E_{1}^{\operatorname{deg} r a u}
$$

onde $E_{1}^{\text {liso }}$ é a energia especifica no pé do vertedouro liso, $\Delta E$ é a perda de energia causada pelos degraus em relação à perda causada pelo vertedouro de face lisa. Se a perda de energia relativa for definida como $\Delta E / E_{1}^{\text {liso }}$, ela pode ser apresentada como:

$$
E D R=\frac{\Delta E}{E_{1}^{\text {liso }}}=\frac{(1-R c)+\frac{F_{o}^{\prime 2}}{2} \frac{\left(R c^{2}-1\right)}{R c^{2}}}{1+\frac{F_{o}^{\prime 2}}{2}}
$$

em que $R c=\left(c_{f} / c_{f}{ }^{1 / 3}\right.$ sendo $c_{f}$, o coeficiente de cisalhamento para vertedouro liso e $F_{o}$, o número de Froude no pé do vertedouro de face lisa. Utilizando $c_{f} \approx 0,18$ e $c_{f}{ }^{\prime} \approx 0,0065, R c \approx 3$ e para um valor relativamente grande de $F_{o}{ }^{\prime}, \Delta E / E_{1}^{\text {liso }}$ é aproximadamente igual a $\left(R c^{2}-1\right) / R c^{2}$, que corresponde ao valor de $89 \%$. Isto indica uma considerável quantidade de perda de energia que pode ser produzida pelos degraus, como foi observado por Sorensen (1985).

Segundo Chanson (1994) para o escoamento com regime tipo skimming grandes perdas de energia ocorrem devido ao cisalhamento existente nos degraus. A maior parte da energia é dissipada na manutenção dos vórtices de recirculação presentes na cavidade abaixo do pseudo-fundo formado pelas arestas dos degraus (Figura 2.1-b). Se a condição uniforme do escoamento for estabelecida antes do término do canal, um cálculo analítico proposto por Chanson (1994) para a dissipação de energia pode ser aplicado:

$$
\frac{\Delta H}{H_{o}}=1-\frac{\frac{y_{o}}{y_{c}} \cos \phi+\frac{1}{2} \alpha_{\mathrm{c}}\left(\frac{y_{c}}{y_{o}}\right)^{2}}{\frac{3}{2}+\frac{H_{\text {barr }}}{y_{c}}} \quad \text { (vertedouro sem comporta) }
$$




$$
\frac{\Delta H}{H_{o}}=1-\frac{\frac{y_{o}}{y_{c}} \cos \phi+\frac{1}{2} \alpha_{\mathrm{c}}\left(\frac{y_{c}}{y_{o}}\right)^{2}}{\frac{H_{b a r r}+h_{o}}{y_{c}}} \quad \text { (vertedouro com comporta) }
$$

onde $H_{o}$ é a carga máxima avaliada, $H_{\text {barr }}$ é a altura da crista da barragem, $y_{o}$ é a altura do escoamento uniforme, $y_{c}$ é a altura crítica do escoamento, $h_{o}$ é a elevação da superfície livre do reservatório em relação à crista. Para vertedouro sem comporta a carga máxima é dada por: $H_{o}=H_{b a r r}+1,5 . y_{c}$, Já para vertedouro com comporta, tem-se: $H_{o}=H_{b a r r}+h_{o}$. O coeficiente de correção da energia cinética ( $\alpha_{c}$, coeficiente de Coriolis), que é dado por:

$$
\alpha_{c}=\frac{\int_{A} v^{3} d A}{V^{3} A}
$$

Substituindo nas equações $2.24 \mathrm{a}$ e $2.24 \mathrm{~b}$, a profundidade para escoamento uniforme é dada pela seguinte expressão:

$$
\frac{y_{o}}{y_{c}}=\sqrt[3]{\frac{f_{e}}{8 . \operatorname{sen} \phi}}
$$

sendo $f_{e}$ o fator de cisalhamento do escoamento aerado uniforme, temos:

$$
\begin{gathered}
\frac{\Delta H}{H_{o}}=1-\frac{\left(\frac{f_{e}}{8 . \operatorname{sen} \phi}\right)^{1 / 3} \cos \phi+\frac{1}{2} \alpha_{c}\left(\frac{f_{e}}{8 . \operatorname{sen} \phi}\right)^{-2 / 3}}{\frac{3}{2}+\frac{H_{\text {barr }}}{y_{c}}} \text { (vertedouro sem comporta) } \\
\frac{\Delta H}{H_{o}}=1-\frac{\left(\frac{f_{e}}{8 . \operatorname{sen} \phi}\right)^{1 / 3} \cos \phi+\frac{1}{2} \alpha_{c}\left(\frac{f_{e}}{8 . \operatorname{sen} \phi}\right)^{-2 / 3}}{\frac{H_{\text {barr }}+h_{o}}{y_{c}}} \quad \text { (vertedouro com comporta) }
\end{gathered}
$$

Para barragens altas, o termo de energia cinética é pequeno e as equações $2.27 \mathrm{a}$ e $2.27 \mathrm{~b}$ tornam-se similares a expressão obtida por Stephenson (1991):

$$
\frac{\Delta H}{H_{o}}=1-\left(\left(\frac{f_{e}}{8 \cdot \operatorname{sen} \phi}\right)^{1 / 3} \cos \phi+\frac{1}{2} \alpha_{c}\left(\frac{f_{e}}{8 . \operatorname{sen} \phi}\right)^{-2 / 3}\right) \frac{y_{c}}{H_{\text {barr }}}
$$

As equações $2.27 \mathrm{a}, 2.27 \mathrm{~b}$ e 2.28 indicam que a dissipação de energia aumenta com a altura da barragem. 


\subsubsection{Regime de Escoamento Nappe - Dissipação de Energia.}

$\mathrm{Na}$ situação de escoamento tipo nappe com um ressalto hidráulico completamente desenvolvido, a perda de carga em qualquer degrau intermediário é igual à altura desse degrau. A dissipação de energia neste tipo de dissipadores acontece com o impacto do jato, com as recirculações, e também com a formação de um ressalto hidráulico sobre o degrau. A perda de carga total ao longo da calha $\Delta H$ é igual à diferença entre a carga máxima $H_{o}$ disponível e a carga residual à jusante fim do canal $H$, e é apresentada como:

$$
\begin{aligned}
& \frac{\Delta H}{H_{o}}=1-\left(\frac{\frac{y_{1}}{y_{c}}+\frac{1}{2}\left(\frac{y_{c}}{y_{1}}\right)^{2}}{\frac{3}{2}+\frac{H_{\text {barr }}}{y_{c}}}\right) \\
& \frac{\Delta H}{H_{o}}=1-\left(\frac{\frac{y_{1}}{y_{c}}+\frac{1}{2}\left(\frac{y_{c}}{y_{1}}\right)^{2}}{\frac{H_{\text {barr }}+h_{o}}{y_{c}}}\right)
\end{aligned}
$$

onde $H_{b a r r}$ é a altura da barragem e $h_{o}$ a elevação da superfície livre sobre a crista do vertedouro, sendo a carga máxima avaliada da seguinte maneira: $H_{o}=H_{b a r r}+1,5 \cdot y_{c}$ (sem comporta) e $H_{o}=H_{\text {barr }}+h_{o}$ (com comporta).

Rand (1955, apud CHANSON, 1994) realizou experimentos e encontrou uma correlação entre $y_{1} / y_{c}$ e $y_{c} / h$, que é dada por:

$$
\frac{y_{1}}{y_{c}}=0,54\left(\frac{y_{c}}{h}\right)^{0,275}
$$

Combinando a equação 2.30 com as equações 2.29 e perda de energia para escoamentos tipo nappe fica:

$$
\begin{aligned}
& \frac{\Delta H}{H_{o}}=1-\left(\frac{0,54\left(\frac{y_{c}}{h}\right)^{0,275}+\frac{3,43}{2}\left(\frac{y_{c}}{h}\right)^{-0,55}}{\frac{3}{2}+\frac{H_{\text {barr }}}{y_{c}}}\right) \quad \text { (vertedouro sem comporta) } \\
& \frac{\Delta H}{H_{o}}=1-\left(\frac{0,54\left(\frac{y_{c}}{h}\right)^{0,275}+\frac{3,43}{2}\left(\frac{y_{c}}{h}\right)^{-0,55}}{\frac{H_{b a r r}+h_{o}}{y_{c}}}\right) \quad \text { (vertedouro com comporta) }
\end{aligned}
$$


Na figura 2.11, a perda de energia para o vertedor sem comporta (equação 2.31a) é plotada em função da altura crítica e do número de degraus, e comparada com dados experimentais de Moore (1943, apud CHANSON, 1994), Rand (1955, apud CHANSON 1994), Horner (1969) e Stephenson (1979). A figura 2.11 indica que a maior parte da energia é dissipada no canal com degraus em grandes barragens (quanto maior o número de degraus maior a energia dissipada). Verifica-se que para uma determinada altura da barragem, a dissipação de energia diminui quando a vazão aumenta. Note que existe uma boa concordância entre equação $2.31 \mathrm{a}$ e os dados observados em modelos de canais de um degrau e de múltiplos-degraus.

As equações 2.29 e 2.31 foram obtidas para o escoamento nappe com ressalto hidráulico totalmente desenvolvido (sub-regime NA1). Peyras et al. (1991) realizaram experimentos para escoamentos nappe com ressalto hidráulico com desenvolvimento total e parcial. A taxa de dissipação de energia para escoamento nappe com desenvolvimento parcial do ressalto hidráulico (sub-regime NA2) foi 10\% inferior ao valor obtido para o escoamento nappe com ressalto hidráulico totalmente desenvolvido para as condições similares de escoamento. Então, acredita-se que as equações 2.31 podem ser aplicadas com razoável exatidão à maioria das situações de escoamento tipo nappe em canais com degraus horizontais.

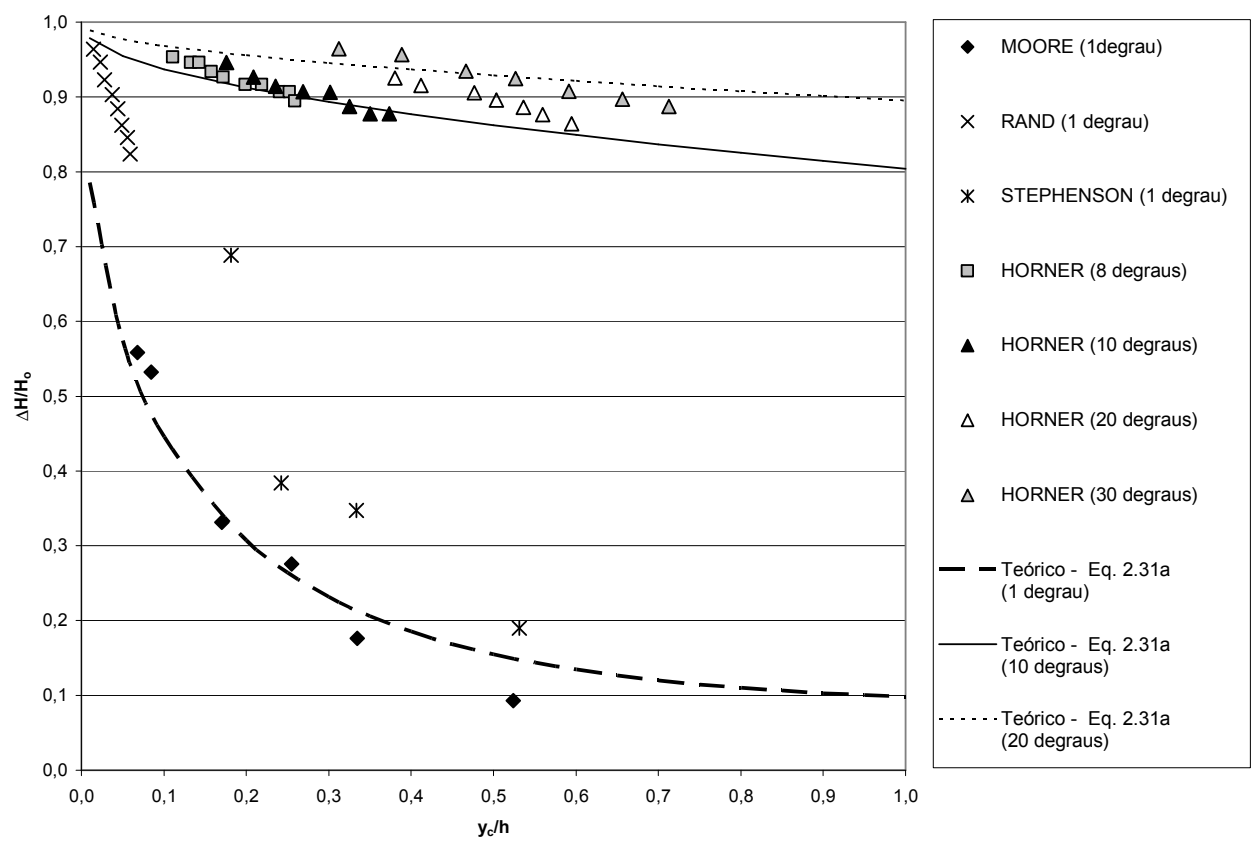

Figura 2.11. Dissipação de Energia no escoamento tipo nappe.

(Fonte: Adaptado de CHANSON, 1994). 


\subsubsection{Comparação entre os Regimes de Escoamento Nappe e Skimming.}

Vários pesquisadores (ELLIS, 1989; PEYRAS et al., 1991; CHAMANI e RAJARATNAM, 1994) sugeriram que a dissipação de energia é maior em escoamento tipo nappe do que as situações de escoamento skimming. E de fato, nos escoamentos tipo nappe a dissipação de energia ocorre pelo impacto do jato e pela formação de um ressalto hidráulico sobre o degrau, podendo retornar ao regime supercrítico passando pela altura crítica antes da formação do novo jato. Dessa forma, o escoamento estará retornando às condições iniciais de energia cinética, sendo toda energia potencial dissipada em cada degrau.

Na figura 2.12 compara-se a taxa de dissipação de energia para os escoamento tipo nappe e tipo skimming. Os dados experimentais para o escoamento tipos skimming para escoamentos aerados são comparados como os calculados utilizando a equação $2.27 \mathrm{a}$ assumindo $f=0,163$ e para o escoamento tipo nappe utilizou-se a equação 2.31 a para 5,10 e 20 degraus. Os resultados sugerem que uma maior taxa de dissipação de energia é observada para o escoamento tipo nappe sendo menor para a condição de escoamento tipo skimming. Deve ser notado, porém que, para uma determinada vazão, um regime de escoamento nappe requer menores declives e degraus maiores que um regime de escoamento skimming. Em alguns casos, tais exigências poderiam aumentar o custo da estrutura ou poderia não ser possível a construção (CHANSON, 2002).
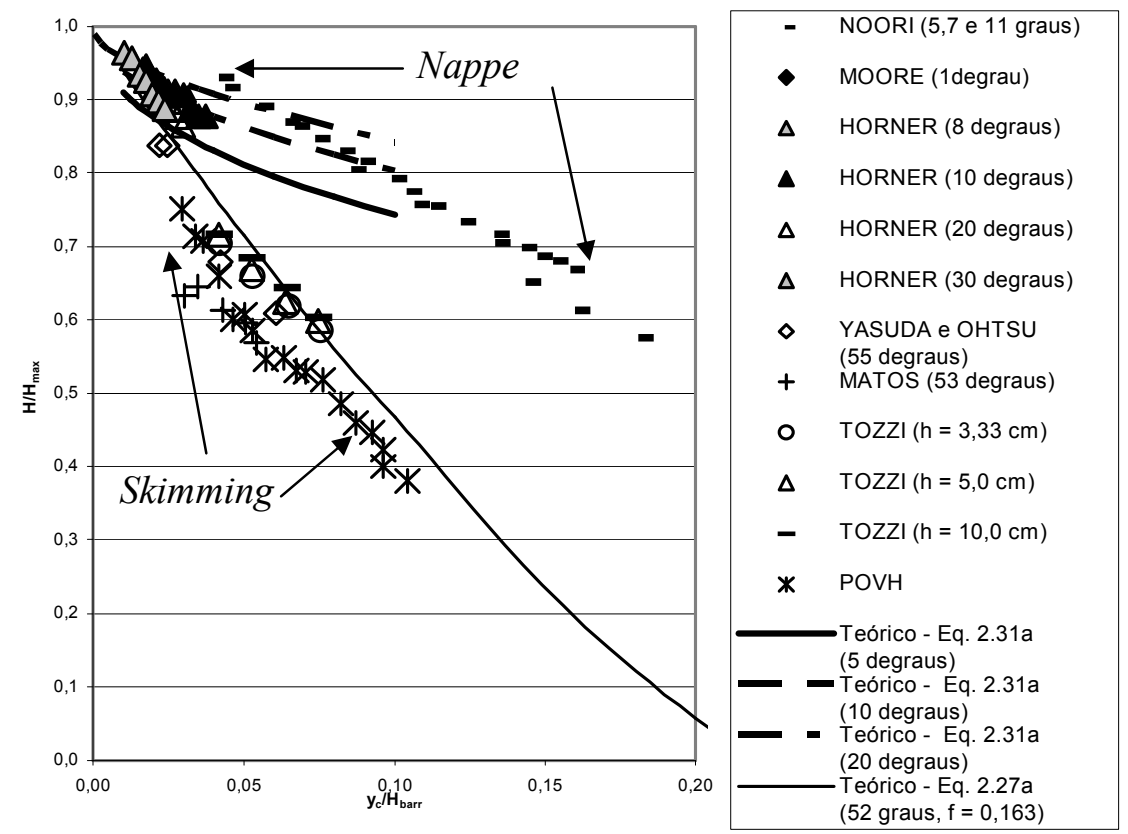

Figura 2.12. Comparação da dissipação de energia no escoamento tipo nappe e skimming

(Fonte: Adaptado de CHANSON, 2002). 


\subsection{Aeração ao Longo de Vertedouros em Degraus.}

\section{Introdução}

A aeração acrescida ao escoamento em vertedouro em degrau amplia a possibilidade de diminuir o risco de potencial de cavitação da estrutura do vertedouro. De acordo com Peterka (1953), uma concentração de ar em torno de 7\% é suficiente para evitar o risco de cavitação em superfície de concreto, porque a compressibilidade da mistura ar-água pode absorver o impacto do colapso das bolhas vaporizadas. Bindo et al. (1993) descreveram que a macroturbulência criada pelos degraus no interior do escoamento favorece o desenvolvimento da camada limite, cuja espessura aumenta mais rapidamente do que em calhas lisas.

A Figura 2.13 (CHANSON e TOOMBES, 2003) ilustra o escoamento sobre um vertedouro em degraus e também algumas de suas características: onde $C$ representa a fração de vazios; $V$, a velocidade; $F$, a taxa de formação de bolha $(\mathrm{Hz})$, ou seja, o número de bolha detectado pelo sensor da sonda por segundo; da profundidade de água limpa equivalente; $y$, a distância medida perpendicularmente ao pseudo-fundo formado pelas extremidades dos degraus; $h$, a altura do degrau e $\phi$, o ângulo entre a horizontal e o pseudo-fundo.

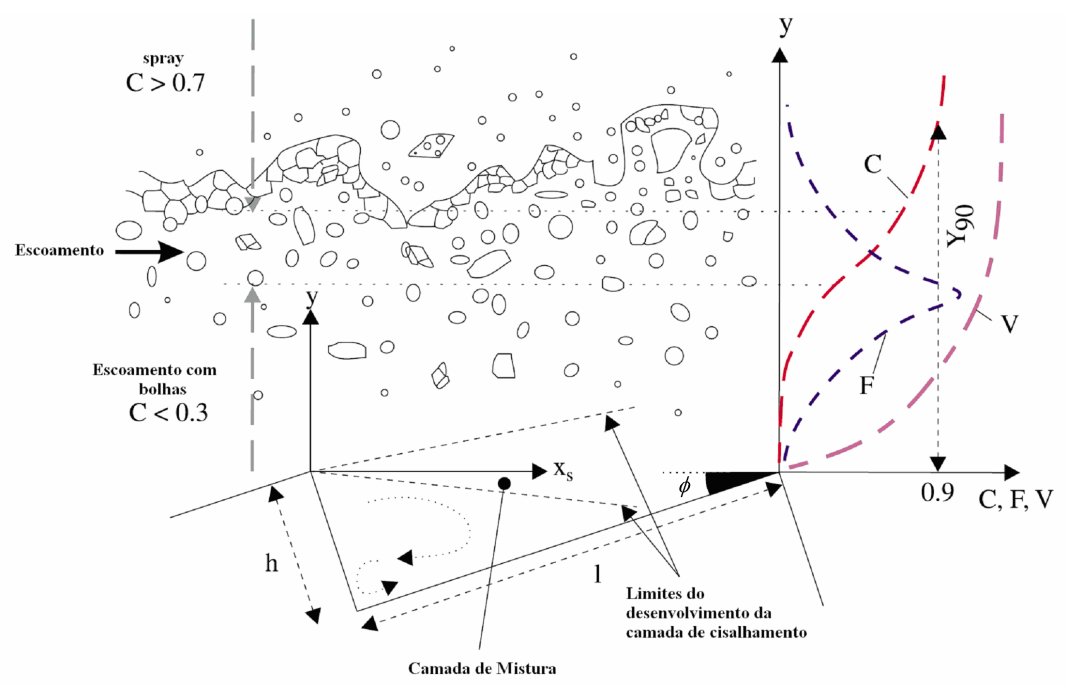

Figura 2.13. Escoamento Ar-Água (Fonte: Adaptado de GONZALEZ e CHANSON, 2004).

Diversos trabalhos experimentais com vertedouros em degraus foram realizados com a finalidade de estudar a aeração do escoamento. Essery e Horner (1978) observaram que a entrada de ar no escoamento é um fator dominante no regime de escoamento deslizante (skimming flow). A aeração do escoamento ao longo da calha em degraus em regime 
skimming foi subdividida por Matos e Quintela (1996) em quatro diferentes regiões, descritas na seqüência e ilustradas na figura 2.14:

- zona sem aeração do escoamento: localizada no trecho de montante da calha, no interior da qual se desenvolve a camada limite turbulenta, até atingir a superfície livre da água.

- zona com aeração parcial do escoamento: trecho em que o ar atmosférico incorpora-se ao escoamento, sem, contudo atingir o fundo da calha;

- zona com aeração total do escoamento: trecho em que o ar, embora ocupando a totalidade da seção transversal, apresenta uma concentração média variável no sentido do escoamento;

- zona com regime uniforme do escoamento: a concentração média de ar e a velocidade média da água não variam ao longo da calha.

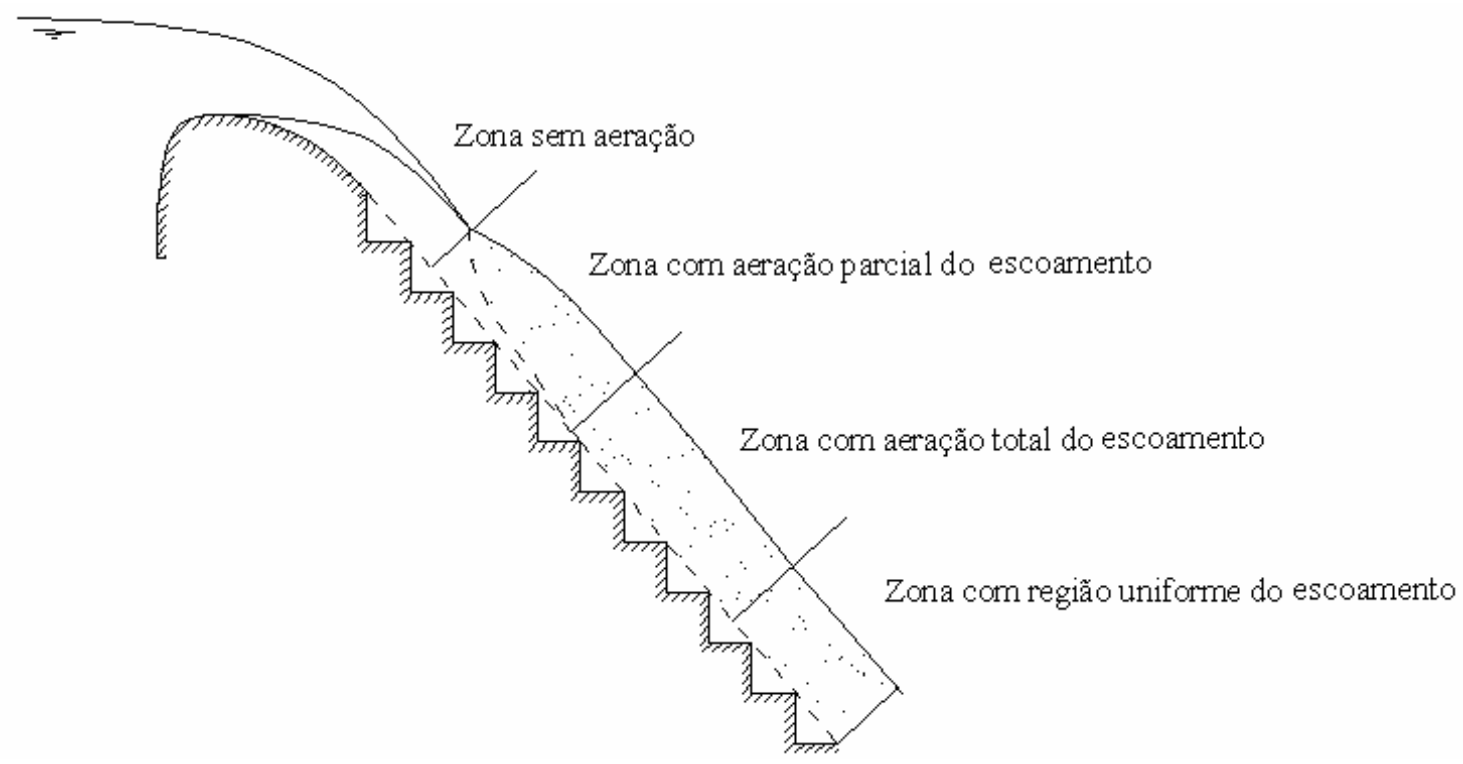

Figura 2.14. Regiões do escoamento ao longo de um vertedouro em degrau com regime skimming (Fonte: Adaptado de MATOS e QUINTELA,1996).

Definições da posição onde o escoamento ao longo de calhas em degraus inicia o processo de aeração da superfície livre da água foram apresentadas por Tozzi (1992) e Chanson (1994). Tozzi (op cit.) propôs, com base nos seus resultados experimentais, a equação (2.32) para determinação da espessura da camada limite turbulenta ao longo da calha em degraus com declividade $1 \mathrm{~V}: 0,75 \mathrm{H}$.

$$
\frac{\delta}{L_{A}}=0,080 \cdot\left(\frac{L_{A}}{k_{a}}\right)^{-0,233}
$$


onde: $\delta$ é a espessura da camada limite; $L_{A}$, a distância, ao longo da calha do vertedouro, entre a posição de inicio do desenvolvimento da camada limite e o inicio da aeração do escoamento e $k_{a}$, a altura da rugosidade $\left[k_{a}=h \cdot \cos (\phi)\right]$.

O cálculo das profundidades do escoamento ao longo da calha, associado ao conhecimento das respectivas espessuras da camada limite, permite definir a posição de início da aeração do escoamento.

Chanson (op cit.) apresentou as equações (2.33) e (2.34) que definem, respectivamente, a distância do início do desenvolvimento da camada limite ao ponto de início da aeração do escoamento $\left(L_{A}\right)$ e a profundidade do escoamento nesta posição $\left(d_{A}\right)$. Essas equações foram obtidas a partir de resultados de modelos reduzidos de vertedouros em degraus com declividade das calhas compreendidas entre $27^{\circ}$ e $52^{\circ}$.

$$
\begin{aligned}
& \frac{L_{A}}{k_{a}}=9,719 \cdot(\operatorname{sen} \phi)^{0,0796} \cdot\left(F_{*}\right)^{0,713} \\
& \frac{d_{A}}{k_{a}}=\frac{0,4034}{(\operatorname{sen} \phi)^{0,04}} \cdot\left(F_{*}\right)^{0,592}
\end{aligned}
$$

sendo: $F_{*}=\frac{q}{\sqrt{g \cdot \operatorname{sen} \phi \cdot k_{a}^{3}}}$ e $q=$ vazão por unidade de largura.

\section{Modelagem da transferência na interface ar-água em escoamento tipo skimming.}

No que tange a alguns aspectos consensuais, a concentração média de ar do escoamento deslizante sobre turbilhões em regime uniforme é semelhante àquela que se obteria no escoamento aerado uniforme em um vertedouro de calha lisa de igual declividade (MATOS, 1999). Os modelos de Wood (1984, apud CHANSON, 1994), deduzidos para paramentos lisos são, em geral, segundo Matos (1999), aplicáveis para estimar a distribuição de concentração de ar no trecho do escoamento gradualmente variado, com exceção da proximidade da pseudosoleira do vertedouro e nas zonas onde o efeito da ondulação da superfície seja relevante. A concentração média de ar na seção de afloramento da camada limite fica em torno de 0,20 .

WOOD, I. R. Air Entrainment in High Speed Flows. Proc. Intl. Symp. on Scale Effects in Modelling Hydraulic Structures, IAHR, Esslingen, Alemanha, editora H. KOBUS, artigo 4.1, 1984. 
Segundo Matos (1999), a concentração média de ar ao longo de vertedouros em degraus depende de:

$$
\begin{aligned}
& \mathrm{C}_{\text {média }}=\mathfrak{I}\left(C_{i} ; s^{\prime} ; \operatorname{sen} \theta ; \frac{v_{b} \delta \cos \theta}{q}\right) \\
& S^{\prime}=\frac{\left(L-L_{A}\right)}{\delta}
\end{aligned}
$$

$v_{b}$ - velocidade ascensional das bolhas no sentido perpendicular do fluxo;

$C_{\mathrm{i}}$ - concentração média de ar na seção de afloramento da camada limite;

$s$ ' - posição longitudinal adimensional ao longo da pseudo-soleira;

$L$ - posição longitudinal ao longo da pseudo-soleira, cuja origem é a crista da ogiva do vertedouro.

A concentração de ar, C, é definida como o volume de ar por unidade de volume total. A altura de água característica em um escoamento, $d$, pode ser definida por:

$$
\mathrm{d}=\int_{0}^{\mathrm{y}_{90}}(1-\mathrm{C}) \mathrm{dy}
$$

onde y é a distância medida perpendicularmente ao pseudo-fundo e y90 é a altura em que a concentração de ar é de $90 \%$. A concentração de ar média para a profundidade y $_{90}, \mathrm{C}_{\text {média, é }}$ definida por:

$$
\left(1-\mathrm{C}_{\text {médio }}\right) \mathrm{y}_{90}=\mathrm{d}
$$

No escoamento auto-aerado, a distribuição de concentração de ar pode ser estimada por um modelo de difusão das bolhas de ar na mistura ar-água (WOOD, 1984, apud CHANSON, 1994).

A equação de conservação para uma mistura em uma região de equilíbrio, independente na direção longitudinal é:

$$
D \frac{d}{d y}[\rho(1-C)]=\rho(1-C) v_{w} \cos \phi
$$

em que $\mathrm{D}$ é a difusividade para a massa específica média, $\rho(1-\mathrm{C})$ e representa o efeito da massa de água por unidade de volume, $v_{\mathrm{w}}$ é a velocidade da água. Quando $\mathrm{C}$ é grande, existe a presença de gotas de água no ar, e quando $\mathrm{C}$ é pequeno, existem bolhas de ar presente na água. Como a velocidade tende a zero próximo à superfície sólida, pode-se assumir que no intervalo entre y $=0$ e y $_{90}=y$ a velocidade da água é:

$v_{\mathrm{w}} \propto \mathrm{C} . \mathrm{y}$

Através de uma simplificação, considerando a difusividade D constante e substituindo 2.40 em 2.39, determina-se a equação para o perfil de concentração: 


$$
C=\frac{\beta}{\beta+\exp \left(-\gamma \cdot \operatorname{Cos} \phi\left(\frac{y}{y_{90}}\right)^{2}\right)}
$$

em que $\beta$ e $\gamma$ são variáveis em função da concentração média de ar e $\phi$ é a inclinação do vertedor. As variáveis $\beta$ e $\gamma$ são empíricas e não têm significado físico.

Chanson $(1995,1997)$ propôs um novo modelo de difusão de bolhas de ar em um desenvolvimento teórico e obteve uma boa comparação com dados experimentais em modelos e em protótipos.

Em um escoamento uniforme, Chanson (2000) propôs uma equação de continuidade para o ar, em um escoamento ar-água similar à apresentada por Wood (1984, apud CHANSON,1994):

$$
\frac{d}{d y}\left(D_{t} \cdot \frac{\partial C}{\partial y}\right)=v_{w} \operatorname{Cos} \varphi \cdot \frac{\partial}{\partial y}(C . \sqrt{1-C})
$$

onde $D_{t}$ é a difusividade turbulenta na direção normal ao escoamento. Da integração de 2.42 tem-se:

$$
C=1-\tanh ^{2}\left(K^{\prime}-\frac{\mathrm{y}}{2 \cdot D^{\prime} \cdot \mathrm{y}_{90}}\right)
$$

em que $D$ 'é a difusividade turbulenta adimensional e $K^{\prime}$ uma constante de integração. $D^{\prime}$ e $K^{\prime}$ são função da concentração média de ar $\mathrm{C}_{\text {médio }}$, que podem ser estimados por:

$$
\begin{aligned}
& D^{\prime}=\frac{0,848 \cdot C_{\text {médio }}-0,00302}{1+1,1375 \cdot C_{\text {médio }}-2,2925 \cdot C_{\text {médio }}^{2}} \\
& K^{\prime}=\operatorname{arctanh}(\sqrt{0,1})+\frac{0,5}{D^{\prime}}
\end{aligned}
$$

Para $\mathrm{C}_{\text {médio }}<0,7$ a equação 2.43 compara-se favoravelmente a dados obtidos em modelos e em protótipos de canais com degraus (BAKER, 1994; RUFF e FRIZELL, 1994; TOZZI et al.,1998; CHAMANI e RAJARATNAM, 1999; MATOS et al, 1999 e CHANSON et al 2002)(Figura 2.15). 


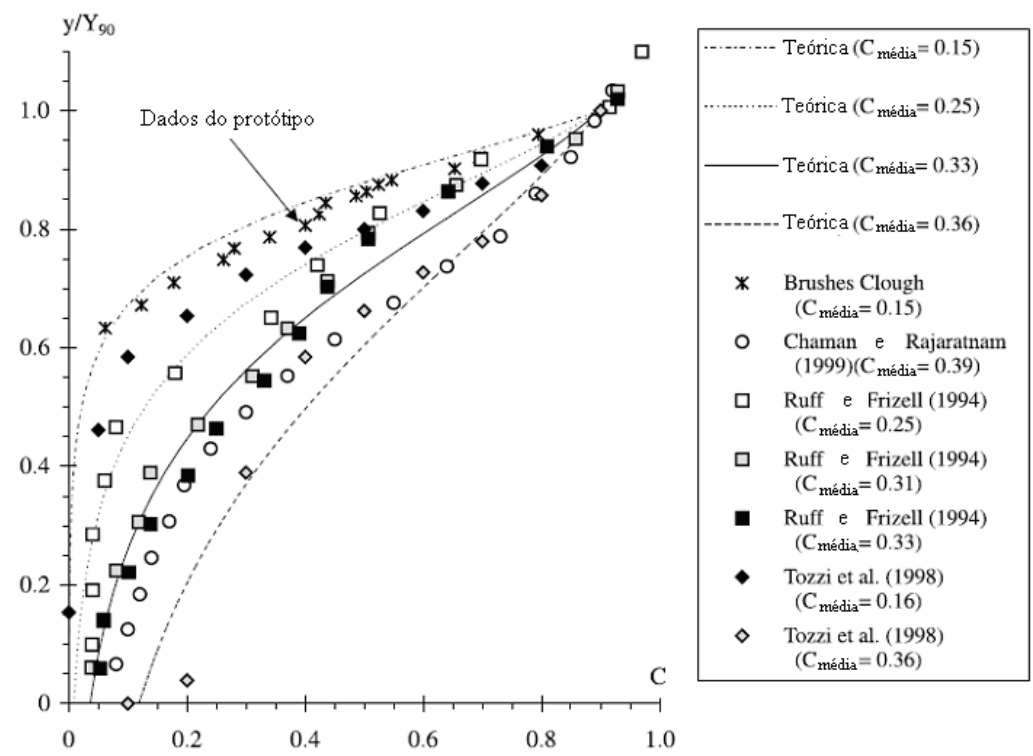

Figura 2.15. Distribuição da concentração de ar com a altura adimensionalisada: comparação com a equação 2.43. (Fonte: CHANSON et al 2002).

Determinação da concentração de ar média em escoamento skimming.

Diez-Cascon et al. (1991) admitiram que o mecanismo de entrada de ar no escoamento em uma calha em degraus é similar ao que ocorre em uma calha lisa, estimando sua concentração média de ar pela fórmula proposta pelo Comitê Científico da American Society of Civil Engineers - ASCE (1961):

$$
C_{\text {médio }}=0,743 \cdot \log \left(\frac{\operatorname{sen} \phi}{q^{1 / 5}}\right)+0,723
$$

onde: $C_{\text {médio }}=$ concentração média de ar; $C_{\text {médio }}=$ volume de ar/(volume de ar + volume de água); $\mathrm{q}=$ vazão específica no protótipo $\mathrm{em} \mathrm{m}^{3} / \mathrm{s} / \mathrm{m}$.

Com base no cálculo da concentração média de ar no trecho de jusante da calha, em degraus de modelos físicos, Matos e Quintela (1996) julgaram razoável admitir que a concentração média de ar é idêntica à que se obtém para um vertedouro com calha convencional plana de concreto (calha lisa) e mesma declividade, para valores de $H_{b a r r} / y_{c}$ superiores a cerca de 25 (sendo $H_{b a r r}$ a altura do vertedouro, calculada pelo desnível entre a crista do vertedouro e a bacia de dissipação ou uma posição ao longo da calha; e $y_{c}$ a profundidade crítica do escoamento). Posteriormente, Matos e Quintela (op cit.) comentaram que a concentração média de ar resultou diretamente proporcional à relação $H_{b a r r} / y_{c}$, atingindo um patamar da ordem de 0,63 para valores de $H_{b a r r} / y_{c}$ acima da faixa entre 35 e 40. 
Tozzi et al. (1998) efetuaram medições de distribuição de concentração de ar em um modelo de um vertedouro em degraus com declividade de $1 \mathrm{~V}: 0,775 \mathrm{H}$ (inclinação da calha $=$ $52,2^{\circ}$ ). Os resultados obtidos, em termos de concentração média, para uma carga de 3,3 m sobre o vertedouro, foram: $24 \%$ para o degrau 23 (21,3 m abaixo da crista), $44 \%$ para o degrau 37 (32,5 m abaixo da crista) e $47 \%$ para o degrau 50 (42,9 $\mathrm{m}$ abaixo da crista).

Matos e Frizell (1997) realizaram medições de concentração de ar em escoamentos turbulentos altamente aerados em um modelo de um vertedouro em degraus com altura $H_{\text {barr }}$ igual a 2,90 m, inclinação da calha igual a 53,13 ${ }^{\circ}$, degraus com $8 \mathrm{~cm}$ de altura e vazão específica igual a $0,1 \mathrm{~m} 3 / \mathrm{s} / \mathrm{m}$. A medição da concentração de ar foi realizada na extremidade de três degraus ao longo da calha: degrau 16 (localizado 0,66 m abaixo da crista), degrau 24 (1,30 m abaixo da crista) e degrau 34 (2,10 m abaixo da crista). A comparação dos perfis da concentração de ar adimensionalisados, obtidos em cada degrau, com a distribuição da concentração de ar para o escoamento uniforme em uma calha lisa, para mesma declividade, mostrou que:

- Um escoamento quase uniforme parece ter sido atingido no degrau 34;

- A concentração de ar diminuiu próximo ao fundo da calha em degraus, tendo aparentemente, os perfis de concentração de ar indicado a presença de uma camada limite de concentração de ar de aproximadamente $13 \mathrm{~mm}$. Para justificar esse fato os autores acharam razoável aceitar que o alto gradiente de velocidade próximo ao fundo, formado pelas extremidades dos degraus e a tensão tangencial resultante, colapsariam as bolhas de ar em micro bolhas de ar de volume negligenciável;

- A conclusão de Matos e Quintela (1996), referente à similaridade da concentração média de ar no escoamento uniforme para vertedouros com calha lisa e em degraus de mesma declividade foi comprovada.

Tozzi et al. (1998) apresentaram resultados de distribuição de concentração de ar obtidos em modelos reduzidos de vertedouros em degraus com declividades iguais a $1 \mathrm{~V}: 6,69 \mathrm{H}\left(\phi=8,5^{\circ}\right)$ e $1 \mathrm{~V}: 0,775 \mathrm{H}\left(\phi=52,2^{\circ}\right)$. Os testes realizados na calha com inclinação $\phi=8,5^{\circ}$ conduziram a um perfil de concentração de ar cuja distribuição apresentou-se praticamente idêntica aos valores apresentados por Straub e Anderson (1958), para calhas lisas. Entretanto, os resultados obtidos para a calha com inclinação de $52,2^{\circ}$ não apresentaram a mesma tendência da proposição de Straub e Anderson (1958), conduzindo a um menor valor de concentração média de ar (47\% na calha em degraus contra os $64 \%$ previstos para as calhas lisas por Straub e Anderson, 1958). Da mesma forma que Matos e Frizell (1997), os autores observaram em seus experimentos que a região próxima ao degrau, contém uma 
menor quantidade de ar que no escoamento turbulento em calhas alisadas. Justificaram, porém, que esse efeito é aparentemente explicado pelo forte gradiente de pressões na região, provocando um empuxo maior às bolhas, que tendem a se distanciar do fundo da calha em degraus.

Chamani e Rajaratnam (1999) comentaram que devido à turbulência produzida pelos degraus, a concentração média de ar resultou maior que a obtida em uma calha lisa - equação 2.46. Um ajuste realizado pelos autores, com seus resultados obtidos em modelo, conduziu à proposição da seguinte equação para o cálculo da concentração média de ar:

$$
C_{\text {médio }}=0,93 \cdot \log \left(\frac{(\operatorname{sen} \phi)^{0,1}}{q^{0,3}}\right)+1,05
$$

$\operatorname{com} q=$ vazão específica no modelo em $1 / \mathrm{s} / \mathrm{m}$.

Matos (2000), para o mesmo estudo realizado por Matos e Frizell (1997), apresentaram os seguintes resultados obtidos nos testes com vazão específica de $0,1 \mathrm{~m} / \mathrm{s} / \mathrm{m}$ : concentração média de ar igual a 35\% no degrau 16 (0,66 m abaixo da crista), 51\% no degrau $24(1,30 \mathrm{~m}$ abaixo da crista) e $57 \%$ no degrau 34 (2,10 m abaixo da crista). Considerando resultados experimentais obtidos por outros pesquisadores, definiu a equação 2.48 , que relaciona a concentração média de ar $C_{\text {média }}$ em função do parâmetro $H_{b a r r} / y_{c}$

$$
C_{\text {médio }}=0,62-\frac{55,9}{\left(\frac{H_{\text {barr }}}{y_{c}}\right)^{2}}
$$

\subsection{Distribuição de Velocidades}

\section{Considerações gerais}

Para escoamentos sobre contornos formados por elementos de rugosidade de pequenas dimensões sabe-se que a distribuição de velocidades nos escoamentos turbulentos é logarítmica (CHOW, 1959).

A partir de constatações efetuadas por diversos pesquisadores, Tozzi (1992) estabeleceu uma equação geral para a distribuição de velocidades, para os adimensionais $v / V_{\max } \mathrm{e} y / y_{o}$. 


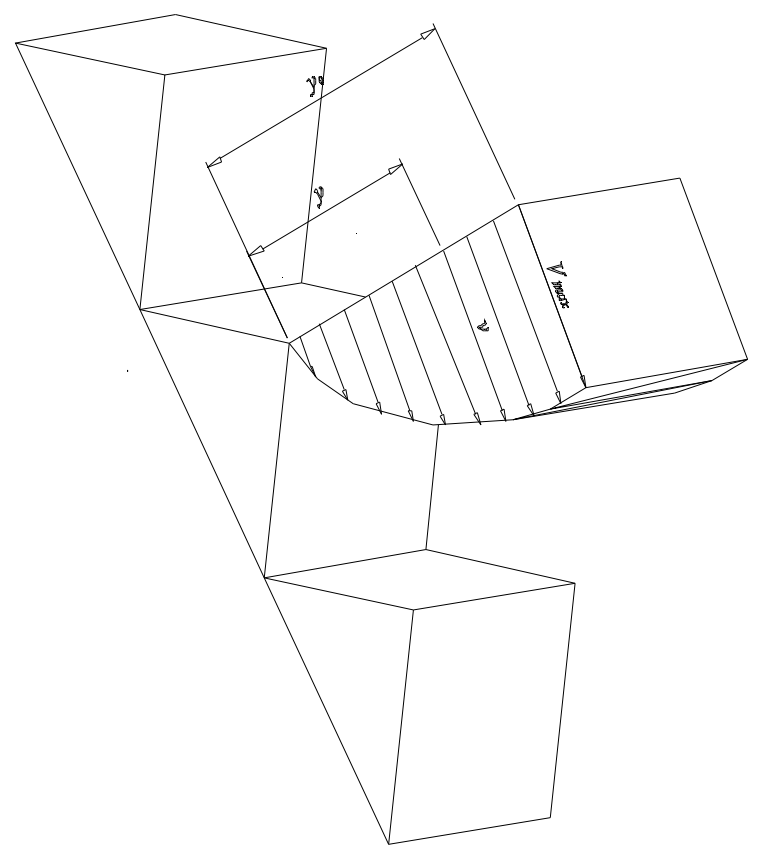

Figura 2.16. Croqui para identificação das variáveis envolvidas na equação.

$$
\frac{v}{V_{\max }}=1+n \cdot \log \left(\frac{y}{y_{o}}\right)
$$

sendo: $v$ é a velocidade do escoamento para altura $y, V_{\max }$, a velocidades máxima do escoamento de água e $y_{o}$ a altura total do escoamento.

Com o valor de $n$ sendo uma variável em função da declividade da calha:

a. $i_{o}=1 \mathrm{~V}: 0,75 \mathrm{H} \Rightarrow n=0,47$

b. $i_{o}=1 \mathrm{~V}: 2,00 \mathrm{H} \Rightarrow n=0,43$

c. $i_{o}=1 \mathrm{~V}: 6,69 \mathrm{H} \Rightarrow n$ variável com o parâmetro adimensional $y_{o} / k_{a}$ até atingir o valor constante de 0,44 para valores $y_{o} / k_{a}>3,0$.

Tozzi (1992) propôs ainda a adoção de distribuição geral de velocidade para escoamento turbulento em condutos.

$$
\frac{v}{V_{\max }}=1+n_{1} \cdot \log \left(\frac{y}{y_{o}}\right)
$$

com $n_{l}=5,75 \frac{V_{*}}{V_{\max }}$, sendo $V_{*}$ a velocidade de cisalhamento. Conduzindo a resultados satisfatório para a calha com declividade $1 \mathrm{~V}: 6,69 \mathrm{H}$, para valores de $y_{o} / k_{a}>3,0$ (TOZZI, 1992). 
A distribuição de velocidade em vertedores pode ser aproximada também por uma equação na forma potencial (CHANSON, 1994):

$$
\frac{v}{V_{\max }}=\left(\frac{y}{y_{o}}\right)^{1 / N}
$$

O expoente da distribuição de velocidade, $\mathrm{N}$ é dado por:

$$
N=\kappa \sqrt{\frac{8}{f}}
$$

onde $\kappa$ é a constante de Von Karman $(\kappa=0,4)$ e $f$ o fator de cisalhamento.

\subsection{Estudos Experimentais em Vertedores em Degraus no Brasil.}

O primeiro trabalho no estudo hidráulico em modelo reduzido do vertedouro em degrau no Brasil foi realizado pelo Centro de Hidráulica e Hidrologia Prof. Parigot de Sousa CEHPAR. Em um modelo reduzido construído na escala geométrica de 1:15, reproduzindo a calha do vertedouro em toda a sua extensão, foram efetuadas as seguintes determinações (OTA et al, 1990):

- Capacidade de descarga do vertedouro;

- Espessura do escoamento ao longo da calha;

- Pressão ao longo da calha;

- Energia dissipada nos degraus;

- Alcance de jato propiciado por defletor implantado na parte terminal do vertedouro. As principais conclusões obtidas do estudo foram:

- A capacidade de descarga da estrutura não foi influenciada pela presença dos degraus;

- As condições de instabilidade da superfície livre da água provocadas pelo escoamento turbulento associadas à aeração ocorrida no escoamento limitaram a precisão dos resultados relativos à determinação da espessura do escoamento ao longo da calha, Entretanto, a tendência do aumento da profundidade do escoamento após o início da aeração pôde ser constatada;

- Medições de pressões efetuadas através de piezômetros instalados no piso e na face vertical dos degraus mostraram que, de forma geral, pressões positivas foram obtidas na parte saliente onde há incidência do escoamento e pressões negativas foram obtidas na parte recuada dos degraus onde há circulação da água com alta velocidade. Pequenos deslocamentos do alinhamento das extremidades dos degraus provocaram alterações sensíveis das pressões; 
- A estimativa da energia dissipada nos degraus indica, para a máxima vazão testada $\left(11,7 \mathrm{~m}^{3} / \mathrm{s} . \mathrm{m}\right)$, que o resultado obtido foi de cerca de $60 \%$ da energia total existente a montante do vertedouro;

- Para o afastamento da dissipação do escoamento do pé da barragem/vertedouro, defletores horizontais implantados na parte terminal do vertedouro apresentaram bom desempenho.

Tozzi (1992) realizou um grande trabalho através de estudo sistemático baseado em investigação experimental, em que se procurou o estabelecimento de parâmetros que permitissem definir o comportamento geral de escoamentos em vertedouros com degraus. Dos resultados obtidos foram inferidas leis gerais para o fator de resistência $f$ da equação de Darcy-Weisbach, para a distribuição de velocidades ao longo da calha e para a posição de início de aeração do escoamento.

Tozzi (op cit) também apresentou uma solução numérica com a utilização do método das diferenças finitas em associação com a expressão geral do fator de resistência conduzindo a avaliações teóricas do perfil da superfície livre da água ao longo da calha e da energia residual na bacia de dissipação, que foram confirmadas pelos resultados experimentais. Adicionalmente, Tozzi (op cit) demonstrou a viabilidade da utilização de defletores no trecho final do vertedouro para o afastamento do local de dissipação de energia do escoamento do pé dessa estrutura, quando necessário, e definiram-se curvas de probabilidade de ocorrência de pressões negativas nos degraus para auxiliar nas decisões de projetos.

Tozzi et al (1998) apresentaram resultados de medição da distribuição de concentração de ar em escoamentos em modelos reduzidos. Este trabalho constituiu, portanto, em uma contribuição para a compreensão do mecanismo da aeração natural em escoamentos sobre vertedouros com degraus. O equipamento de medição da concentração de ar utilizado foi fabricado no Centro de Hidráulica e Hidrologia Prof. Parigot de Souza - CEHPAR.

Como conclusão deste trabalho Tozzi et al (1998) verificaram que a jusante da posição de início da aeração, a superfície livre do escoamento em calhas rugosas apresenta-se totalmente branca, indicando a presença de uma quantidade substancial de aeração. Eles tiveram como objetivo de trabalho, a análise da distribuição da concentração de ar nessas calhas, na região onde o escoamento se caracteriza como totalmente estabelecido. Os resultados obtidos para estudos com calha de menor declividade (de 8,5 a 26,6 ) a distribuição da concentração de ar apresenta-se praticamente idêntica para as calhas lisas e rugosas. Entretanto, os resultados obtidos para a calha de $52,2^{\circ}$ de inclinação não só modificaram essa tendência como apresentaram um menor valor da concentração média de ar 
( $47 \%$ contra os $64 \%$ previstos para as calhas lisas por STRAUB e ANDERSON,1958). Estes resultados mostraram que a distribuição da concentração de ar segundo a normal ao escoamento em calhas com degraus não é muito uniforme. Ao contrário da aparente uniformidade da mistura água-ar, caracterizada pelo aspecto bastante emulsionado do escoamento, a região próxima ao degrau contém menor quantidade de ar que no escoamento turbulento em calhas alisadas. O forte gradiente de pressões deve provocar um empuxo maior às bolhas que tendem, portanto, a se distanciar do fundo da calha com degraus.

Com base nessa constatação, Tozzi et al (1998) concluíram ainda que a afirmação efetuada por Ruff e Frizell (1994) e por Chanson e Toombes (1997), de que os perfis de concentração para as calhas rugosas exibem a mesma forma que para as calhas lisas tem sua validade limitada a um determinado valor de inclinação de calha, entre $30^{\circ}$ e $50^{\circ}$.

Olinger (2001) defendeu sua tese de dourado pela Escola Politécnica da Universidade de São Paulo apresentando um estudo que foi realizado no CEHPAR. Ele deixou a sua contribuição ao estudo da distribuição de pressão nos vertedouros em degraus com escoamento totalmente submerso (skimming). A partir de resultados experimentais esta pesquisa visou estabelecer parâmetros adimensionais que permitissem relacionar o número de Froude do escoamento com as pressões em qualquer posição dos degraus. A obtenção dessas relações constituiu a principal contribuição deste estudo para a verificação da possibilidade de cavitação incipiente nos degraus na região não aerada do escoamento. Para o seu desenvolvimento construiu-se um canal experimental com degraus de 12 x $9 \mathrm{~cm}$ (altura x largura) e declividade de $1 \mathrm{~V}: 0,75 \mathrm{H}$, onde o escoamento atinge velocidades de $10-12 \mathrm{~m} / \mathrm{s}$. Neste canal realizaram-se ensaios observando, nos degraus, as características médias do escoamento, linhas de corrente, a distribuição de pressões médias, a distribuição de velocidade e flutuações de pressões instantâneas.

Em trabalhos mais recentes, foram realizados estudos para caracterização dos escoamentos em vertedouros com degraus no Instituto de Pesquisas Hidráulicas da Universidade Federal do Rio Grande do Sul com o financiamento de FURNAS. Sanagiotto (2003) realizou uma análise experimental do escoamento de vertedouros em degraus de declividade $1 \mathrm{~V}: 0,75 \mathrm{H}$ para três macro-rugosidades e comparou com um vertedouro com calha lisa. Dai Prá (2004) realizou um trabalho similar ao de Sanagiotto (2003) para vertedouros em degraus com declividade $1 \mathrm{~V}: 1 \mathrm{H}$. Gomes (2006) realizou um estudo das condições de pressão nas paredes dos degraus na incipiência da cavitação. 


\subsection{Estudos Numéricos do Escoamento em Vertedouros em Degraus.}

Chen et al (2002) realizaram uma simulação numérica do escoamento de vertedouros em degrau utilizando o modelo de turbulência $k-\mathcal{E}$. Uma malha não estruturada (figura 2.17) foi utilizada para adaptar o contorno irregular e o método de volume de fluido (VOF) foi usado para resolver o complexo problema da superfície-livre. A superfície-livre (Figura 2.18), a pressão nos degraus do vertedouro (Figura 2.19) e os campos de velocidades (Figura 2.20) foram obtidos numericamente e comparados com resultados experimentais. Esse estudo indicou que a simulação numérica da turbulência é um método eficiente e proveitoso para o estudo do escoamento em vertedouros em degraus.

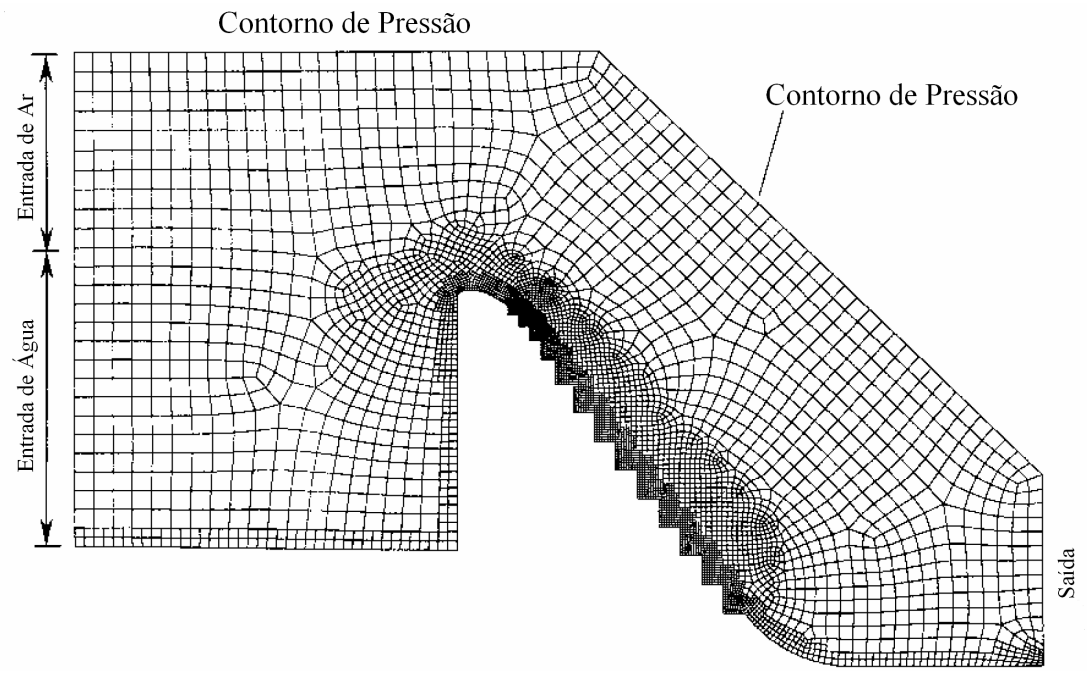

Figura 2.17. Malhas gerada e utilizada na simulação (Fonte: CHEN et al, 2002).

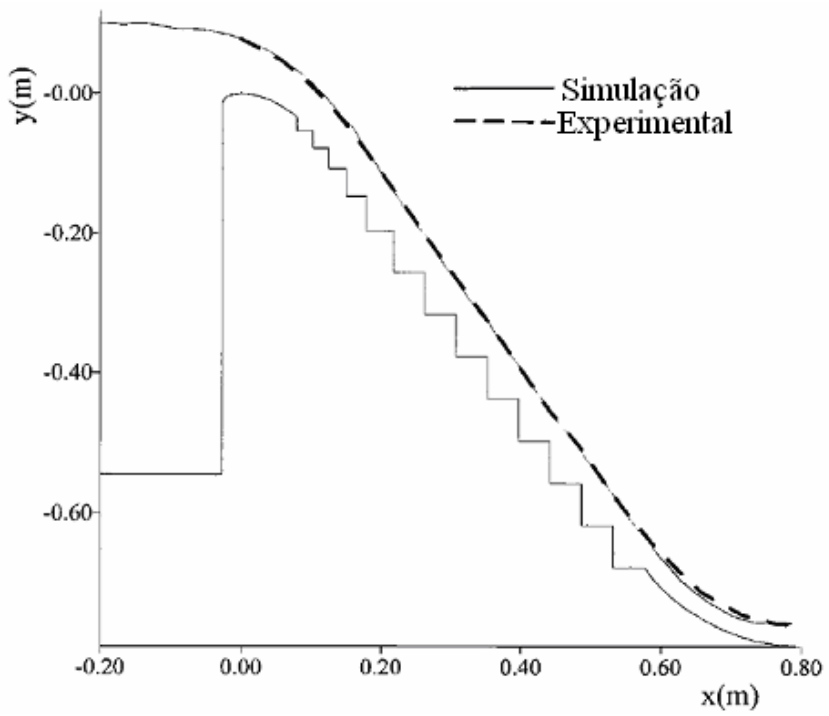

Figura 2.18. Superfície livre obtida pela simulação e experimental.

(Fonte: CHEN et al, 2002). 


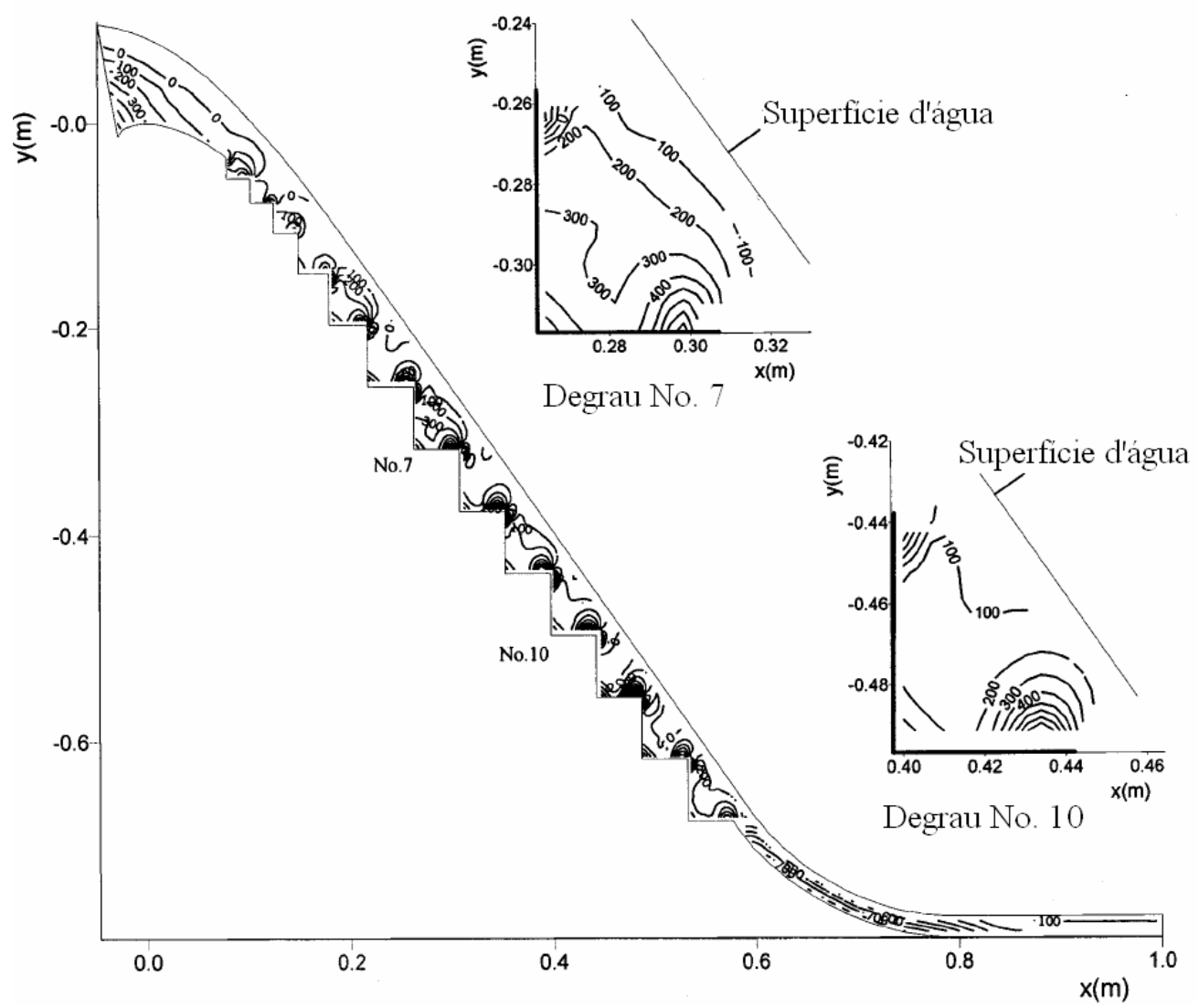

Figura 2.19. Isolinhas de Pressão no vertedor em degrau

(Fonte: CHEN et al, 2002).

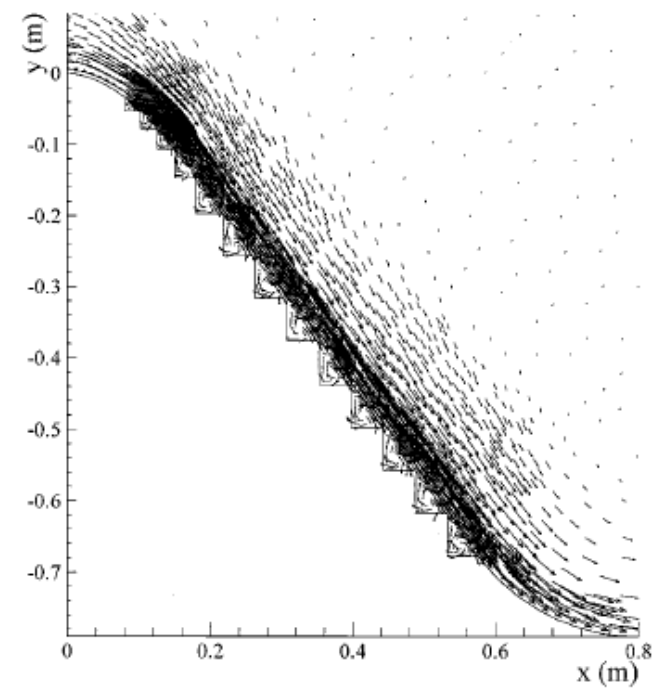

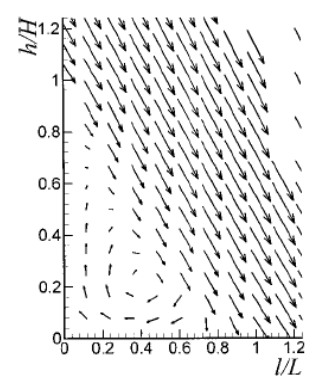

(a) Simulação

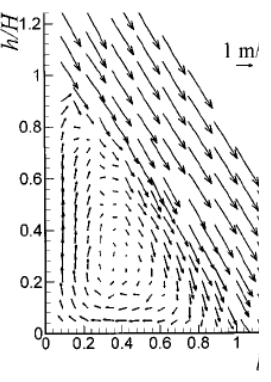

(b) Experimental

Figura 2.20. Vetores velocidade dos fluidos no vertedor em degrau e comparação entre numérico e experimental no Degrau № 7 (Fonte: CHEN et al, 2002). 
Cheng et al (2004) também simularam o escoamento em vertedouros com degraus utilizando o modelo de turbulência $k-\varepsilon$ e o modelo de volume de fluidos. (VOF). Eles implementaram uma malha não estruturada para ajustar a forma complexa do domínio. $\mathrm{O}$ método de acoplamento para as equações de pressão e de velocidades utilizado foi o método PISO (Pressure-Implicit with Splitting of Operators). Na simulação numérica, além dos vetores velocidade (Figura 2.21), eles determinaram os perfis de concentração de ar adimensionalisados em três degraus (Figura 2.22), obtendo bons resultados comparando com os experimentos.

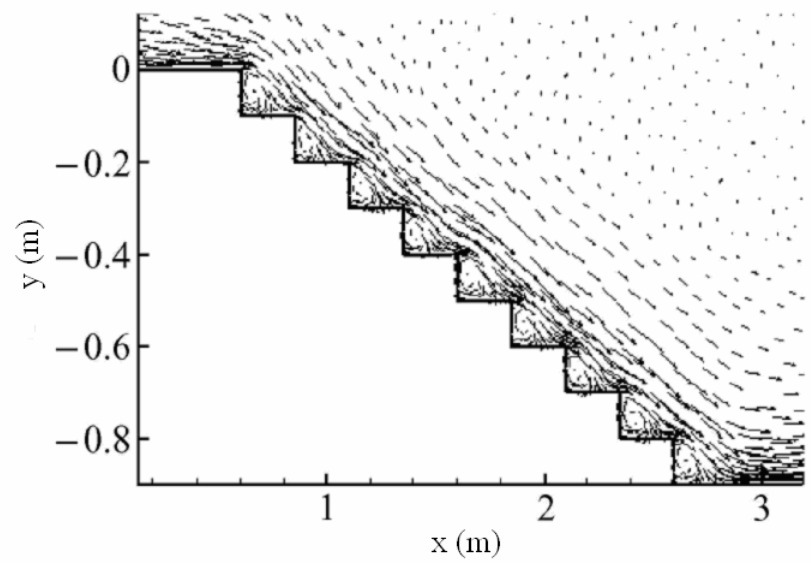

Figura 2.21. Vetores velocidade dos fluidos no vertedor em degrau

(Fonte: CHENG et al, 2004).

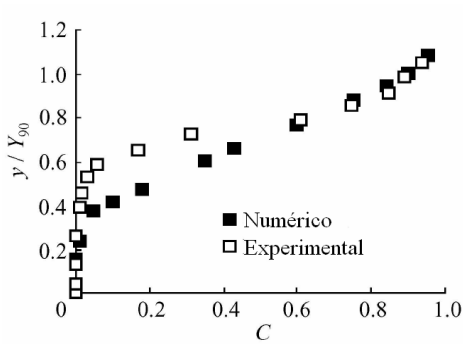

Degrau 6

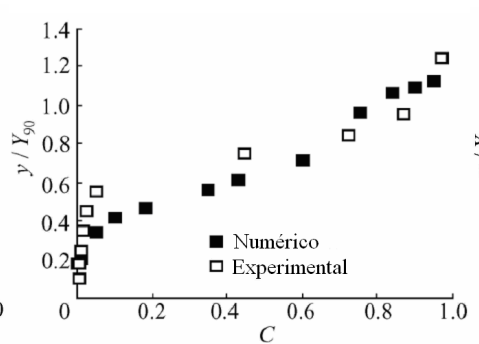

Degrau 7

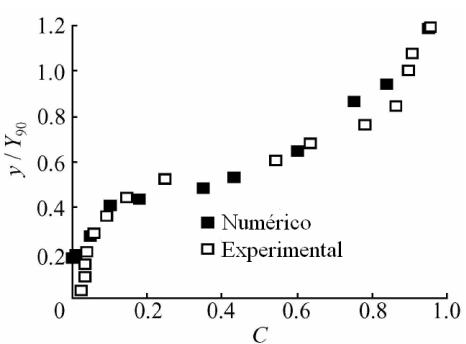

Degrau 8

Figura 2.22. Concentração de ar em relação a altura adimensionalisada y/y90.

(Fonte: CHENG et al, 2004). 


\section{MATERIAIS E MÉTODOS.}

\subsection{Modelagem Computacional.}

Da revisão bibliográfica, verifica-se que experimentos com modelos reduzidos foram muito utilizados para a caracterização do escoamento em vertedouros em degraus. Considerando o grande avanço tecnológico dos últimos tempos, a utilização de modelos computacionais apresenta-se como uma alternativa viável, com vantagens em termos de maior facilidade de realização de ensaios variados, envolvendo detalhes geométricos de vertedouros em degraus e condições de escoamento. Eliminam-se os problemas técnicos de ensaios de laboratório, os problemas de semelhança dinâmica dos escoamentos em escalas reduzidas e as dificuldades de viabilização econômica dos estudos experimentais quando se recorre à simulação numérica. Entretanto, a adequação das previsões numéricas do escoamento requer uma cuidadosa avaliação através da escolha dos modelos representativos dos fenômenos envolvidos e da validação dos modelos computacionais, frente às características observadas via experimental.

Para validação do estudo dos escoamentos em vertedouros em degraus através de simulação numérica, algumas características do escoamento estudadas experimentalmente, pelos diversos autores citados na revisão bibliográfica, foram comparadas com os ensaios computacionais. Então, abordaram-se os seguintes estudos do escoamento em vertedouros em degraus:

- Mudança do escoamento de nappe flow para skimming flow.

- Determinação do ponto de início da aeração e das regiões do escoamento ao longo de um vertedouro em degraus com regime skimming flow. Estudo da concentração de ar no escoamento ao longo do vertedouro e de aeradores de fundo.

- Estudo da distribuição de pressões nos degraus.

- Estudo da perda de energia ao longo de todo o vertedouro.

Após validação da utilização do CFD através dessa calibração, uma nova configuração da geometria para vertedouros foi estudada, com a utilização de um aerador de fundo em conjunto com o vertedouro em degraus. 


\subsection{Modelação Numérica via "Computational Fluid Dynamic - CFD”.}

Para estudo do escoamento sobre um vertedouro em degraus é necessário utilizar um software CFD, que permita simular escoamentos turbulentos sobre geometrias complexas e também com código de interface ar-água - escoamento bifásico.

Atualmente existem diversos softwares CFDs no mercado que são aplicáveis em diversos problemas de Mecânica dos Fluidos. Entres os problemas mais pesquisados, via CFD, podem-se destacar: aerodinâmica ou funcionamento de turbinas de aeronaves, transporte de calor e massa, mecanismos de bombas hidráulicas, misturadores, transporte de sedimentos, cavitação e muitos outros.

No mercado mundial existem programas que simulam os mais variados tipos de escoamento (bidimensionais ou tridimensionais, monofásico ou multifásicos, compressível ou incompressível, etc). Entre eles, podem-se citar CFX ${ }^{\circledR}$, FLUENT $^{\circledR}$, STAR-CD $^{\circledR}$, Flow-3D ${ }^{\circledR}$, Polyflow $^{\circledR}$, Fidap $^{\circledR}, \mathrm{CFD}++^{\circledR}, \mathrm{CFD}^{\mathrm{A}} \mathrm{ACE}{ }^{\circledR}$, etc. Muitos fornecedores utilizam o Método de Volumes Finitos ou o Método dos Elementos Finitos, e também, apresentam soluções complexas (ambientes de simulação), que incluem desde sistemas de definição da geometria e de geração de malhas estruturadas ou não-estruturadas, até diferentes modelos de turbulência, modelagem de escoamento multifásica e ferramentas de visualização científica.

\subsection{Escolha do Software.}

Dentre os pacotes computacionais citados acima, os únicos que possuíam representantes de vendas no Brasil no início da pesquisa eram, CFX $^{\circledR}$ e FLUENT $^{\circledR}$. Sabe-se que ambos os softwares possuem as ferramentas necessárias para a simulação dos escoamentos multifásicos e também credibilidade quanto aos métodos computacionais utilizados, sendo os líderes mundiais em CFD, tendo diversas publicações, principalmente nas áreas de aeronáutica/automobilismo, petróleo, etc.

Após o contato com as empresas Engineering Simulation and Scientific Software (ESSS - representante do software $\mathrm{CFX}^{\circledR}$ ) e a Smarttech (representante do software FLUENT ${ }^{\circledR}$ ) decidiu-se utilizar o $\mathrm{CFX}^{\circledR}$ por já existirem equipes utilizando este software na EESC e também pelo preço mais acessível. 


\subsection{Equações Representativas dos Escoamentos.}

Considerando-se a hipótese do contínuo (Figura 3.1) e que o fluido seja newtoniano, têm-se as equações associadas aos princípios de conservação.

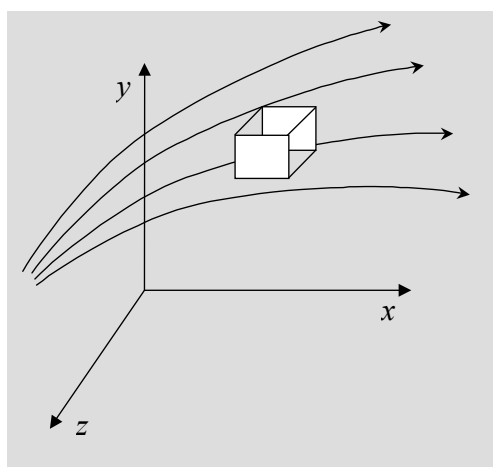

Figura 3.1. Volume de controle para balanços de massa e de quantidade de movimento.

- Conservação da massa.

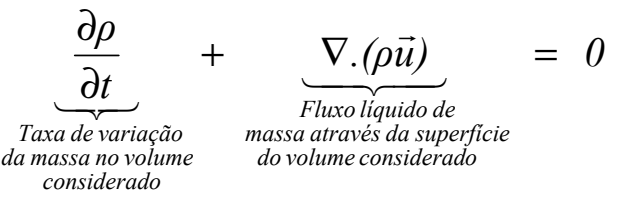

em que $\vec{u}$ é o vetor velocidade.

- Conservação da quantidade de movimento (Equações de Navier-Stokes).

$$
m \vec{a}=F_{\text {superficie }}+F_{\text {corpo }} \quad \text { onde } \quad \vec{a}=\frac{D \vec{u}}{D t}=\frac{\partial(\vec{u})}{\partial t}+(\vec{u} . \nabla)(\vec{u})
$$

sendo $\vec{a}$ a aceleração, $F$ a força e $m$ a massa.

Fazendo as hipóteses de escoamentos incompressíveis e propriedades físicas constantes, tem-se:

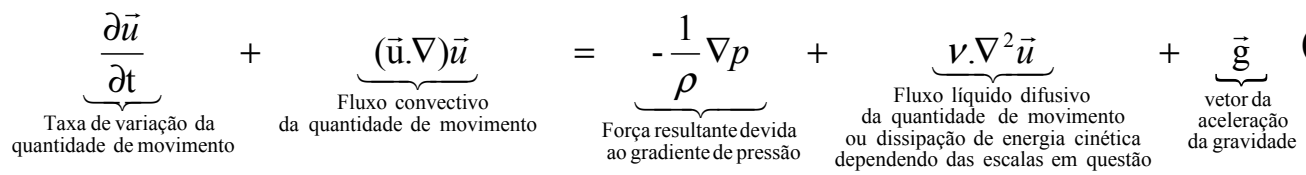

em que p é a pressão, $v$, a viscosidade cinemática e $\overrightarrow{\mathrm{g}}$, o vetor da aceleração da gravidades.

O termo relativo ao escoamento líquido convectivo de quantidade de movimento, também expressa as interações não lineares entre as diversas escalas que compõem o espectro de energia típico do escoamento. 
- Conservação da Energia

$$
\underbrace{\frac{\partial T}{\partial \mathrm{t}}}_{\begin{array}{c}
\text { Taxa de acumulode } \\
\text { energiai interna no } \\
\text { volume considerado }
\end{array}}+\underbrace{(\vec{u} . \nabla) T}_{\begin{array}{c}
\text { Fluxo líquido convectivo } \\
\text { de energia interna }
\end{array}}=\underbrace{\alpha \nabla^{2} T}_{\begin{array}{c}
\text { Fluxo líquido difusivo } \\
\text { de energia interna }
\end{array}}+\underbrace{\phi_{e}}_{\begin{array}{c}
\text { Termo fonte de } \\
\text { energia interna devido } \\
\text { à dissipacão de energia } \\
\text { interna }
\end{array}}
$$

sendo $T$ a temperatura, $\alpha$ a condutividade térmica, $\phi_{\mathrm{e}} \mathrm{o}$ termo fonte de energia.

\subsection{Equações da Média de Reynolds para Navier-Stokes. (RANS)}

As equações básicas de Navier-Stokes são modificadas para representar a variação instantânea como uma composição média da variável. Usando uma função média, as equações do escoamento médio são obtidas. Estas novas equações, devido às equações não lineares, contêm termos que envolvem o produto de flutuações de velocidades em diferentes direções. Estes termos de flutuação não têm equações definitivas e dão origem à viscosidade turbulenta. Por exemplo, um vetor velocidade, $\vec{u}$, pode ser dividido em uma componente média, $\bar{u}$, e um componente variável no tempo, $u^{\prime}$.

$$
\vec{u}=\bar{u}+u^{\prime}
$$

A componente média é dada por: $\bar{u}=\frac{1}{\Delta t} \int_{t}^{t+\Delta t} \vec{u} \cdot d t$

As equações abaixo representam as equações Reynolds para escoamento incompressível.

$$
\begin{aligned}
& \frac{\partial \rho}{\partial t}+\nabla \cdot(\rho \bar{u})=0 \\
& \frac{\partial \rho \bar{u}}{\partial t}+\nabla \cdot(\rho \bar{u} \times \bar{u})=\nabla \cdot\left(\tau-\rho \overline{u^{\prime} \times u^{\prime}}\right)+S_{M}
\end{aligned}
$$

sendo $\tau=\mu . \nabla \cdot \overline{\boldsymbol{u}}$ o tensor de tensões molecular, $S_{M}$ o termo fonte da equação de momento.

$$
\frac{\partial \rho \phi_{t}}{\partial t}+\nabla \cdot\left(\rho \bar{u} \phi_{t}\right)=\nabla \cdot\left(\Gamma \nabla \phi_{t}-\rho \overline{u^{\prime} \phi_{t}}\right)+S_{\phi}
$$

em que $\phi_{t}$ é a variável transportada, $\Gamma$ é a difusividade e $S_{\phi}$ é o termo fonte da equação de transporte.

Com a aplicação da Média de Reynolds, a equação da continuidade não se altera, mas as equações da quantidade de movimento e do transporte escalar que contêm os termos adicionais do escoamento turbulento que pode ser acrescentada à difusão molecular do escoamento. Considera-se a tensão de Reynolds, $\rho \overline{u^{\prime} \times u^{\prime}}$, e o termo de fluxo de Reynolds, $\rho \overline{u^{\prime} \phi}$. Estes termos aumentam de forma não linear o termo convectivo na equação original. 
Isto reflete o fato de que o transporte convectivo devido à flutuação turbulenta da velocidade age para melhorar a mistura causada pela flutuação térmica no nível molecular. Para altos números de Reynolds, a flutuação turbulenta de velocidade ocorre sobre um comprimento escalar muito maior que o caminho médio livre da flutuação térmica, assim o fluxo turbulento é muito maior que o fluxo molecular (CFX, 2004).

\subsection{Modelos de Turbulência.}

Escoamentos turbulentos são caracterizados através de campos de velocidades flutuantes. Esta combinação do escoamento e quantidades de movimento, de energia e de concentração, gera as flutuações das quantidades transportadas. Considerando que estas flutuações podem ser de pequena escala e alta freqüência, elas também são computacionalmente dispendiosas para serem simuladas diretamente em cálculos práticos de engenharia. Ao invés das equações para quantidades instantâneas, podem ser utilizadas médias temporais ou manipulação para remover as pequenas escalas, resultando em um grupo modificado de equações que são computacionalmente amenas para resolver. Porém, as equações modificadas contêm variáveis desconhecidas adicionais, e precisa-se de modelos de turbulência para determinar estas variáveis em termos de quantidades conhecidas (CFX, 2004).

Entre os modelos de turbulência existentes podemos destacar os seguintes, que são muito utilizados na atualidade em mecânica dos fluidos, são eles (CFX, op cit e FLUENT, 2000).

- Modelos de Uma Equação.

○ Modelo Spalart-Allmaras.

- Modelos de Duas Equações.

○ Modelo $k-\varepsilon$ (Padrão).

○ Modelo $k-\varepsilon(\mathrm{RNG})$.

$\circ$ Modelo $k-\varepsilon$ (Realizable).

- Modelo de Tensões de Reynolds (RSM).

- Modelo de Simulação de Grandes Escalas “Large Eddy Simulation” (LES).

- Modelos de Simulação Híbridos “Detached Eddy Simulation”(DES).

Considerando os itens acima, há um aumento do esforço computacional nos modelos de cima para baixo, devido ao acréscimo de variáveis físicas. 
O modelo Spalart-Allmaras foi desenvolvido especificamente para aplicações em aeronaves, por isso seu estudo não é oportunamente de nosso interesse.

\subsubsection{Os Modelos $k-\varepsilon$}

Os modelos $k-\varepsilon$ padrão, RNG e Realizable têm formas semelhantes, com equação de transporte para $k$ (energia cinética turbulenta) e $\mathcal{E}$ (taxa de dissipação da energia cinética turbulenta). As diferenças principais nos modelos são as seguintes:

- o método para calcular viscosidade turbulenta.

- o número de Prandtl turbulento que governa a difusão turbulenta de $k$ e $\varepsilon$.

- $\quad$ os termos de geração e dissipação na equação para $\varepsilon$.

As equações de transporte, métodos para calcular viscosidade turbulenta e as constantes envolvidas no modelo são apresentadas separadamente para cada modelo. As características que são essencialmente comuns a todos os modelos incluem a produção de turbulência, geração devido à flutuação da velocidade, os efeitos de compressibilidade, e modelos transferência de calor massa.

\subsubsection{Modelo $k-\varepsilon$ (Padrão).}

O modelo $k-\varepsilon$ padrão (LAUNDER e SPALDING, 1972) é um modelo semi-empírico baseado nas equações do modelo de transporte para a energia cinética turbulenta $(k)$ e sua taxa de dissipação $(\varepsilon)$. A equação do modelo de transporte para $k$ é derivada da equação exata de Navier-Stokes, enquanto que a equação de modelo de transporte para $\varepsilon$ foi obtida usando raciocínio físico e sustenta pouca semelhança à outra matematicamente exata.

$\mathrm{Na}$ dedução do modelo $k-\varepsilon$, supõe-se que o escoamento é completamente turbulento, e que os efeitos de viscosidade molecular são desprezíveis. Assim, o modelo $k-\varepsilon$ padrão só é válido então para escoamentos completamente turbulentos.

Equações de Transporte para o modelo $k-\varepsilon$ (Padrão).

A energia cinética turbulenta, $k$, e sua taxa de dissipação, $\varepsilon$, são obtidas das equações de transporte a seguir:

$$
\begin{aligned}
& \frac{\partial(\rho k)}{\partial t}+\frac{\partial\left(\rho k u_{i}\right)}{\partial x_{i}}=\frac{\partial}{\partial x_{j}}\left[\left(\mu+\frac{\mu_{t}}{\sigma_{k}}\right) \frac{\partial k}{\partial x_{j}}\right]+G_{k}+G_{b}-\rho \varepsilon-Y_{M} \\
& \frac{\partial(\rho \varepsilon)}{\partial t}+\frac{\partial\left(\rho \varepsilon u_{i}\right)}{\partial x_{i}}=\frac{\partial}{\partial x_{j}}\left[\left(\mu+\frac{\mu_{t}}{\sigma_{\varepsilon}}\right) \frac{\partial \varepsilon}{\partial x_{j}}\right]+C_{1 \varepsilon} \frac{\varepsilon}{k}\left(G_{k}+C_{3 \varepsilon} G_{b}\right)-C_{2 \varepsilon} \rho \frac{\varepsilon^{2}}{k}
\end{aligned}
$$


Quando a turbulência é homogênea temos:

$$
\varepsilon=v \overline{\frac{\partial u_{i}}{\partial x_{i}} \frac{\partial u_{i}}{\partial x_{j}}}
$$

onde $v$ é a viscosidade cinemática do fluido.

Nestas equações, $G_{k}$ representa a geração de energia cinética turbulenta devido aos gradientes de velocidade média. $G_{b}$ é a geração de energia cinética turbulenta devido às flutuação das velocidades. $Y_{M}$ representa a contribuição na taxa de dissipação total devido à variação volumétrica para o caso compressível. $C_{1 \varepsilon} C_{2 \varepsilon}$ e $C_{3 \varepsilon}$ são constantes. $\sigma_{k}$ e $\sigma_{\varepsilon}$ são os números de Prandtl turbulentos para $k$ e $\varepsilon$, respectivamente.

A viscosidade turbulenta é relacionada a $k$ e $\varepsilon$ da seguinte forma:

$$
\mu_{t}=\rho C_{\mu} \frac{k^{2}}{\varepsilon}
$$

onde $C_{\mu}$ é uma constante.

As constantes $C_{1 \varepsilon}, C_{2 \varepsilon}, C_{\mu}, \sigma_{k}$ e $\sigma_{\varepsilon}$ foram atribuídas os seguintes valores por Launder e Spalding (1972).

$$
C_{1 \varepsilon}=1,44 ; C_{2 \varepsilon}=1,92 ; C_{\mu}=0,09 ; \sigma_{k}=1,0 ; \sigma_{\varepsilon}=1,3 \text {. }
$$

Eles foram determinados a partir de experimentos com ao mais variados escoamentos em duto sob pressão e de superfície livre.

\subsubsection{O Modelo $k-\varepsilon(R N G)$.}

O modelo $\mathrm{k}-\varepsilon(\mathrm{RNG})$ de turbulência é derivado das equações instantâneas de NavierStokes, usando uma técnica matemática chamada de métodos de "renormalização de grupo" (RNG). A derivação analítica resulta em um modelo com constantes diferentes do modelo $k$ $\mathcal{E}$ (padrão), e termos e funções adicionais nas equações de transporte para $k$ e $\varepsilon$. Uma descrição mais compreensiva da teoria RNG e sua aplicação para turbulência podem ser achadas em Choudhury (1993).

Equações de Transporte para o modelo $k-\varepsilon(R N G)$.

O Modelo $k-\varepsilon(\mathrm{RNG})$ tem uma forma similar ao Modelo $k-\varepsilon$ (padrão)

$$
\begin{aligned}
& \frac{\partial(\rho k)}{\partial t}+\frac{\partial\left(\rho k u_{i}\right)}{\partial x_{i}}=\frac{\partial}{\partial x_{j}}\left[\alpha_{k} \mu_{e f f} \frac{\partial k}{\partial x_{j}}\right]+G_{k}+G_{b}-\rho \varepsilon-Y_{M} \\
& \frac{\partial(\rho \varepsilon)}{\partial t}+\frac{\partial\left(\rho \varepsilon u_{i}\right)}{\partial x_{i}}=\frac{\partial}{\partial x_{j}}\left[\alpha_{\varepsilon} \mu_{e f f} \frac{\partial \varepsilon}{\partial x_{j}}\right]+C_{1 \varepsilon} \frac{\varepsilon}{k}\left(G_{k}+C_{3 \varepsilon} G_{b}\right)-C_{2 \varepsilon} \rho \frac{\varepsilon^{2}}{k}-R_{\varepsilon}
\end{aligned}
$$


Nestas equações, $G_{k}$ representa a geração de energia cinética turbulenta devido aos gradientes de velocidade media. $G_{b}$ é a geração de energia cinética turbulenta devido às flutuação das velocidades. $Y_{M}$ representa a contribuição na taxa de dissipação total devido à variação volumétrica para o caso compressível, e $\alpha_{k}$ e $\alpha_{\varepsilon}$ são os inversos dos números de Prandtl turbulentos para $k$ e $\varepsilon$, respectivamente.

Modelação da Viscosidade Efetiva.

$\mathrm{O}$ procedimento de adimensionalisação na teoria RNG resulta em uma equação diferencial para viscosidade turbulenta:

$$
d\left(\frac{\rho^{2} k}{\sqrt{\varepsilon \mu}}\right)=1,72 \frac{\hat{v}}{\sqrt{\hat{v}-1+C_{v}}} d \hat{v}
$$

sendo $\hat{v}=\mu_{e f f} / \mu$ e $C_{v} \approx 100$

A equação (3.13) é integrada para obter uma descrição precisa de como o transporte turbulento efetivo varia com o número de Reynolds efetivo (ou Escala de Vórtice), permitindo o modelo controlar melhor os escoamentos com baixo número de Reynolds próximo às paredes.

Para altos números de Reynolds limite, a equação (3.13) torna-se:

$$
\mu_{t}=\rho C_{\mu} \frac{k^{2}}{\varepsilon}
$$

com $C_{\mu}=0,0845$, derivado da teoria RNG. É interessante notar que este valor de $C_{\mu}$ é muito próximo do valor empírico determinado para o modelo $k-\varepsilon$ padrão $\left(C_{\mu}=0,09\right)$.

Cálculo do inverso do número de Prandtl efetivo.

Os inversos do número de Prandtl efetivo, $\alpha_{k}$ e $\alpha_{\varepsilon}$, são computados usando a seguinte formula derivada analiticamente da teoria RNG:

$$
\left|\frac{\alpha-1,3929}{\alpha_{0}-1,3929}\right|^{0,6321}\left|\frac{\alpha+2,3929}{\alpha_{0}+2,3929}\right|^{0,3679}=\frac{\mu}{\mu_{e f f}}
$$

em que $\alpha_{0}=1,0$. Para alto número de Reynolds limite $\left(\mu / \mu_{\text {eff }}<<1\right), \alpha_{k}=\alpha_{\varepsilon} \approx 1,393$.

$O$ termo $R_{\varepsilon}$ na equação de $\mathcal{E}$

A principal diferença entre os modelos $k-\varepsilon$ padrão e RNG está no termo adicional na equação 3.12, dada por:

$$
R_{\varepsilon}=\frac{C_{\mu} \rho \eta^{3}\left(1-\eta / \eta_{0}\right)}{1+\beta \eta^{3}} \frac{\varepsilon^{2}}{k}
$$


onde $\eta=S k / \varepsilon, \eta_{0}=4,38$ e $\beta=0,012$.

O efeito deste termo na equação de $\varepsilon$ no modelo RNG pode ser visto mais claramente pelo rearranjo da equação 3.12. Usando a equação 3.16, o terceiro e o quarto termos do lado direito da equação 3.12 podem ser reunidos, e a equação para $\varepsilon$ pode ser reescrita.

$$
\rho \frac{D \varepsilon}{D t}=\frac{\partial}{\partial x_{i}}\left[\alpha_{\varepsilon} \mu_{e f f} \frac{\partial \varepsilon}{\partial x_{i}}\right]+C_{1 \varepsilon} \frac{\varepsilon}{k}\left(G_{k}+C_{3 \varepsilon} G_{b}\right)-C_{2 \varepsilon}^{*} \rho \frac{\varepsilon^{2}}{k}
$$

em que $C_{2 \varepsilon}^{*}$ é dado por

$$
C_{2 \varepsilon}^{*}=C_{2 \varepsilon}+\frac{C_{\mu} \rho \eta^{3}\left(1-\eta / \eta_{0}\right)}{1+\beta \eta^{3}}
$$

Na região onde $\eta<\eta_{0}$, o termo $R_{\varepsilon}$ pode ter uma contribuição positiva e $C_{2 \varepsilon}^{*}$ torna-se maior que $C_{2 \varepsilon}$. No perfil logarítmico, por exemplo, pode ser mostrado que $\eta \approx 3,0$, resultando $C_{2 \varepsilon}^{*} \approx 2,0$ que é próximo ao valor de $C_{2 \varepsilon}$ para modelo $k-\varepsilon$ padrão $\left(C_{2 \varepsilon}=1,92\right)$. Para baixos a moderados escoamentos forçados, o modelo RNG tende a dar resultado similar ao modelo padrão. Em regiões de grandes taxa de pressão $\left(\eta>\eta_{0}\right)$, entretanto, o termo $R_{\mathcal{\varepsilon}}$ contribui de forma negativa tornando o valor de $C_{2 \varepsilon}^{*}$ menor que $C_{2 \varepsilon}$. Em comparação com o modelo $k-\varepsilon$ padrão, a menor distribuição de $\varepsilon$, reduz $k$ e, também, a viscosidade efetiva. Como resultado, em escoamentos rápidos forçados, o modelo RNG produz uma viscosidade turbulenta menor que o modelo padrão. Assim, o modelo de RNG responde aos efeitos de tensões rápidas melhor que o modelo padrão, o que explica o desempenho superior do modelo RNG para certas classes de escoamentos.

As constantes do Modelo RNG, $C_{1 \varepsilon}$ e $C_{2 \varepsilon}$ na equação (3.12) têm valores derivados analiticamente. Estes valores são:

$$
C_{1 \varepsilon}=1,42 ; C_{2 \varepsilon}=1,68
$$

\section{Modelação da Geração da energia cinética turbulenta}

O termo $G_{k}$, representa a geração de energia cinética turbulenta e é modelado de forma idêntica para os modelos $k-\varepsilon$ Padrão e RNG. Para a equação de transporte de $k$ este termo pode ser definido como:

$$
G_{k}=-\rho \overline{u_{i}^{\prime} u_{j}^{\prime}} \frac{\partial u_{j}}{\partial x_{i}}
$$

Uma maneira de avaliar $G_{k}$ consiste na hipótese de Boussinesq,

$$
G_{k}=\mu_{t} S^{2}
$$


onde $S$ é o modulo do tensor médio da taxa de força, definido como:

$$
S \equiv \sqrt{2 S_{i j} S_{i j}}
$$

Efeito da flutuação na turbulência.

Quando o campo gravitacional e o gradiente de temperatura estão presentes simultaneamente, os modelos $k-\boldsymbol{\varepsilon}$ necessitam da geração de $k$ devido às flutuações $\left(G_{b}\right.$ nas Equações 3.7 e 3.11), e a contribuição correspondente para a produção de $\boldsymbol{\varepsilon}$ nas Equações 3.8 e 3.12 .

A geração da turbulência devido à flutuação é dada por:

$$
G_{i j}=\beta \frac{\mu_{t}}{\operatorname{Pr}_{t}}\left(g_{i} \frac{\partial T}{\partial x_{i}}\right)
$$

em que $\operatorname{Pr}_{\mathrm{t}}$ é número de Prandtl turbulento para a energia e $g_{i}$ é a componente gravitacional na direção i. O coeficiente de expansão térmica, $\beta$, é definido como:

$$
\beta=-\frac{1}{\rho}\left(\frac{\partial \rho}{\partial T}\right)_{p}
$$

Para gás ideal, a Equação 3.22 se reduz a:

$$
G_{i j}=-\frac{\mu_{t}}{\rho \operatorname{Pr}_{t}}\left(g_{i} \frac{\partial \rho}{\partial x_{i}}\right)
$$

\subsubsection{Modelos de Tensões de Reynolds.}

Estes modelos estão baseados em equações de transportes para todas as componentes dos tensores de Tensões de Reynolds e na taxa de dissipação. Estes modelos não usam a hipótese de viscosidade turbulenta, mas resolvem uma equação para o transporte de tensões de Reynolds no fluido. As equações de transporte do Modelo Tensões de Reynolds são resolvidas para as componentes de tensão individuais.

O Modelo de Tensões de Reynolds resolve equações algébricas para as tensões de Reynolds, considerando que o diferencial do Modelo de Tensões de Reynolds é resolver equações diferenciais de transporte individualmente para cada componente das tensões de Reynolds.

O resultado da modelação inerente das tensões anisotrópicas faz, teoricamente, o Modelo de Tensões de Reynolds mais adequado para escoamentos complexos, porém, na prática eles não são freqüentemente superiores aos modelos de duas equações. 
As equações para transporte de tensões de Reynolds, $\rho \overline{u_{i}^{\prime} u_{i}^{\prime}}$, podem ser escritas da seguinte forma:

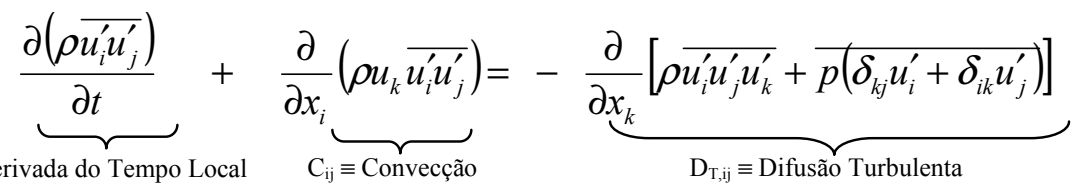

$$
\begin{aligned}
& \underbrace{\frac{\partial}{\partial x_{k}}\left[\mu \frac{\partial}{\partial x_{k}}\left(\overline{u_{i}^{\prime} u_{j}^{\prime}}\right)\right]}_{\mathrm{D}_{\mathrm{L}, \mathrm{j}} \equiv \text { Difusão Molecular }}-\rho \underbrace{\left(\overline{u_{i}^{\prime} u_{k}^{\prime}} \frac{\partial u_{j}}{\partial x_{k}}+\overline{u_{j}^{\prime} u_{k}^{\prime}} \frac{\partial u_{i}}{\partial x_{k}}\right)}_{\mathrm{P}_{\mathrm{ij}} \equiv \text { Produção de Tensão }}-\underbrace{\rho \beta\left(g_{i} \overline{u_{j}^{\prime} \theta}+g_{j} \overline{u_{i}^{\prime} \theta}\right)}_{\mathrm{G}_{\mathrm{ij}} \equiv \text { Produção de Flutuação }} \\
& +\underbrace{p\left[\frac{\partial u_{i}^{\prime}}{\partial x_{j}}+\frac{\partial u_{j}^{\prime}}{\partial x_{i}}\right]}_{\phi_{i j} \equiv \text { Efeito de Pressão }}-2 \underbrace{\overline{\mu \frac{\partial u_{i}^{\prime}}{\partial x_{k}} \frac{\partial u_{j}^{\prime}}{\partial x_{k}}}}_{\varepsilon_{j} \equiv \text { Dissipação }} \\
& \underbrace{2 \rho \Omega_{k}\left(\overline{u_{j}^{\prime} u_{m}^{\prime}} \epsilon_{i k m}+\overline{u_{i}^{\prime} u_{m}^{\prime}} \epsilon_{j k m}\right)}_{\text {Fiڤ = Produção pela rotação do Sistema }}+\underbrace{\mathrm{S}_{\text {user }}}_{\text {Termo Fonte }}
\end{aligned}
$$

Dos vários termos desta equação, $\mathrm{C}_{\mathrm{ij}}, \mathrm{D}_{\mathrm{L}, \mathrm{ij}}, \mathrm{P}_{\mathrm{ij}}$ e $\mathrm{F}_{\mathrm{ij}}$ não requerem nenhum modelo, entretanto, $\mathrm{D}_{\mathrm{T}, \mathrm{ij}}, \mathrm{G}_{\mathrm{ij}}, \phi_{i j}$ e $\varepsilon_{\mathrm{ij}}$ precisam ser modelados para fechamento da equação. Logo abaixo são descritos os modelos normalmente requeridos para fechamento destas equações.

\section{Modelo do Transporte de Difusão Turbulenta.}

O transporte de Difusão Turbulenta, $D_{T, i j}$, pode ser modelado pelo modelo generalizado de gradiente de difusão (DALY e HARLOW, 1970)

$$
D_{T, i j}=C_{s} \frac{\partial}{\partial x_{k}}\left(\rho \frac{k \overline{u_{k}^{\prime} u_{l}^{\prime}}}{\varepsilon} \frac{\partial \overline{u_{i}^{\prime} u_{j}^{\prime}}}{\partial x_{l}}\right)
$$

Porém, esta equação pode resultar em uma instabilidade numérica, então ela tem sido simplificada com o uso de uma difusividade turbulenta escalar como a seguir:

$$
D_{T, i j}=\frac{\partial}{\partial x_{k}}\left(\frac{\mu_{t}}{\sigma_{k}} \frac{\partial \overline{u_{i}^{\prime} u_{j}^{\prime}}}{\partial x_{k}}\right)
$$

A viscosidade turbulenta, $\mu_{\mathrm{t}}$, é calculada da mesma forma do modelo $k-\varepsilon$ (Equação 3.10). Lien e Leschziner (1994) encontraram um valor para $\sigma_{k}=0,82$ pela aplicação do modelo generalizado do gradiente de difusão, Equação 3.26, para o caso de um escoamento cisalhante homogêneo planar. Note que este valor de $\sigma_{k}$ é diferente do valor para os modelos $k-\varepsilon$, em que $\sigma_{k}=1,0$. 
Modelação do Termo do Efeito da Pressão.

O termo do efeito da pressão, $\phi_{i j}$, na equação 3.25 pode ser modelado de acordo com a proposta de Gibson e Launder (1978).

A aproximação clássica para a modelação de $\phi_{\mathrm{ij}}$ usa a seguinte decomposição:

$$
\phi_{i j}=\phi_{i j, 1}+\phi_{i j, 2}+\phi_{i j, w}
$$

onde $\phi_{i j, 1}$ é o termo de efeito lento da pressão, $\phi_{i j, 2}$ é o termo de efeito rápido da pressão, e $\phi_{i j, w}$ é o termo de reflexão nas paredes.

O termo de efeito lento da pressão, $\phi_{i j, 1}$ é modelado como:

$$
\phi_{i j, 1}=C_{1} \rho \frac{\varepsilon}{k}\left(\overline{u_{i}^{\prime} u_{j}^{\prime}}-\frac{2}{3} \delta_{i j} k\right)
$$

$\operatorname{com~} \mathrm{C}_{1}=1,8$.

O termo de efeito rápido da pressão, $\phi_{i j, 2}$ é modelado como:

$$
\phi_{i j, 2}=-C_{2}\left[\left(P_{i j}+F_{i j}+G_{i j}-C_{i j}\right)-\frac{2}{3} \delta_{i j}(P+G+C)\right]
$$

em que $C_{2}=0,60 . P_{i j}, F_{i j}, G_{i j}$ e $C_{i j}$ são definidos como na equação $3.25, P=\frac{1}{2} P_{k k}, G=\frac{1}{2} G_{k k}$ e $C=\frac{1}{2} C_{k k}$.

O termo de reflexão nas paredes, $\phi_{\mathrm{ij}, \mathrm{w}}$, é responsável pela redistribuição da tensão normal perto da parede. Tende a diminuir a tensão normal à parede, enquanto aumenta as tensões paralelas. Este termo é modelado como:

$$
\begin{aligned}
& \phi_{i j, w}=C_{1}^{\prime} \frac{\varepsilon}{k}\left(\overline{u_{k}^{\prime} u_{m}^{\prime}} n_{k} n_{m} \delta_{i j}-\frac{3}{2} \overline{u_{i}^{\prime} u_{k}^{\prime}} n_{j} n_{k}-\frac{3}{2} \overline{u_{j}^{\prime} u_{k}^{\prime}} n_{i} n_{k}\right) \frac{k^{3 / 2}}{C_{\ell} \varepsilon d} \\
& +C_{2}^{\prime}\left(\phi_{k m, 2} n_{k} n_{m} \delta_{i j}-\frac{3}{2} \phi_{i k, 2} n_{j} n_{k}-\frac{3}{2} \phi_{j k, 2} n_{i} n_{k}\right) \frac{k^{3 / 2}}{C_{\ell} \varepsilon d}
\end{aligned}
$$

sendo $C_{1}^{\prime}=0,5, C_{2}^{\prime}=0,3, n_{k}$ a componente $x_{k}$ normal à parede, $d$ a distância normal à parede, $C_{\ell}=C_{\mu}^{3 / 4} / \kappa$, onde $C_{\mu}=0,09$ e $\kappa$ é a constante de Von Kármán $(\kappa=0,4187)$.

\section{Modelo do Efeito da flutuação na Turbulência.}

O termo de produção devido à flutuação é modelado como:

$$
G_{i j}=\beta \frac{\mu_{t}}{\operatorname{Pr}_{t}}\left(g_{i} \frac{\partial T}{\partial x_{j}}+g_{j} \frac{\partial T}{\partial x_{i}}\right)
$$

onde $\operatorname{Pr}_{t}$ é o número de Prandtl turbulento para a energia.

Usando a definição do coeficiente de expansão térmica, $\beta$, dado pela Equação 3.23 , a expressão a seguir é obtida para $G_{i j}$ para gás ideal: 


$$
G_{i j}=-\frac{\mu_{t}}{\rho \operatorname{Pr}_{t}}\left(g_{i} \frac{\partial \rho}{\partial x_{j}}+g_{j} \frac{\partial \rho}{\partial x_{i}}\right)
$$

\section{Modelo da Energia cinética turbulenta.}

Em geral, quando a energia cinética turbulenta é necessária para modelar algum termo específico, ela é obtida através do tensor de Reynolds.

$$
k=\frac{1}{2} \overline{u_{i}^{\prime} u_{i}^{\prime}}
$$

Nas condições de contorno, normalmente, utilizam-se uma equação similar ao modelo de transporte usado no modelo $k-\varepsilon$ padrão:

$$
\frac{\partial(\rho k)}{\partial t}+\frac{\partial\left(\rho k u_{i}\right)}{\partial x_{i}}=\frac{\partial}{\partial x_{j}}\left[\left(\mu+\frac{\mu_{t}}{\sigma_{k}}\right) \frac{\partial k}{\partial x_{j}}\right]+\frac{1}{2}\left(P_{i i}+G_{i i}\right)-\rho \varepsilon\left(1+2 M_{t}^{2}\right)
$$

Modelo da taxa de dissipação.

O tensor de dissipação, $\varepsilon_{i j}$ é modelado como:

$$
\varepsilon_{i j}=\frac{2}{3} \delta_{i j}\left(\rho \varepsilon+Y_{M}\right)
$$

onde $Y_{M}=2 \rho \varepsilon M_{t}^{2}$ é um termo adicional de "dissipação-dilatação". O número de Mach turbulento é definido como:

$$
M_{t}=\sqrt{\frac{k}{a^{2}}}
$$

em que $(a \equiv \sqrt{\Re R T})$ é a velocidade do som.

A taxa de dissipação escalar, $\mathcal{E}$, é calculada com uma equação similar ao modelo de transporte usado no modelo $k-\varepsilon$ padrão:

$$
\frac{\partial(\rho \varepsilon)}{\partial t}+\frac{\partial\left(\rho \varepsilon u_{i}\right)}{\partial x_{i}}=\frac{\partial}{\partial x_{j}}\left[\left(\mu+\frac{\mu_{t}}{\sigma_{\varepsilon}}\right) \frac{\partial \varepsilon}{\partial x_{j}}\right]+C_{1 \varepsilon} \frac{1}{2} \frac{\varepsilon}{k}\left(P_{i i}+C_{3 \varepsilon} G_{i i}\right)-C_{2 \varepsilon} \rho \frac{\varepsilon^{2}}{k}
$$

\subsubsection{Simulação de Grandes Escalas (Large Eddy Simulation - LES).}

Escoamentos turbulentos são caracterizados por diversas escalas de comprimentos e de tempo. As recirculações maiores são tipicamente comparáveis em tamanho ao comprimento característico do escoamento. As escalas menores são responsáveis pela dissipação da energia cinética turbulenta.

Teoricamente, é possível solucionar o espectro inteiro de escalas turbulentas através da Simulação Numérica Direta (Direct Numerical Simulation - DNS), mas isto não é possível 
para os problemas práticos em engenharia. Para entendimento do grande custo computacional da DNS, considere que a relação de grandes escalas e de pequenas escalas são proporcionais a $\mathrm{Re}_{t}^{3 / 4}$, onde $\mathrm{Re}_{t}$ é o número de Reynolds turbulento. Entretanto, para resolver todas as escalas, o tamanho da malha tridimensional será proporcional $\operatorname{Re}_{t}^{9 / 4}$. Um simples cálculo aritmético com números de Reynolds altos mostra que o tamanho da malha requerida para a Simulação Numérica Direta é inviável. Acrescenta-se ao custo computacional o fato de que a simulação terá passos de tempo muito pequenos em problemas transientes, uma vez que as exigências de resolução no tempo são governadas pelas escalas de dissipação, ao invés do escoamento médio.

Como explanado anteriormente, uma aproximação convencional para simulações de escoamentos turbulentos é aplicar as Equações da Média de Reynolds de Navier-Stokes (RANS). Na aproximação de RANS, todo o movimento turbulento é modelado, resultando em uma significante redução no esforço de computacional.

Conceitualmente, a Simulação de Grande Escalas (Large Eddy Simulation - LES) está entre a Simulação Numérica Direta e a aproximação pela Média de Reynolds de NavierStokes. Basicamente, as grandes escalas são resolvidas diretamente no método LES, enquanto pequenas escalas são modeladas. O princípio do método LES pode ser resumido como a seguir:

- Momento, massa, energia, e outros escalares passivos são transportados principalmente através das grandes escalas.

- Grandes escalas são mais dependentes dos problemas envolvidos. Elas são ditadas pela geometria e condições de contorno do escoamento envolvido.

- Pequenas escalas são menos dependentes das geometrias, tendem a ser mais isotrópicas, e são conseqüentemente mais universais.

- A chance de se achar um modelo universal é muito mais alta quando são modeladas só pequenas escalas.

As seções seguintes dão detalhes das equações para a Simulação de Grandes Escalas, apresentam-se as duas opções para modelação das tensões de sub-malhas (necessárias para o fechamento das equações).

Equações de Navier-Stokes Filtradas.

Para Resolver somente para as grandes escalas e modelar as escalas menores são necessárias malhas que são menos restritas que com Simulação Numérica Direta. Tipicamente, o tamanho da malha pode ser pelo menos uma ordem grandeza menor que com 
DNS. Além disso, os passos de tempo serão proporcionais ao tempo de mudança de escala, que também é menos limitado que com DNS. Em condições práticas, porém, são requeridas ainda malhas extremamente finas. Devido aos aumentos em desempenho de hardware acrescentado à disponibilidade de processamento paralelo, a Simulação de Grandes Escalas pode ser considerado como uma possibilidade de cálculos.

As equações aplicadas na Simulação de Grandes Escalas são obtidas filtrando a dependência temporal nas equações de Navier-Stokes ou no espaço de Fourier (número de ondas) ou no espaço configurado (físico). O processo de filtragem separa as escalas menores do que um tamanho específico, que normalmente são restritos ao tamanho de malha computacionalmente viável. Uma variável qualquer do escoamento $\Phi$ pode ser escrita como:

$$
\Phi=\bar{\Phi}+\Phi^{\prime}
$$

em que $\bar{\Phi}$, é a parte referente à Grande Escala, que é definida através do volume médio, dado por:

$$
\bar{\Phi}\left(x_{i}, t\right)=\int_{V o l} G\left(x_{i}-x_{i}^{\prime}\right) \Phi\left(x_{i}^{\prime}, t\right) d x_{i}^{\prime}
$$

sendo $G\left(x_{i}-x_{i}^{\prime}\right)$ uma função filtro (chamada de filtro Gaussiano).

Filtrando as equações de Navier-Stokes para escoamento incompressível, obtém-se:

$$
\frac{\partial \rho}{\partial t}+\frac{\partial}{\partial x_{i}}\left(\rho \bar{u}_{i}\right)=0
$$

e

$$
\frac{\partial}{\partial t}\left(\rho \bar{u}_{i}\right)+\frac{\partial}{\partial x_{j}}\left(\rho \bar{u}_{i} \bar{u}_{j}\right)=\frac{\partial}{\partial x_{j}}\left(\mu \frac{\partial \bar{u}_{i}}{\partial x_{j}}\right)-\frac{\partial \bar{p}}{\partial x_{i}}-\frac{\partial \tau_{i j}}{\partial x_{j}}
$$

onde $\tau_{i j}$ é a tensão de sub-malha definida como:

$$
\tau_{i j} \equiv \rho \overline{u_{i} u_{j}}-\rho \bar{u}_{i} \bar{u}_{j}
$$

Modelo de Sub-malha.

As tensões de sub-malha resultante da operação de filtragem são desconhecidas, e necessárias para a simulação do escoamento. A maiorias dos modelos de sub-malha em uso são modelos de viscosidades turbulentas, da seguinte forma:

$$
\tau_{i j}-\frac{1}{3} \tau_{k k} \delta_{i j}=-2 \mu_{t} \bar{S}_{i j}
$$

em que $\mu_{t}$ é a viscosidade turbulenta de sub-malha e $\bar{S}_{i j}$ é o tensor de taxa de força, definido como: 


$$
\bar{S}_{i j} \equiv \frac{1}{2}\left(\frac{\partial \bar{u}_{i}}{\partial x_{j}}+\frac{\partial \bar{u}_{j}}{\partial x_{i}}\right)
$$

Modelo de Smagorinsky-Lilly.

Um modelo de sub-malha foi proposto por Smagorinsky (1963) e posteriormente desenvolvido por Lilly (1966). No modelo de Smagorinsky-Lilly, a viscosidade turbulenta é modelada como:

$$
\mu_{t}=\rho L_{s}^{2}|\bar{S}|
$$

onde $L_{s}$ é o comprimento de mistura de sub-malha e $|\bar{S}| \equiv \sqrt{2 \bar{S}_{i j} \bar{S}_{i j}}$. $C_{s}$ é a constante de Smagorinsky. $L_{s}$ pode de determinado por:

$$
L_{s}=\min \left(\kappa d, C_{s} \mathrm{Vol}^{1 / 3}\right)
$$

sendo $\kappa$ a constante de Von Kármán, $d$ a distância da parede e $V o l$ o volume computacional da célula.

Lilly (op cit.) encontrou o valor de $C_{s}=0,23$, para a turbulência isotrópica e homogênea. Porém, este valor resultou em excessivas flutuações na presença de meios cisalhantes ou de escoamentos transientes. O valor de $C_{s}=0,1$ tem sido usado para obter melhores resultados para a maioria dos escoamentos.

\subsection{Modelos Multifásicos.}

Os modelos multifásicos são utilizados em simulações em fluido dinâmica computacional, de forma a representar as diferentes fases ou misturas dos fluidos presentes nos escoamentos. Estes modelos são divididos basicamente em modelos multifasicos euleriano-euleriano ou euleriano-lagrangeano (CFX, 2004). Os modelos multifásicos euleriano-euleriano representam duas ou mais fases do escoamento pelo método de Euler de abordagem no estudo de escoamento, em que, as determinações das grandezas características do campo do escoamento são representadas em função do tempo, na superfície de controle e no volume de controle. Os modelos multifásicos euleriano-lagrangeano representam uma das fases na forma de Euler e a outra na forma de Lagrange. Esta última consiste em isolar um sistema e estudar o comportamento individual de cada molécula ou partícula desse sistema (ROMA, 2006). Para este trabalho de doutorado somente foi utilizado o modelo multifásico euleriano-euleriano. 
Os modelos multifásicos euleriano-euleriano podem ser divididos em dois outros submodelos: homogêneo e não-homogêneo (ou modelo de transferência entre fluidos) (CFX, 2004).

No modelo homogêneo, as equações representativas do escoamento são resolvidas de forma compartilhada para todos os fluidos, assim a quantidade e equações resolvidas é menor do que em um modelo não-homogêneo, onde cada fluido possui um sistema de equações representativas.

Notações

As diferentes fases de fluidos podem ser denotadas com as seguintes letras gregas minúsculas: $\alpha, \beta, \gamma$, etc. A fração de volume de $\alpha$ é denotado por $r_{\alpha}$. Assim, o volume Vol $_{\alpha}$ ocupado pela fase $\alpha$ em um pequeno volume $V o l$ ao redor de um ponto de fração de volume $r_{\alpha}$ é determinado por:

$$
\mathrm{Vol}_{\alpha}=r_{\alpha} \mathrm{Vol}
$$

O total de número fases é $N_{P}$. A fração de volume de cada fase é denotado por $r_{\alpha}$, em que $\alpha=1$ a $N_{P}$.

É importante distinguir entre a massa específica do fluido e a massa específica efetiva do fluido $\alpha$. Sendo, $\rho_{\alpha}$, a massa específica do fluido se este for a única fase presente, exemplo; a massa de $\alpha$ dividida pela unidade de volume de $\alpha$.

A massa específica efetiva da fase é definida como:

$$
\widetilde{\rho}_{\alpha}=r_{\alpha} \rho_{\alpha}
$$

Ou seja: $\widetilde{\rho}_{\alpha}$ é massa por unidade de volume da fase $\alpha$, dado que a fase $\alpha$ ocupe somente uma fração do volume.

A massa especifica da mistura é dada por:

$$
\rho_{m}=\sum_{\alpha} \rho_{\alpha} r_{\alpha}
$$

A pressão total em uma simulação multifásica é definida por:

$$
p_{\text {tot }}=p_{\text {est }}+\sum_{\alpha} \frac{1}{2} \rho_{\alpha} r_{\alpha} u_{\alpha}^{2}
$$

\subsubsection{Modelo Não-homogêneo.}

Nos modelos multifásicos não-homogêneos cada fluido é processado com seu próprio campo de escoamento e as interações entre as fases são calculadas por meio de um termo de transferência. Assim, nesses modelos há um campo de solução em separado para cada fase. 
Por exemplo: duas fases podem ter campos de velocidade e temperatura separados, mas há uma tendência para que ele fique em equilíbrio na interface através do termo de arrasto e de transferência de calor (CFX, 2004).

As equações da continuidade e transporte da quantidade de movimento para o modelo não-homogêneo são:

Continuidade:

$$
\frac{\partial}{\partial t}\left(r_{\alpha} \rho_{\alpha}\right)+\nabla .\left(r_{\alpha} \rho_{\alpha} u_{\alpha}\right)=S_{M S \alpha}+\sum_{\beta=1}^{N_{P}} \Gamma_{\alpha \beta}
$$

Quantidade de Movimento:

$$
\begin{aligned}
& \frac{\partial}{\partial t}\left(r_{\alpha} \rho_{\alpha} u_{\alpha}\right)+\nabla \cdot\left(r_{\alpha}\left(\rho_{\alpha} u_{\alpha} \times u_{\alpha}\right)\right)= \\
& -r_{\alpha} \nabla p_{\alpha}+\nabla \cdot\left(r_{\alpha} \mu_{\alpha}\left(\nabla u_{\alpha}+\left(\nabla u_{\alpha}\right)^{T}\right)\right)+\sum_{\beta=1}^{N_{P}}\left(\Gamma_{\alpha \beta}^{+} u_{\beta}-\Gamma_{\beta \alpha}^{+} u_{\alpha}\right)+S_{M \alpha}+M_{\alpha}
\end{aligned}
$$

onde $S_{M S \alpha}$ é uma fonte de massa; $\Gamma_{\alpha \beta}$ é a taxa de fluxo de massa por unidade de volume da fase $\beta$ para a fase $\alpha$, maiores detalhes sobre esta variável são apresentados na seqüência. Estes termos somente ocorrem na região de transferência de massa na interface; $S_{M \alpha}$ é o termo fonte de quantidade de movimento devido às forças externas; $M_{\alpha}$ é a forca interfacial que age na fase $\alpha$ devido a presença da outra fase. O termo $\Gamma_{\alpha \beta}^{+} u_{\beta}-\Gamma_{\beta \alpha}^{+} u_{\alpha}$ representa a transferência de quantidade de movimento induzida pela transferência de massa.

É simples constatar que o somatório das frações de volume é igual à unidade:

$$
\sum_{\alpha=1}^{N_{P}} r_{\alpha}=1
$$

Temos, até então, $4 N_{p}+1$ equações para completar as $5 N_{p}$ equações necessárias para determinação de $u_{\alpha}, v_{\alpha}, w_{\alpha}, r_{\alpha}$ e $p_{\alpha}$. Necessitam-se mais $N_{p}-1$ equações para determinação do sistema. Este fechamento é determinado através do compartilhamento do campo pressão para todas as fases:

$$
p_{\alpha}=p \quad \text { para todo } \alpha=1, \ldots, N_{P}
$$

Quando existe uma variável adicional $\Phi$ para a fase $\alpha$, o campo correspondente para esta variável é denotado por $\Phi_{\alpha .}$ A equação de transporte para esta variável é dada por:

$$
\frac{\partial}{\partial t}\left(r_{\alpha} \rho_{\alpha} \phi_{\alpha}\right)+\nabla \cdot\left(r_{\alpha}\left(\rho_{\alpha} u_{\alpha} \phi_{\alpha}\right)\right)-\nabla .\left(r_{\alpha}\left(\rho_{\alpha} D_{\alpha}^{(\phi)}+\frac{\mu_{t \alpha}}{S c_{t \alpha}}\right) \nabla \phi_{\alpha}\right)=S_{\alpha}^{(\phi)}+T_{\alpha}^{(\phi)}
$$


em que $\phi_{\alpha}$ é a variável por unidade de massa na fase $\alpha, \Phi_{\alpha}$ é a variável por unidade de volume

da fase $\alpha$, sendo $\Phi_{\alpha}=\rho_{\alpha} \phi_{\alpha} . D_{\alpha}^{(\phi)}$ é a difusividade cinemática do escalar na fase $\alpha . S_{\alpha}^{(\phi)}$ é o termo fonte volumétrico externo na fase $\alpha . T_{\alpha}^{(\phi)}$ representa a fonte total de $\phi_{\alpha}$ devido à transferência de uma fase para outra.

\subsubsection{Modelo Homogêneo.}

No escoamento multifásico homogêneo, um campo de escoamento comum é compartilhado por todos os fluidos, como também outros campos relevantes como a temperatura e a turbulência. Isto permite algumas simplificações para construção do modelo multifluido, resultando no modelo homogêneo. Para um dado processo de transporte, o modelo homogêneo assume que as quantidades transportadas para aquele processo (com exceção da fração de volume) são as mesmas para todas a fases, ou seja (CFX, 2004):

$$
\phi_{\alpha}=\phi_{t}
$$

Como as quantidades transportadas são compartilhadas no escoamento multifásico homogêneo, é suficiente para resolver os campos compartilhados usando uma equação de transporte simplificada em lugar da solução individual da equação de transporte da fase.

A equação de transporte simplificada pode ser determinada da equação 3.56 considerando a equação de transporte para uma fase única resultado na seguinte equação para $\phi_{t}:$

$$
\frac{\partial}{\partial t}\left(\rho \phi_{t}\right)+\nabla \cdot\left(\rho u \phi_{t}-\Gamma \nabla \phi_{t}\right)=S
$$

onde

$$
\rho=\sum_{\alpha=1}^{N_{P}} r_{\alpha} \rho_{\alpha}, u=\frac{1}{\rho} \sum_{\alpha=1}^{N_{P}} r_{\alpha} \rho_{\alpha} u_{\alpha} \text { e } \Gamma=\sum_{\alpha=1}^{N_{P}} r_{\alpha} \Gamma_{\alpha}
$$

O modelo homogêneo não necessita de aplicação consistente em todas equações. Por exemplo; o campo de velocidade pode ser modelado como não-homogêneo, mas acoplado como um modelo de turbulência homogêneo. Alternativamente, um campo de velocidade homogêneo pode ser acoplado com um campo de temperatura não-homogêneo.

As equações da continuidade e transporte da quantidade de movimento para o modelo homogêneo são:

\section{Continuidade:}

$$
\frac{\partial}{\partial t}\left(r_{\alpha} \rho_{\alpha}\right)+\nabla .\left(r_{\alpha} \rho_{\alpha} u\right)=S_{M S \alpha}+\sum_{\beta=1}^{N_{P}} \Gamma_{\alpha \beta}
$$


Quantidade de Movimento:

O modelo homogêneo para a equação de quantidade de movimento assume-se:

$$
u_{\alpha}=u, 1 \leq \alpha \leq N_{P}
$$

e a equação fica:

$$
\frac{\partial}{\partial t}(\rho u)+\nabla \cdot\left(\rho u \times u-\mu\left(\nabla u+(\nabla u)^{T}\right)\right)=S_{M}-\nabla p
$$

em que

$$
\rho=\sum_{\alpha=1}^{N_{P}} r_{\alpha} \rho_{\alpha} \text { e } \mu=\sum_{\alpha=1}^{N_{P}} r_{\alpha} \mu_{\alpha}
$$

Podem-se notar os seguintes pontos:

- O termo de transferência de interface é cancelado na equação de quantidade de movimento, mas é mantida na continuidade.

- Esta é uma equação de transporte para uma fase simples, com densidade e viscosidade variável.

A equação para conservação do volume para o modelo homogêneo é a mesma do nãohomogêneo (equação 3.54). E o campo de pressão também é compartilhado para fechamento do sistema de equações (equação 3.55) (CFX, 2004).

\subsubsection{Transferência de Massa na Interface.}

A transferência de massa na interface ocorre quando a massa é transmitida de uma fase para outra. Este modelo de transferência de massa é aplicado em ambos os modelos multifásicos, não-homogêneo ou homogêneo.

A transferência de massa é representada pelo termo fonte na equação da continuidade das fases.

$$
\frac{\partial}{\partial t}\left(r_{\alpha} \rho_{\alpha}\right)+\nabla \cdot\left(r_{\alpha} \rho_{\alpha} u_{\alpha}\right)=S_{\alpha}+\Gamma_{\alpha}
$$

onde $S_{\alpha}$ descreve a fonte de massa especificada pelo usuário; $\Gamma_{\alpha}$ é a fonte de massa por unidade de volume na fase $\alpha$, devido à transferência de massa na interface.

$$
\Gamma_{\alpha}=\sum_{\beta=1}^{N_{P}} \Gamma_{\alpha \beta}
$$

em que $\Gamma_{\alpha \beta}$ é a taxa de fluxo de massa por unidade de volume da fase $\beta$ para a fase $\alpha$, sendo:

$$
\Gamma_{\alpha \beta}=-\Gamma_{\beta \alpha} \quad \Rightarrow \quad \sum_{\alpha=1}^{N_{P}} \Gamma_{\alpha}=0
$$


Como é importante manter a indicação de direção do processo transferência de massa, é conveniente expressar $\Gamma_{\alpha \beta}$ da seguinte forma:

$$
\Gamma_{\alpha \beta}=\Gamma_{\alpha \beta}^{+}-\Gamma_{\beta \alpha}^{+}
$$

O termo $\Gamma_{\alpha \beta}^{+}>0$ representa a taxa de fluxo de massa positivo por unidade de volume da fase $\beta$ para a fase $\alpha$.

Para o processo de transferência de massa através de uma interface é usualmente expresso como uma fonte de massa no volume de controle em termos do fluxo de massa.

$$
\Gamma_{\alpha \beta}=\dot{m}_{\alpha \beta} A_{\alpha \beta}
$$

onde $\dot{m}_{\alpha \beta}$ é a taxa de massa de fluxo por unidade de área da fase $\beta$ para a fase $\alpha$ e $A_{\alpha \beta}$ é a área interfacial entre as duas fases.

Como a área interfacial é comumente proporcional à fração de volume, isto permite uma linearização do termo de transferência de massa relativo à fração de volume.

\subsubsection{Modelo de Mistura (Mixture Model).}

O Modelo de Mistura é o modelo mais simples, pois trata ambas as fases $\alpha$ e $\beta$ de forma simétrica. A área de superfície por unidade de volume é calculada por:

$$
A_{\alpha \beta}=\frac{r_{\alpha} r_{\beta}}{d_{\alpha \beta}}
$$

em que $d_{\alpha \beta}$ é uma escala de comprimento na interface, que é especificado por (em caso de duas fases):

$$
d_{\alpha \beta}=\frac{r_{\alpha} d_{\beta}+r_{\beta} d_{\alpha}}{6}
$$

Os coeficientes adimensionais de transferência interfases podem ser correlacionados em termo do número de Reynolds de mistura e o número de Prandtl, definidos como:

$$
\begin{aligned}
& \operatorname{Re}_{\alpha \beta}=\frac{\rho_{\alpha \beta}\left|U_{\beta}-U_{\alpha}\right| d_{\alpha \beta}}{\mu_{\alpha \beta}} \\
& \operatorname{Pr}_{\alpha \beta}=\frac{\mu C_{P \alpha \beta}}{\lambda_{\alpha \beta}}
\end{aligned}
$$

onde $\rho_{\alpha \beta}, \mu_{\alpha \beta}, C_{P \alpha \beta}$ e $\lambda_{\alpha \beta}$ são a massa específica, viscosidade, capacidade específica de calor e a condutividade térmica da mistura, respectivamente, em que:

$$
\rho_{\alpha \beta}=r_{\alpha} \rho_{\alpha}+r_{\beta} \rho_{\beta}
$$




$$
\mu_{\alpha \beta}=r_{\alpha} \mu_{\alpha}+r_{\beta} \mu_{\beta}
$$

\subsubsection{Modelo de Superfície Livre.}

Esta seção descreve a teoria do escoamento de superfície livre que é a aplicação mais comum em escoamentos homogêneos multifásicos (CFX, 2004).

O propósito do modelo de superfície livre é solucionar a interface entre os fluidos. Se houver uma simulação com somente duas fases, a seguinte equação é usada para calcular a área de superfície por unidade de volume.

$$
A_{\alpha \beta}=\left|\nabla r_{\alpha}\right|
$$

Quando mais de duas fases estão presentes, a equação generalizada fica:

$$
A_{\alpha \beta}=\frac{2\left|\nabla r_{\alpha}\right|\left|\nabla r_{\beta}\right|}{\left|\nabla r_{\alpha}\right|+\left|\nabla r_{\beta}\right|}
$$

\section{Tensão superficial}

O modelo de tensão superficial usado é baseado no Modelo de Força Superficial Continua de Brackbill et al (1992). Neste modelo a força de devido à tensão superficial é modelada como uma força concentrada na interface, ao invés de uma força de superfície. Considere a interface de superfície livre mostrada na figura abaixo:

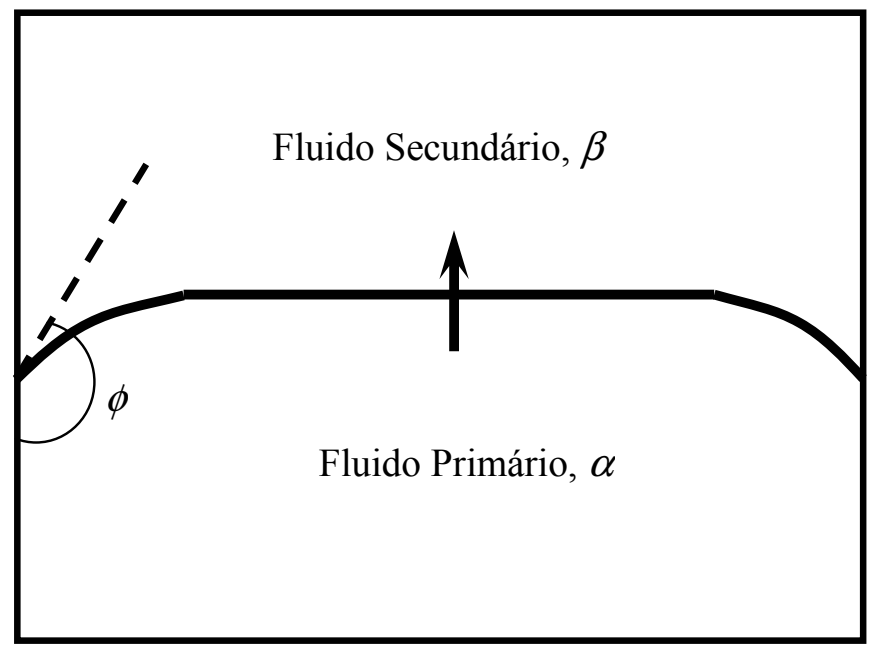

Figura 3.2. Interface da superfície livre.

A força de tensão superficial pelo modelo de força superficial continua é:

$$
F_{\alpha \beta}=f_{\alpha \beta} \delta_{\alpha \beta}
$$


sendo:

$$
\begin{aligned}
& f_{\alpha \beta}=-\sigma_{\alpha \beta} \kappa_{\alpha \beta} n_{\alpha \beta}+\nabla_{S} \sigma \\
& \delta_{\alpha \beta}=\left|\nabla r_{\alpha \beta}\right|
\end{aligned}
$$

onde $\sigma$ é a tensão superficial do fluido, $n_{\alpha \beta}$ é o vetor normal à interface do fluido primário para o secundário (calculado usando o gradiente de fração de volume), $\nabla_{S}$ é o operador gradiente na interface e $\kappa_{\alpha \beta}$ é a curvatura da superfície, definida por:

$$
\kappa_{\alpha \beta}=\nabla . n_{\alpha \beta}
$$

Os dois termos do lado direito da equação 3.78 representam as componentes normais e tangenciais da força de tensão superficial, respectivamente. A componente normal surge da curvatura de interface e a componente tangencial das variações no coeficiente de tensão superficial (efeito de Marangoni).

O termo $\delta_{\alpha \beta}$ é chamado de função delta de interface; ele é nulo fora de interface, assegurando assim que a força de tensão de superfície só é ativa perto da interface.

Quando a interface entre os dois fluidos cruza-se com uma parede, é possível determinar a adesão à parede especificando o ângulo de contato que a interface, no fluido primário, faz com esta parede. O vetor normal de interface usado para os cálculos de curvatura e a força de tensão superficial tem que satisfazer o ângulo de contato de parede.

\subsection{Discretização Numérica.}

A solução analítica para as equações de Navier-Stokes existe para somente escoamentos simples sob condições ideais. Para obter soluções para o escoamento real, uma aproximação numérica deve ser adotada, de maneira que as equações são substituídas por aproximações algébricas que podem ser resolvidas usando um método numérico (CFX, 2004).

Discretização das Equações Governantes.

Esta aproximação envolve uma discretização espacial em volumes de controles finitos utilizando-se uma malha. As equações governantes são integradas em cada volume de controle, tal que as quantidades relevantes (massa, quantidade de movimento, energia, etc.) são conservadas em valores distintos para cada volume de controle.

A figura 3.3 abaixo apresenta uma malha típica em duas dimensões, cada superfície do volume finito é representada pela área hachurada. 


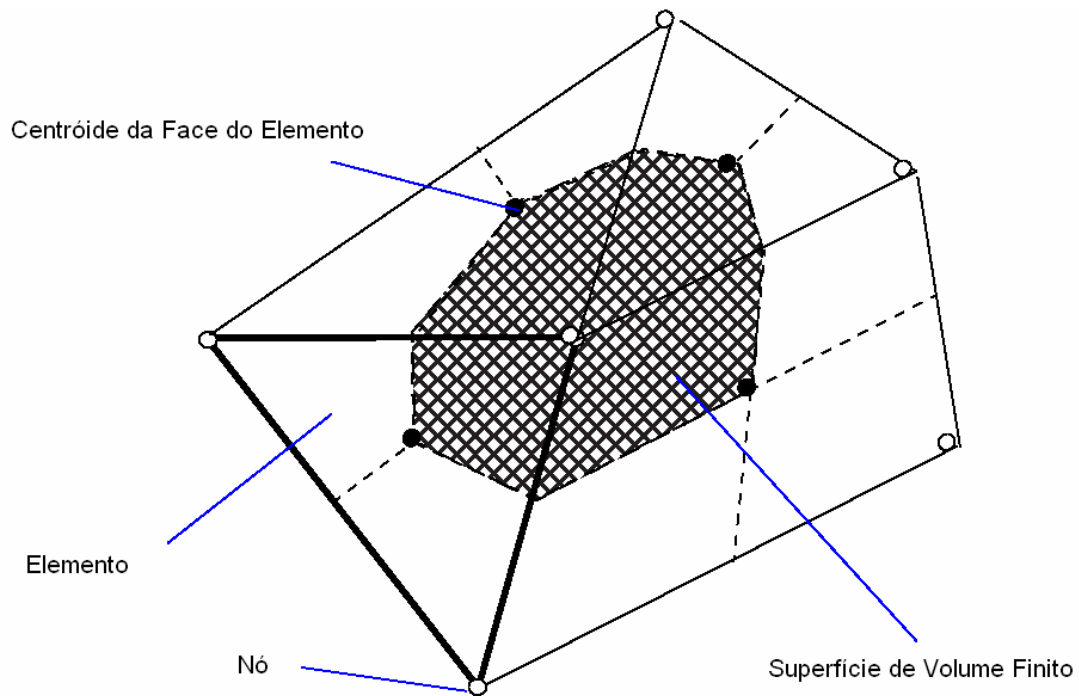

Figura 3.3. Malha típica bidimensional (Fonte: Adaptado de CFX, 2004).

É claro que cada nó é cercado por um grupo de superfícies que compreende o volume finito. Todas as variáveis de solução e as propriedades do fluido são armazenadas nos nós dos elementos. Considerando a forma média das equações de conservação de massa, quantidade de movimento, e uma variável passiva escalar, expressa em coordenadas cartesiana, temos:

$$
\begin{aligned}
& \frac{\partial \rho}{\partial t}+\frac{\partial\left(\rho u_{j}\right)}{\partial x_{j}}=0 \\
& \frac{\partial}{\partial t}\left(\rho u_{i}\right)+\frac{\partial}{\partial x_{j}}\left(\rho u_{j} u_{i}\right)=-\frac{\partial P}{\partial x_{i}}+\frac{\partial}{\partial x_{j}}\left(\mu_{e f f}\left(\frac{\partial u_{i}}{\partial x_{j}}+\frac{\partial u_{j}}{\partial x_{i}}\right)\right) \\
& \frac{\partial}{\partial t}(\rho \phi)+\frac{\partial}{\partial x_{j}}\left(\rho u_{j} \phi\right)=\frac{\partial}{\partial x_{j}}\left(\Gamma\left(\frac{\partial \phi}{\partial x_{j}}\right)\right)+S_{\phi}
\end{aligned}
$$

Estas equações são integradas em um volume de controle. Aplicando-se o teorema de divergência de Gauss, convertem-se as integrais de volume em integrais de superfície. Para volume de controle que não deforma no tempo, a derivada do tempo pode ser retirada da integral de volume, e a equação torna-se:

$$
\begin{aligned}
& \frac{d}{d t} \int_{V o l} \rho d V o l+\int_{S} \rho u_{j} d n_{j}=0 \\
& \frac{d}{d t} \int_{V o l} \rho u_{i} d V o l+\int_{S} \rho u_{j} u_{i} d n_{j}=-\int_{S} P d n_{j}+\int_{S} \mu_{e f f}\left(\frac{\partial u_{i}}{\partial x_{j}}+\frac{\partial u_{j}}{\partial x_{i}}\right) d n_{j}+\int_{V o l} S_{u_{i}} d V o l \\
& \frac{d}{d t} \int_{V o l} \rho \phi d V o l+\int_{S} \rho u_{j} \phi d n_{j}=\int_{S} \Gamma\left(\frac{\partial \phi}{\partial x_{j}}\right) d n_{j}+\int_{V o l} S_{\phi} d V o l
\end{aligned}
$$


onde $V o l$ e $S$ são respectivamente, a região de integração no volume e de superfície e $d n_{j}$ é a componente cartesiana do diferencial do vetor normal à superfície. As integrais de superfície são as integrações dos escoamentos, enquanto as integrais dos volumes representam termos iniciais ou acumulativos. Mudanças nestas equações, devido a deformações no volume de controle são apresentadas mais adiante.

O primeiro passo para resolver estas equações numericamente é aproximá-las usando funções discretas. Considerando um elemento de malha isolado, tal como apresentado na figura 3.4.

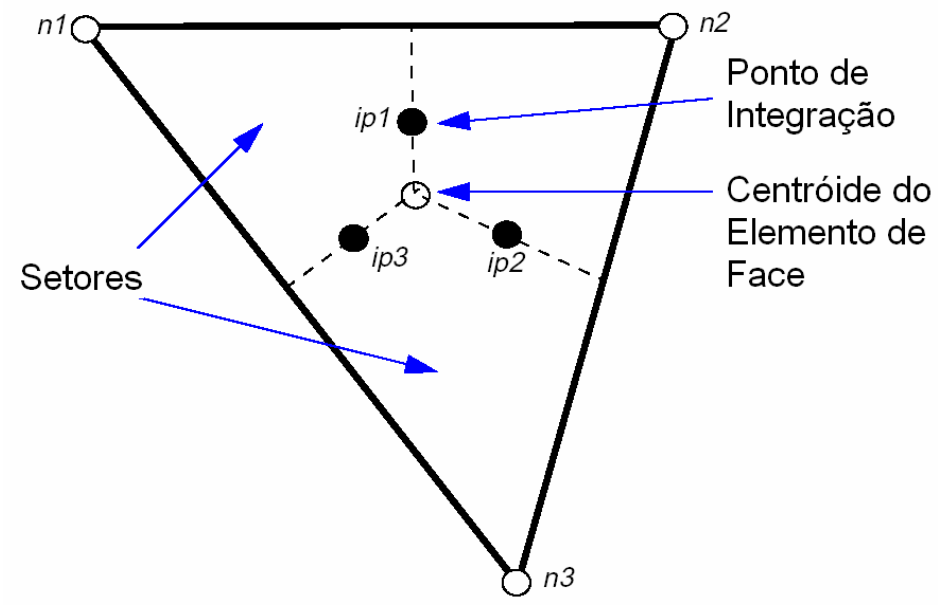

Figura 3.4. Elemento de malha isolado (Fonte: Adaptado de CFX, 2004).

Os fluxos de superfície devem ser discretamente representados nos pontos de integração para completar a conversão da equação contínua em sua forma discreta. Os pontos de integração, $i p_{n}$, são localizados no centro de cada segmento de superfície no elemento 3D que cerca o volume finito.

A forma discreta da equação integral é dada por:

$$
\begin{aligned}
& \rho \operatorname{Vol}\left(\frac{\rho-\rho^{o}}{\Delta t}\right)+\sum_{i p}\left(\rho u_{j} \Delta n_{j}\right)_{i p}=0 \\
& \rho \operatorname{Vol}\left(\frac{u_{i}-u_{i}^{o}}{\Delta t}\right)+\sum_{i p} \dot{m}_{i p}\left(u_{i}\right)_{i p}=\sum_{i p}\left(P \Delta n_{i}\right)_{i p}+\sum_{i p}\left(\mu_{e f f}\left(\frac{\partial u_{i}}{\partial x_{j}}+\frac{\partial u_{j}}{\partial x_{i}}\right) \Delta n_{j}\right)_{i p}+\overline{S_{u_{i}}} \operatorname{Vol}(3.8)+\overline{S_{\phi}} V o l \\
& \left.\rho \operatorname{Vol}\left(\frac{\phi-\phi^{o}}{\Delta t}\right)+\sum_{i p} \dot{m}_{i p} \phi_{i p}=\sum_{i p}\left(\Gamma \frac{\partial \phi}{\partial x_{j}} \Delta n_{j}\right)_{i p}\right)\left(\frac{\rho u_{i}-\rho^{o} u_{i}^{o}}{\Delta t}\right)+\sum_{i p} \dot{m}_{i p}\left(u_{i}\right)_{i p}=\sum_{i p}\left(P \Delta n_{i}\right)_{i p}+\sum_{i p}\left(\mu_{e f f}\left(\frac{\partial u_{i}}{\partial x_{j}}+\frac{\partial u_{j}}{\partial x_{i}}\right) \Delta n_{j}\right)_{i p}+\overline{S_{u_{i}}} \operatorname{Vol}
\end{aligned}
$$




$$
V o l\left(\frac{\rho \phi-\rho^{o} \phi^{o}}{\Delta t}\right)+\sum_{i p} \dot{m}_{i p} \phi_{i p}=\sum_{i p}\left(\Gamma \frac{\partial \phi}{\partial x_{j}} \Delta n_{j}\right)_{i p}+\overline{S_{\phi}} V o l
$$

em que Vol é o volume de controle, o sub-índice ip denota um ponto de integração pertencente ao volume finito, $\Delta n j$ é o vetor de superfície discreto, $\Delta t$ é o passo de tempo. Note que o esquema Euleriano de Primeira Ordem foi assumido nestas equações. O super-índice ${ }^{o}$ refere-se ao tempo anterior. O fluxo de massa sobre uma superfície do volume finito é denotado por $\dot{m}_{i p}$ e é dada por:

$$
\dot{m}_{i p}=\left(\rho u_{j} \Delta n_{j}\right)_{i p}^{o}
$$

\subsection{Utilização do CFX ${ }^{\circledR}$.}

A ferramenta computacional utilizada para a simulação do escoamento em vertedouros em degraus foi o software Ansys CFX 10.0. Este software foi desenvolvido AEA Technology - Engineering Software dos Estados Unidos.

O processo de utilização da ferramenta Ansys CFX 10.0 é dividido nos seguintes módulos: CFX-Pre, CFX-Solver e CFX-Post.

Em uma etapa anterior a utilização da ferramenta CFX-Pre é necessário a construção da geometria nas dimensões do domínio de fluido a ser simulado. A geometria pode ser desenhada tanto nas ferramentas de geometria no Workbench da Ansys, no ICEM-CFD ou ainda outros softwares de desenho tipo CAD (Solid Edge, AutoCAD, etc.) e importado nos software geradores de malha.

Os Softwares geradores de malha compatível com o Ansys CFX ${ }^{\circledR} 10.0$ são o CFXMesh que é uma atualização do antigo CAD2Mesh e o ICEM-CFD.

\subsubsection{Geração da Geometria e da Malha.}

A geração da geometria e da malha são processos em que a experiência do usuário do software é importante. Para a geração da geometria é necessário o conhecimento dos fenômenos envolvidos de forma que as faces do contorno sejam adequadas para que os resultados obtidos para os escoamentos sejam representativos. Por exemplo: em escoamentos em canais é necessário que a entrada do domínio e a saída do domínio sejam localizadas em seções de condições de escoamento conhecidas ou possuir uma geometria adequada para possibilitar o desenvolvimento do escoamento. 
A geometria do domínio de fluido que foi construída é importada em um software de geração de malha, em que são nomeadas as faces da geometria e são geradas as malhas, inicialmente nas faces e posteriormente em todo o domínio. Mais uma vez, cabe ao usuário do software a escolha do tamanho da malha, de forma a melhor caracterizar as grandezas do escoamento, levando-se em conta a capacidade computacional disponível.

As malhas podem ser ortogonais ou não ortogonais. As malhas não ortogonais podem ser tetraédricas ou hexaédricas, com faces triangulares ou quadrangulares. Existe a possibilidade de gerar malhas prismáticas nas faces que representam paredes, de forma a representar de forma mais adequada o comportamento da camada limite. Desta forma alguns elementos piramidais são criados na adaptação da malha prismática com a tetraédrica. $O$ software utilizado neste estudo $\left(\mathrm{CFX}-\mathrm{Mesh}^{\circledR}\right)$ possibilita a geração de malha tetraédrica com malhas prismáticas próximas ás paredes.

Os softwares para a geração da malha permitem determinar o grau de refinamento da malha para determinadas faces ou contornos, possibilitando a construção de malhas mais finas em regiões de interesse e mais grosseira em regiões de menor valia para os resultados da simulação, sempre estando de acordo com as condições de angulação da malha e da diferenciação do tamanho das malhas adjacentes.

\subsubsection{Condições de Simulação.}

No módulo de pré-processamento do CFX (CFX-Pre) são implementados as condições do domínio, do contorno, iniciais e a condições numéricas das simulações.

As condições de domínio utilizadas nas simulações foram basicamente as seguintes:

- Fases do escoamento: As fases presentes no escoamento em canais são água e ar. Estas fases são consideradas fluidos contínuos e foi utilizada a diferença de massa específica com parâmetro de separação de fases.

- Utilizou-se a pressão nula como pressão de referência, de modo que todas as pressões calculadas representam a pressão relativa em relação.

- Considerou-se a aceleração da gravidade igual a 9,806 m/ $\mathrm{s}^{2}$, além massa específica de referência igual à massa específica média do $\operatorname{ar}\left(1,185 \mathrm{~kg} / \mathrm{m}^{3}\right)$.

- O modelo de turbulência adotado em todas as simulações foi o SSG Reynolds Stress, que constitui o modelo de Tensões de Reynolds para a condição anisotrópica com a possibilidade de uso da lei da parede. 
- O modelo multifásico escolhido foi o homogêneo (Multiphase Homogeneous Model) com o modelo de mistura na interface (Mixture Model) e coeficiente de tensão superficial de $0,0732 \mathrm{~N} / \mathrm{m}$.

As condições de contorno para os estudos realizados podem ser divididas em cinco condições:

- Entrada (inlet): É a face do domínio de fluido em que é inserida a condição de entrada no escoamento, onde o fluido escoa somente para dentro do domínio. Para o escoamento multifásico em condutos livres é utilizada uma função step para representar a mudança da condição de fluido de água para fluido ar, caracterizando a presença da superfície livre.

- Saída (outlet): As condições de saída representam o fluido que escoa somente para fora do domínio.

- Aberto (opening). O fluido pode escoar para fora ou para dentro do domínio, simultaneamente, dependendo das condições do escoamento. Normalmente utilizase esta condição na região do domínio em contato com a pressão atmosférica e as condições do escoamento estabelecem a condição de entrada ou saída do escoamento.

- Parede (wall). As paredes representam as condições de contorno impermeável para o escoamento. Existem as condições de parede sem resistência (free slip), parede lisa (smooth wall) ou parede rugosa (rough wall), esta última condição de parede foi a adotada em todas as simulações desenvolvida nesta tese. Para habilitação da condição de parede rugosa é necessário que a função parede esteja disponível para o modelo de turbulência escolhido.

- Plano de simetria (symmetry): Nesta condição de contorno o escoamento é simétrico de forma que o gradiente normal à face das variáveis é nulo e o escoamento de um lado do plano é uma imagem espelhada do escoamento do outro lado. Esta condição foi utilizada para representar os escoamentos através da simulação de um domínio de menor espessura que o real, considerando a distância suficientemente grande das paredes laterais, de forma a minimizar o seu efeito no escoamento. Sabe-se que esta simplificação prejudica a representação da turbulência anisotrópica, mas a simulação com a condição real de largura do vertedouro seria de difícil aplicação devido à grandeza da malha necessária para representação do escoamento e o grande esforço computacional requerido. 
Nas condições iniciais de uma simulação são estabelecidas as grandezas representativas da condição do escoamento ao iniciar o cálculo numérico. O campo de velocidade inicial do escoamento, os perfís iniciais de pressão, bem como as condições iniciais de turbulência, são estabelecidos nestas configurações de partida da simulação.

Para as simulações do escoamento, os vertedouros foram iniciados na forma inoperante e todo o desenvolvimento do escoamento foi realizado com frentes de escoamentos iniciando a operação do vertedouro. Para tanto, como condição inicial do escoamento o volume de fluido foi iniciado com a presença de ar em todo o domínio e o campo de velocidade nulo. A partir do inicio da simulação na condição de contorno de entrada do domínio foi inserido um escoamento de água com a vazão a ser estudada. O escoamento foi desenvolvido em todo o domínio até estabelecer a condição de estacionário.

Finalizando as configurações necessárias para o início das simulações numéricas é necessário o estabelecimento das condições numéricas da simulação. Nas simulações realizada neste trabalho utilizou-se as seguinte configurações:

- Tipo de simulação: A simulação pode ser realizada na forma transiente ou em estado estacionário. Nas simulações transientes é realizado o cálculo numérico estabelecendo um critério de convergência para cada passo de tempo (time step). Nas simulações em estado estacionário (ou falso transiente) o passo de tempo e adiantado em cada iteração, de forma que ao estabelecer o regime estacionário a convergência é alcançada. Tendo em vista a consideração de regime estacionário nas condições finais do escoamento em vertedouros, utilizou-se a condição de estado estacionário para a maioria das simulações realizadas neste trabalho.

- Esquema de advecção: O esquema de Alta Resolução (High Resolution) utiliza um fator de combinação, que depende dos gradientes das grandezas calculadas para a escolha da melhor for de resolução. Esse esquema é o mais robusto numericamente, mas é o que melhor representa os resultados da simulação.

Controle de convergência: Nas simulações realizadas com a condição de regime estacionário, utilizou-se, como controle da escala de tempo, a condição física com valor constante do passo de tempo. Dependendo das condições da simulação, como velocidade e tamanho da malha, o passo de tempo foi calculado utilizando o critério de BULGARELLI (FORTUNA - 2000):

$\Delta t \leq \tau_{s}\left[\frac{|u|_{\max }}{\Delta x}+\frac{|v|_{\max }}{\Delta y}+2 v\left(\frac{1}{(\Delta x)^{2}}+\frac{1}{(\Delta y)^{2}}\right)\right]^{-1}$ 
em que $0<\tau_{\mathrm{s}}<1$ é um fator de segurança.

Os critérios de convergência disponíveis no pacote computacional Ansys CFX 10.0 são: erro médio quadrático (RMS - Root Mean Square) ou o valor residual máximo normalizado no domínio (MAX). Nas simulações realizadas neste trabalho utilizou-se a opção RMS com valor para objetivo de convergência de $10^{-5}$.

\subsubsection{Acompanhamento da Resolução e Visualização dos Resultados.}

Após a preparação das definições no módulo de pré-processamento inicia-se a resolução da simulação do módulo de resolução (CFX - Solver). O processo numérico da simulação é apresentado durante o cálculo, sendo possível acompanhar a convergência e verificar possíveis problemas numéricos no decorrer dos cálculos.

Após o término dos cálculos, com o estabelecimento da convergência da simulação utilizou-se o modulo de pós-processamento (CFX - Post) para aquisição dos resultados. Neste módulo é possível representar graficamente as características dos escoamentos, através de vetores de velocidades, contornos que representam isolinhas de pressão, velocidade, concentração de ar, etc; além de ferramentas diversas que permitem visualizar iso-superfícies e gráficos para as variáveis diversas em todo o domínio.

A possibilidade de visualizar as variáveis resultantes das simulações em todo o domínio é uma atribuição da solução numérica. Muitas vezes existem dificuldades em determinar experimentalmente algumas características dos escoamentos em locais de difícil aquisição de dados, já para as simulações numéricas não existem estas dificuldades. 


\section{RESULTADOS E ANÁLISES.}

\subsection{Considerações Gerais.}

Considerando as propostas deste trabalho em relação à caracterização dos escoamentos em vertedouros em degraus, foram realizados os estudos referentes à simulação do escoamento em ferramentas de fluidodinâmica computacional. Os estudos através da análise dos resultados da simulação numérica foram realizados com base em estudos experimentais existente na literatura internacional e brasileira.

O primeiro estudo consistiu na simulação de quatro exemplos de escoamento sobre vertedouro em degraus que foram comparados com ensaios experimentais realizados por Olinger (2000). O segundo estudo realizado teve como modelo os estudos experimentais realizados por Sorensen (1985) e Christodoulou (1993), em que a perda de energia foi quantificada e comparada. As configurações dos estudos realizados por Tozzi (1992) e Tozzi et al(1998) também foram simuladas e analisadas comparativamente. Neste item do trabalho foram realizadas ainda algumas análises teóricas, como validação dos resultados numéricos. A análise realizada no estudo seguinte foi da mudança do regime de escoamento de nappe flow para skimming flow. E para finalizar esta etapa, realizou-se um último estudo para quantificar o perfil de aeração em um canal de alta declividade com um aerador de fundo, usando como dados experimentais para comparação o trabalho realizado por Lima (2003). Este último estudo tem como propósito utilizar dados experimentais do estudo do carreamento de ar determinados com uma sonda de Césio 137, como calibração no estudo da aeração do vertedouro em degrau. Além da comparação entre os resultados experimentais e numéricos, realizou-se um estudo dos diversos métodos de determinação da vazão de ar na região inferior ao jato.

Todas as análises realizadas no estudo, a utilização das ferramentas de fluidodinâmica computacional tiveram como objetivo verificar a representatividade dos resultados obtidos na simulação numérica em relação os resultados experimentais existentes na literatura. Finalmente, como complemento a este estudo foi apresentada uma proposta para a geometria de um vertedouro em degrau. Esta proposta tem como objetivo minimizar os problemas relativos à cavitação em escoamento em canais com degraus. A existência de um aerador de fundo anterior ao inicio dos degraus proporciona a aeração da região inferior do escoamento, 
próximo às paredes. Segundo Peterka (1953) uma concentração de ar em torno de 7\% é suficiente para evitar o risco de cavitação em superfície de concreto, porque a compressibilidade da mistura ar-água pode absorver o impacto do colapso das bolhas vaporizadas.

Frisa-se que o intuito deste trabalho não é substituir os ensaios experimentais, mas sim estabelecer critérios iniciais para estudo de novas geometrias, através de análises preliminares, permitindo propor a construção do modelo reduzido para melhorar o direcionamento para a verificação dos dados encontrados e para possíveis visualizações de problemas insensíveis na simulação computacional.

\subsection{Estudo do Escoamento em Vertedouros em Degraus.}

\subsubsection{Perfil de Pressão e de Velocidades.}

Quatro dos experimentos realizados por Olinger (2000), em que a geometria é apresentada a seguir (Figura 4.1), foram simulados numericamente, utilizando-se o Modelo de Tensões de Reynolds e o modelo multifásico VOF.

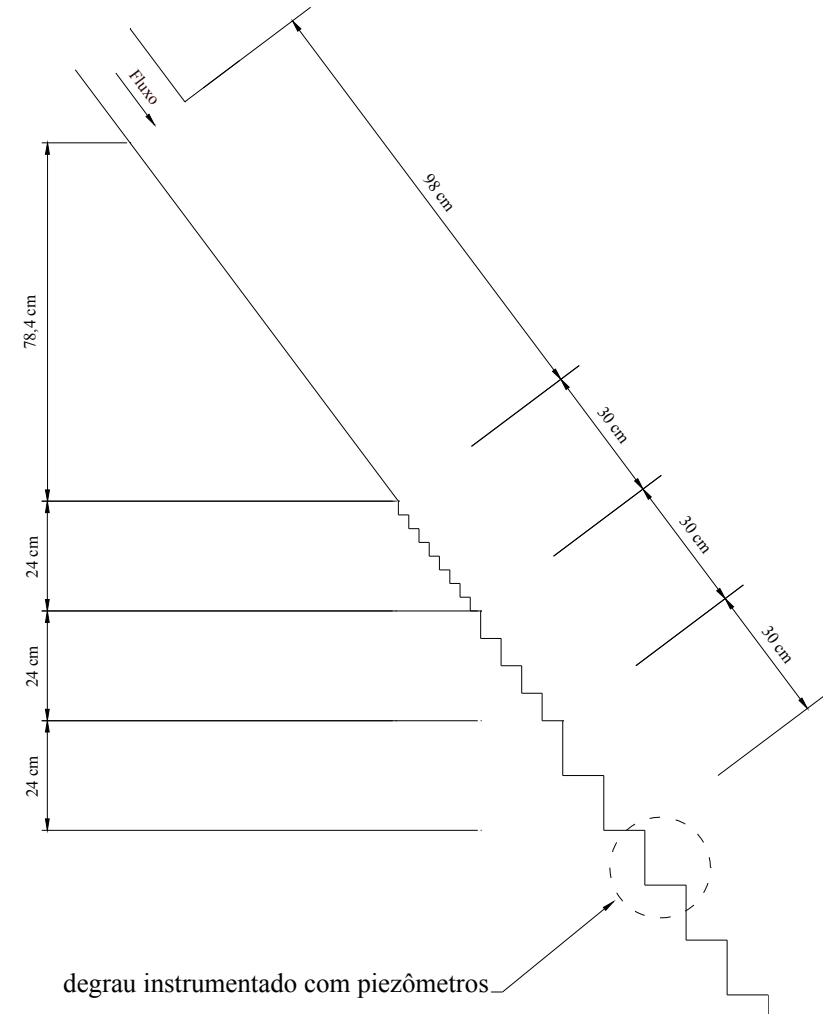

Figura 4.1. Configuração geral do trecho do vertedouro simulado por Olinger (2000) - degraus com $12 \times 9 \mathrm{~cm}$. 
Para realização das simulaçãos numéricas, geraram-se malhas, através de um programa gerador, para todo o domínio do vertedouro (Figura 4.2). Na região onde necessitava-se de um maior detalhe do escoamento utilizaram-se malhas triangulares, com tamanhos de aproximadamente $1 \mathrm{~cm}$. Na região de menor interesse, superior ao escoamento, utilizaram-se malhas com tamanhos aproximados de $5 \mathrm{~cm}$.

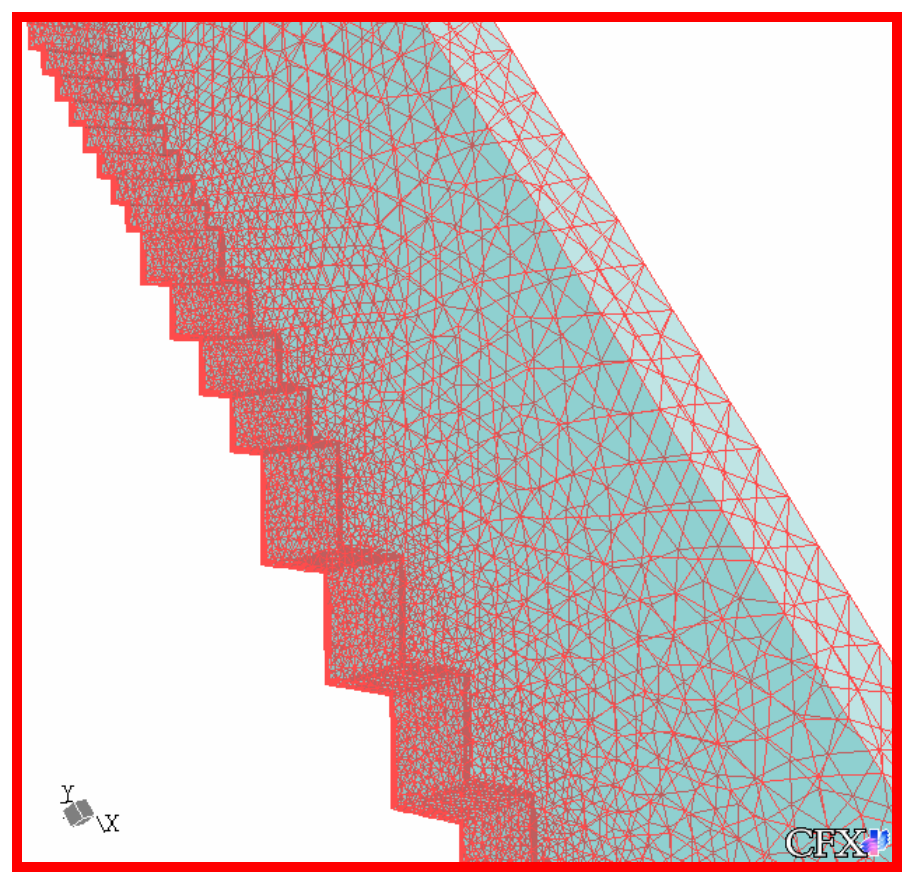

Figura 4.2. Detalhe da Malha (Triangular-Refinada nas proximidades dos degraus).

As simulações foram realizadas com os dados de altura, $y_{0}$, e de velocidade $\mathrm{V}$, na entrada, apresentados na Tabela 4.1. Todo o domínio foi iniciado, também com uma lâmina d'água $y_{0}$ sobre os degraus, e com velocidade inicial em toda altura d'água igual à velocidade na entrada, V. A região do domínio formada por ar foi iniciada com velocidade nula.

Tabela 4.1. Valores das alturas de água $\left(\mathrm{y}_{\mathrm{o}}\right)$ e das velocidades $(\mathrm{V})$ na entrada nas quatro simulações realizadas.

\begin{tabular}{ccc} 
Ensaio & $\mathrm{y}_{\mathrm{o}}(\mathrm{cm})$ & $\mathrm{V}(\mathrm{m} / \mathrm{s})$ \\
\hline \hline 1 & 15 & 8,0 \\
2 & & 10,7 \\
\hline 3 & 20 & 8,0 \\
4 & & 9,84 \\
\hline
\end{tabular}

$\mathrm{O}$ passo de tempo utilizado para as quatro simulações foi de $10^{-3} \mathrm{~s}$, e foi estimado através do critério de BULGARELLI (Equação 3.92): 
Nas simulações uma primeira verificação foi que os campos de velocidades formavam recirculações nos degraus, como era esperado (Figura 4.3).

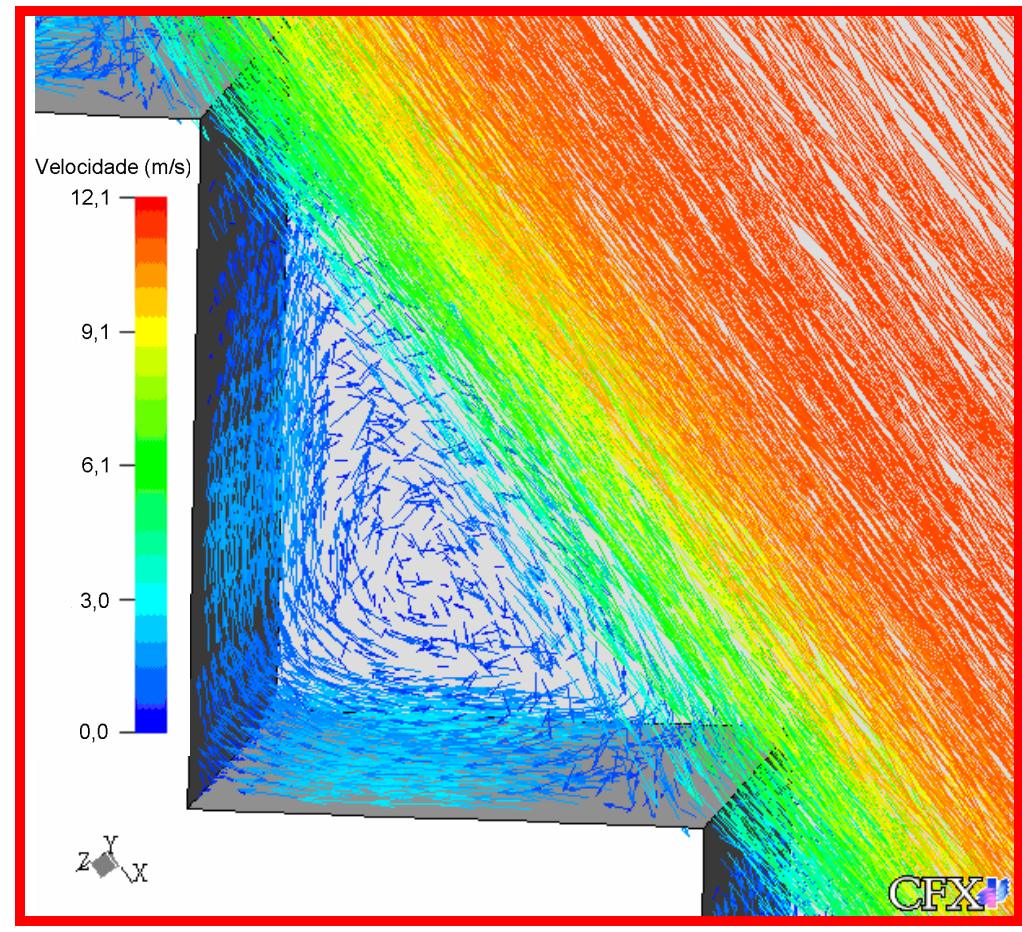

Figura 4.3. Detalhe da recirculação nos degraus (Tridimensional).

Adicionalmente as simulações numéricas também permitiram posicionar adequadamente as superfícies livres do escoamento (Figura 4.4).

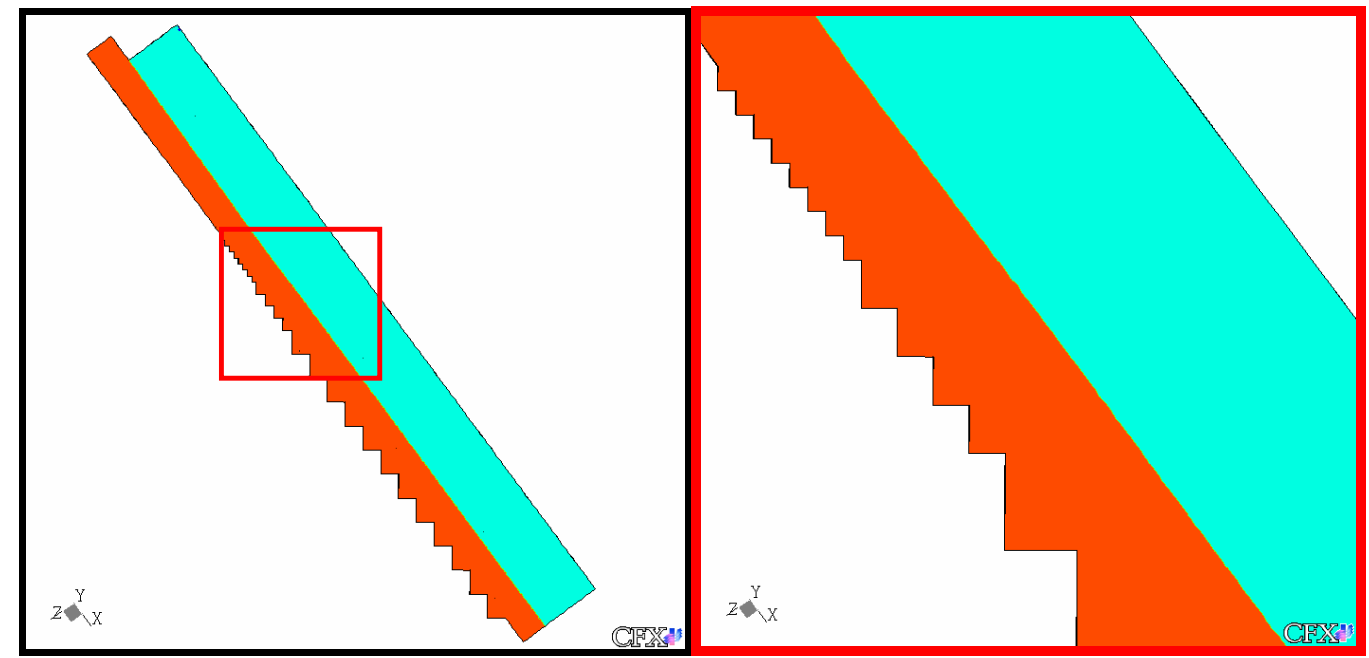

Figura 4.4. Superfície Livre no escoamento sobre os degraus.

OLINGER (2000) determinou experimentalmente, através de um tubo de estagnação, o perfil de velocidades sobre a quina superior do degrau instrumentado, indicado na Figura 4.1. Nesta mesma seção determinaram-se, numericamente, para os quatro ensaios, esses perfis de velocidades (Figura 4.5). 
Verificou-se que os perfis de velocidades experimentais e numéricos comparam-se favoravelmente, mas na região próxima à superfície livre os valores das velocidades adquiridos de forma experimental são menores que os numéricos. De fato, existem dificuldades na determinação da velocidade experimental próximo à superfície livre com a utilização tubos de estagnação. Estes erros podem ocorrer devido às interferências da presença de ar próximo a superfície livre ou devido à forma invasiva desta metodologia que pode inserir possíveis erros sistemáticos. Ou ainda, embora as equações governantes sejam fisicamente robustas, os termos modelados podem eventualmente estar superestimando as velocidades próximas à superfície livre.

O Ensaio 1 foi realizado para as configurações bidimensional e tridimensional. Como pode ser verificado na Figura 4.5 (Ensaio 1), o perfil de velocidades bidimensional diferiu mais do experimental do que o tridimensional devido ao efeito das paredes laterais existentes no ensaio experimental, criando um patamar de velocidades praticamente uniforme da posição 0,07 à $0,14 \mathrm{~m}$. Esse patamar de velocidades foi visualizado nos outros três ensaios, em que somente a simulação tridimensional foi realizada. 


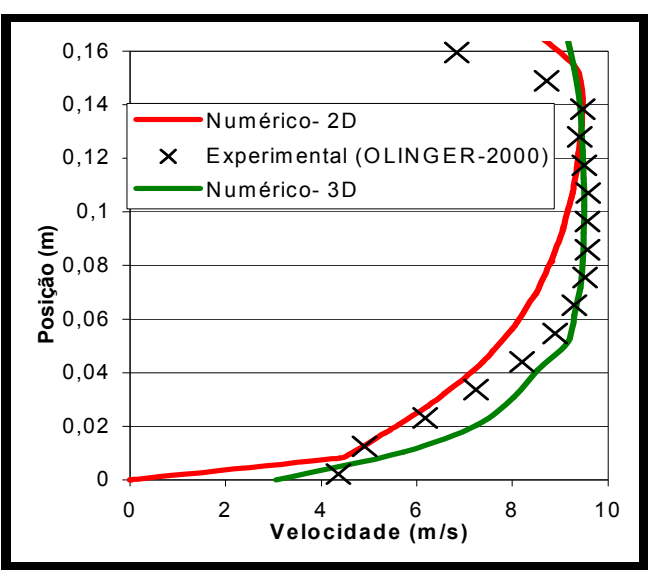

Ensaio 1

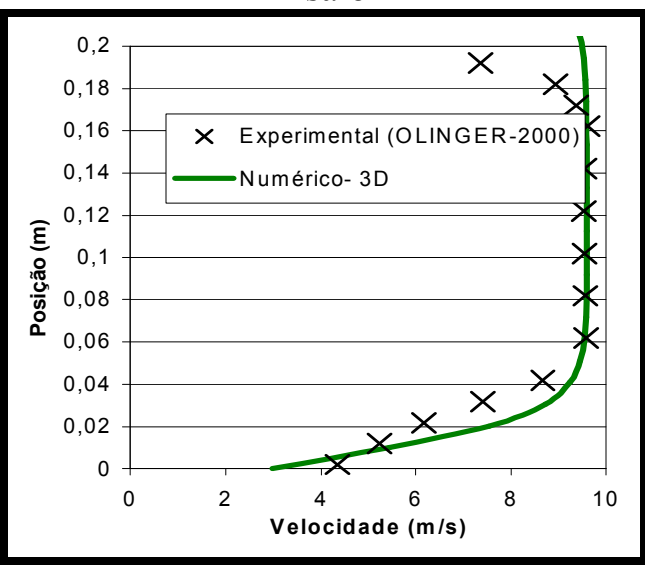

Ensaio 3

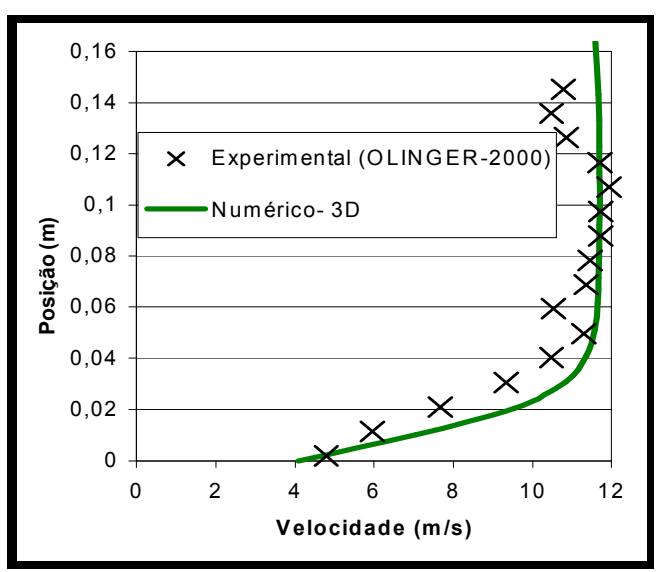

Ensaio 2

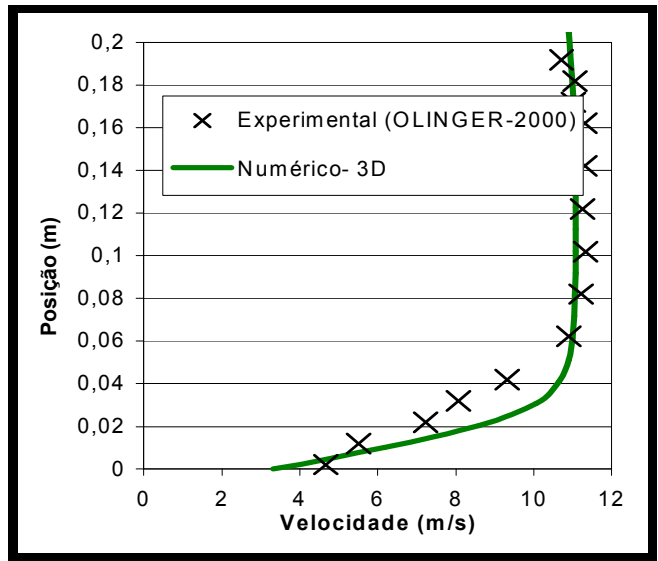

Ensaio 4

Figura 4.5. Perfis de velocidade sobre o degrau instrumentado (Ensaios 1, 23 e 4).

Olinger (2000) determinou também o valor da pressão na parede horizontal e vertical do degrau através de piezômetros. Após simulação numérica, para as quatro configurações, compararam-se os valores médios determinados por Olinger (op cit.) com os valores encontrados numericamente. Verifica-se que os valores das pressões experimentais comportam-se de forma similar aos numéricos, tanto na parte vertical quanto na horizontal dos degraus (Figura 4.6). Os picos de pressão no ponto de impacto no piso dos degraus, apesar de coincidirem em sua localização, discordam em termos de valores, sendo os resultados numéricos da ordem de até 35\% menores que os experimentais. Nos espelhos verificou-se também discrepâncias nos valores das pressões para os ensaios 1 e 2 . 


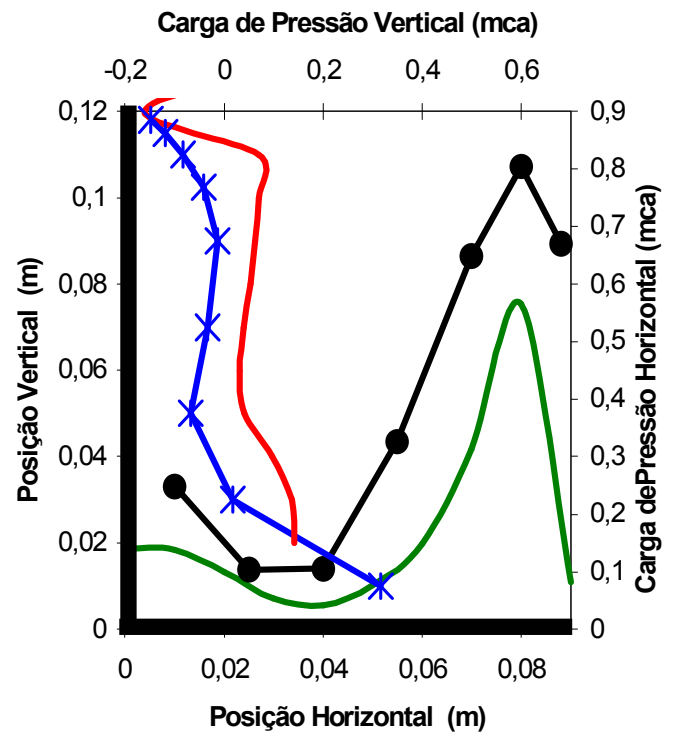

(Ensaio 1)

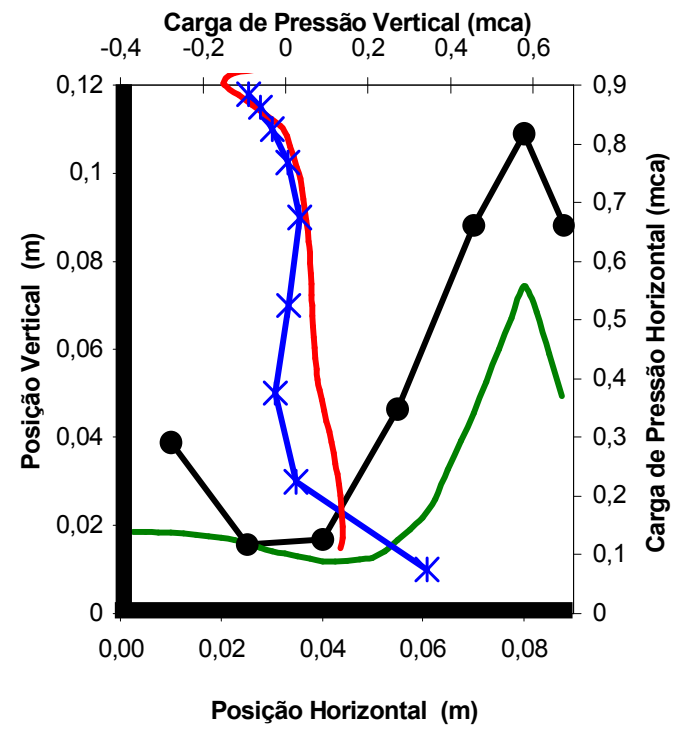

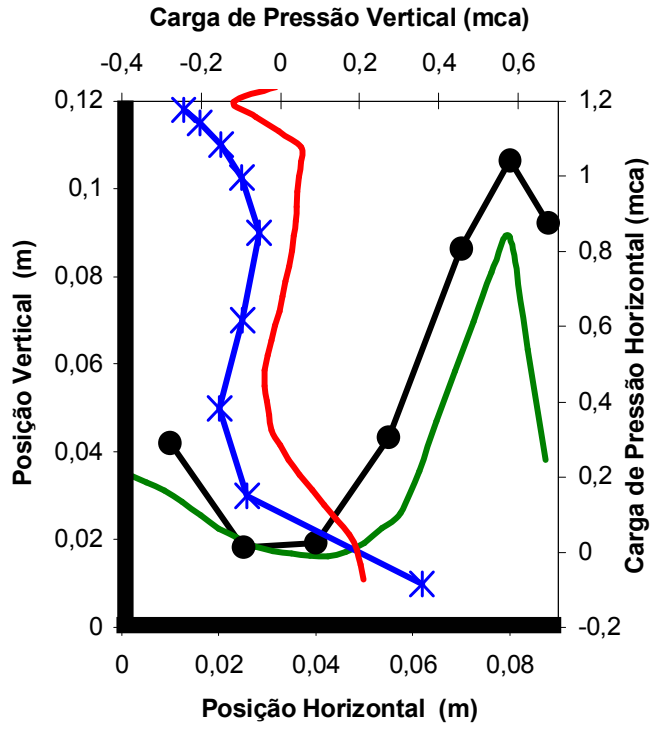

(Ensaio 2)

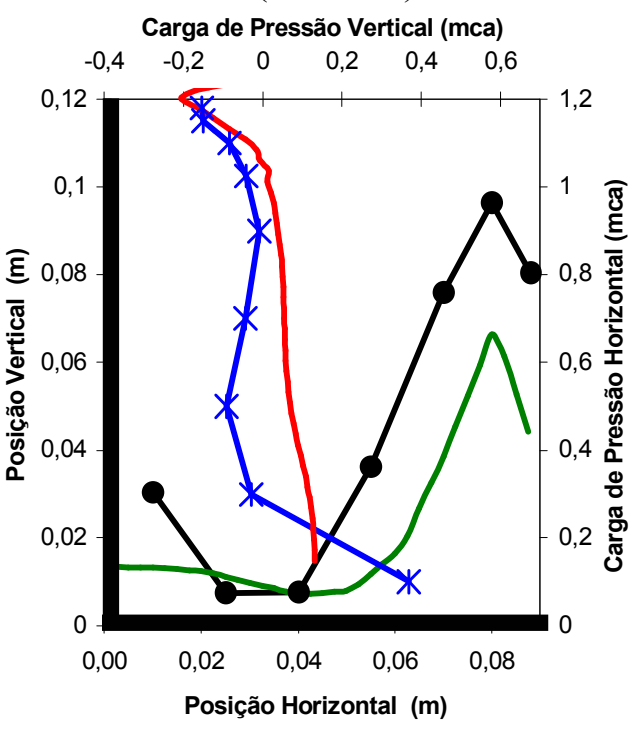

(Ensaio 3)

\begin{tabular}{l} 
- Experimental (Olinger 2000) - Horizontal \\
* Horizontal CFX \\
- Experimental (Olinger 2000) - Vertical \\
\hline
\end{tabular}

Figura 4.6. Pressão nos degraus (Ensaios 1, 2, 3 e 4).

\section{Conclusões}

Nas simulações numéricas dos vertedouros em degraus, algumas características do escoamento, como as regiões de recirculação, as superfícies livres, os perfis de velocidades foram apresentados e comportam-se de forma muito similar à realidade experimental. 
Os perfis de velocidade encontrados computacionalmente apresentam-se com valores próximos aos encontrados experimentalmente por Olinger (2000), com exceção do resultado nas proximidades da superfície livre.

O comportamento da pressão nos degraus instrumentados também foi comparado e verificou-se que sua evolução espacial apresentou-se de forma similar à evolução experimental em ambas as paredes, horizontal e vertical.

\subsubsection{Estudo da Perda de Energia em Vertedouros em Degraus.}

Para o estudo da perda de energia em vertedouro em degraus, utilizaram-se como referência os trabalhos de Sorensen (1985) e Christodoulou (1993). Esses autores realizaram ensaios experimentais em modelos reduzidos com o perfil ogiva recomendado pelo WES (Waterways Experiment Station, do Corps of Engineers).

Para a simulação numérica utilizou-se o perfil apresentado na figura 2.2, em que o modelo reduzido tem escala 1:25. Decidiu-se utilizar a geometria do modelo reduzido na simulação para a realização de uma comparação mais objetiva e o posterior estudo do efeito de escala.

Para diminuir o número de elementos da simulação, a geometria utilizada para o cálculo possui uma largura bem menor $(1 \mathrm{~cm})$ que o modelo experimental $(50 \mathrm{~cm})$. A condição de simetria nas paredes laterais foi utilizada, caracterizando uma simulação praticamente bidimensional. Considerando que o modelo experimental é suficientemente largo, o efeito da parede pode ser desprezado.

A malha utilizada para a simulação é apresentada na figura 4.7. Os elementos variam de $1 \mathrm{~mm}$ na proximidade das paredes dos degraus a $10 \mathrm{~mm}$ no topo. Na região próxima às parede utilizou-se também malha prismática para uma melhor aproximação no cálculo da camada limite. Os passos de tempo utilizados para as simulações foram de $10^{-3} \mathrm{~s}$.

Foram realizadas as simulações numéricas para sete vazões equivalentes ao modelo experimental: $\mathrm{Q}=5,0 \mathrm{l} / \mathrm{s}\left(y_{c} / h=0,867\right), \mathrm{Q}=10,01 / \mathrm{s} \quad\left(y_{c} / h=1,377\right), \quad \mathrm{Q}=15,01 / \mathrm{s}$ $\left(y_{c} / h=1,804\right), Q=20,01 / \mathrm{s}\left(y_{c} / h=2,186\right), \mathrm{Q}=25,01 / \mathrm{s}\left(y_{c} / h=2,536\right), \mathrm{Q}=30,01 / \mathrm{s}\left(y_{c} / h=\right.$ 2,864) e $\mathrm{Q}=35,0 \mathrm{l} / \mathrm{s}\left(y_{c} / h=3,174\right)$. A figura 4.8 representa os perfis das superfícies livres para três das sete vazões calculadas numericamente. 


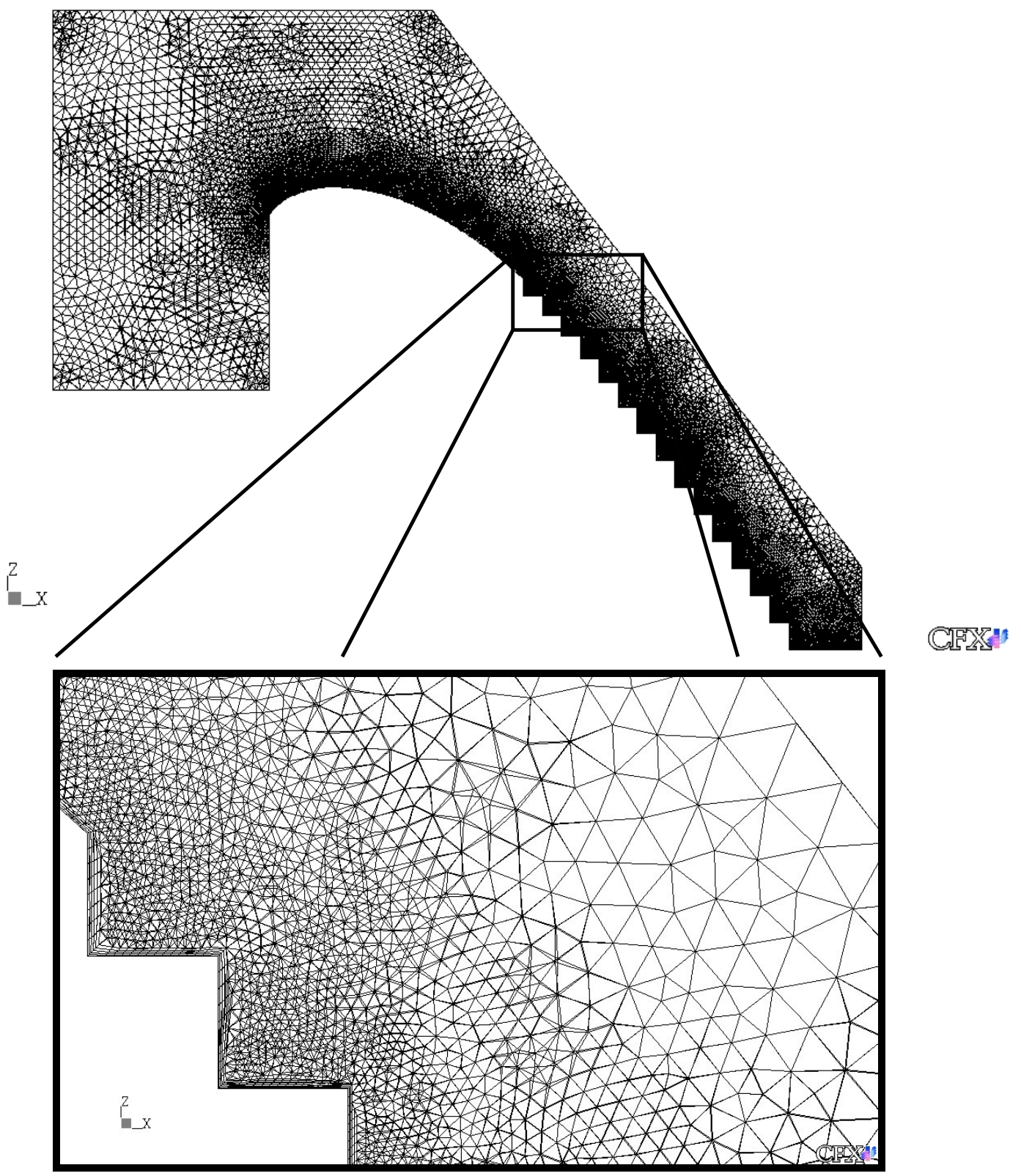

Figura 4.7. Detalhe da Malha Utilizada.

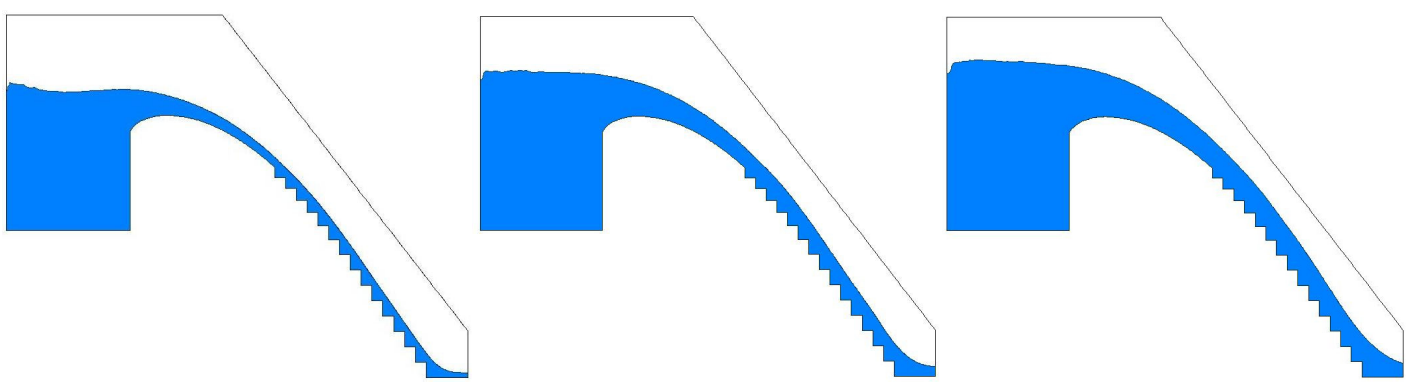

Figura 4.8. Perfis da Superfície Livre Para: $y_{c} / h=1,377, y_{c} / h=2,186, y_{c} / h=2,864$. 
Os campos de velocidade que foram determinados pela simulação numérica são apresentados nas figuras $4.9,4.10$ e 4.11 .

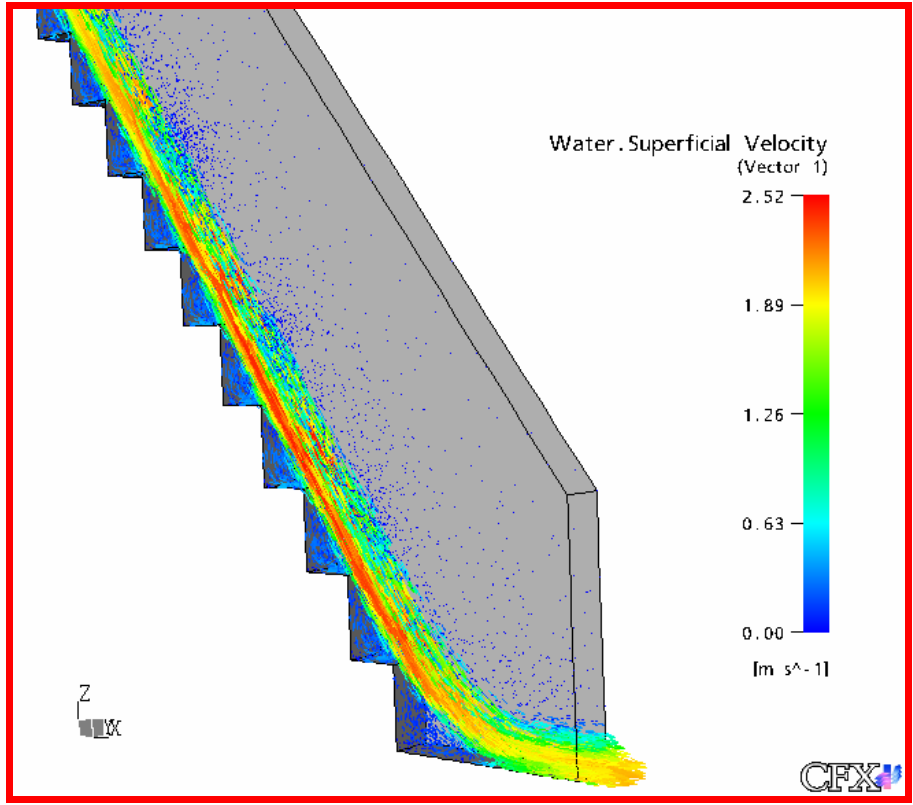

Figura 4.9. Campo de velocidades para $y_{c} / h=1,377$.

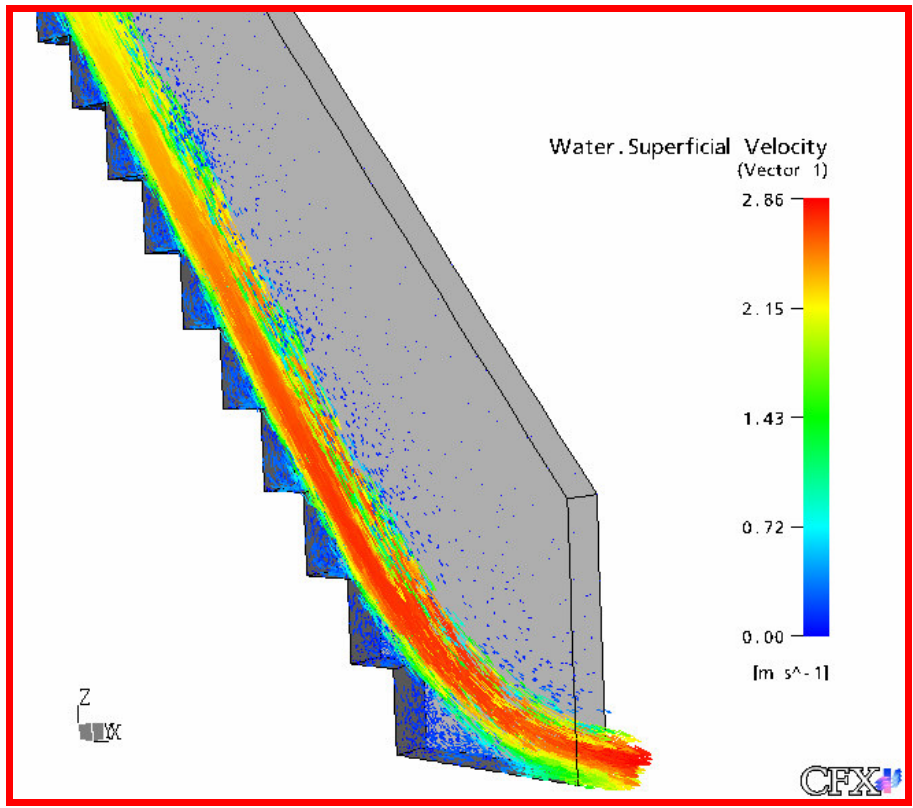

Figura 4.10. Campo de velocidades para $y_{c} / h=2,186$. 


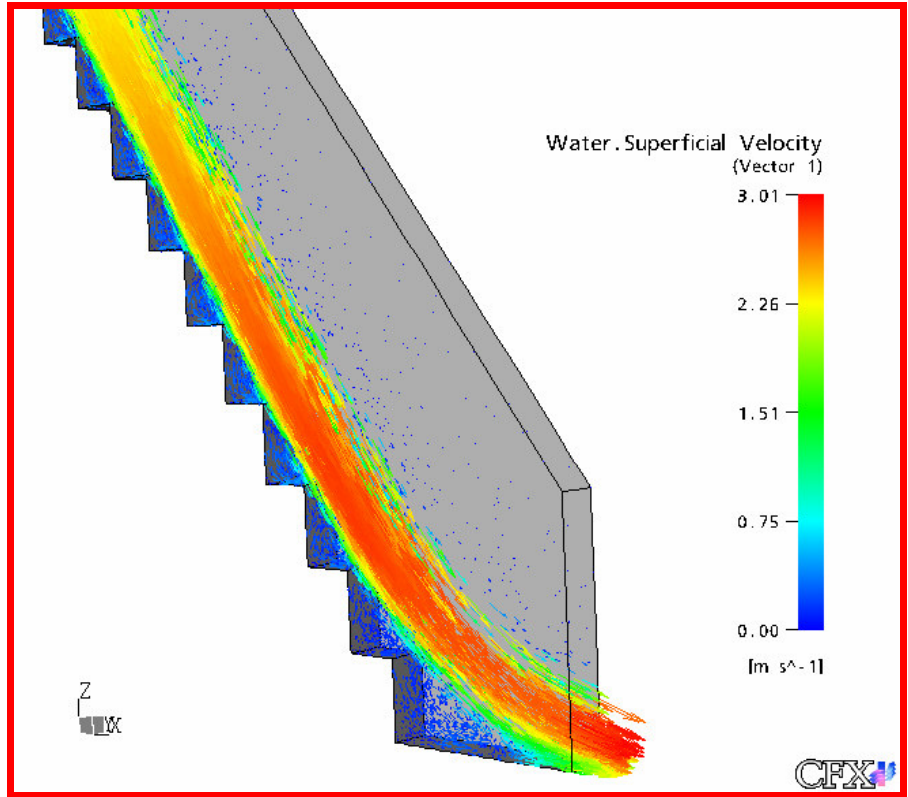

Figura 4.11. Campo de velocidades para $y_{c} / h=2,864$.

Os perfis de velocidades da água (Figuras 4.12 e 4.13) sobre os degraus de número 10 e 13 foram utilizados para o cálculo da velocidade média e do coeficiente de Coriolis.

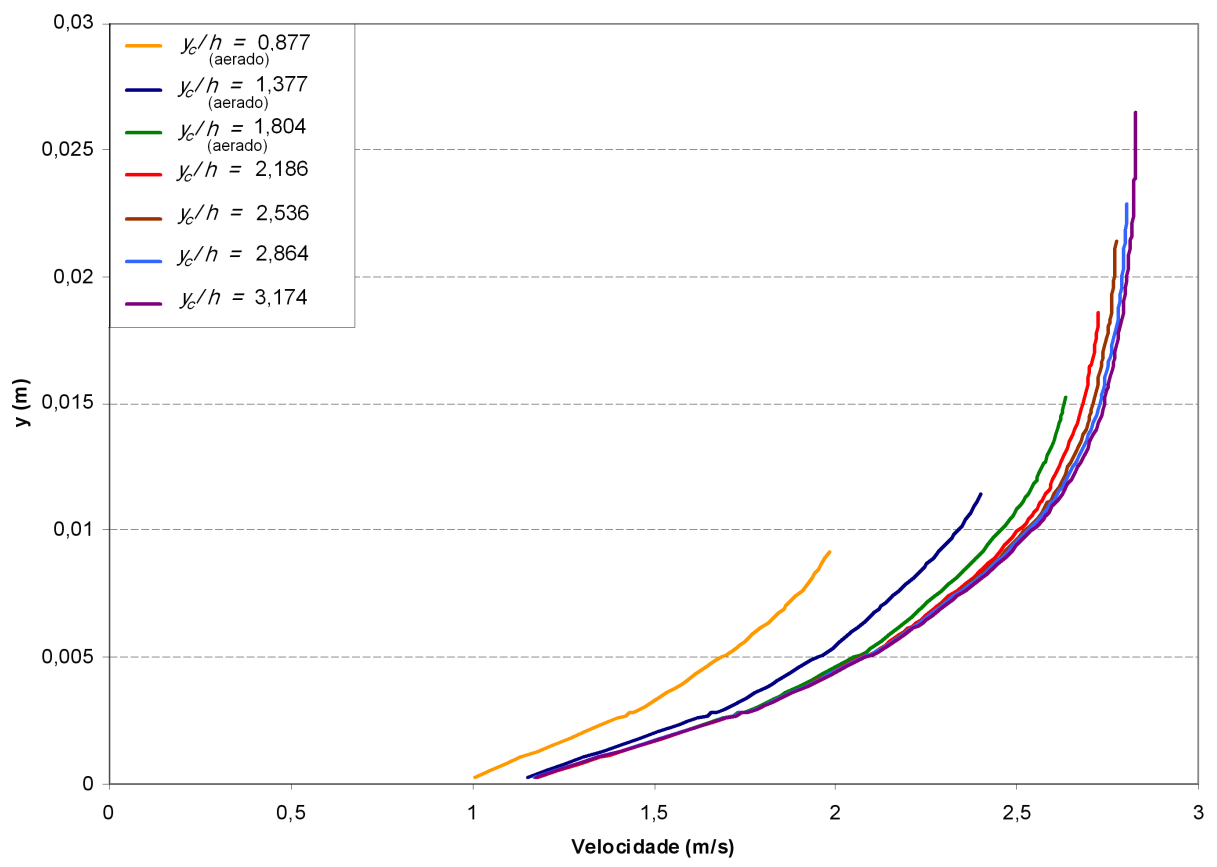

Figura 4.12. Perfis de velocidade no degrau 10. 


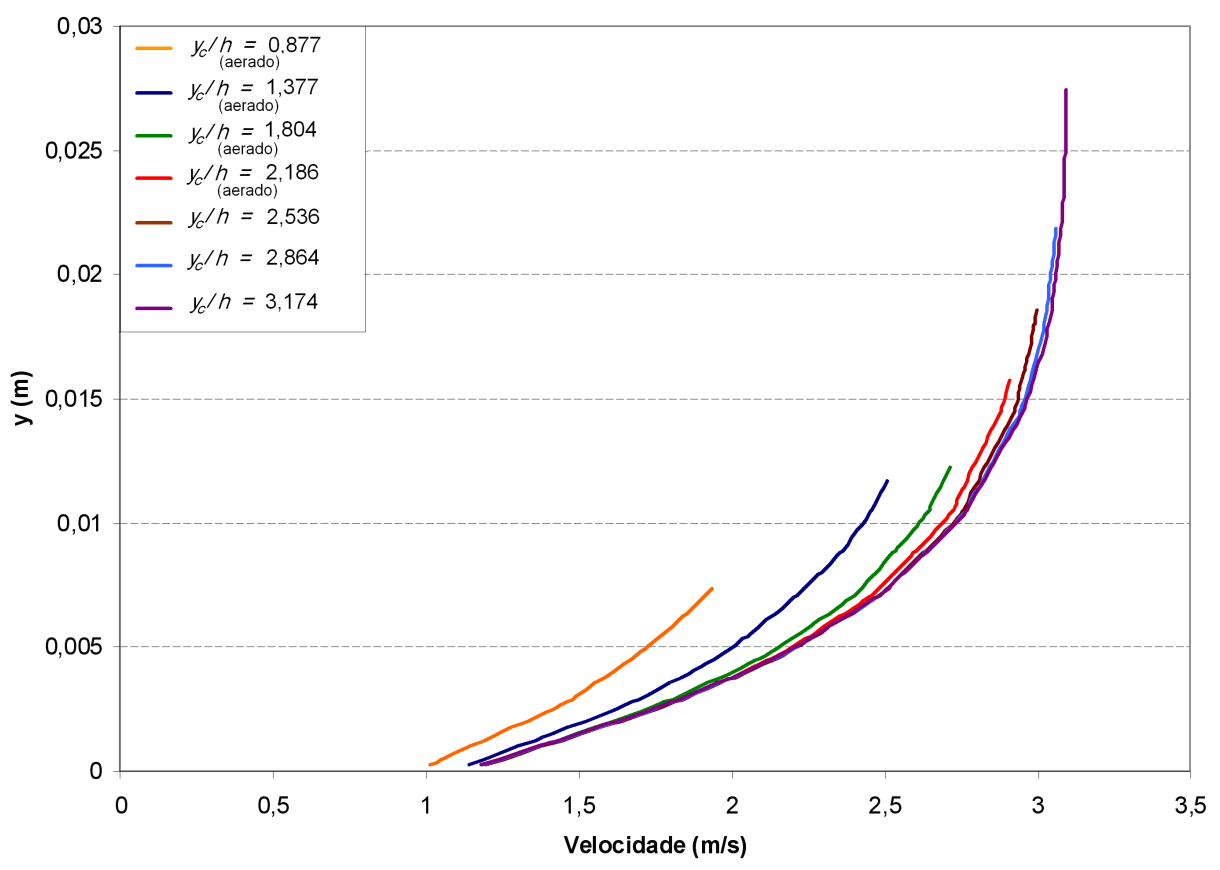

Figura 4.13. Perfis de velocidade no degrau 13.

Com base nos dados de velocidade e com as alturas das lâminas d'água, utilizando-se o equacionamento apresentado no item 2.4 da Revisão Bibliográfica, calculou-se a perda de energia para comparação com os dados experimentais de Sorensen (1985) e Christodoulou (1993). O coeficiente de rugosidade efetiva $c_{f}$ dado pela seguinte equação também foi determinado:

$$
c_{f}=\frac{2 y g \operatorname{Sen} \phi}{V^{2}}
$$

Onde $y$ é a altura da lamina d'água normal ao escoamento, $V$ é a velocidade média e $\phi$ é a inclinação do vertedouro.

Nos dados da tabela 4.2 são apresentados os valores de velocidade média, cargas hidráulicas antes do vertedouro e sobre os degraus e o coeficiente de rugosidade efetiva. Os valores médios encontrados para o coeficiente de rugosidade efetiva foram de 0,067 para o degrau de número 10 e 0,062 para o degrau de número 13, um pouco menor que os encontrados por Christodoulou (op cit.) de 0,076 e 0,089, respectivamente.

Além do coeficiente de rugosidade efetiva, determinou-se o fator de cisalhamento, $f$, para as sete vazões simuladas numericamente, sendo:

$$
f=\frac{8 \cdot g \cdot \operatorname{sen} \phi \cdot y_{o}}{q_{w}} \cdot \frac{D_{h}}{4}
$$

onde o diâmetro hidráulico, $D_{h}=4 . A_{w} / \mathrm{P}_{\mathrm{w}}$, sendo, $A_{w}$, a área molhada da seção de estudo e $P_{w}$ é o perímetro molhado para a mesma seção. 
Tabela 4.2. Resultados da Simulação Numérica.

\begin{tabular}{|c|c|c|c|c|c|c|c|c|c|}
\hline \multicolumn{10}{|c|}{ Degrau 10} \\
\hline$Q(1 / \mathrm{s})$ & $y_{o}(\mathrm{~cm})$ & $V(\mathrm{~m} / \mathrm{s})$ & $H_{o}(\mathrm{~cm})$ & $H(\mathrm{~cm})$ & $\Delta H / H o$ & $y_{c} / h$ & $y_{c} / N h$ & $c_{f}$ & $f$ \\
\hline 5 & 0,735 & 1,36 & 29,25 & 10,17 & 0,652 & 0,867 & 0,087 & 0,064 & 0,242 \\
\hline 10 & 1,144 & & 3 & 16 & 0,463 & 1,377 & 0,138 & 0,060 & 0,225 \\
\hline 15 & & & & & 0,343 & 1,804 & 0,180 & 0,062 & 0,228 \\
\hline 20 & 1,8 & 16 & 34 , & 25 & 0,249 & 2,186 & 0,219 & 0,064 & 0,231 \\
\hline 25 & & & & & & 2,536 & 0,254 & 0,067 & 0,241 \\
\hline 30 & 2,5 & & & & 0,160 & 2,864 & 0,286 & 0,074 & 0,261 \\
\hline & 2,890 & & & 32,80 & 0,135 & 3,174 & 0,317 & 0,079 & 0,277 \\
\hline \multicolumn{10}{|c|}{ Degrau 13} \\
\hline$Q(1 / \mathrm{s}$ & $y_{o}(\mathrm{~cm})$ & $V(\mathrm{~m} / \mathrm{s})$ & & $H(\mathrm{~cm})$ & $\Delta H / H o$ & $y_{c} / h$ & $y_{c} / N h$ & $c_{f}$ & $f$ \\
\hline 5 & 0,740 & 1,35 & & & 0,727 & 0,867 & 0,067 & 0,065 & 0,247 \\
\hline 10 & & & & & & 1,377 & 0,106 & 0,059 & 0,220 \\
\hline 15 & 1,490 & 2,01 & & & 0,450 & 1,804 & 0,139 & 0,059 & 0,218 \\
\hline 20 & & 2,21 & & & & 2,186 & 0,168 & 0,059 & 0,216 \\
\hline 25 & & & & & 0,271 & 2,536 & 0,195 & 0,058 & 0,211 \\
\hline 30 & 2,439 & 2,46 & 44,24 & 33,29 & 0,247 & 2,864 & 0,220 & 0,065 & 0,230 \\
\hline 35 & 2,744 & 2,55 & 45,40 & 35,92 & 0,209 & 3,174 & 0,244 & 0,068 & 0,239 \\
\hline
\end{tabular}

Nos gráficos das figuras 4.14 e 4.15 estão representados os valores para as perdas de energia para o degrau 10 e 13. No primeiro gráfico (Figura 4.14), apresenta-se uma comparação entre os dados experimentais e numéricos de perda de energia relativa $\Delta H / H_{o}$ versus $y_{c} / h$. Os valores encontrados para perda de energia relativa da simulação numérica apresentaram-se com valores próximos aos experimentais, discrepando-se para valores menores de $y_{c} / h$ em que os resultados da simulação numérica foram de até aproximadamente $33 \%$ menor que o experimental.

E no gráfico seguinte (Figura 4.15) a comparação é realizada para a perda de energia relativa $\Delta H / H_{o}$ em relação à $y_{c} / N h$. Nesta comparação visualiza-se uma boa concordância dos resultados numéricos com os experimentais, com exceção de pontos referentes aos menores valores de $y_{c} / N h$ em que as diferenças chegam a mais de $15 \%$ da curva proposta por Christodoulou (1993), esta diferença poder ser atribuída a dificuldade na determinação a altura da lamina d'água para os valores menores de vazão, tendo em vista a presença da aeração no escoamento, ou ainda, alguma dificuldade da solução numérica. 


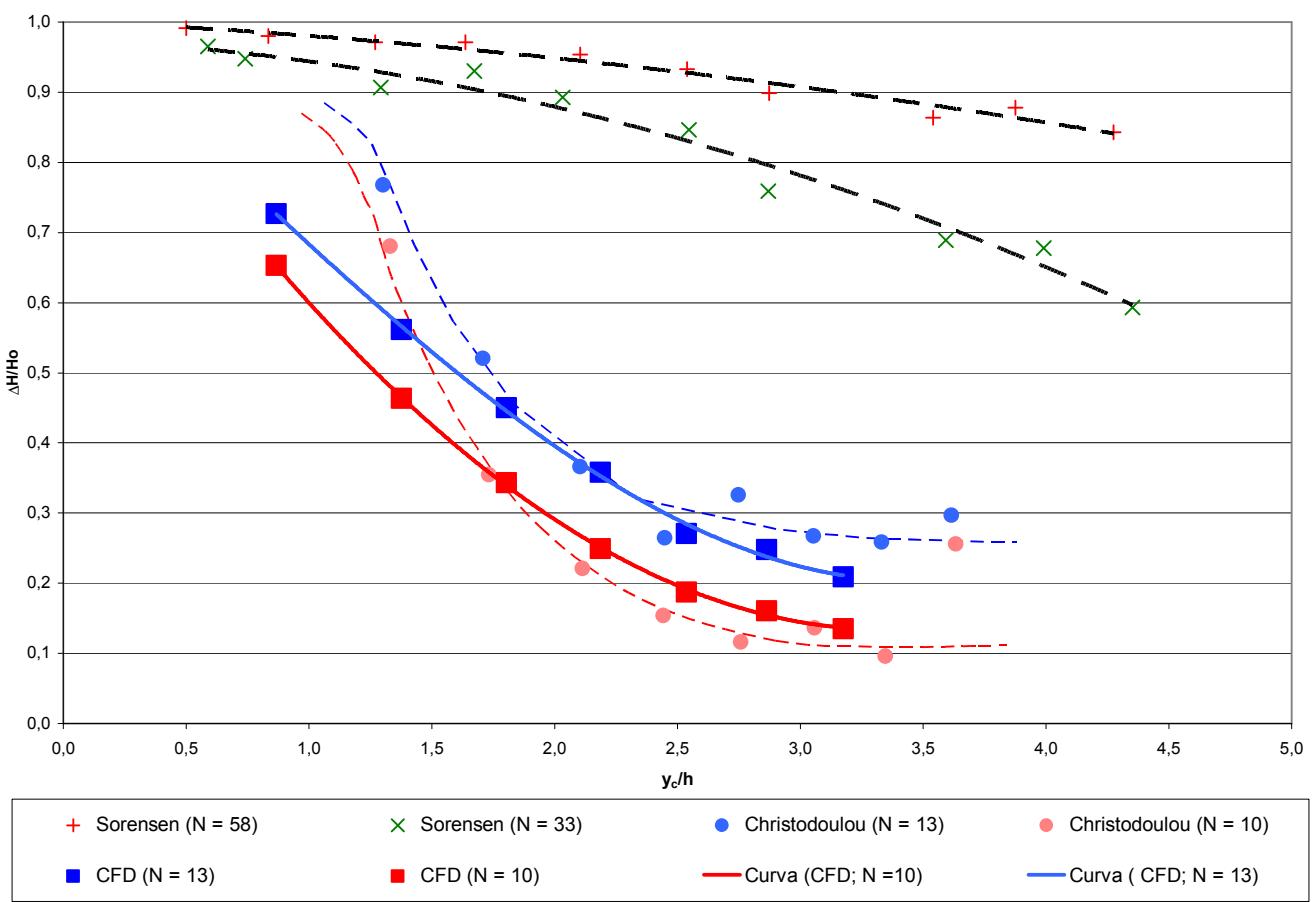

Figura 4.14. Comparação da Variação da Perda de Carga Relativa $\Delta H / H_{o}$ com $y_{c} / h$ e $N$.

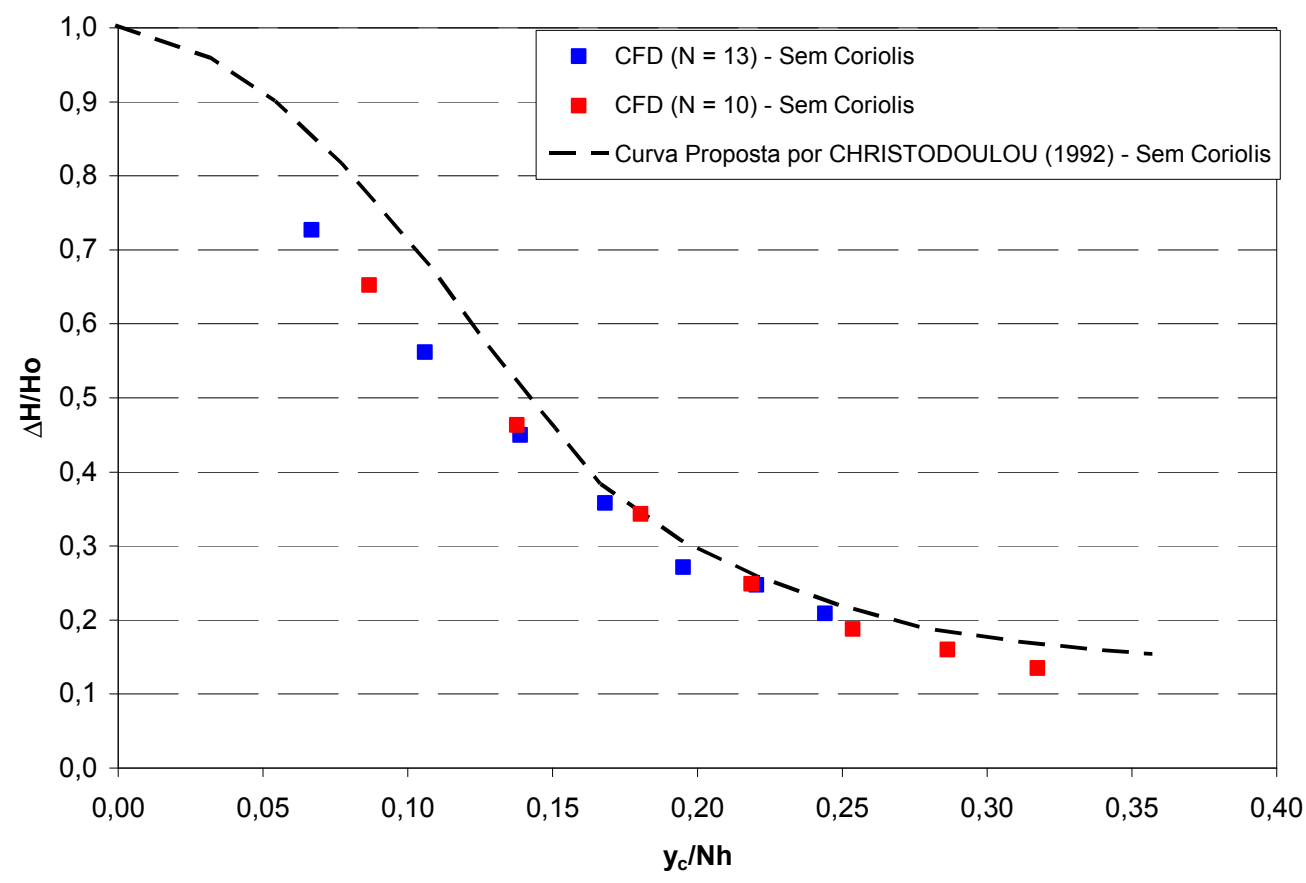

Figura 4.15. Comparação da Variação da Perda de Carga Relativa $\Delta H / H_{o}$ com $y_{c} / N h$. 
Nos resultados experimentais analisados por Christodoulou (1993), em que não foram determinados os perfis de velocidades nas seções de estudo e desse modo, não foram considerados os fatores de correção da energia cinética (ou coeficiente de Coriolis), que é dado por:

$$
\alpha_{c}=\frac{\int_{A} v^{3} d A}{V^{3} A}
$$

Tendo em vista que a simulação numérica fornece os perfis de velocidade na seção de interesse, é possível determinar os coeficientes de Coriolis. A perda de energia total passa a ser expressa como:

$$
\Delta H=H_{o}-H
$$

onde: $H=y \cos \phi+\alpha_{c}\left(V^{2} / 2 g\right)$ é a carga hidráulica sobre o degrau considerado; $\alpha_{c}$ é o coeficiente de Coriolis; $H_{o}=\Delta z+Y+\left(V_{o}^{2} / 2 g\right)$ é a carga hidráulica à montante do vertedouro; $V=Q /(y B)$ é a velocidade média local; $V_{o}=Q /(Y B)$ é a velocidade de aproximação e $B$ é a largura do canal.

Na tabela 4.3 são apresentados os valores do coeficiente Coriolis calculados com base nos perfis de velocidade numéricos.

Os coeficientes de Coriolis variaram de 1,085 a 1,149, sendo para os calculados para o degrau 13 um pouco maiores que os calculados para o degrau 10. A média geral deste coeficiente foi de aproximadamente 1,10 , sendo este valor utilizado na curva teórica do figura 4.18. Tozzi (1992) propôs o mesmo valor para o coeficiente de Coriolis com base em seu dados experimentais.

Com a determinação do coeficiente de Coriolis foram feitas as correções na perda de energia (Tabela 4.3). Nos gráficos da figuras 4.16 e 4.17 estão representados os efeitos do coeficiente de Coriolis. 
Tabela 4.3. Resultados da Simulação Numérica com o Coeficiente de Coriolis.

\begin{tabular}{|c|c|c|c|c|c|c|c|c|}
\hline \multicolumn{9}{|c|}{ Degrau 10 - Com Coriolis } \\
\hline$Q(1 / \mathrm{s})$ & $y_{o}(\mathrm{~cm})$ & $\alpha_{c}$ & $V(\mathrm{~m} / \mathrm{s})$ & $H_{o}(\mathrm{~cm})$ & $H(\mathrm{~cm})$ & $\Delta H / H o$ & $y_{c} / h$ & $H_{\text {barr }} / y_{c}$ \\
\hline 5 & 0,735 & 1,091 & 1,36 & 29,25 & 11,02 & 0,660 & 0,867 & 13,93 \\
\hline 10 & 1,144 & 1,100 & 1,75 & 31,16 & 18,29 & 0,457 & 1,377 & 8,78 \\
\hline 15 & 1,514 & 1,088 & 1,98 & 32,77 & 23,28 & 0,330 & 1,804 & 6,70 \\
\hline 20 & 1,850 & 1,104 & 2,16 & 34,20 & 28,16 & 0,211 & 2,186 & 5,53 \\
\hline 25 & 2,186 & 1,096 & 2,29 & 35,51 & 31,41 & 0,141 & 2,536 & 4,77 \\
\hline 30 & 2,546 & 1,088 & 2,36 & 36,74 & 33,33 & 0,108 & 2,864 & 4,22 \\
\hline 35 & 2,890 & 1,085 & 2,42 & 37,90 & 35,34 & 0,074 & 3,174 & 3,67 \\
\hline \multicolumn{9}{|c|}{ Degrau 13 - Com Coriolis } \\
\hline$Q(1 / \mathrm{s})$ & $y_{o}(\mathrm{~cm})$ & $\alpha_{c}$ & $V(\mathrm{~m} / \mathrm{s})$ & $H_{o}(\mathrm{~cm})$ & $H(\mathrm{~cm})$ & $\Delta H / H o$ & $y_{c} / h$ & $H_{\text {barr }} / y_{c}$ \\
\hline 5 & 0,740 & 1,091 & 1,35 & 36,75 & 10,89 & 0,727 & 0,867 & 17,39 \\
\hline 10 & 1,135 & 1,149 & 1,76 & 38,66 & 18,53 & 0,550 & 1,377 & 10,96 \\
\hline 15 & 1,490 & 1,125 & 2,01 & 40,27 & 24,72 & 0,415 & 1,804 & 8,36 \\
\hline 20 & 1,807 & 1,115 & 2,21 & 41,70 & 29,66 & 0,313 & 2,186 & 6,90 \\
\hline 25 & 2,086 & 1,111 & 2,40 & 43,01 & 34,61 & 0,214 & 2,536 & 5,95 \\
\hline 30 & 2,439 & 1,107 & 2,46 & 44,24 & 36,60 & 0,184 & 2,864 & 5,27 \\
\hline 35 & 2,744 & 1,101 & 2,55 & 45,40 & 39,28 & 0,140 & 3,174 & 4,75 \\
\hline
\end{tabular}

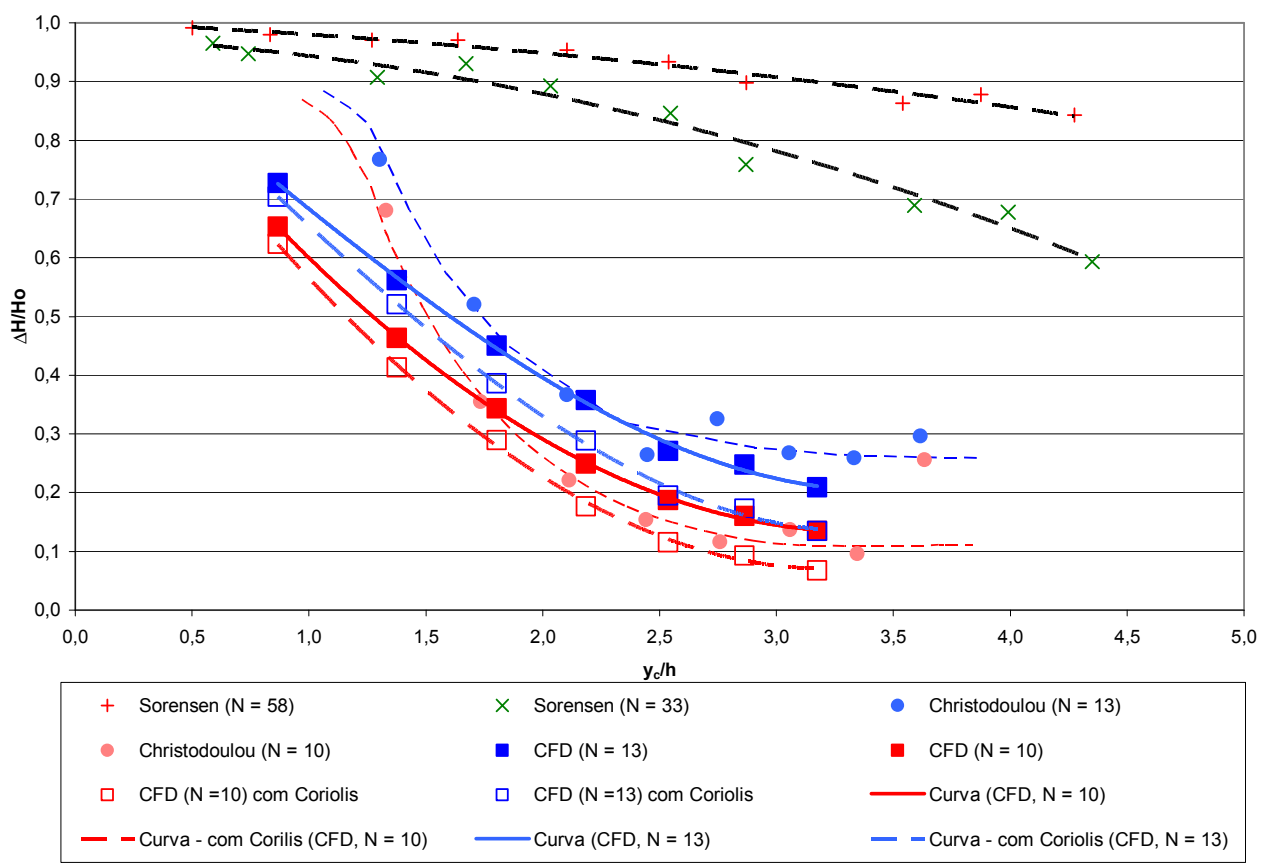

Figura 4.16: Efeito do Coeficiente de Coriolis na Perda de Energia Relativa.

Os efeitos do coeficiente de Coriolis para correção dos valores da perda de energia foram verificados para os degraus de número 10 e 13 (Figura 4.16 e 4.17). Esta correção em aproximadamente $10 \%$ na parcela cinética da equação de energia representa uma redução de 
até $47,5 \%$ na perda de energia. Fato que fortalece a necessidade de determinação deste coeficiente para correção. No gráfico da figura 4.17 propõe-se uma nova curva para de energia relativa considerando o coeficiente de Coriolis.

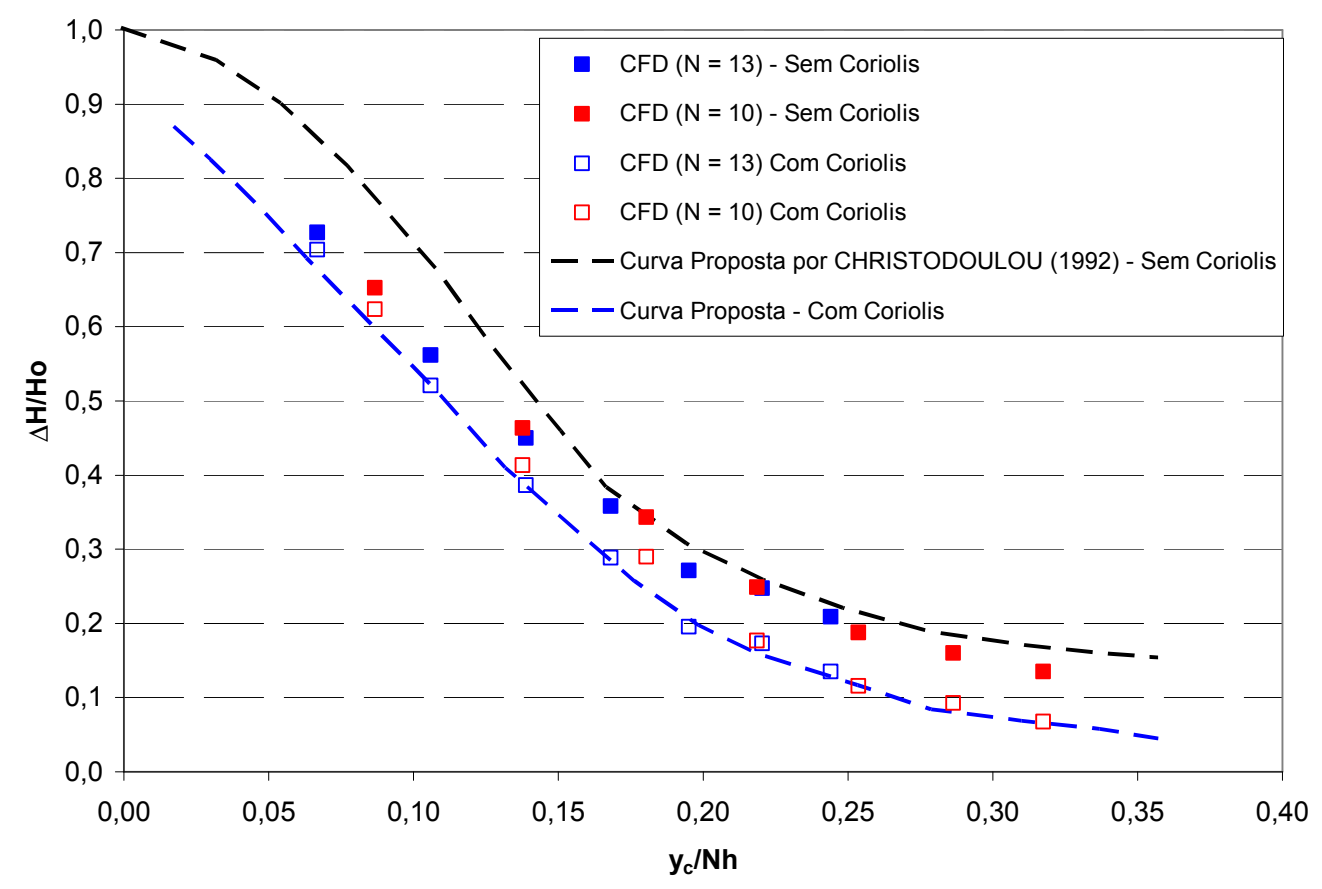

Figura 4.17: Efeito do Coeficiente de Coriolis na Perda de Energia Relativa.

Os resultados de perda de energia encontrados para as configurações ensaiadas por Christodoulou (1993) foram comparados com a equação teórica (2.27a) proposta por Chanson (1994). Nesta equação a perda de energia $\left(\Delta H / H_{o}\right)$ está relacionada à altura da crista da barragem em relação à seção de medição, dividida pela altura crítica do escoamento $\left(H_{b a r r} / y_{c}\right)$. Esta equação também depende do fator de cisalhamento, $f$ e do coeficiente de Coriolis, $\alpha_{c}$, sendo este dois determinados com base nos resultados numéricos e os valores médios encontrados foram: $f=0,235$ e $\alpha_{c}=1,10$.

No gráfico da figura 4.18 pode-se verificar que os resultados numéricos têm uma boa representação, comparando-se com a equação proposta por Chanson (op cit.) para a perda de energia em função da altura da barragem, com uma pequena discrepância para valores pequenos de $H_{b a r r} y_{c}$. A influência da correção pelo coeficiente de Coriolis também pode ser visualizada nesta representação gráfica, verificando-se a importância da consideração deste coeficiente, pois a sua negligencia iria superestimar a perda de energia relativa. 


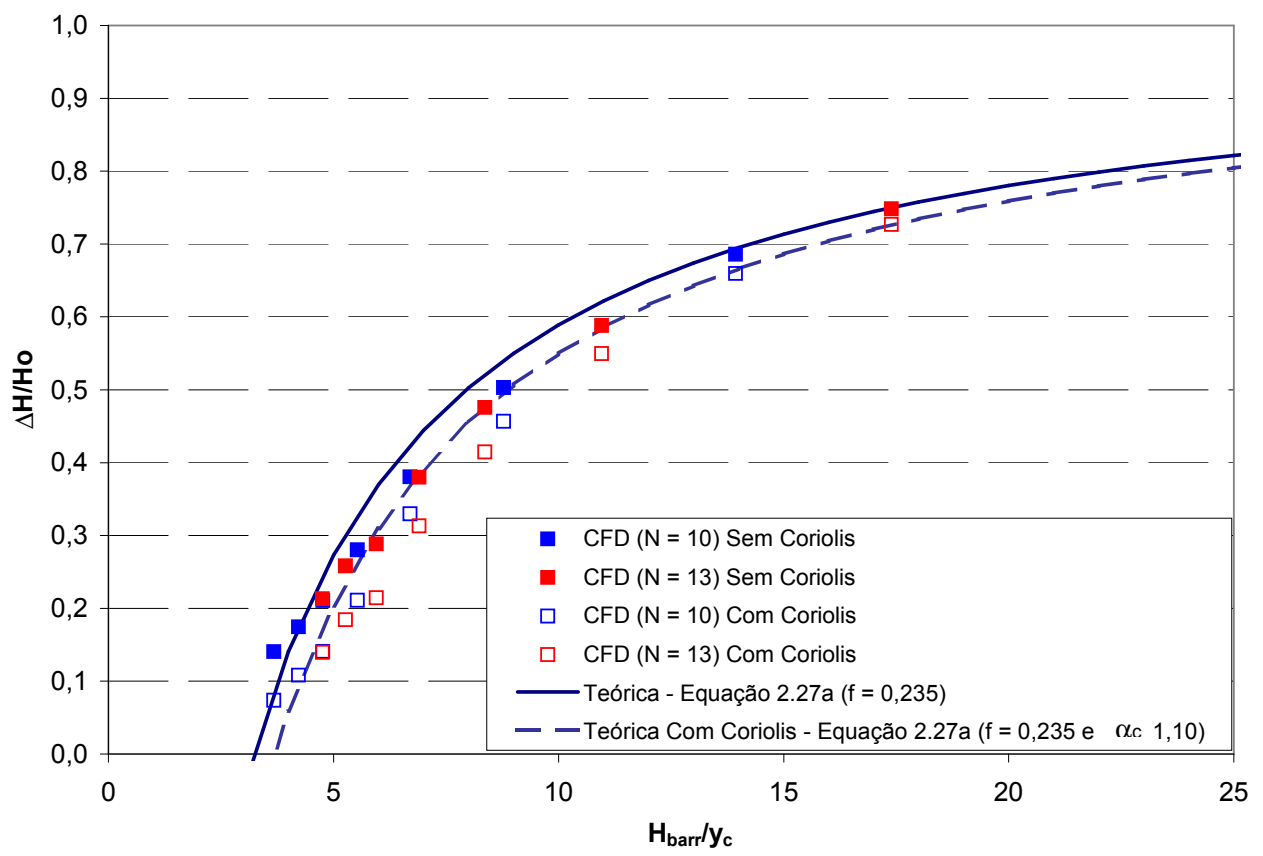

Figura 4.18: Efeito do Coeficiente de Coriolis na Perda de Energia Relativa.

\section{Conclusões.}

O estudo da perda de energia em vertedoures em degraus foi realizado através de uma comparação entre simulação numérica e os resultados experimentais determinados por Christodoulou (1993). Os resultados numéricos obtidos pela simulação no programa de fluidodinâmica computacional puderam ser comparados com os resultados experimentais e uma boa representatividade foi observada, com uma discrepância nos valores da perda de energia para as menores vazões, devido a uma provável dificuldade experimental ou ainda, nas hipóteses do modelo numérico na determinação da lâmina d'água do escoamento aerado para estas vazões. O coeficiente de correção de Coriolis foi considerado neste estudo e seu efeito foi quantificado, resultando em uma diminuição na eficiência de dissipação de energia de até 47,5\%. Uma equação teórica proposta por Chanson (1994) foi representada utilizandose os parâmetros obtidos com os resultados da simulação e uma comparação com estes resultados foi realizada, verificando-se um bom comportamento tanto para a perda de energia com e sem a correção utilizando o coeficiente de Coriolis. 


\subsubsection{Estudo Numérico da Caracterização do Escoamento em Vertedouros em Degraus.}

Para esta etapa do trabalho, a simulação do escoamento em vertedouros em degraus constituiu-se na reedição dos ensaios realizados por Tozzi (1992), utilizando-se as ferramentas de fluidodinâmica computacional para caracterização do escoamento em vertedouros em degraus. O vertedouro estudado por Tozzi (1992) apresenta as configurações apresentadas nas figuras 4.19 e 4.20 .

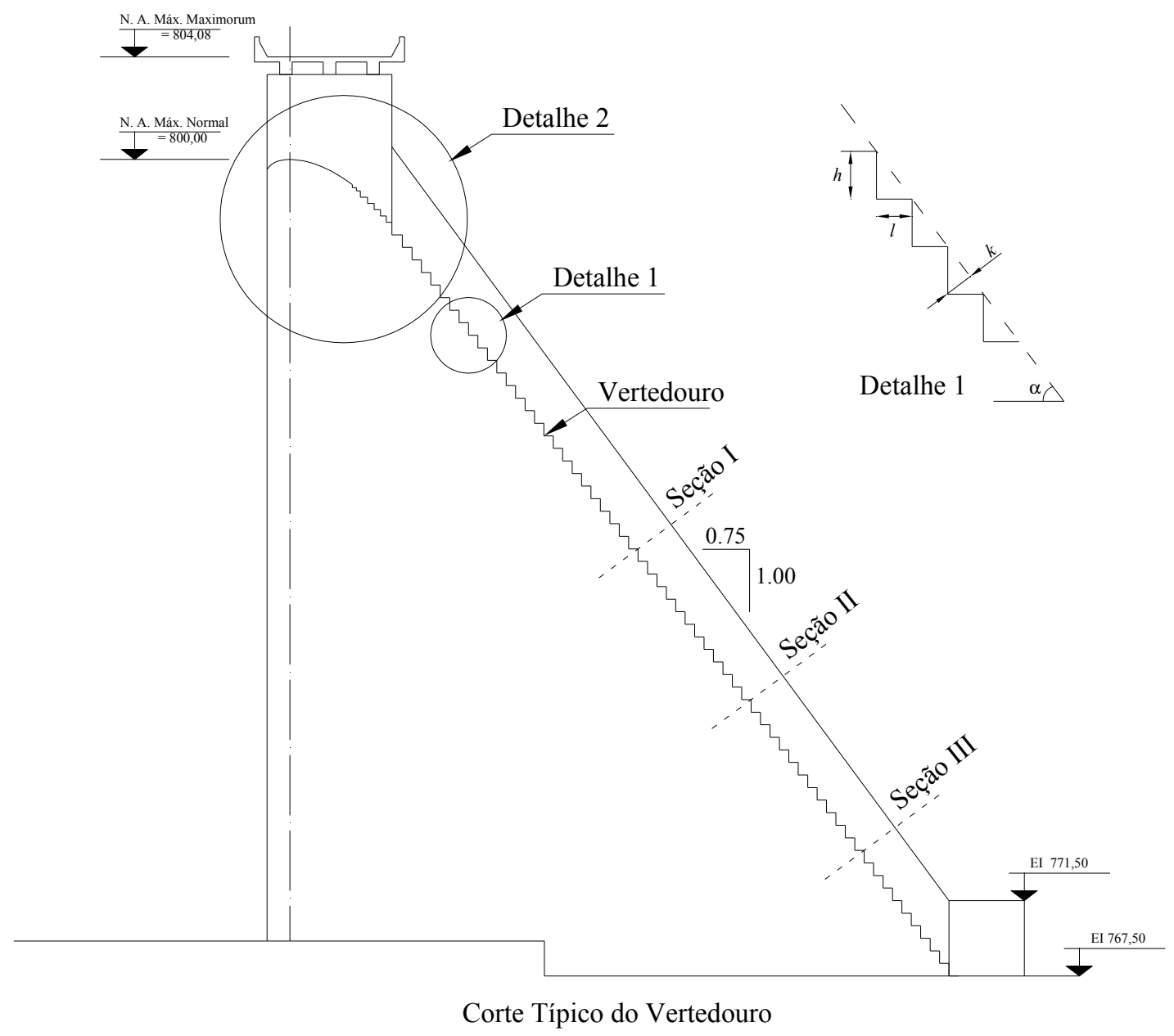

Figura 4.19. Dimensões principais do Vertedouro do Aproveitamento Hidroelétrico de Cubatão. (Fonte: Adaptado de TOZZI,1992). 

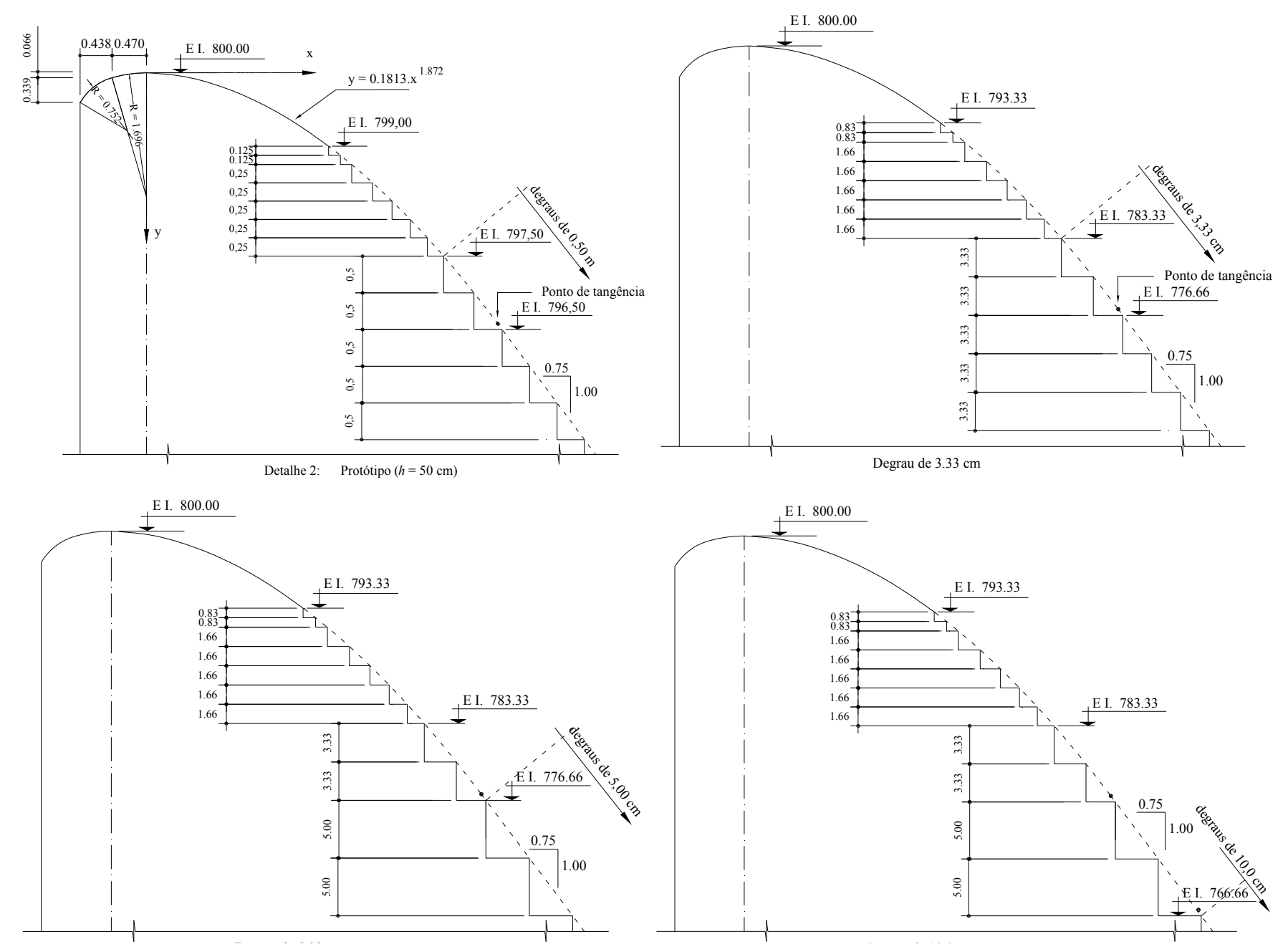

Figura 4.20. Configuração/transições adotadas para os degraus do protótipo $(h=50 \mathrm{~cm})$ e do modelo reduzido $(h=3.33 \mathrm{~cm}, 5.00 \mathrm{~cm}$ e $10.0 \mathrm{~cm})$ (Fonte: Adaptado de TOZZI,1992) 
As condições das simulações, quanto a: tamanho da malha, características dos fluidos e o tempo de simulação são apresentadas na tabela 4.4. Verifica-se que o tempo de processamento em cada condição do escoamento foi de aproximadamente 28 horas, e seria maior se a malha fosse refinada em todo o domínio do escoamento. Para melhor caracterizar a condição de aeração do escoamento realizou-se uma adaptação na malha em função do gradiente de aeração aumentando o número de elementos próximo a interface ar-água. $\mathrm{O}$ tempo de simulação de 16,25 segundos para escoamento no vertedouro em degraus são suficientes para o estabelecimento do escoamento, isto pode ser verificado através de uma análise do balanço de massa de entrada e saída do escoamento no domínio, que devem ser iguais na condição final. Outra forma de verificar a condição de finalização da simulação em regimes estacionários é através do erro médio quadrático (RMS), que segundo o manual do CFX deve ser menor que $5 * 10^{-4}$.

Tabela 4.4. Domínio, Características do Fluido e da Simulação.

\begin{tabular}{|c|c|c|}
\hline \multicolumn{3}{|c|}{ Domínio (antes da adaptação da malha) } \\
\hline Número de Nó & & $\approx 74259$ \\
\hline Número de Elementos & & $\approx 365224$ \\
\hline \multicolumn{3}{|c|}{ Domínio (depois da adaptação da malha) } \\
\hline Número de Nós & & $\approx 317000$ \\
\hline Número de Elementos & & $\approx 1550000$ \\
\hline \multicolumn{3}{|c|}{ Fluidos } \\
\hline \multicolumn{2}{|c|}{ Água } & $\mathrm{Ar}$ \\
\hline Temperatura & $25^{\circ} \mathrm{C}$ & Temperatura \\
\hline Viscosidade Dinâmica & $8,899 * 10^{-4} \mathrm{~kg} \cdot \mathrm{m}^{-1} \cdot \mathrm{s}^{-1}$ & Viscosidade Dinâmica $1,831 * 10^{-5} \mathrm{~kg} \cdot \mathrm{m}^{-1} \cdot \mathrm{s}^{-1}$ \\
\hline Massa Específica & $998 \mathrm{~kg} \cdot \mathrm{m}^{-3}$ & Massa Específica \\
\hline \multicolumn{3}{|c|}{ Coef. de Tensão Superf. 0,0732 N.m ${ }^{-1}$} \\
\hline \multicolumn{3}{|c|}{ Simulação } \\
\hline Passo de Tempo & & $0,05 \mathrm{~s}$ \\
\hline Tempo de Simulação & & $16,25 \mathrm{~s}$ \\
\hline Erro Médio Quadrático & (RMS) & $10^{-5}$ \\
\hline Características dos Proc & cessadores & Processadores 3,2 GHz (Opteron 64 bits) \\
\hline Tempo de Processamen & to no $\mathrm{CPU}(\approx)$ & $1 * 10^{5} \mathrm{~s}$ (por simulação) $(\approx 28$ horas $)$ \\
\hline
\end{tabular}


Neste estudo foram comparados os resultados dos perfis de velocidade em três seções de estudo (seção I, II e III da Figura 4.19). Os pontos de início da aeração do escoamento também foram determinados utilizando-se os dados dos resultados das simulações e comparados com os resultados encontrados experimentalmente por Tozzi (1992). Realizou-se ainda um estudo da aeração no escoamento comparando-se os perfis de concentração de ar com equações teóricas. Resultados experimentais para concentração de ar existente na literatura foram comparados com as simulações realizadas.

\subsubsection{Distribuição de Velocidades do Escoamento.}

As velocidades médias resultantes das simulações foram comparadas com as obtidas por Tozzi (op cit.). Na Figura 4.21 são apresentados os perfis de velocidade para a rugosidade $k_{a}$ de $2 \mathrm{~cm}$ na seção III. No APÊNDICE A são apresentados os perfis de velocidade nas seções I, II, e III para as vazões específicas (86,1 1/s/m; 120,5 1/s/m; 163,5 1/s/m e 201,4 1/s/m) e ainda para diferentes rugosidades $\left(k_{a}=2 \mathrm{~cm}, k_{a}=3 \mathrm{~cm}\right.$ e $k_{a}=6 \mathrm{~cm}$ ). Tozzi (op cit.) quantificou o perfil de velocidades utilizando um tubo de estagnação em todos os experimentos realizados e comparou o resultado de três experimentos utilizando-se técnicas com eletrodos para o perfil de velocidades submerso e elementos flutuantes para as velocidades da superfície livre. Verifica-se uma boa aproximação para esses perfis de velocidade em relação ao crescimento da camada limite, indicando a eficácia na modelagem numérica. A diferença dos valores das velocidades próximas à superfície livre, quantificada utilizando-se o tubo de estagnação, não representou adequadamente as velocidades na região com aeração. Este problema já é conhecido da literatura, sendo que Tozzi (op cit.) corrigiu os resultados encontrados, considerando, para o cálculo da perda de energia, um perfil uniforme a partir da velocidade máxima, determinada com o crescimento da camada limite, até a superfície livre.

Duas equações teóricas para a distribuição das velocidades (equações 2.49 e 2.51) foram comparadas com os resultados adimensionalizados da simulação numérica. No gráfico da Figura 4.22 é apresentada a comparação dos perfis de velocidades adimensionalizado, $V / V_{\max }$, onde $V_{\max }$ é o valor da velocidade máxima do escoamento de água, contra a altura adimensionalizada, $y / y_{o}$ para quatro vazões unitárias nas condições de modelo reduzido e de protótipo. 

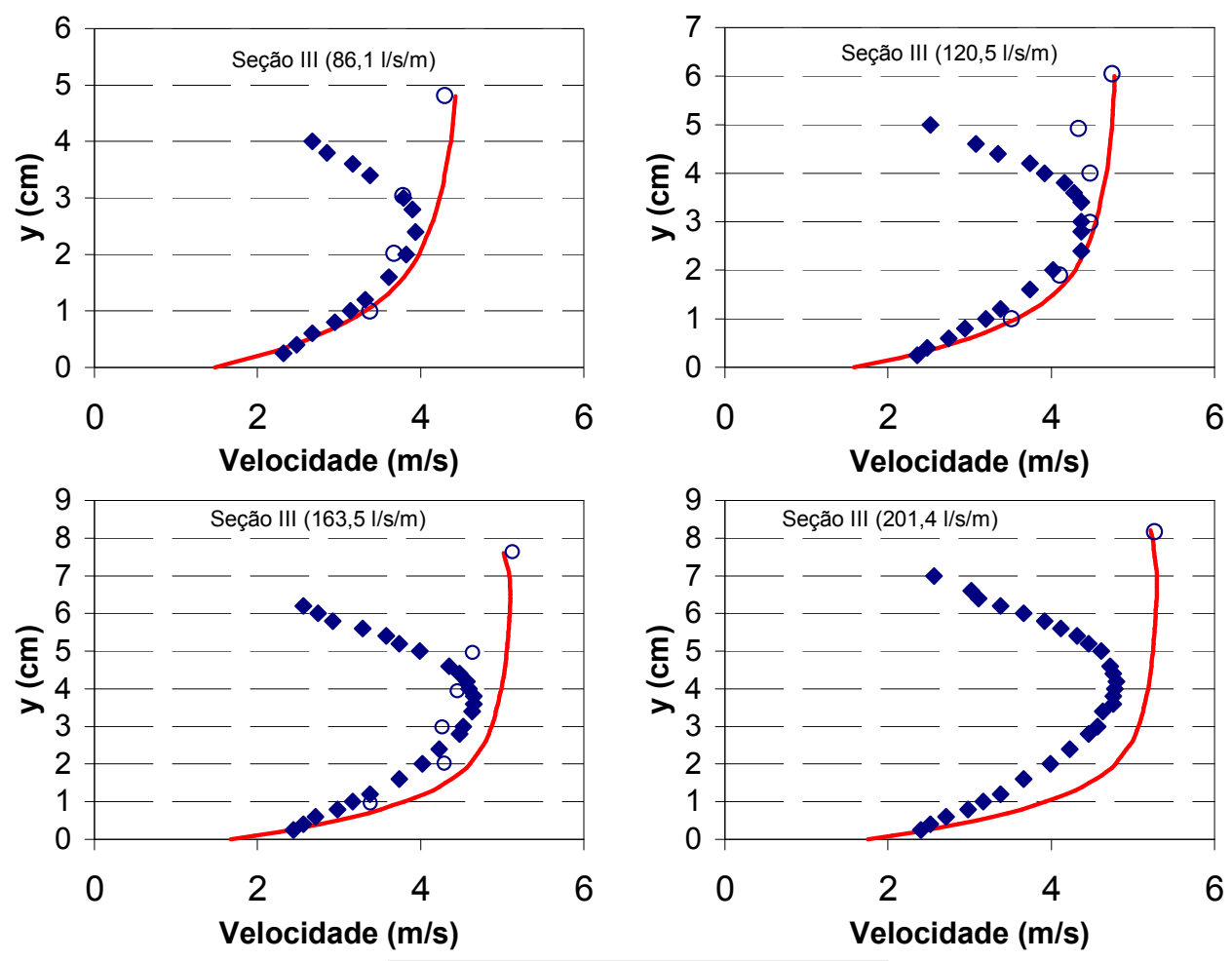

Tubo de Estagnação (TOZZI, 1992)
O Eletrodos ou Flutuantes (TOZZI, 1992)
_ Numérico - CFD

Figura 4.21. Comparação entre os perfis de velocidade experimental (TOZZI,1992) e numérico - Seção III $-k_{a}=2 \mathrm{~cm}$.

Verifica-se que os perfis de velocidade adimensionais do protótipo e do modelo reduzido foram praticamente idênticos indicando a boa representatividade do modelo de escala para este estudo. Entre as duas equações teóricas comparadas com os perfis resultantes do estudo numérico, a equação 2.49 foi a que melhor aproximou. E esta aproximação foi mais complacente para as vazões menores, pois, possivelmente, para as vazões maiores, ainda não chegaram às condições de escoamento plenamente desenvolvido. No APÊNDICE B estão apresentados os perfis adimensionalizados para as seções I, II e III e para as rugosidades $k_{a}=$ $3 \mathrm{~cm} \mathrm{e} k_{a}=6 \mathrm{~cm}$. 

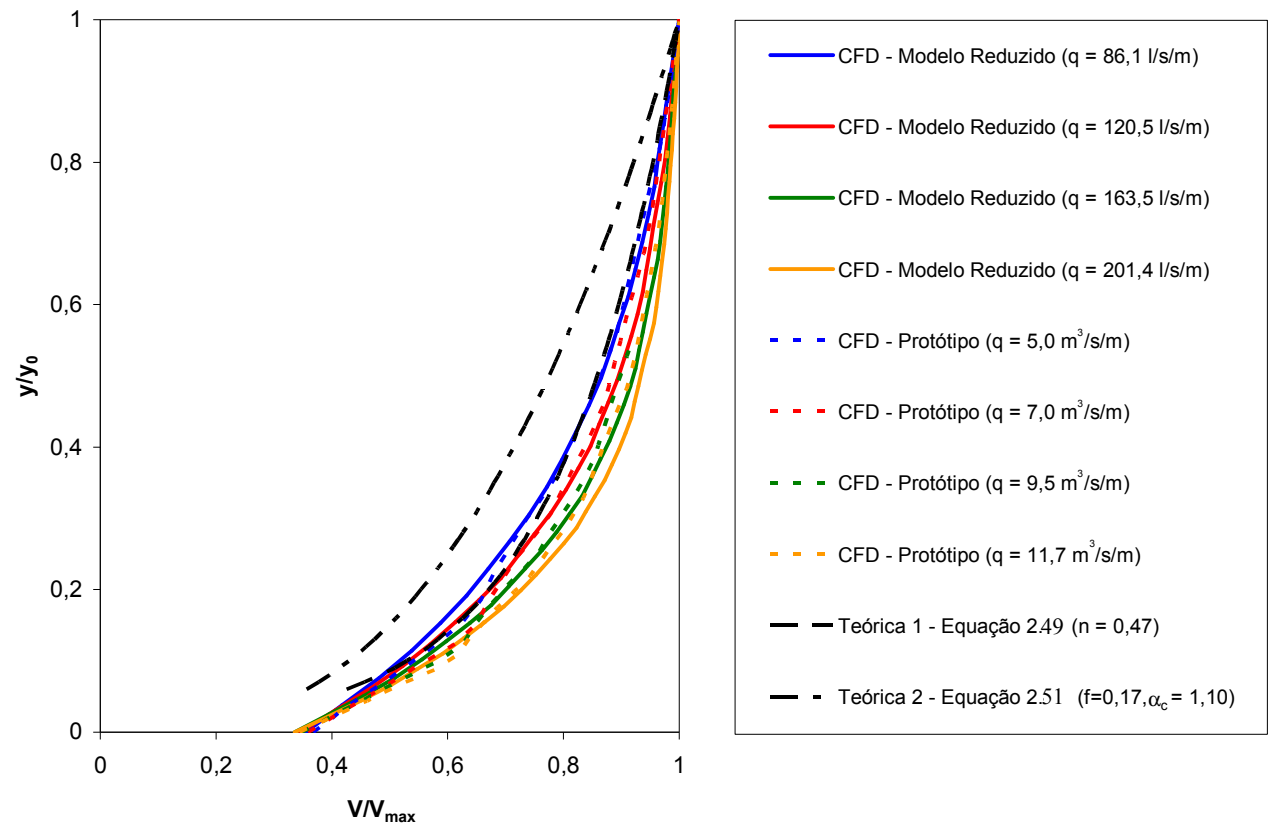

Figura 4.22. Perfis de velocidades adimensionalisados para seção III $-k_{a}=2 \mathrm{~cm}$.

Para complementar a estudo da distribuição de velocidades, foi realizada uma comparação entre os resultados experimentais obtido por Amador et al (2004) e resultados da simulação numérica. A velocidade da água, para uma vazão específica de aproximadamente $10 \mathrm{~m}^{3} / \mathrm{s} / \mathrm{m}$, em um plano paralelo ao escoamento, foi obtida por Amador et al (op cit.) utilizando a técnica de velocimetria a LASER (PIV). Na Figura 4.23 são apresentas os resultados da distribuição das velocidades, através de curvas de iso - velocidades, obtidos com o LASER (PIV) e com a ferramenta de fluidodinâmica computacional. Verifica-se que os valores e os formatos da curvas de iguais velocidades são similares, indicando uma boa representatividade da simulação para a distribuição bidimensional das velocidades. 


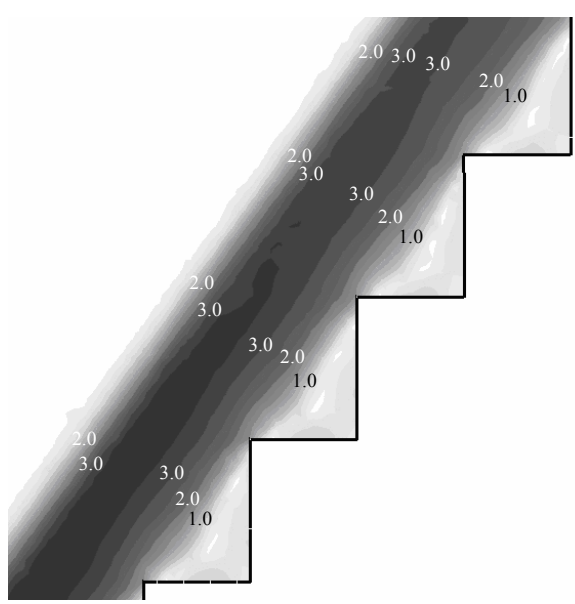

(a)

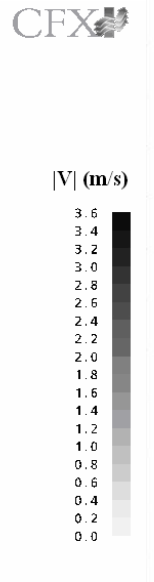

$\mathbf{V} \mid \mathbf{( m} / \mathbf{s})$
3.6
3.4
3.2
3.0
2.8
2.6
2.4
2.2
2.0
1.8
1.6
1.4
1.2
1.0
0.8
0.6
0.4
0.2
0.0

$1 / 11$

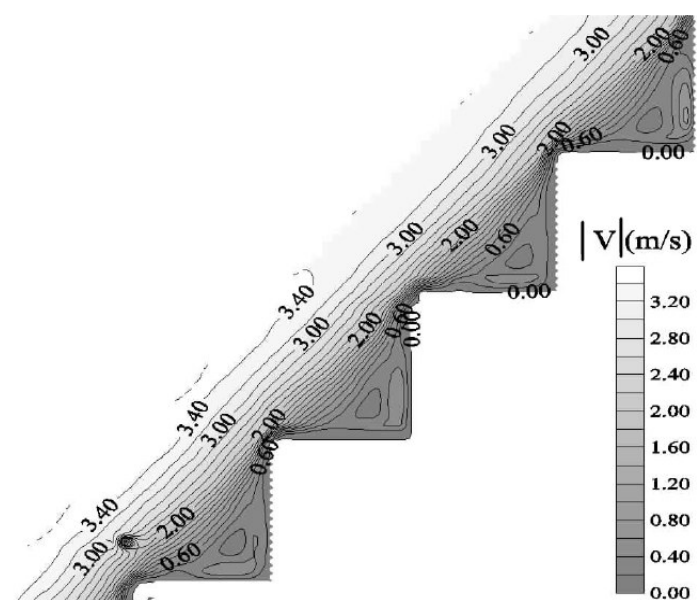

(b)

Figura 4.23. Comparação entre a simulação numérica (a - CFD) e a velocimetria a LASER (PIV) (b - Fonte: AMADOR et al., 2004).

\subsubsection{Perda de Energia Específica ao Longo do Vertedouro.}

A taxa de dissipação da energia específica $\left(\Delta H / H_{o}\right)$ nas Seções de estudo I, II e III em função da altura da barragem dividido pela altura crítica do escoamento $\left(H_{b a r r} / y_{c}\right)$ foi comparada com a equação teórica (equação 2.27a) proposta por Chanson (1994). O valor do fator de cisalhamento $(f)$ utilizado para a equação teórica foi o valor médio entre todos encontrados nas três seções de estudos e para as cinco vazões estudadas.

$\mathrm{Na}$ tabela 4.5 estão apresentados os valores da altura crítica do escoamento $\mathrm{y}_{\mathrm{c}}$, da velocidade média $V$, da altura do escoamento $y_{o}$, do coeficiente de Coriolis $\alpha_{c}$, da energia específica na seção de estudo $H$, da energia especifica inicial para a seção de estudo $H_{o}$, da taxa de dissipação da energia $\Delta H / H_{o}$, da altura da barragem dividida pela altura crítica. $H_{b a r r} y_{c}$ e do fator de cisalhamento $f$, calculados utilizando os resultados das simulações para as cinco vazões de estudo e rugosidade $k_{a}=2 \mathrm{~cm}$. No APÊNDICE C estão apresentas as tabelas para a condição de protótipo $\left(k_{a}=30 \mathrm{~cm}\right)$ e para os modelos reduzidos com $k_{a}=3 \mathrm{~cm}$ e $k_{a}=6 \mathrm{~cm}$. 
Tabela 4.5. Resultados da Simulação Numérica (CFD) para rugosidade $k_{a}=2 \mathrm{~cm}$.

\begin{tabular}{ccccccccccc}
\hline Seção & $\begin{array}{c}q \\
(1 / \mathrm{m} / \mathrm{s})\end{array}$ & $\begin{array}{c}y_{c} \\
(\mathrm{~cm})\end{array}$ & $\begin{array}{c}V \\
(\mathrm{~m} / \mathrm{s})\end{array}$ & $\begin{array}{c}y_{o} \\
(\mathrm{~cm})\end{array}$ & $\alpha_{\mathrm{c}}$ & $\begin{array}{c}H \\
(\mathrm{~m})\end{array}$ & $\begin{array}{c}H_{o} \\
(\mathrm{~m})\end{array}$ & $\Delta H / H_{o}$ & $H_{\text {barr }} / y_{c}$ & $f$ \\
\hline & 68,8 & 7,84 & 2,83 & 2,43 & 1,078 & 0,478 & 1,151 & 0,585 & 13,17 & 0,191 \\
I & 86,1 & 9,11 & 3,04 & 2,84 & 1,105 & 0,574 & 1,170 & 0,510 & 11,34 & 0,193 \\
& 120,5 & 11,40 & 3,42 & 3,55 & 1,111 & 0,721 & 1,204 & 0,402 & 9,07 & 0,193 \\
& 163,5 & 13,97 & 3,72 & 4,40 & 1,135 & 0,831 & 1,243 & 0,331 & 7,40 & 0,200 \\
& 201,4 & 16,05 & 3,91 & 5,15 & 1,105 & 0,899 & 1,274 & 0,295 & 6,44 & 0,212 \\
\hline \multirow{4}{*}{ II } & 68,8 & 7,84 & 2,95 & 2,34 & 1,119 & 0,531 & 1,517 & 0,650 & 18,27 & 0,169 \\
& 86,1 & 9,11 & 3,19 & 2,70 & 1,123 & 0,643 & 1,532 & 0,580 & 15,73 & 0,167 \\
& 120,5 & 11,40 & 3,60 & 3,35 & 1,130 & 0,785 & 1,559 & 0,497 & 12,58 & 0,163 \\
& 163,5 & 13,97 & 3,97 & 4,12 & 1,166 & 0,961 & 1,591 & 0,396 & 10,26 & 0,164 \\
& 201,4 & 16,05 & 4,20 & 4,79 & 1,133 & 1,075 & 1,618 & 0,335 & 8,93 & 0,170 \\
\hline \multirow{4}{*}{ III } & 68,8 & 7,84 & 3,09 & 2,23 & 1,118 & 0,580 & 1,951 & 0,703 & 23,37 & 0,146 \\
& 86,1 & 9,11 & 3,32 & 2,59 & 1,133 & 0,702 & 1,970 & 0,644 & 20,13 & 0,147 \\
& 120,5 & 11,40 & 3,75 & 3,24 & 1,158 & 0,866 & 2,004 & 0,568 & 16,09 & 0,147 \\
& 163,5 & 13,97 & 4,17 & 3,92 & 1,184 & 1,062 & 2,043 & 0,480 & 13,12 & 0,141 \\
& 201,4 & 16,05 & 4,45 & 4,53 & 1,145 & 1,191 & 2,074 & 0,426 & 11,42 & 0,144 \\
& & & & & & & & & &
\end{tabular}

$\mathrm{Na}$ figura 4.24 estão apresentados os resultados da dissipação da energia adimensionalizada para a simulação numérica via CFD na condição de modelo reduzido $\left(k_{a}=\right.$ $2 \mathrm{~cm})$ e de protótipo $\left(k_{a}=30 \mathrm{~cm}\right)$ para a comparação das duas situações. Também, nesta mesma figura, é representada a equação teórica (equação 2.27a) deduzida por Chanson (1992) usando o valor médio do fator de cisalhamento e do coeficiente de Coriolis.

No gráfico da figura 4.24 pode-se verificar que a dissipação de energia adimensionalizada para as condições de modelo reduzido e protótipos foi similar à condição de protótipo, verificando a adequada utilização de modelos de escala para o estudo da dissipação de energia para projetos de vertedouros em degraus.

A equação 2.27a também representou uma boa aproximação para o estudo da dissipação de energia comparando-se aos resultados da simulação numérica. 


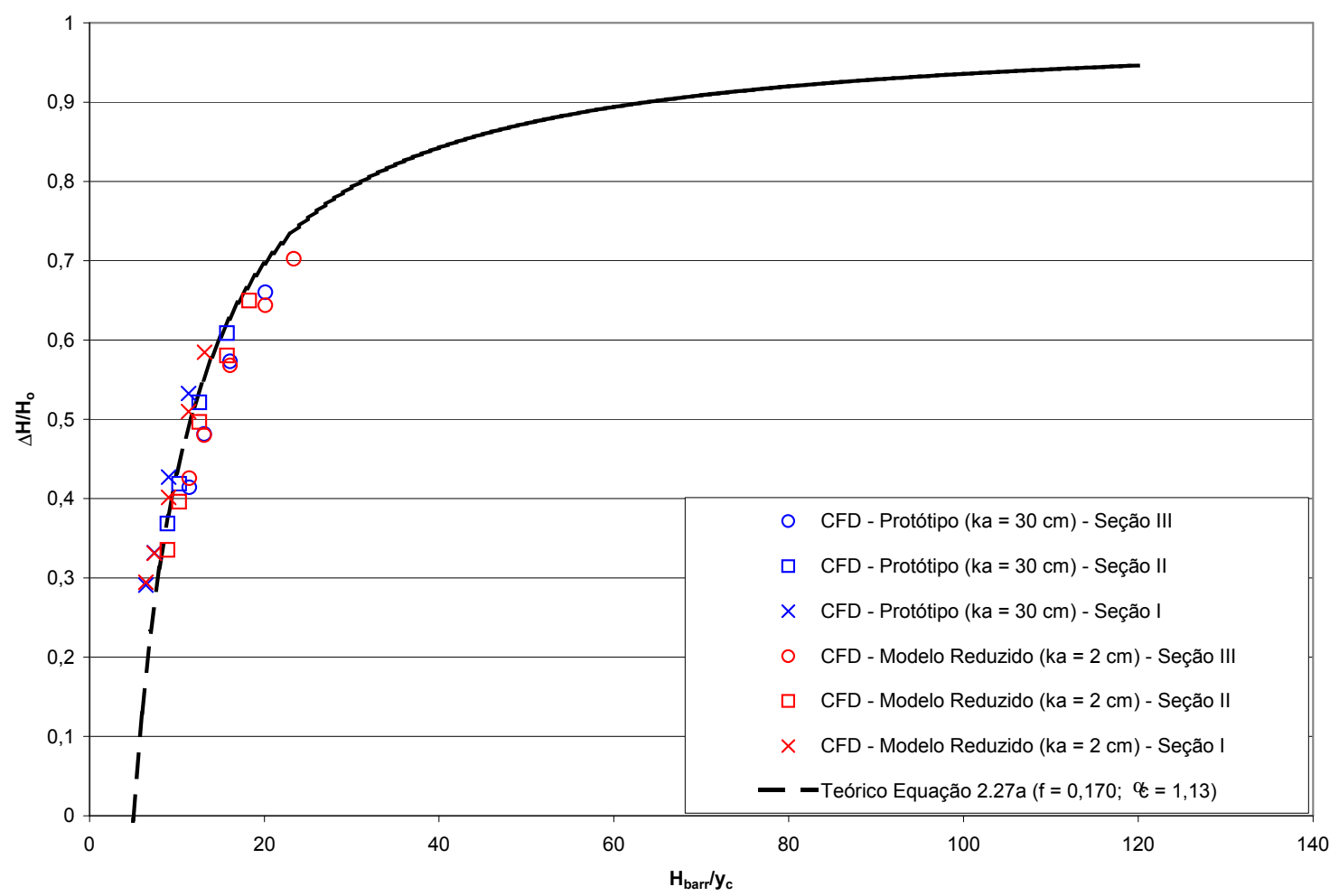

Figura 4.24. Dissipação de energia adimensionazada para a condição de modelo reduzido e protótipo e comparação com a equação teórica $2.27 \mathrm{a}$.

\subsubsection{Fator de Resistência do Escoamento.}

Tozzi (1992) realizou um estudo para estabelecimento de leis gerais para o fator de resistência para calhas de vertedouros em degraus.

Os estudos já realizados visando a definição de leis de resistência associadas a rugosidade artificiais mostraram que essas leis são da forma:

$$
\frac{1}{\sqrt{f}}=\Phi\left(\frac{y_{o}}{k_{a}}, S_{o}\right) \quad \text { ou } \frac{V}{V_{*}}=\Phi^{\prime}\left(\frac{y_{o}}{k_{a}}, S_{o}\right)
$$

Observa-se que para obtenção dessas leis é necessário determinar, para a declividade $S_{o}$ e altura de rugosidade $k_{a}$, a velocidade de cisalhamento $\left(V_{*}=V \cdot \sqrt{f / 8}\right)$, a altura do escoamento $y_{o}$ e a velocidade média do escoamento $(V)$.

A resistência decorrente da presença dos contornos sólidos concentra-se na região da camada limite, com os perfis de velocidades variando desde a velocidade nula no contorno sólido até o ponto onde a velocidade é máxima, na região pertencente ao escoamento com volume de fração de água de no mínimo de 50 \%. Este valor de concentração de água (50\%) foi considerado como superfície livre do escoamento, pois se verificou durante a simulação 
numérica que com o refinamento da malha o gradiente de concentração de ar transladava-se em torno de uma concentração de ar aproximadamente $50 \%$. Acredita-se que energia calculada utilizando esta representação de altura da superfície livre represente melhor a energia total existente naquela seção de estudo. A velocidade média foi determinada como no croqui seqüente.

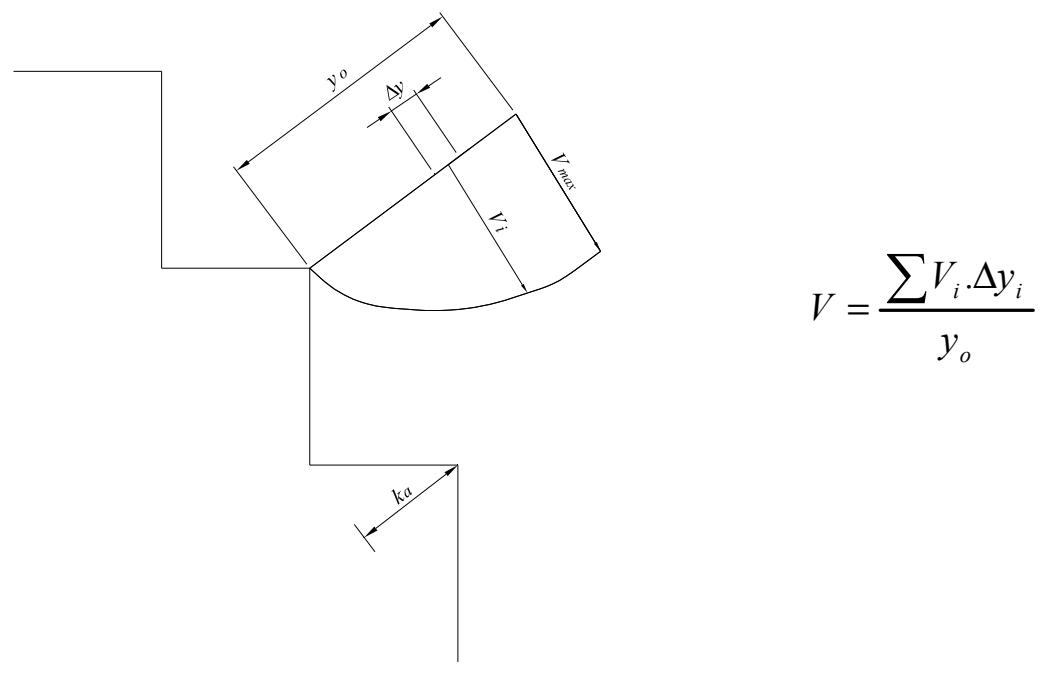

Figura 4.25. Esquema para a determinação da velocidade média do escoamento de água.

Tozzi (1992) determinou a relação entre os $V / V *$ e $y_{o} / k_{a}$ para os vertedouros com declividade $1 \mathrm{~V}: 0,75 \mathrm{H}$ e identificou um concordância satisfatória entre os resultados obtidos nos ensaios com água e com ar e a existência de duas regiões distintas, definidas pelas equações.

a) $\frac{V}{V_{*}}=\frac{1}{\sqrt{f / 8}}=6,10+3,50 \log \left(\frac{y_{o}}{k_{a}}\right)$

ou,

$\frac{1}{\sqrt{f}}=2,16+1,24 \log \left(\frac{y_{o}}{k_{a}}\right) \quad \quad \mathrm{p} / \frac{y_{o}}{k_{a}}>1,80$

b) $\frac{V}{V_{*}}=\frac{1}{\sqrt{f / 8}} \approx 7,00$

ou,

$\mathrm{f} \approx 0,163$

$\mathrm{p} / \frac{y_{o}}{k_{a}} \geq 1,80$

Em seu trabalho, Tozzi (1992) concluiu que na região definida pela equação (4.8), o aumento do fator de resistência $f$ com o decréscimo de $y_{o} / k_{a}$ está relacionado à energia 
consumida na formação dos vórtices junto aos degraus e à troca de quantidade de movimento entre camadas adjacentes do escoamento. À medida que $y_{o} / k_{a}$ tende a valores menores, a parcela da perda de energia devido à troca de quantidade de movimento se reduz, até se tornar insignificante em relação à perda decorrente da formação dos vórtices junto aos degraus, conduzindo a um valor de $f$ constante - equação (4.9).

Com base nos conceitos apresentados por Tozzi (op cit.) determinaram-se os valores dos adimensionais $V / V *$ e $y_{o} / k_{a}$ para os resultados das simulações numéricas na ferramenta CFD.

No gráfico da figura 4.26 está apresentada a relação entre os valores dos adimensionais $V / u *$ e $y_{o} / k_{a}$ para as três seções de estudo (I, II e III da figura 4.19) e para as três rugosidades $\left(k_{a}=2 \mathrm{~cm}, k_{a}=3 \mathrm{~cm}\right.$ e $\left.k_{a}=6 \mathrm{~cm}\right)$, comparando-se com as equações empíricas propostas por Tozzi (op cit.).

Pode-se verificar que os resultados da simulação numérica em CFD aproximaram-se dos valores propostos por Tozzi (op cit.), na região de fator de resistência considerado constante. Visualiza-se ainda um aumento no valor do adimensional $V / u *$ de montante para jusante do canal, caracterizando uma diminuição no fator de cisalhamento neste mesmo sentido, decorrente da maior dissipação de energia no início do escoamento.

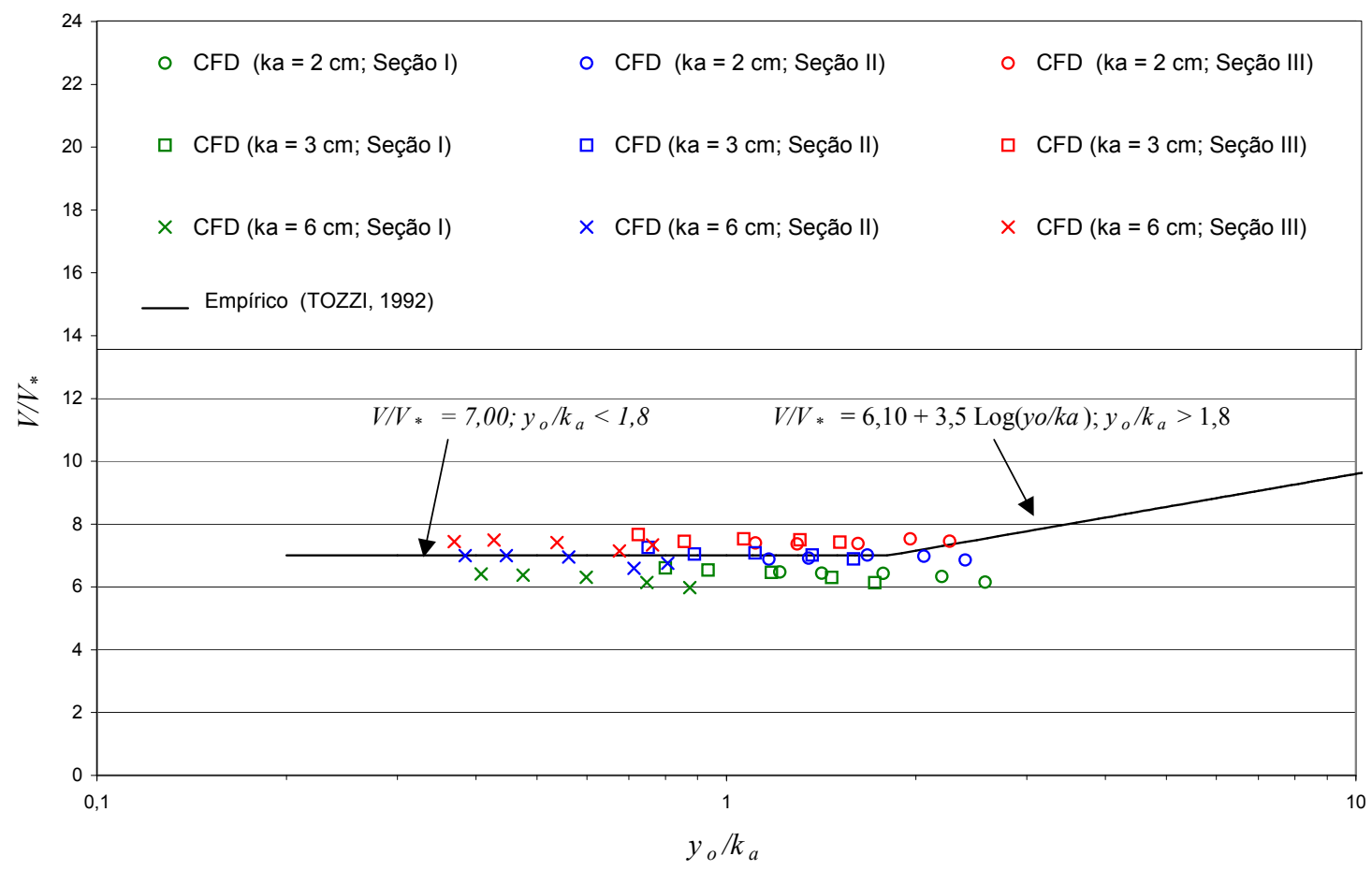

Figura 4.26. Relação entre $V / V * \mathrm{e} y_{o} / k_{a}$ - comparação entre resultados da simulação numérica e curva proposta por Tozzi (1992). 


\subsubsection{Posição de Início de Aeração do Escoamento.}

Tozzi (1992) realizou um estudo da posição do início da aeração em que determinou uma equação que define a espessura da camada limite turbulenta $(\delta)$, na posição de seu afloramento na superfície livre da água.

$$
\frac{\delta}{L_{A}}=0,080 \cdot\left(\frac{L_{A}}{k_{a}}\right)^{-0,233}
$$

O ponto de início da aeração do escoamento foi determinado utilizando-se os resultados da simulação numérica na ferramenta CFD. Sabe-se que o início da aeração do escoamento em vertedouros ocorre com o encontro da linha de crescimento da camada limite, com a linha de desenvolvimento da superfície livre. Dessa forma, foram obtidos os valores da espessura desta camada e da superfície livre ao longo do vertedouro em degrau, buscando a determinação do ponto de início da aeração caracterizado pelo encontro destas duas linhas.

$\mathrm{Na}$ figura 4.27, é apresentado o desenvolvimento da superfície livre obtido experimentalmente por Tozzi (1992) e o determinado numericamente para a vazão específica de $120,5 \mathrm{l} / \mathrm{s} / \mathrm{m}$ e rugosidade $k_{a}$ igual a $2 \mathrm{~cm}$, verificando-se uma boa aproximação. Nesta figura também é apresentado o crescimento da camada limite, determinada pelo ponto onde a velocidade equivale a $99 \%$ da velocidade máxima. Verifica-se que o ponto de encontro entre a camada limite e a superfície livre ocorreu a um comprimento de $124,5 \mathrm{~cm}$, a uma altura de $3,69 \mathrm{~cm}$.

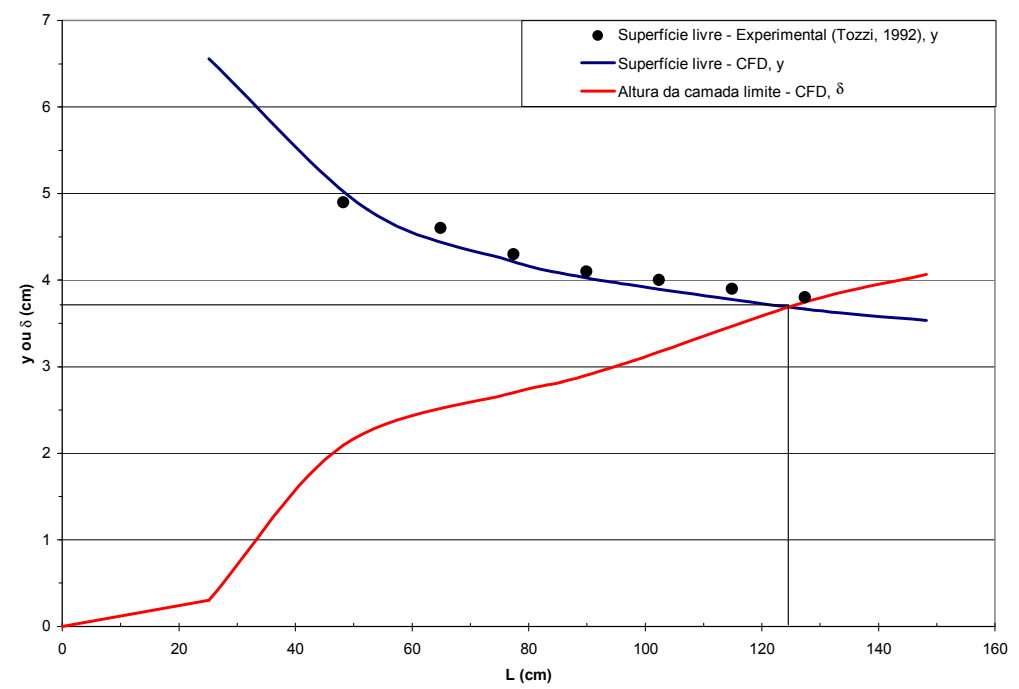

Figura 4.27. Crescimento da camada limite e altura da superfície livre (início a aeração) para vazão de 120,5 1/s.m $\left(k_{a}=2 \mathrm{~cm}\right)$. 
Este mesmo procedimento para determinação do início da aeração do escoamento foi realizado para as outras vazões especifica e rugosidades, utilizando os resultados das simulações. Nas figuras do APÊNDICE D estão apresentados os gráficos para determinação do início da aeração com o desenvolvimento da camada limite e da superfície livre e também os pontos para esta superfície determinados experimentalmente por Tozzi (1992).

$\mathrm{Na}$ tabela 4.6 estão apresentados os resultados de comprimento $\left(L_{a}\right)$ e a espessura da camada limite $(\delta)$ no ponto de início da aeração, para as vazões específica e rugosidades simuladas. Também são mostrados os adimensionais $L_{a} / k_{a}$ e $\delta / L_{a}$ calculados para comparação com os resultados experimentais determinados por Tozzi (op cit.).

Tabela 4.6. Resultados da Simulação Numérica (CFD) para diferentes rugosidades.

\begin{tabular}{cccccc} 
& & \multicolumn{4}{c}{ Vazão específica $(1 / \mathrm{s} / \mathrm{m})$} \\
\cline { 2 - 6 }$k_{a}=2 \mathrm{~cm}$ & 86,1 & 120,5 & 163,5 & 201,4 \\
\hline & $L_{a}(\mathrm{~cm})$ & 95,9 & 124,5 & 161 & 159,4 \\
& $\delta(\mathrm{cm})$ & 3,09 & 3,69 & 4,3 & 5,23 \\
& $L_{a} / k_{a}$ & 47,95 & 62,25 & 80,5 & 79,7 \\
& $\delta / L_{a}$ & 0,0322 & 0,0296 & 0,0267 & 0,0328 \\
\hline \multirow{5}{*}{$k_{a}=3 \mathrm{~cm}$} & $L_{a}(\mathrm{~cm})$ & 84,4 & 116,8 & 122,9 & 136,6 \\
& $\delta(\mathrm{cm})$ & 3,18 & 3,7 & 4,7 & 5,47 \\
& $L_{a} / k$ & 28,13 & 38,93 & 40,97 & 45,53 \\
& $\delta / L_{a}$ & 0,0377 & 0,0317 & 0,0382 & 0,0400 \\
\hline \multirow{5}{*}{$k_{a}=6 \mathrm{~cm}$} & $L_{a}(\mathrm{~cm})$ & 79 & 84,1 & 104,9 & 125,9 \\
& $\delta(\mathrm{cm})$ & 3,32 & 4,41 & 5,1 & 5,69 \\
& $L_{a} / k_{a}$ & 13,17 & 14,02 & 17,48 & 20,98 \\
& $\delta / L_{a}$ & 0,0420 & 0,0524 & 0,0486 & 0,0452 \\
\hline
\end{tabular}

No gráfico da figura 4.28 estão apresentados os pontos dos adimensionais $L_{a} / k_{a}$ e $\delta / L_{a}$ encontrados numericamente neste trabalho e experimentalmente por Tozzi (op cit.) e ainda a curva da equação 4.10. Verifica-se que os resultados para os adimensionais encontrados numericamente, utilizando-se o conceito de início da aeração caracterizada pelo encontro da camada limite com a superfície livre, representaram de forma similar os resultados encontrados por Tozzi (op cit.), fortalecendo mais uma vez a utilização da ferramenta CFD para caracterização deste tipo de escoamento. 


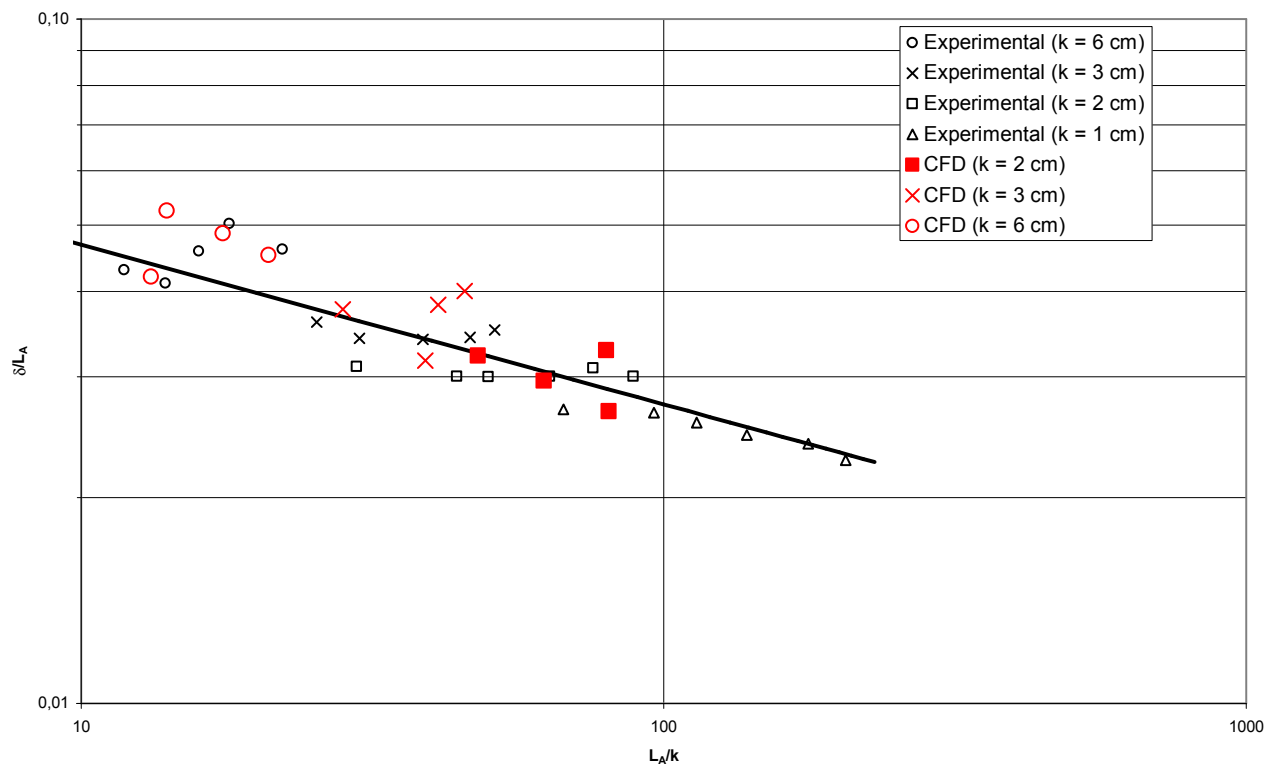

Figura 4.28. Relação entre os adimensionais $L_{a} / k_{a}$ e $\delta / L_{a}$.

Utilizando os dados da posição de início da aeração, $L_{a}$, e altura da camada limite, $\delta$, foram calculados, na tabela 4.7, os valores do adimensional s' (equação 2.36) para as condições de vazões e rugosidades para as três seções para os dados das simulações numéricas na condição de modelo reduzido.

Tabela 4.7. Valores de s'.

\begin{tabular}{|c|c|c|c|c|c|c|}
\hline & & & \multicolumn{4}{|c|}{ Vazão Específica $(\mathrm{I} / \mathrm{s} / \mathrm{m})$} \\
\hline & \multirow[b]{2}{*}{ Seçao } & \multirow[b]{2}{*}{$\mathrm{Li}$} & 86,1 & 120,5 & 163,5 & 201,4 \\
\hline & & & \multicolumn{4}{|c|}{$\mathrm{s}^{\prime}$} \\
\hline \multirow{3}{*}{$\mathrm{ka}=2 \mathrm{~cm}$} & 1 & 148,23 & 16,93 & 6,43 & --- & ---- \\
\hline & II & 198,23 & 33,11 & 19,98 & 8,66 & 7,42 \\
\hline & III & 248,23 & 49,30 & 33,53 & 20,29 & 16,99 \\
\hline \multirow{3}{*}{$\mathrm{ka}=3 \mathrm{~cm}$} & 1 & 148,23 & 20,07 & 8,50 & 5,39 & 2,13 \\
\hline & II & 198,23 & 35,80 & 22,01 & 16,03 & 11,27 \\
\hline & III & 248,23 & 51,52 & 35,52 & 26,67 & 20,41 \\
\hline \multirow{3}{*}{$\mathrm{ka}=3 \mathrm{~cm}$} & 1 & 148,23 & 20,85 & 14,54 & 8,50 & 3,92 \\
\hline & II & 198,23 & 35,91 & 25,88 & 18,30 & 12,71 \\
\hline & III & 248,23 & 50,97 & 37,22 & 28,10 & 21,50 \\
\hline
\end{tabular}

\subsubsection{Estudo da Aeração do Escoamento.}

A variação da aeração do escoamento na seção III da figura 4.19 foi determinada para as vazões específicas $(68,8 \mathrm{1} / \mathrm{s} / \mathrm{m} ; 86,11 / \mathrm{s} / \mathrm{m} ; 120.1 \mathrm{1} / \mathrm{s} / \mathrm{m} ; 163,51 / \mathrm{s} / \mathrm{m}$ e $201,41 / \mathrm{s} / \mathrm{m})$ e rugosidades $\left(k_{a}=2 \mathrm{~cm} ; k_{a}=3 \mathrm{~cm}\right.$ e $k_{a}=6 \mathrm{~cm}$ ). Na figura 4.29 são apresentados os perfis de aeração para as vazões específicas $68,81 / \mathrm{s} / \mathrm{m}$ e $86,11 / \mathrm{s} / \mathrm{m}$ com rugosidade $k_{a}$ igual a $2 \mathrm{~cm}$ e comparados com as equações 2.41 e 2.43, propostas respectivamente por Wood et. al (1989) e 
Chanson et. al (2004). Os resultados para outras configurações de vazão específica e rugosidades estão apresentados nas figuras do APÊNDICE E.

Para determinação dos perfis de aeração do escoamento em vertedouros em degraus foi necessária a realização do refinamento da malha, utilizando o gradiente de concentração de ar como parâmetro. Pode-se verificar na figura 4.29 que as duas equações teóricas, determinadas utilizando-se os parâmetros dos resultados da simulação, se aproximam dos valores de concentração determinados numericamente, sendo a equação 2.41 a que melhor representou o perfil de concentração.

Na equação 2.41 é necessária a determinação dos parâmetros $\beta$ e $\gamma$ para a aproximação da curva teórica à curva resultante da simulação. Os valores destes parâmetros foram determinados para a variação da concentração de ar na seção de estudo III, para as vazões e rugosidades de estudo. Na tabela 4.8 são apresentados os valores da concentração média e dos valores dos parâmetros $\beta$ e $\gamma$.
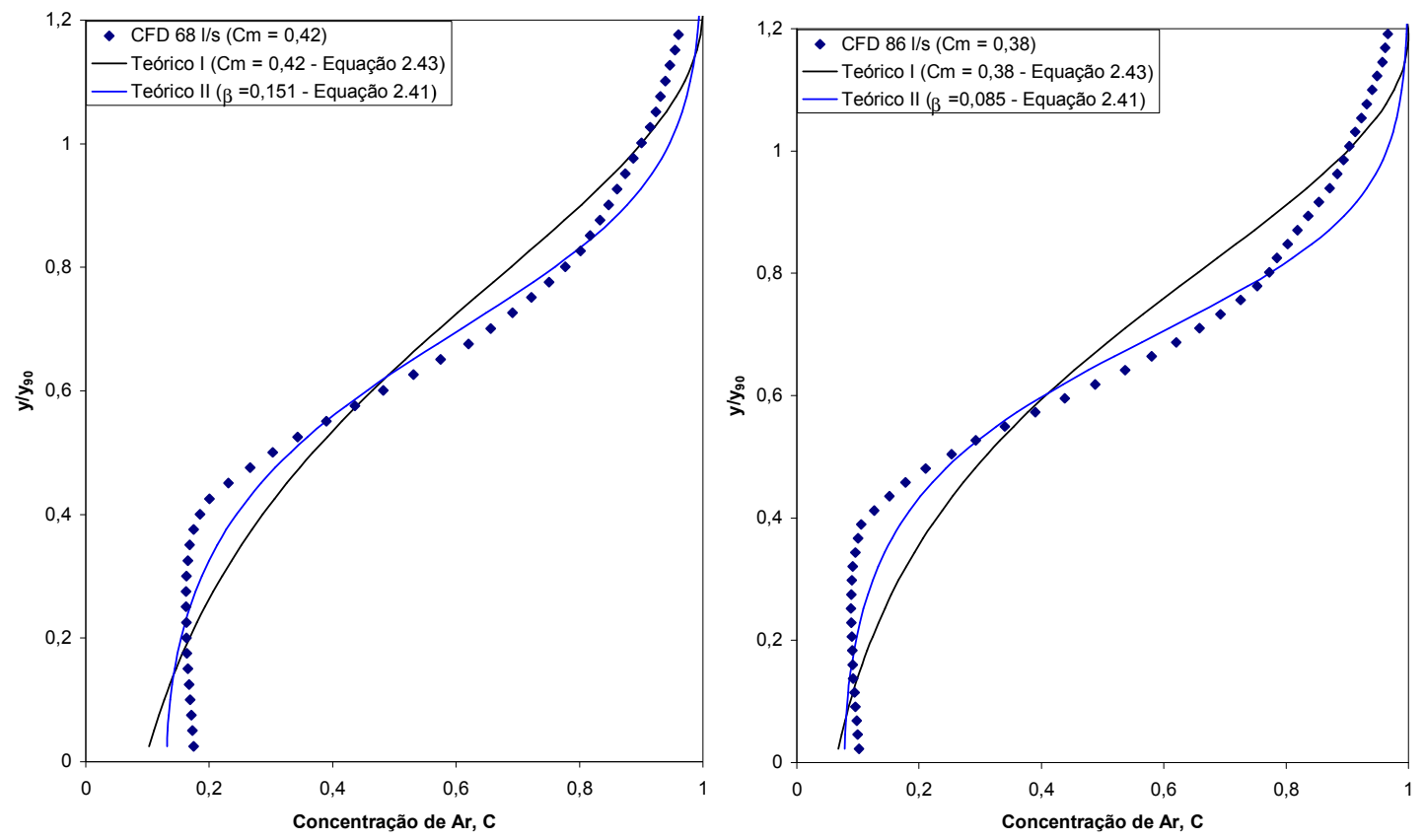

Figuras 4.29. Perfil de aeração do escoamento na seção III $\left(68,81 / \mathrm{s} / \mathrm{m}\right.$ e $\left.86,11 / \mathrm{s} / \mathrm{m}, k_{a}=2 \mathrm{~cm}\right)$. 
Tabela 4.8. Valores da concentração média e dos parâmetros $\beta$ e $\gamma$.

\begin{tabular}{ccccccc} 
& & \multicolumn{5}{c}{ Vazão específica $(1 / \mathrm{s} / \mathrm{m})$} \\
\cline { 3 - 7 } & & 68,8 & 86,1 & 120,5 & 163,5 & 201,4 \\
\hline \multirow{3}{*}{$k_{a}=2 \mathrm{~cm}$} & $C_{\text {médio }}$ & 0,421 & 0,378 & 0,289 & 0,238 & 0,211 \\
& $\beta$ & 0,151 & 0,085 & 0,024 & 0,011 & 0,007 \\
& $\gamma$ & 7,91 & 9,61 & 12,23 & 12,66 & 12,94 \\
\hline \multirow{3}{*}{$k_{a}=3 \mathrm{~cm}$} & $C_{\text {médio }}$ & 0,464 & 0,418 & 0,314 & 0,251 & 0,218 \\
& $\beta$ & 0,256 & 0,137 & 0,034 & 0,015 & 0,011 \\
& $\gamma$ & 6,39 & 8,34 & 11,46 & 12,38 & 12,04 \\
\hline \multirow{3}{*}{$k_{a}=6 \mathrm{~cm}$} & $C_{\text {médio }}$ & 0,497 & 0,438 & 0,329 & 0,272 & 0,248 \\
& $\beta$ & 0,354 & 0,205 & 0,061 & 0,023 & 0,015 \\
& $\gamma$ & 5,62 & 6,77 & 9,24 & 11,40 & 12,21 \\
\hline
\end{tabular}

Os parâmetros encontrados para o ajuste da equação 2.41 foram comparados com duas curvas propostas por Straub e Anderson (1958) para o escoamento em um canal liso. $\mathrm{Na}$ figura 4.30 é apresentado um gráfico que mostra a relação entre a concentração média $\left(C_{m e ́ d i a}\right)$ e o parâmetro $\gamma \cdot \operatorname{Cos}(\phi)$. Verifica-se que a ordem de grandeza dos valores encontrados numericamente são próximos aos valores experimentais, determinados por Straub e Anderson (op cit.), sendo os resultados numéricos maiores. Os resultados para as diferentes rugosidades $\left(k_{a}=2 \mathrm{~cm} ; k_{a}=3 \mathrm{~cm}\right.$ e $\left.k_{a}=6 \mathrm{~cm}\right)$ diferenciaram-se entre si, tanto no formato da curva, como na proximidade à curva teórica. Esta diferenciação pode ser atribuída ao processo de refinamento da malha, para melhor caracterizar os perfis de aeração, o ocorre em regiões de diferentes tamanhos de malha para as diferentes vazões específicas.

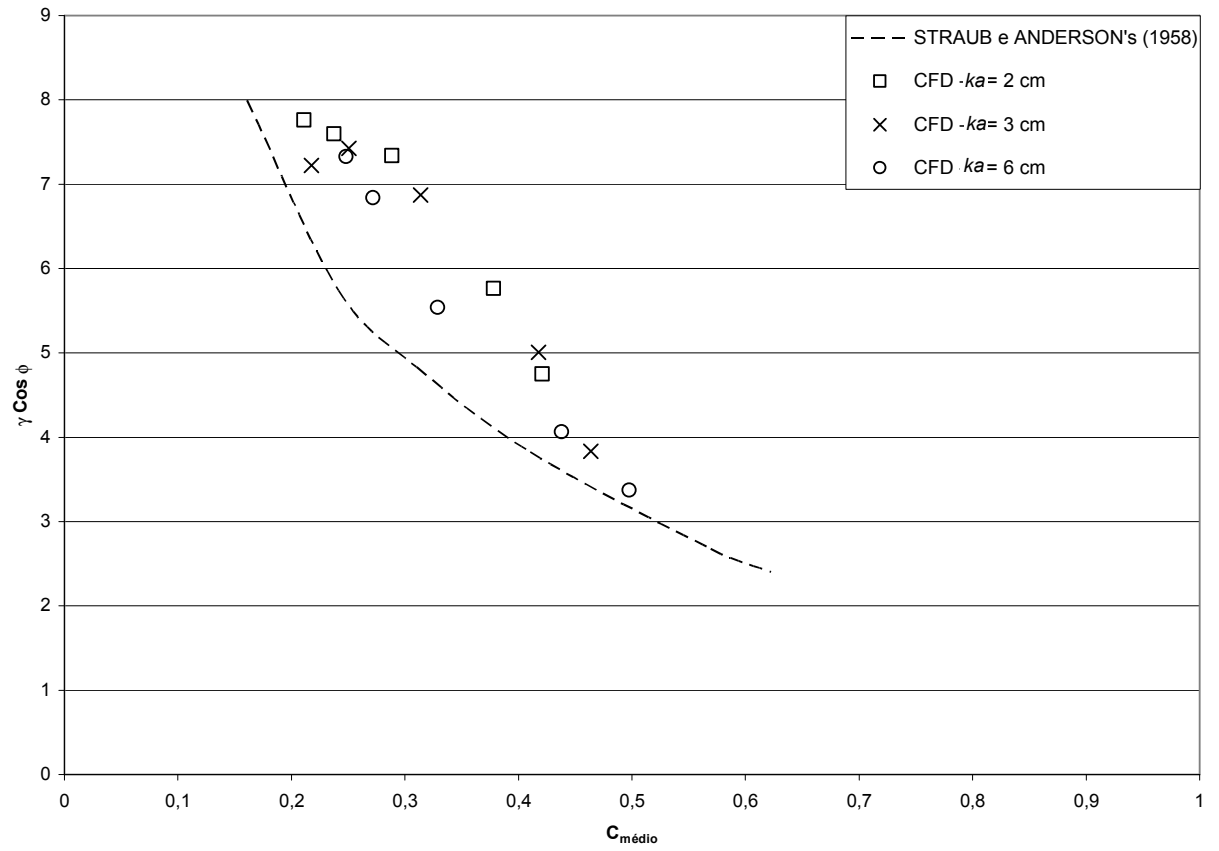

Figura 4.30. Relação entre a concentração média e $\gamma \cdot \operatorname{Cos}(\phi)$. 
O parâmetro $\beta$ em relação à concentração média também foi comparado com uma curva proposta por Straub e Anderson (1958). Na figura 4.31 é apresentada esta comparação e verifica-se que os pontos determinados na simulação numérica representam os resultados de forma similar à curva experimental de Straub e Anderson (op cit.), sendo os valores do parâmetro $\beta$ menores para os dados numéricos. Na comparação entre os resultados numéricos, não se visualizou uma grande diferença entre o comportamento das curvas para as diferentes rugosidades.

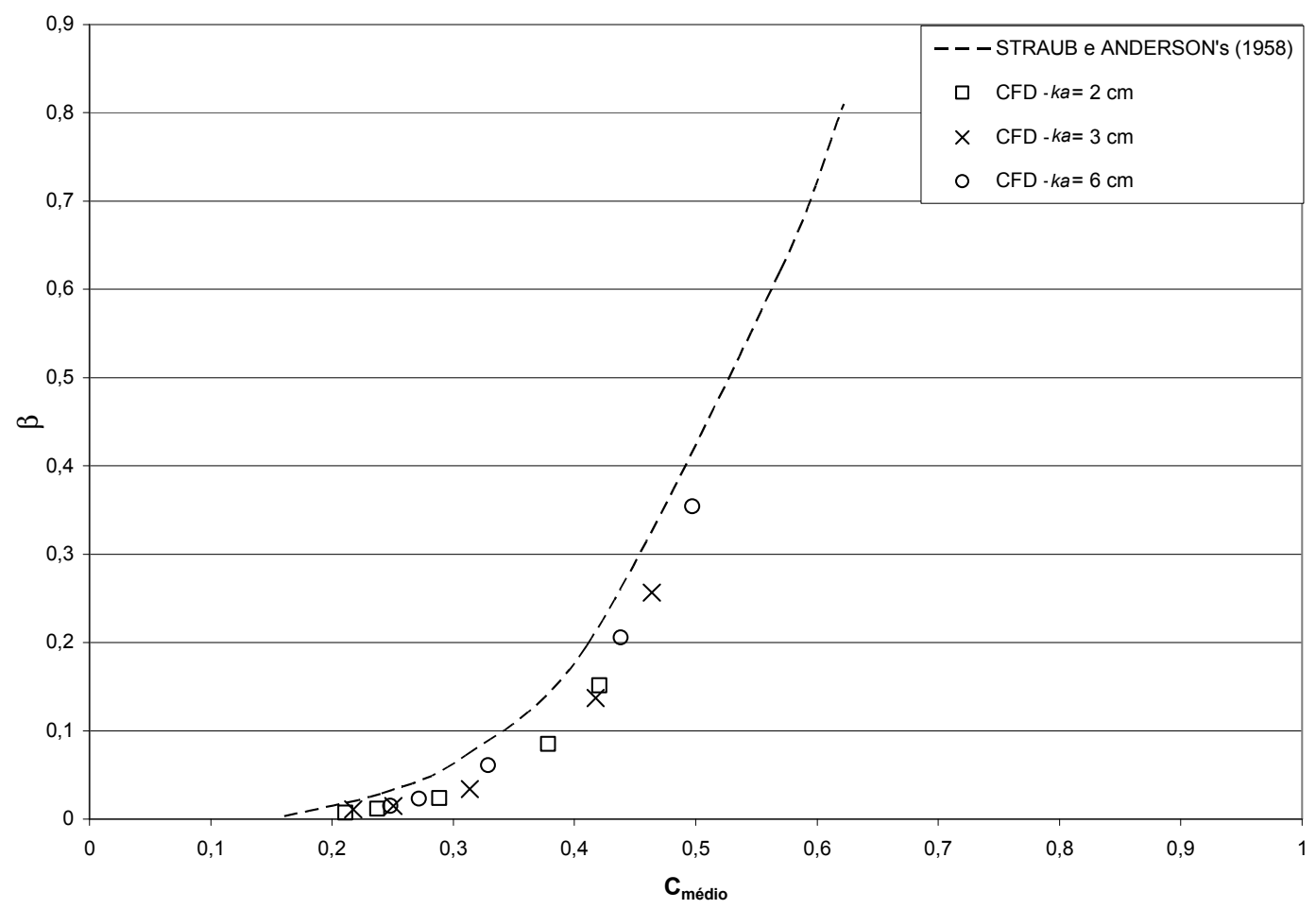

Figura 4.31. Relação entre a concentração média e o parâmetro $\beta$.

Os resultados obtidos numericamente para a concentração média de ar na seção de estudo III em relação ao parâmetro $H_{b a r r} / y_{c}$, foram comparados com uma equação teórica proposta por Matos (2000) para vertedouro em degrau - equação 2.48 e com os resultados experimentais de Tozzi (1992), Matos (op cit) e Diez-Cascon et al (1991). Estas comparações são apresentadas na figura $4.32 \mathrm{em}$ que se pode visualizar que os resultados numéricos possuem a mesma tendência que os resultados experimentais de Tozzi (op cit.) e de Matos (op cit.), se aproximando da equação proposta por Matos (2000), sendo os resultados para a rugosidade maior $\left(0,27<k_{a} / D_{h} \leq 0,57\right.$ ou $k_{a}=6 \mathrm{~cm}, D_{h}$ o diâmetro hidráulico) as que se aproximam melhor desta curva. Comparando-se os adimensionais $k_{a} / D_{h}$ para os resultados numéricos e experimentais, verifica-se que a concentração de ar obtida numericamente no CFD está aquém dos resultados obtidos da forma experimental, pois segundo Matos (op cit.) a 
concentração de ar cresce com o aumento do adimensional $k_{a} / D_{h}$. Acredita-se que esta diferenciação entre os resultados para as diferentes rugosidades pode ser atribuída ao desenvolvimento do perfil de aeração, que deve estar mais próximo da região uniforme do escoamento para a maior rugosidade e em desenvolvimento para as menores rugosidades, nesta mesma seção de estudo.

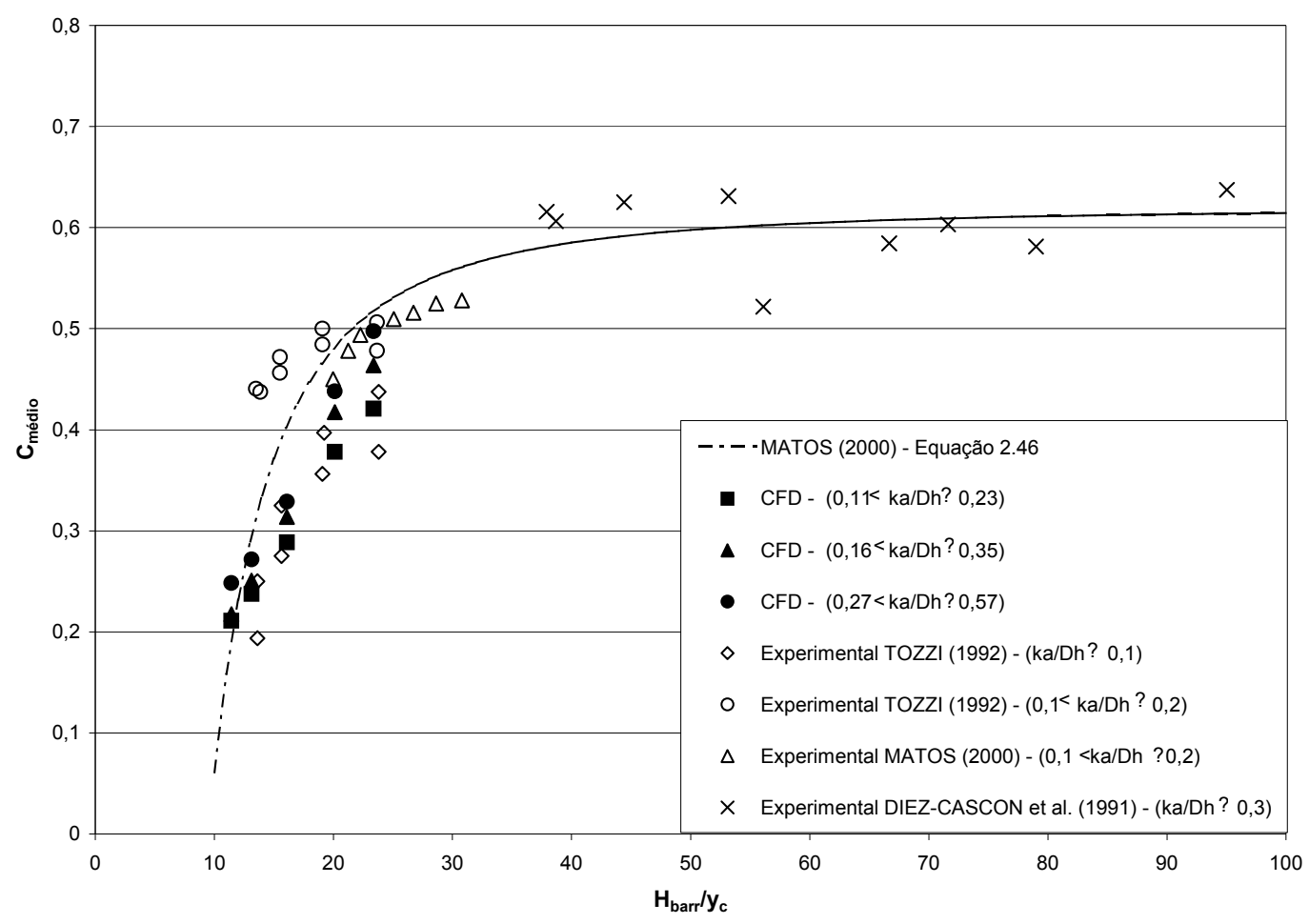

Figura 4.32. Relação entre a concentração média e o adimensional $H_{b a r r} / y_{c}$.

\subsubsection{Estudo da Cavitação em Vertedouro em Degraus.}

Segundo Novák et al (1990), em um modelo em escala reduzida não ocorre a cavitação, mesmo que essa condição transportada ao protótipo indique a ocorrência da cavitação, isso porque a pressão atmosférica ambiente não é reduzida para a condição do modelo.. Por exemplo, se a escala do modelo for 1:25, e existir uma carga de pressão relativa negativa de 0,5 m.c.a., a cavitação pode ocorrer no protótipo, pois a carga de pressão relativa neste mesmo ponto deverá ser dado pela multiplicação $25 \times-0,5=-12,5$ m.c.a. abaixo da pressão atmosférica, o que é fisicamente impossível. Com a cavitação a carga de pressão iria atingir o valor mínimo possível de aproximadamente -10 m.c.a (pressão de vapor da água).

Com base nestes conceitos teóricos de efeito escala para a pressão, foi possível comparar os resultados numéricos realizados para as configurações utilizadas por Tozzi (1992), na condição de modelo reduzido e protótipo. Na tabela 4.9 as pressões mínimas 
encontradas na simulação numérica do protótipo foram comparadas com as pressões mínimas da simulação do modelo reduzido. Se for considerado que a cavitação ocorre para valores de pressão menores que a pressão de vapor de $-98000 \mathrm{~Pa}$ para o protótipo e $-6533 \mathrm{~Pa}$ para o modelo reduzido, verifica-se que não estaria ocorrendo cavitação tanto para a condição do modelo reduzido quanto para o protótipo.

Na tabela 4.9 apresenta-se ainda a divisão entre a pressão do protótipo e a do modelo reduzido, verificando-se que esta relação esta próxima ao valor de 15 que é a relação de escala do modelo reduzido (1:15).

Tabela 4.9. Relação de Pressão mínima entre da simulação do protótipo e do modelo.

\begin{tabular}{cccc}
\hline $\begin{array}{c}\text { Vazão do Modelo } \\
\text { (Vazão do Protótipo) }\end{array}$ & $\mathrm{P}_{\text {min,Modelo }}(\mathrm{Pa})$ & $\mathrm{P}_{\text {min, Protótipo }}(\mathrm{Pa})$ & Relação $\left(\mathrm{P}_{\text {prot }} / \mathrm{P}_{\text {mod }}\right)$ \\
\hline & $\mathrm{k}_{\text {mod }}=2 \mathrm{~cm} \mathrm{ou} \mathrm{k}_{\text {prot }}=30 \mathrm{~cm}$ \\
\hline $201,4 \mathrm{l} / \mathrm{s} / \mathrm{m}\left(11,7 \mathrm{~m}^{3} / \mathrm{s} / \mathrm{m}\right)$ & $-2239,78$ & $-31654,5$ & 14,13 \\
$163,5 \mathrm{l} / \mathrm{s} / \mathrm{m}\left(9,5 \mathrm{~m}^{3} / \mathrm{s} / \mathrm{m}\right)$ & $-1784,63$ & $-26532,5$ & 14,87 \\
$120,5 \mathrm{l} / \mathrm{s} / \mathrm{m}\left(7,0 \mathrm{~m}^{3} / \mathrm{s} / \mathrm{m}\right)$ & $-1436,74$ & $-21786,7$ & 15,16 \\
$86,1 \mathrm{l} / \mathrm{s} / \mathrm{m}\left(5,0 \mathrm{~m}^{3} / \mathrm{s} / \mathrm{m}\right)$ & $-1176,99$ & $-17855,3$ & 15,17 \\
\hline
\end{tabular}

As simulações no modelo numérico para a condição do protótipo foram realizadas para quatro vazões, para a rugosidade de $30 \mathrm{~cm}\left(11,7 \mathrm{~m}^{3} / \mathrm{s} / \mathrm{m} ; 9,5 \mathrm{~m}^{3} / \mathrm{s} / \mathrm{m} ; 7,0 \mathrm{~m}^{3} / \mathrm{s} / \mathrm{m}\right.$ e 5,0 $\mathrm{m}^{3} / \mathrm{s} / \mathrm{m}$ ). Nas figuras 4.33 e 4.34 são representadas as regiões onde a pressão resultante da simulação, para a maior vazão (o mais crítico) de forma a identificar os locais mais propícios à existência de cavitação, buscando minimizar os efeitos deste fenômeno, possibilitando a utilização de vazões maiores em projetos.

Verificam-se nos detalhes das figuras 4.33 e 4.34 que as menores pressões ocorrem nas partes inferiores dos espelhos dos degraus, sendo o menor valor encontrado localizado no espelho do primeiro degrau (figura 4.34). É interessante também identificar regiões de baixas pressões no centro das recirculações, tanto no início como no fim do vertedouro. Uma solução para estes problemas seria a existência de um aerador de fundo no inicio do vertedouro, de forma a aumentar a concentração de ar próximo às paredes dos degraus, minimizando os problemas da cavitação. Esta solução foi estudada mais adiante neste trabalho. 


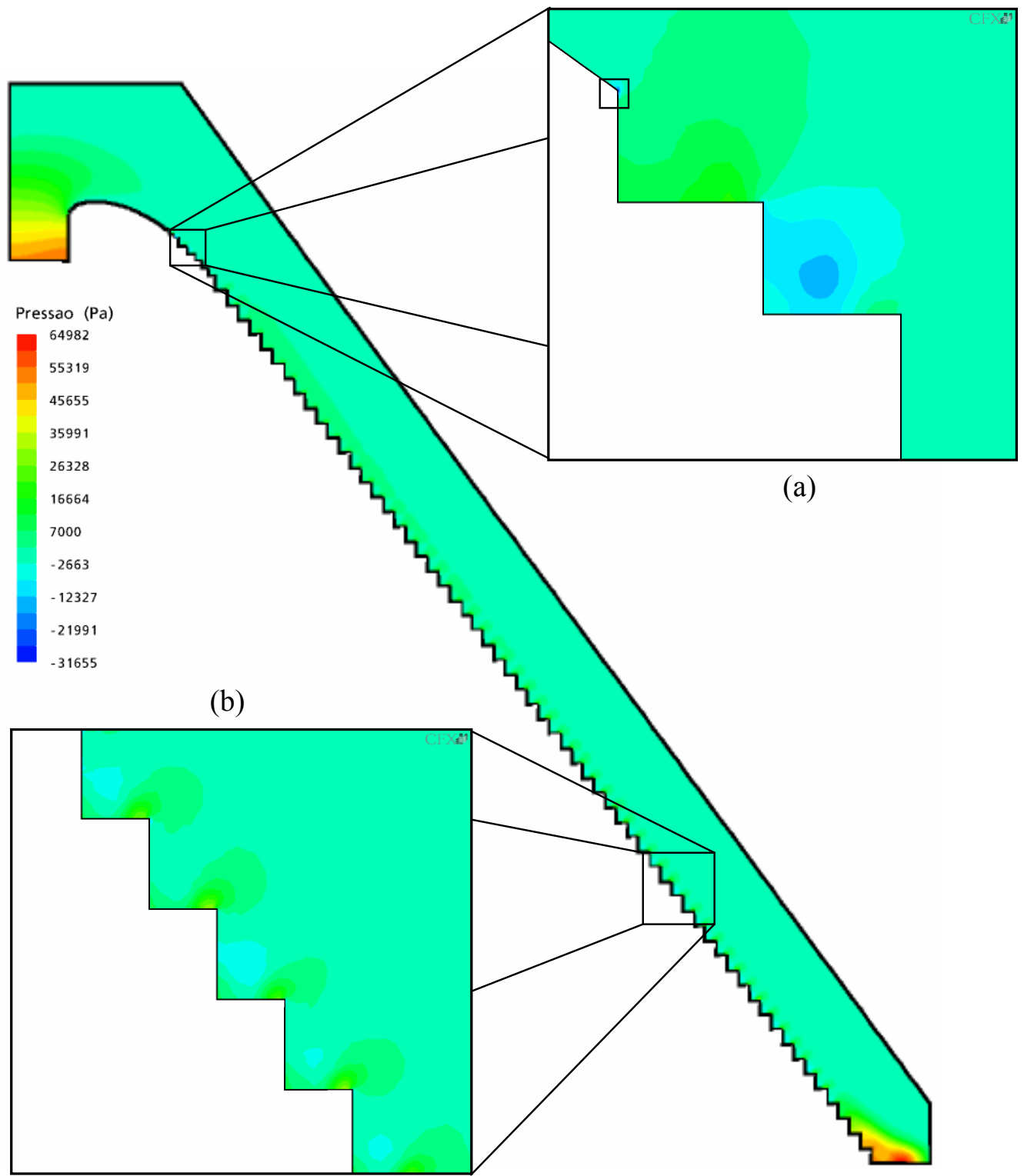

Figura 4.33. Pressão nos degraus.

(a) - Na região de transição dos degraus, (b) - Na região próxima ao fim do vertedouro. 


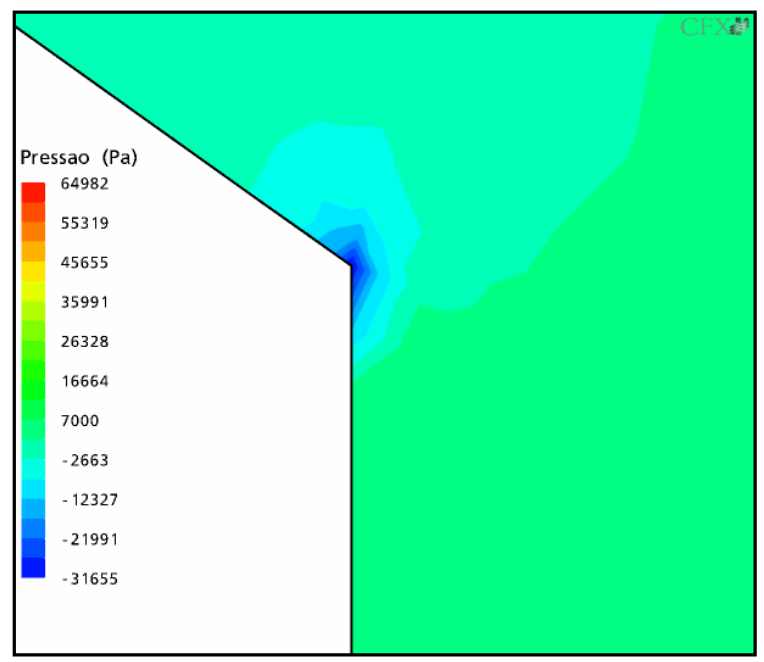

Figure 4.34. Pressão nos degraus - No início dos degraus.

\subsection{Estudo da Mudança de Escoamento do Regime Skimming Flow para Nappe Flow.}

Um estudo inicial foi realizado para determinação da mudança de escoamento do regime nappe flow para skimming flow. Seguindo os critérios descritos na literatura, foram realizadas simulações para duas configurações de degraus variando-se a vazão, com o intuito de determinar o inicio do escoamento tipo skimming. Para minorar o tempo de cálculo, as simulações foram realizadas para as configurações com somente dois ou três degraus e com geometrias bidimensionais. Nos quadros das figuras abaixo estão representadas as superfícies livres para as simulações com $h / l$ igual a 0,2 e 0,5 . Para a inclinação $h / l$ de 0,2 foram realizadas as simulações com $y_{c} / h$ de 0,$5 ; 0,75 ; 1,0$ e 2,0. Para h/1 de 0,5 realizaram-se com $y_{c} / h$ de 0,$5 ; 0,75$ e 1,0 .

Nos quadros da figura 4.35 visualiza-se a diminuição da bolha de ar sob o salto e o aumento do comprimento do jato para valores maiores de $y_{c} / h$. Para o maior valor de $y_{c} / h$ a bolha de ar é inexistente, mas ainda existe uma ondulação na superfície livre.

$\mathrm{Na}$ figura 4.36 ocorreu um fenômeno interessante no primeiro quadro, pois após o impacto com o primeiro degrau ocorre um salto em que o jato não interceptou o degrau adjacente, isso pode ocorrer nos modelos experimentais. Isso ocorre devido à grande aceleração ocorrida antes da chegada ao degrau e ao valor alto do ângulo de impacto neste primeiro degrau. Este mesmo fenômeno não foi visualizado nas outras simulações, pois o ângulo de impacto era menor. 


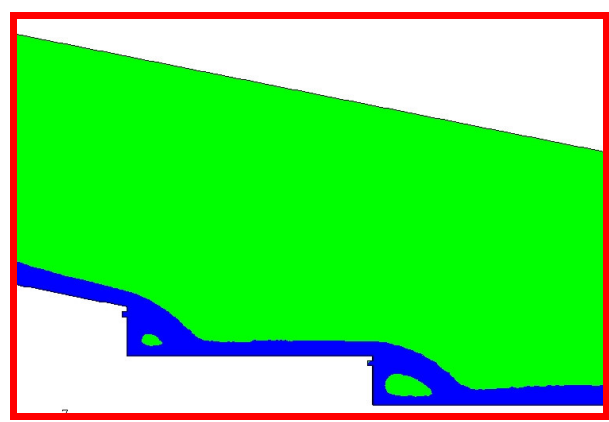

$\left(y_{c} / h=0,5\right)$

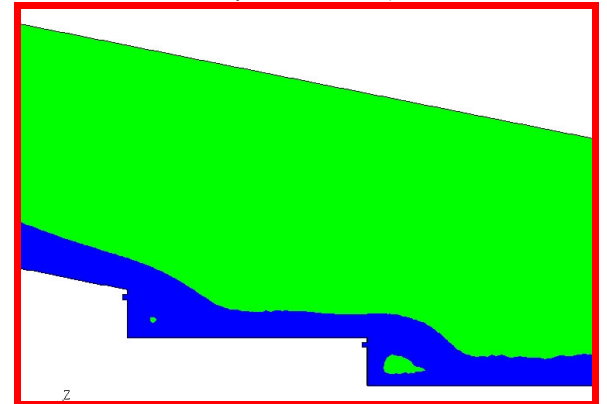

$\left(y_{c} / h=1,0\right)$

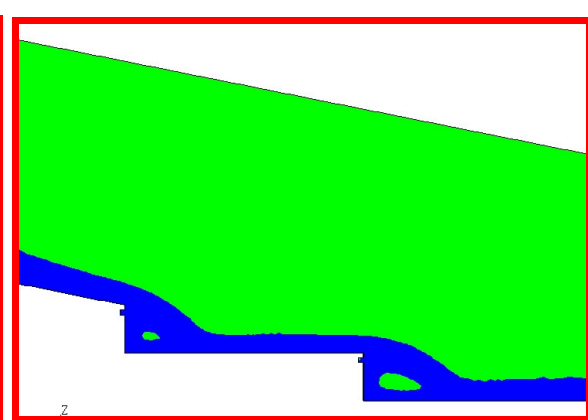

$\left(y_{c} / h=0,75\right)$

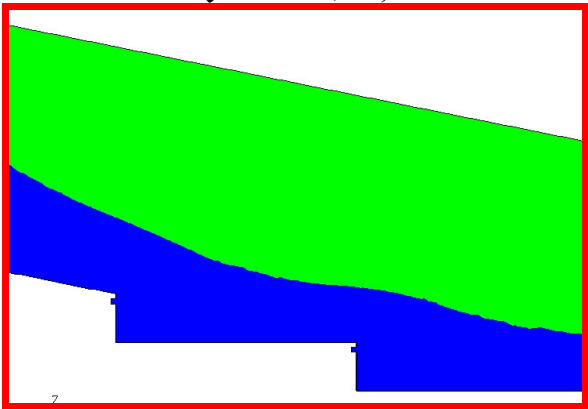

$\left(y_{c} / h=2,0\right)$

Figura 4.35. Mudança de Regime $(h / l=0,2)$.

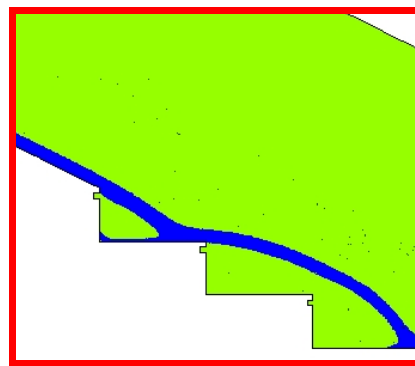

$\left(y_{c} / h=0,5\right)$

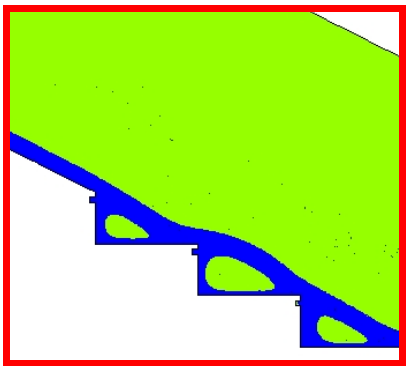

$\left(y_{c} / h=0,75\right)$

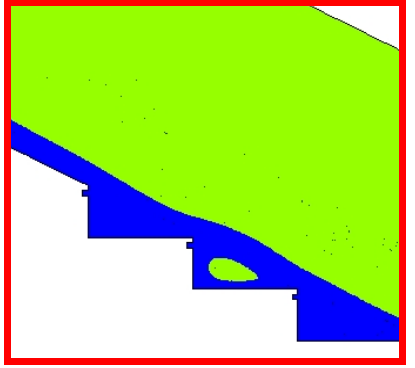

$\left(y_{c} / h=1,0\right)$

Figura 4.36. Mudança de Regime $(h / l=0,5)$.

\subsection{Aplicação da Ferramenta CFD em Escoamento em Canal com Forte Declividade.}

Nove experimentos apresentados por Lima (2003) foram simulados utilizando as ferramentas de fluidodinâmica computacional. O trabalho de Lima (op cit.) constituiu-se em quantificar a concentração de bolhas de ar na zona de transição e aeração do escoamento, através de técnicas de Raios Gama, e a determinação das intensidades de turbulência, tensões de Reynolds, vorticidade, velocidades médias, e outras grandezas do escoamento, através de métodos de visualização do escoamento por PIV (Particle Image Velocimetry) - Figura 4.37. 


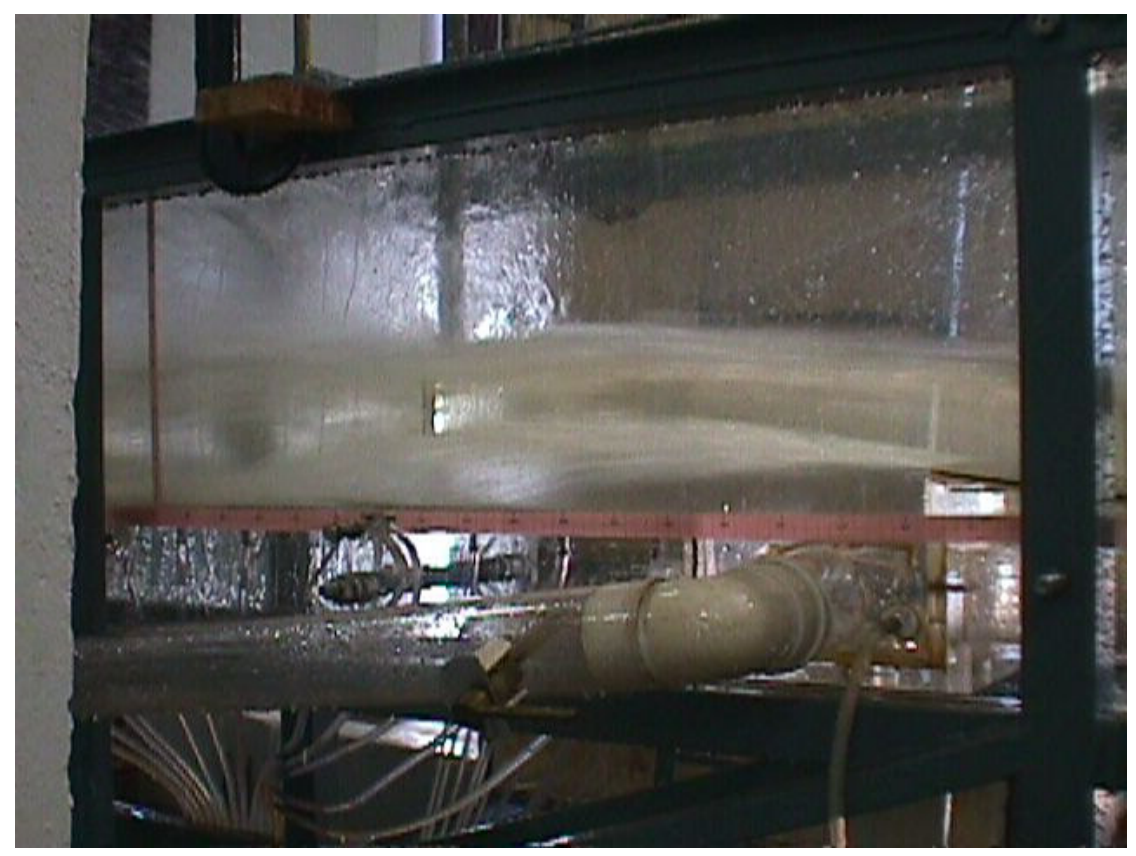

Figura 4.37. Bancada experimental de Lima (2003).

Vazão de Ar Sob o Jato.

$\mathrm{O}$ ar incorporado no escoamento pode ser avaliado para a região de entrada de ar sob o jato. Embora exista a aeração na superfície superior e inferior da cunha de aeração, na presente análise, é considerada somente a aeração da parte inferior do escoamento.

Seis métodos de determinação da descarga de ar sobre o jato serão comparados. Estes métodos são apresentados a seguir:

Carvalho (1997) realizou uma calibração de um micro-manômetro usando um bocal na entrada do tubo de aeração e determinou a distribuição de velocidades com um tubo de Pitot, resultando na seguinte equação:

$$
q_{a r}=0,01593 . \Delta h_{\text {estatico }}^{0,5089}
$$

onde: $\Delta h_{\text {estático }}$ é a pressão estática na cavidade do bocal (mm de água) e $q_{a r}$ é a vazão de ar $\left(\mathrm{m}^{3} / \mathrm{s}\right)$.

Lima (2003) propôs uma equação através da correlação dos dados de velocidade, comprimento do jato e a altura da lamina de água (equação 4.12).

$$
q_{a r, L I M A}=\left(\frac{V^{2}}{L}\left(2,01928+0,10284 \cdot h-0,001523 \cdot h^{2}+7,2466 \cdot 10^{6} \cdot h^{3}\right)\right)^{1 / 0,6}
$$

A vazão de ar foi calculada por Lima (2003) usando a variação da entrada de ar ao longo do escoamento sob o jato (por meio da determinação a concentração de ar com sonda de raio Gama). A equação 4.13 representa a vazão de ar $\mathrm{q}_{\text {ar } 1}$ para este método: 


$$
q_{a r 1}=C_{\text {média }} \cdot B \cdot V \cdot\left(\frac{\Delta \delta}{\Delta x} \frac{L}{2}\right)
$$

onde: $C_{\text {média }}$ é a concentração de ar média entra duas seções de estudos, $B$ é a largura do canal, $\Delta x$ é a distância entre duas seções, $V$ é a velocidade media do jato, $\Delta \delta$ é a variação entre altura de aeração em duas seções, considerando em cada seção o limite de concentração de ar $>5 \%$.

Ervine et al (1995) propôs uma equação para determinar a vazão de ar. O autor assumiu que a vazão de ar é proporcional ao comprimento do jato e as flutuações transversais das velocidades $\left(w^{\prime}\right)$. Através destas condições a equação (4.14) foi determinada:

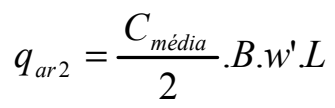

\section{Relação Matemática Qw/Qair.}

O professor Dr. Podalyro Amaral de Souza da Escola Politécnica da Universidade de São Paulo, propôs a seguinte modelação matemática para a relação entre a Vazão de Ar e a Vazão de Água, Lima (2003):

Para a obtenção da vazão de ar faz-se necessária a aplicação da Primeira Lei da Termodinâmica, já simplificada na forma da equação de Bernoulli para o volume de controle que coincide com o tubo aerador:

$$
\frac{p_{a t m}}{\rho_{a r} \cdot g}+\frac{V^{2}}{2 \cdot g}=\frac{p}{\rho_{a r} \cdot g}+\frac{V^{2}}{2 \cdot g}+\Delta H+K \frac{V^{2}}{2 \cdot g}
$$

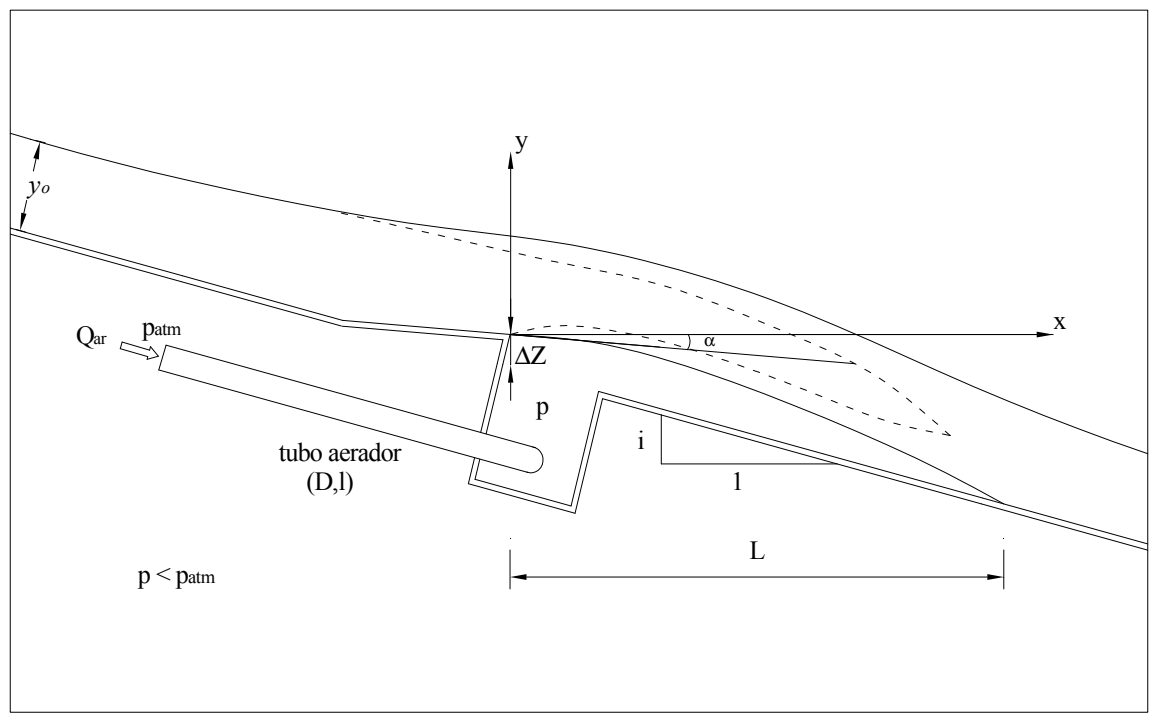

Figura 4.38. Esquema do Modelo.

$$
-\frac{p}{\rho_{a r} \cdot g}=\frac{8 \cdot Q_{a r}^{2}}{\pi^{2} D^{4} g}\left(\frac{f_{a r} \cdot l_{t}}{D}+K\right)
$$


Definindo $C_{\text {média }}$ como;

$$
\frac{1}{C_{\text {média }}^{2}}=\left(\frac{f_{a r} \cdot l_{t}}{D}+K\right)
$$

A equação 4.12 torna-se:

$$
Q_{a r}=C_{\text {média }} \frac{\pi \cdot D^{2}}{4} \sqrt{-\frac{2 \cdot p}{\rho_{a r}}}
$$

em que: $p$ é a pressão reinante na cavidade gerada pela deflexão do jato $\left(p-p_{a t m}\right), \rho_{a r}$ é a massa específica do ar, g é a aceleração da gravidade, $V$ é a velocidade média no tubo aerador, $\Delta H$ é perda de carga no tubo de aeração, $K$ é o somatório dos coeficientes de perdas de carga localizadas, $D$ é o diâmetro do tubo aerador, $l_{t}$ é o comprimento do tubo aerador, $f_{a r}$ é o fator de cisalhamento associado à perda de carga distribuída no tubo aerador.

A vazão de água $Q_{\text {água }}$ pode ser expressa pela velocidade de um jato de água. Usando-se a equação da balística, tem-se:

$$
\begin{aligned}
& y=\left(V_{j} \cdot \sin \alpha\right) \cdot t-\frac{1}{2} \cdot g \cdot t^{2} \\
& x=\left(V_{j} \cdot \cos \alpha\right) \cdot t
\end{aligned}
$$

Substituindo a equação 4.20 na equação 4.19, obtêm-se:

$$
y=\frac{V_{j} \cdot \sin \alpha}{V_{j} \cdot \cos \alpha} \cdot x-\frac{1}{2} \cdot g^{\prime} \cdot \frac{x^{2}}{V_{j}^{2} \cdot \cos ^{2} \alpha}
$$

A aceleração $g$ ' não é exatamente a aceleração gravitacional, trata-se de uma aceleração fictícia que, além da aceleração gravitacional é composta também pelo efeito da pressão $p$ sob o jato. Este efeito propicia uma deflexão mais acentuada na trajetória do jato.

Quando $x=L$ e $y=-(\Delta Z+i . L)$ ocorre o impacto do jato como o fundo, obtendo-se:

$$
-(\Delta Z+i . L)=L \cdot \tan \alpha-\frac{1}{2} \cdot g^{\prime} \cdot \frac{L^{2}}{V_{j}^{2} \cdot \cos ^{2} \alpha}
$$

Então a velocidade $V_{j}$ é:

$$
V_{j}=\sqrt{\frac{g^{\prime} L^{2}}{2 \cdot[L .(\tan \alpha+i)+\Delta Z] \cos ^{2} \alpha}}
$$

Desprezando-se a curvatura do jato, a força aplicada pela pressão $\mathrm{p}$ contra o jato é dada por: $p . B . L \sqrt{1+i}$. Esta força é perpendicular ao fundo do canal. A componente desta força na direção vertical é p.B.L. Se esta força for concebida como um efeito da diferença em relação à ação gravitacional real e ação gravitacional fictícia, pode-se fazer: 
p.B.L $\approx \rho .\left(g-g^{\prime}\right) . L . B . y_{o}$

$g^{\prime}=g-\frac{p}{\rho \cdot y_{o}}$

A velocidade $V_{j}$ torna-se:

$$
V_{j}=\frac{L}{\cos \alpha} \sqrt{\frac{\rho \cdot g \cdot y_{o}-p}{2 \cdot[L \cdot(\tan \alpha+i)+\Delta Z] \rho \cdot y_{o}}}
$$

A vazão de água por ser expressa como:

$$
Q_{\text {agua }}=\frac{B \cdot L \cdot y_{o}}{\cos \alpha} \sqrt{\frac{\rho \cdot g \cdot y_{o}-p}{2 \cdot[L \cdot(\tan \alpha+i)+\Delta Z] \rho \cdot y_{o}}}
$$

A razão entre a vazão de ar e a vazão de água poder se obtida por:

$$
\frac{Q_{a r}}{Q_{\text {agua }}}=\frac{C_{\text {média }} \cdot \pi \cdot D^{2} \cdot \cos \alpha}{4 \cdot B \cdot L \cdot y_{o}} \sqrt{-\frac{4 \cdot p \cdot[L \cdot(\tan \alpha+i)+\Delta Z]}{\rho_{a r}\left(g-\frac{p}{\rho \cdot y_{o}}\right)}}
$$

Resultado da Simulação e Análise.

As propostas deste estudo são: Primeiramente, pretende-se demonstrar que uma complexa ferramenta computacional pode ser utilizada para simulação do escoamento de um aerador de fundo. Em segundo lugar, pretende-se comparar os resultados numéricos com dados experimentais em termos de aeração do escoamento e do perfil de velocidade.

Na solução numérica para este problema utilizou-se o Modelo de Tensão de Reynolds como modelo de turbulência. E o modelo multifásico utilizado para o cálculo foi o Modelo de Superfície Livre com a opção com o Coeficiente de Tensão Superficial.

A figura 4.39 representa o formato esperado para a cunha de aeração que se desenvolve no escoamento de um aerador de fundo, e as seções indicadas, $\mathrm{S} i$, correspondem às seções em os resultados de aeração foram quantificas, utilizando uma sonda de Césio. Já a seção $\mathrm{V}_{1}$ indica a seção em que foi quantificada a velocidade com o LASER. 


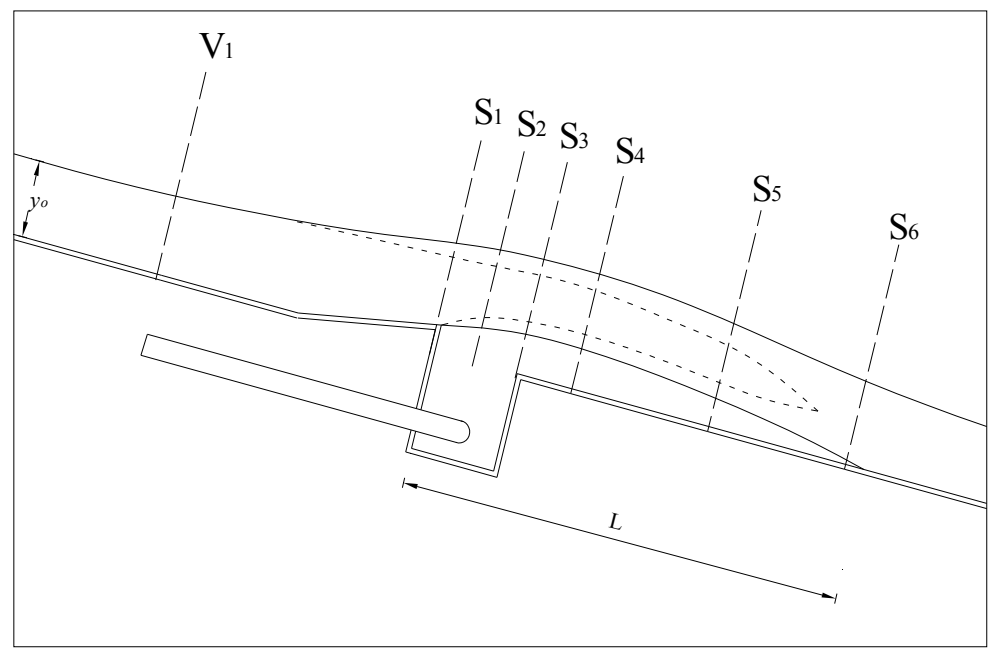

Figura 4.39. Seções de interesse para o estudo.

A malha inicial utilizada para a simulação possui elementos que variam de 1 a $10 \mathrm{~cm}$, como pode ser visualizado na figura 4.40. Os menores elementos localizam-se próximos à parede de fundo para melhor caracterizar o escoamento nesta região de interesse.

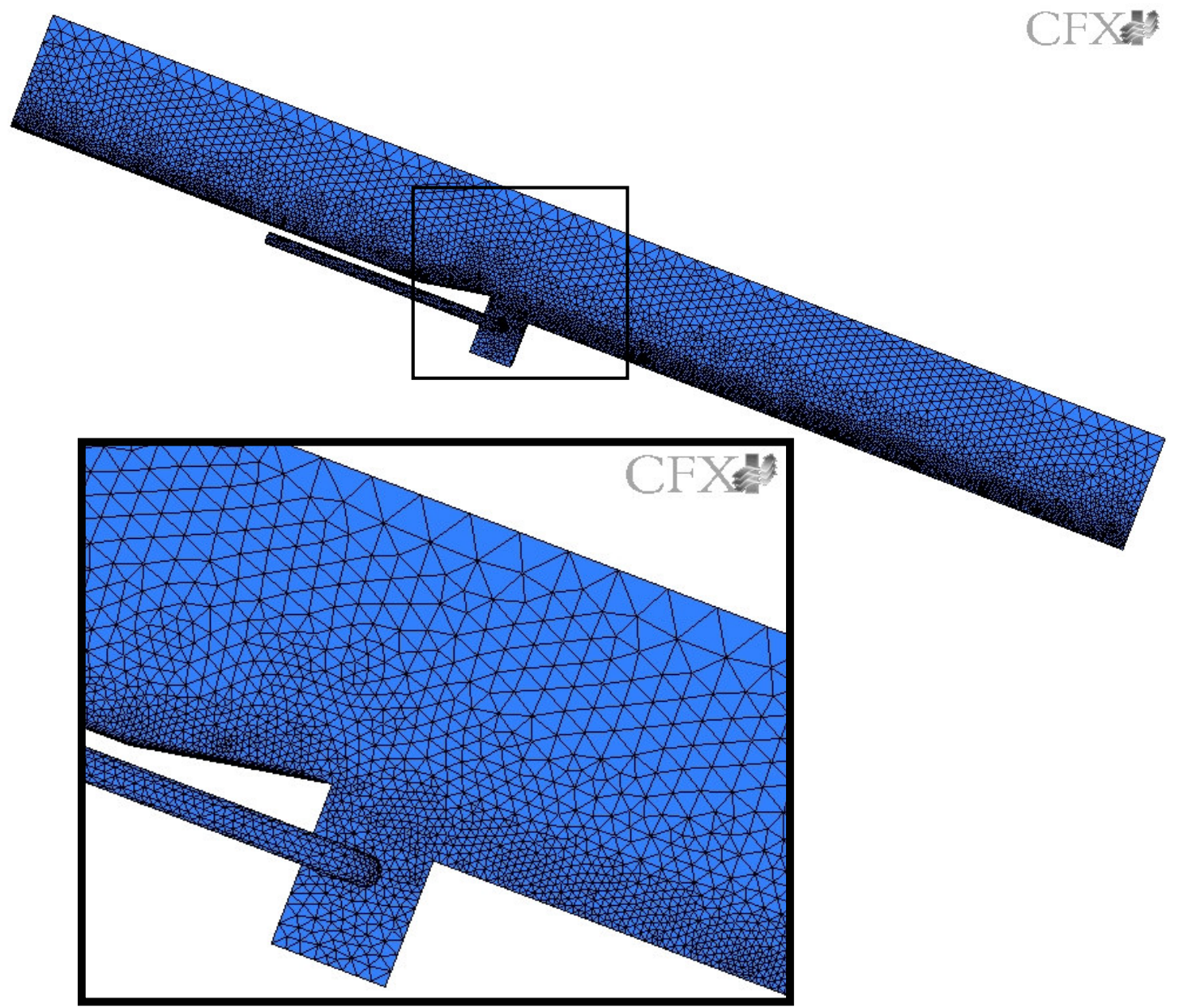

Figura 4.40. Malha Inicial Usada na Simulação Numérica. 
Após a simulação nestas condições de malha verificou-se que a interface na superfície livre apresentava-se de forma muito difusa. De acordo com indicações do manual de usuários do software utilizado, é necessário um refinamento na região da superfície livre para melhor representar a interface. Utilizou-se uma ferramenta para adaptação de malha usando como parâmetro de refinamento os dados de perfil de aeração anteriormente simulado (Figura 4.41).

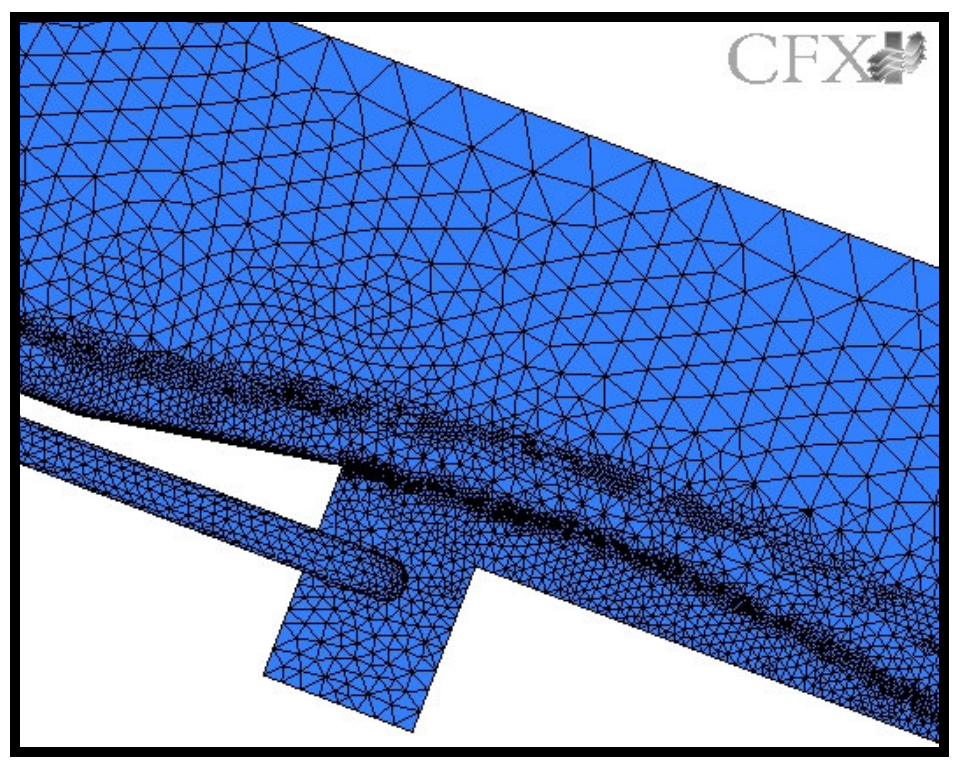

Figura 4.41. Malha na simulação numérica após o refinamento.

Este procedimento de simulação foi realizado para nove configurações de escoamento deste canal de alta declividade. Os valores das vazões, altura da comporta de entrada, as velocidades médias, número de Froude e o comprimento dos jatos estão apresentados na tabela 4.10 .

Tabela 4.10. Grandezas Básicas e Comprimento dos Jatos.

\begin{tabular}{ccccccc}
\hline Teste & $\begin{array}{c}\text { Abertura } \\
\text { da } \\
\text { comporta }\end{array}$ & $\begin{array}{c}Q_{a g u a} \\
(\mathrm{l} / \mathrm{s})\end{array}$ & $\begin{array}{c}V \\
(\mathrm{~m} / \mathrm{s})\end{array}$ & Froude & $\begin{array}{c}\text { L (Experimental) } \\
(\mathrm{m})\end{array}$ & $\begin{array}{c}\mathrm{L} \\
(\text { Numérico }) \\
(\mathrm{m})\end{array}$ \\
\hline 1 & $3 \mathrm{~cm}$ & 45,77 & 6,79 & 11,81 & - & 1,10 \\
2 & & 63,93 & 9,99 & 17,83 & - & 1,20 \\
3 & & 47,64 & 4,53 & 6,31 & 1,06 & 1,17 \\
4 & $6 \mathrm{~cm}$ & 64,37 & 5,96 & 8,19 & 1,45 & 1,18 \\
5 & & 92,05 & 7,92 & 10,49 & & 1,42 \\
6 & $9 \mathrm{~cm}$ & 64,38 & 4,57 & 5,49 & 0,98 & 1,02 \\
7 & & 98,20 & 5,99 & 6,68 & 1,45 & 1,32 \\
8 & $11 \mathrm{~cm}$ & 64,38 & 4,05 & 4,59 & 0,88 & 0,88 \\
9 & 94,63 & 5,20 & 5,50 & 1,18 & 1,18 \\
\hline
\end{tabular}


$\mathrm{Na}$ figura 4.42 é apresentado o perfil final de volume de fluido para uma das simulações realizadas. É interessante verificar a existência do cone de aeração, em que as camadas limites crescem em ambos os lados do jato após o salto.
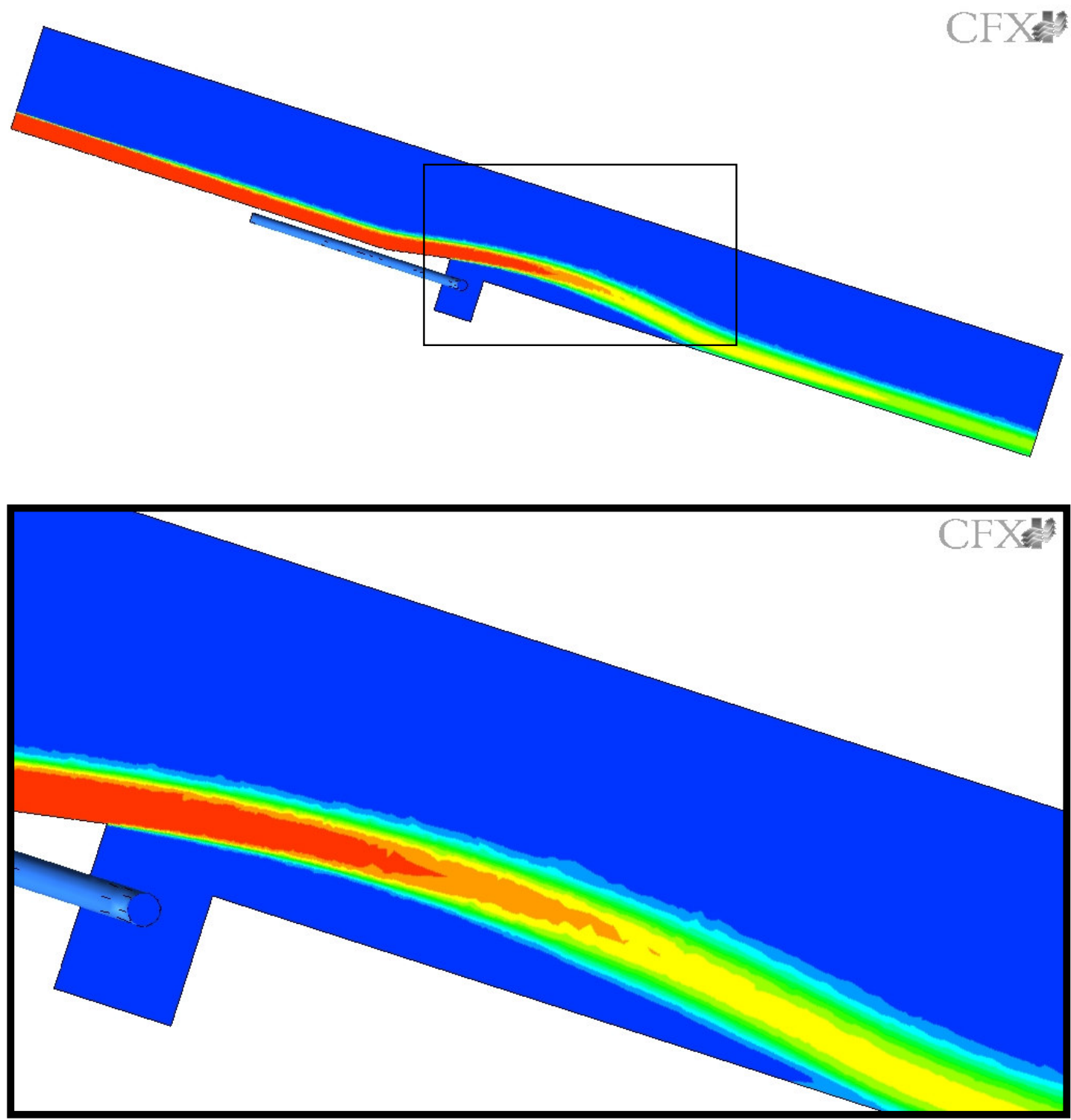

Figura 4.42. Perfil de aeração.

$\mathrm{Na}$ tabela 4.11 estão apresentadas as características dos fluidos, da malha e da simulação, utilizadas na realização do estudo numérico. Verifica-se que o tempo de processamento em cada condição do escoamento foi de aproximadamente 28 horas, e seria maior se a malha fosse refinada em todo o domínio do escoamento. A simulação do escoamento foi realizada até o estabelecimento do regime estacionário, sendo posteriormente refinada a malha na região de superfície livre. Após o refinamento foram realizadas as 
simulações transientes em mais dois segundos do escoamento para coleta de dados para a condição transiente.

Tabela 4.11. Domínio, Características do Fluido e da Simulação.

Domínio (antes da adaptação da malha)

\begin{tabular}{|c|c|}
\hline Número de Nó & 107326 \\
\hline Número de Elementos & 476748 \\
\hline Número de Elementos Tetraédricos & 436016 \\
\hline Número de Elementos Prismáticos & 40622 \\
\hline Número de Elementos Piramidais & 110 \\
\hline \multicolumn{2}{|c|}{ Domínio (depois da adaptação da malha) } \\
\hline Número de Nós & $\approx 550000$ \\
\hline Número de Elementos & $\approx 2750000$ \\
\hline \multicolumn{2}{|c|}{ Fluidos } \\
\hline Água & $\mathrm{Ar}$ \\
\hline Temperatura $\quad 25{ }^{\circ} \mathrm{C}$ & Temperatura \\
\hline Viscosidade Dinâmica $\quad 8,899 * 10^{-4} \mathrm{~kg} \cdot \mathrm{m}^{-1} \cdot \mathrm{s}^{-1}$ & Viscosidade Dinâmica $1,831 * 10^{-5} \mathrm{~kg} \cdot \mathrm{m}^{-1} \cdot \mathrm{s}^{-1}$ \\
\hline Massa Específica $\quad 998$ kg.m ${ }^{-3}$ & Massa Específica \\
\hline \multicolumn{2}{|l|}{ Coef. de Tensão Superf. $\quad 0,0732$ N.m ${ }^{-1}$} \\
\hline \multicolumn{2}{|c|}{ Simulação } \\
\hline Passo de Tempo & $0,1 \mathrm{~s}$ \\
\hline Tempo de Simulação & $10 \mathrm{~s}$ \\
\hline Erro Médio Quadrático (RMS) & $10^{-5}$ \\
\hline Características dos Processadores & Processadores 3,2 GHz (Opteron 64 bits) \\
\hline Tempo de Processamento no CPU $(\approx)$ & $10^{5} \mathrm{~s}$ (por simulação) $(\approx 28$ horas $)$ \\
\hline
\end{tabular}

Os dados de aeração foram comparados para as nove configurações de escoamento estudadas. Nas figuras 4.43 estão representados os perfis de aeração nas seis seções representadas na figura 4.39, para a condição experimental número 4. Para as condições experimentais de 5 até 9 os perfis de aeração nas seis seções são apresentados no APÊNDICE F. 


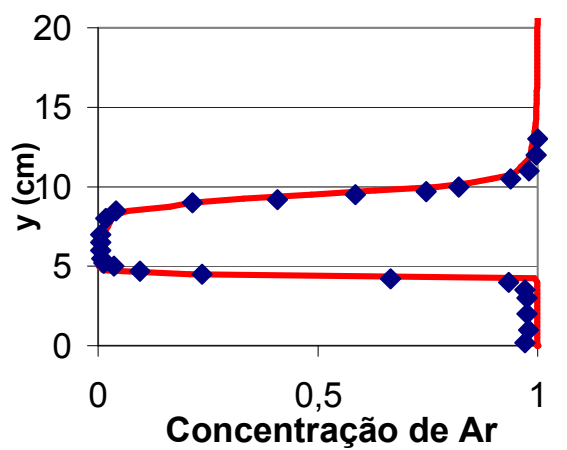

Seção 1

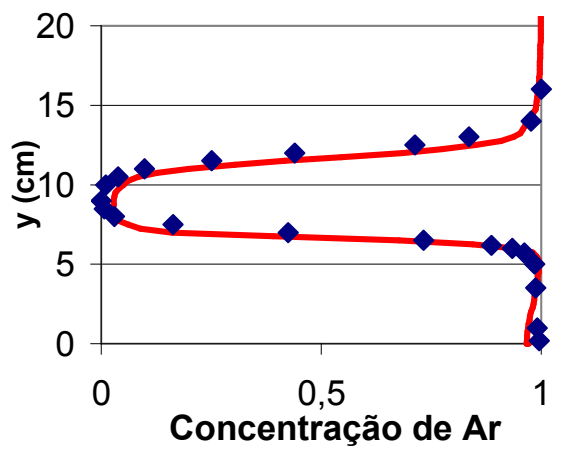

Seção 3

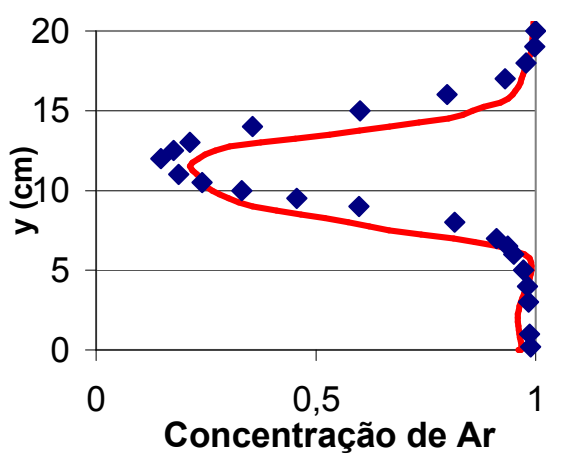

Seção 5

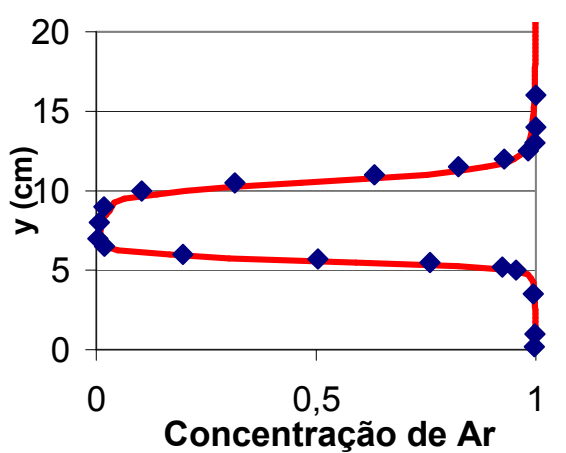

Seção 2

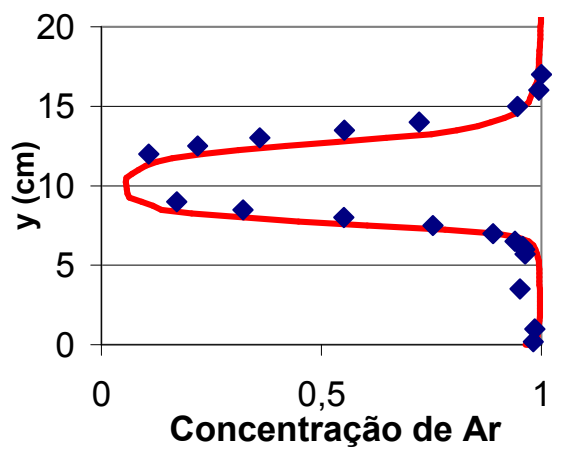

Seção 4

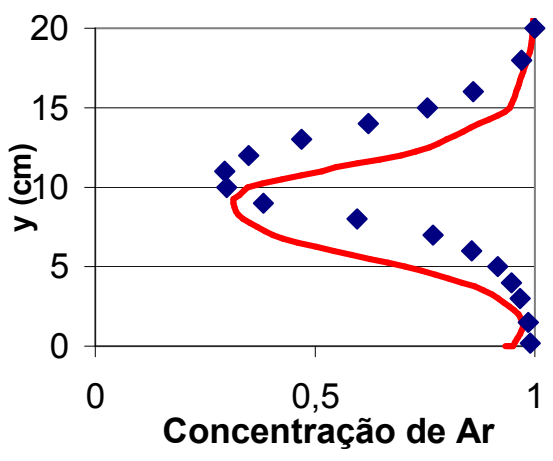

Seção 6

\section{- Experimental \\ Numérico - CFD}

Figura 4.43. Concentração de Ar para o Experimento 4.

Verifica-se que os valores para os perfis de aeração encontrados numericamente estão muito próximos aos experimentais para a maioria dos ensaios realizados. Com isto além da caracterização do escoamento com os valores de fração de volume, indica que os posicionamentos dos jatos e dos picos de aeração estão concordando com o experimental. Algumas discordâncias ocorreram, quanto aos posicionamentos do jato (seções 5 e 6 dos experimentos 4 e 5) e quanto aos picos de concentração de água (seções 5 e 6 do experimento 8). Estas pequenas diferenças podem ser explicadas, provavelmente, por algumas dificuldades na representação das mesmas condições experimentais e numéricas. 
Outro parâmetro interessante na caracterização do escoamento de um aerador de fundo por meio de um salto é a quantificação do comprimento deste salto. Este comprimento pode ser determinado através da localização do pico de pressão no ponto de impacto do jato (Figura 4.44). Nas figuras do APÊNDICE G estão apresentados os diagramas de pressão na parede de fundo sob o jato.
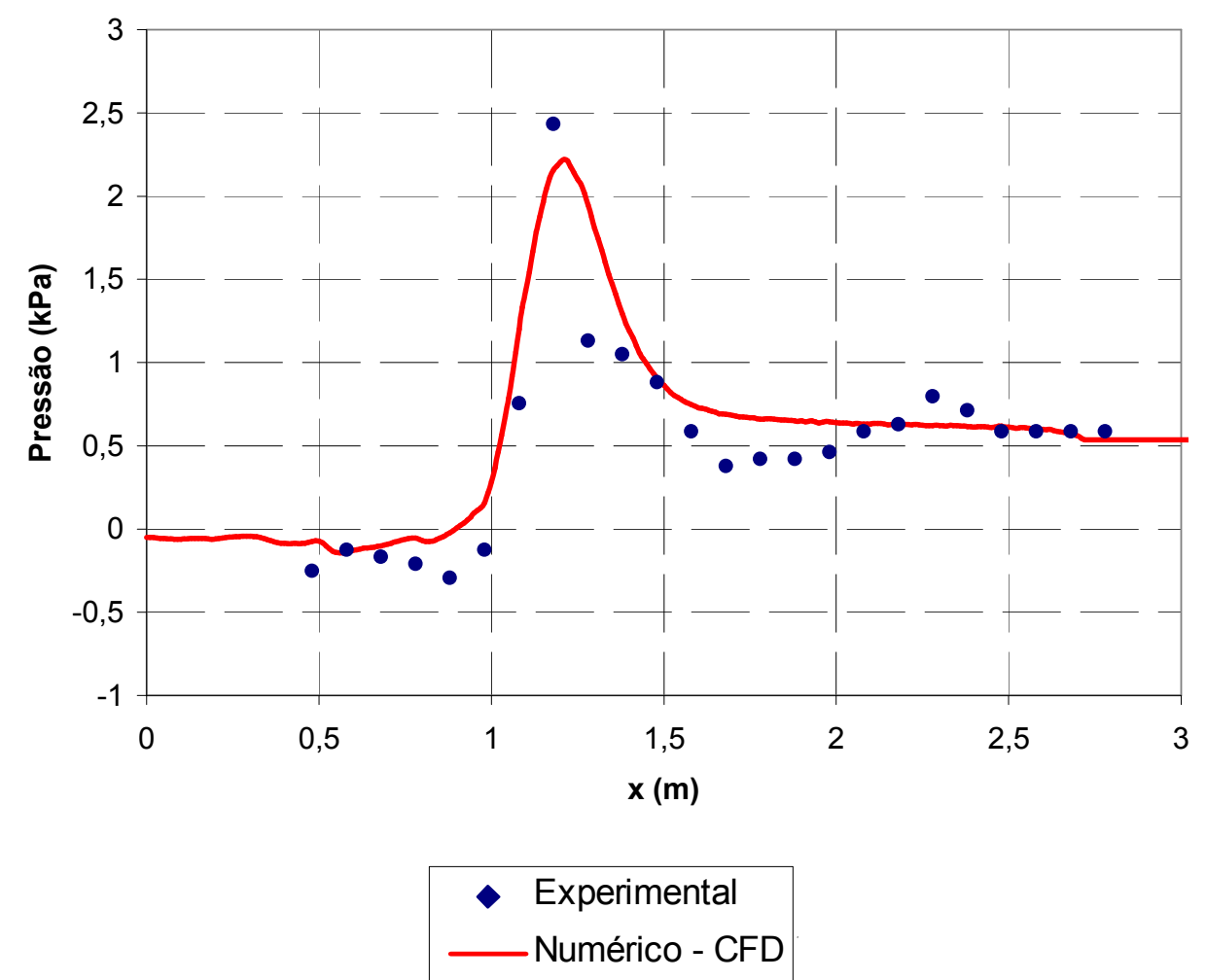

Figura 4.44. Pressão Sob o Jato para o Experimento 9.

Os valores da pressão na parede sob o jato possuem um comportamento similar ao simulado numericamente, com exceção para alguns pontos que estão difusos. Os picos de pressão localizam-se praticamente no mesmo ponto para os experimentos $3,6,8$ e 9, mas para os experimentos 4 e 7 há uma pequena discordância, com isto podemos concluir que os comprimentos dos jatos comparam-se favoravelmente. Os valores de comprimento do jato encontrado por meio de medida da distância entre o início do jato ao pico de pressão são comparados na tabela 4.10 .

Os perfis de velocidade na seção $\mathrm{V}_{1}$ (Figura 4.39) foram determinados para a simulação numérica e comparados com os dados experimentais obtidos por velocimetria a LASER em Lima (2003). Nas figuras 4.45, 4.46 e 4.47 estão apresentados os perfís de velocidades numérico e experimental para comparação. 


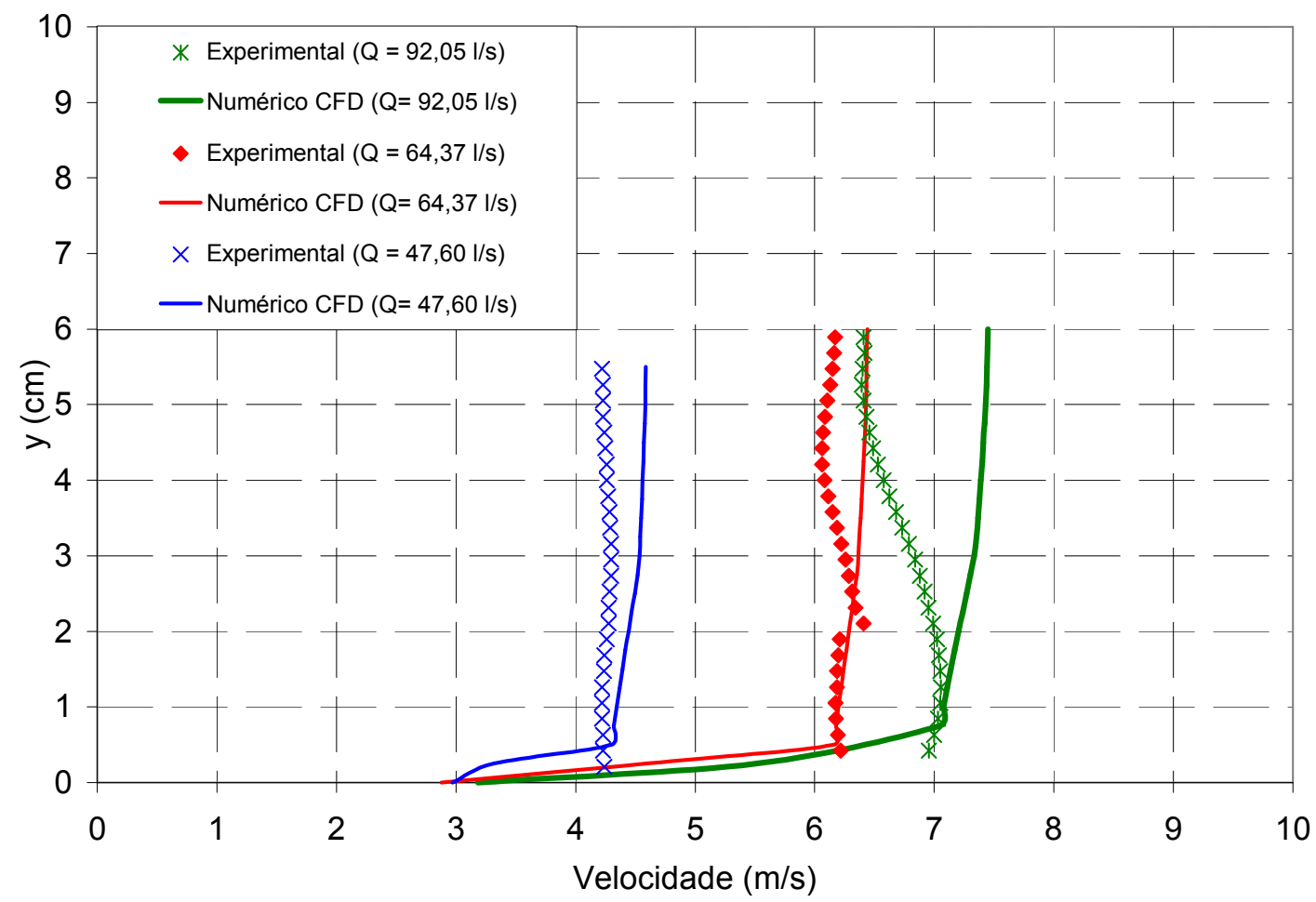

Figura 4.45. Velocidade para abertura da comporta de $6 \mathrm{~cm}$ (Experimentos 3, 4 e 5).

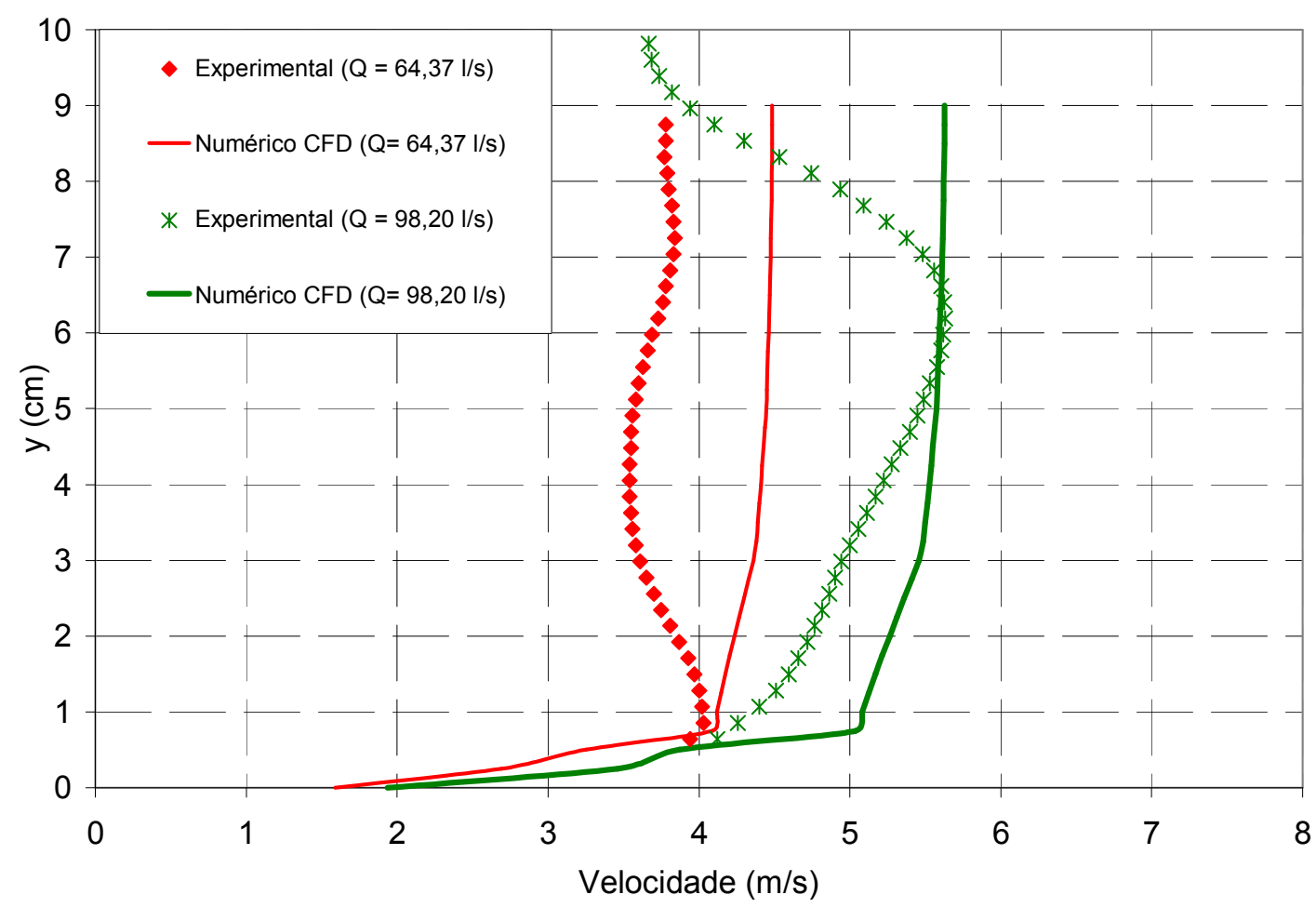

Figura 4.46. Velocidade para abertura da comporta de $9 \mathrm{~cm}$ (Experimentos 6 e 7). 


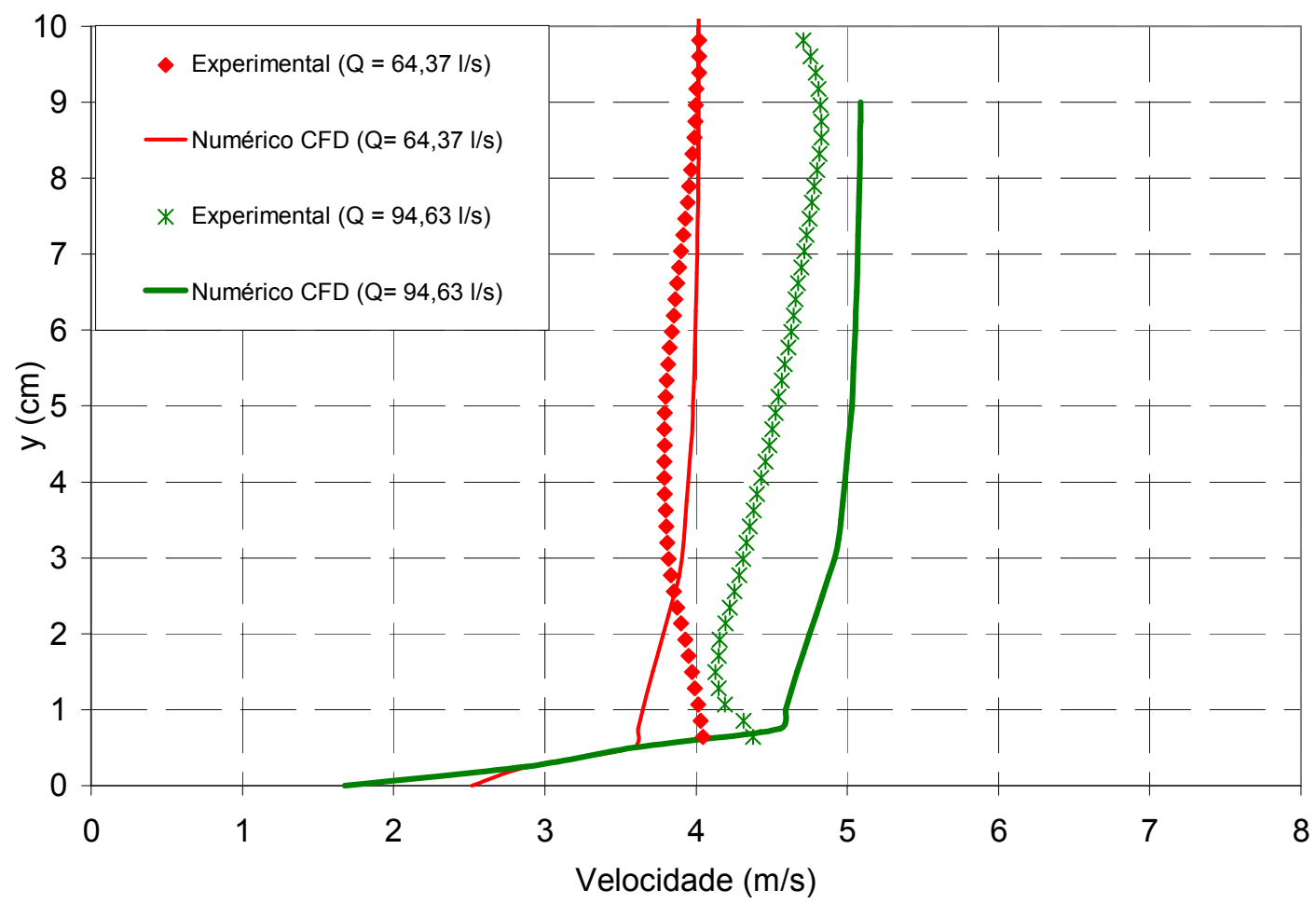

Figura 4.47. Velocidade para abertura da comporta de $11 \mathrm{~cm}$ (Experimentos 8 e 9).

Os valores médios das velocidades obtidas pela simulação numérica e experimental apresentados nos gráficos acima se comportam de forma similar, com erros máximos de aproximadamente $10 \%$. Os valores pontuais de velocidades numéricas discordam do obtidos por velocimetria a LASER, mas esta diferença pode ser atribuída à natureza instantânea dos dados experimentais obtidos com esse equipamento.

Um fator interessante na quantificação dos perfis de velocidade foi que nos dados experimentais, não foi possível visualizar a camada limite, mas na simulação numérica ela foi visualizada, utilizando-se malha prismática nas paredes. O tamanho desta camada obtido numericamente foi pequeno, mas verificou-se que esta espessura depende do tamanho da malha utilizada, e acredita-se que para determinar o valor real desta espessura é necessário um refinamento que pode ser inviável computacionalmente.

A vazão de ar no tubo do aerador foi quantificada nas simulações numéricas e uma comparação foi realizada. Lima (2003) quantificou a vazão de ar com os dados experimentais utilizando as equações 4.12, 4.13 e 4.14 e também através de bocal instrumentado com Pitot.

Para este trabalho utilizaram-se as equações 4.18 e 4.28 com dado de simulação no CFD para determinar também as vazões de ar. Devido a grande variabilidade do valor da pressão sobre o jato, as pressões usadas para o cálculo foram às médias espaciais encontrados 
na simulação numérica. $\mathrm{O}$ valor de $\mathrm{C}_{\text {média }}$ utilizado foi determinado através de um ajuste, resultando em: $\mathrm{C}_{\text {média }}=0,8721$.

Através destas sete metodologias para determinação das vazões de ar sob o jato foi possível comparar os valores encontrados, como pode ser visualizado na figura 4.48.

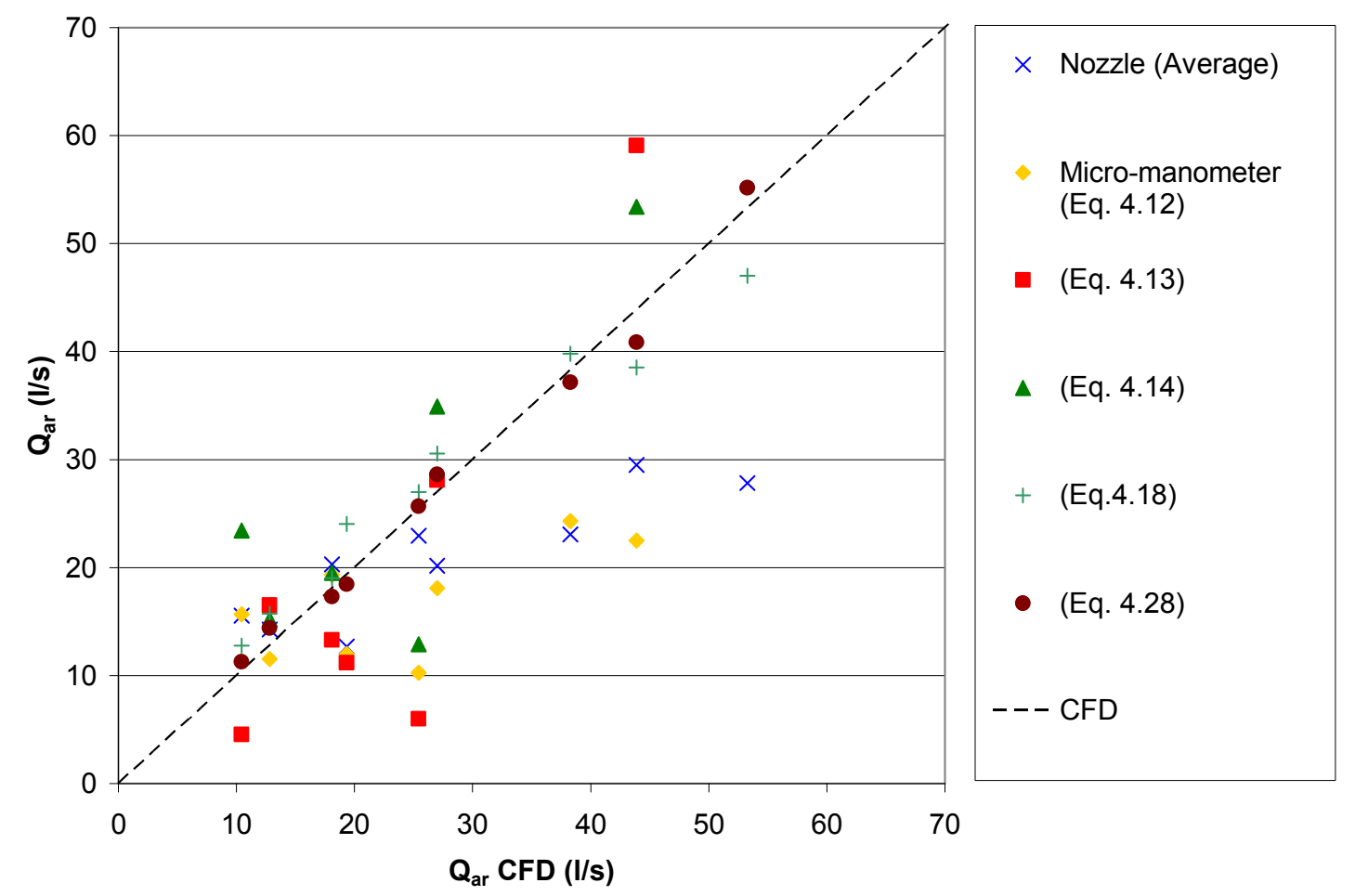

Figura 4.48. Comparação dos valores de vazão de ar.

Os valores de vazão de ar utilizando-se os métodos das equações 4.13, 4.14, 4.18 e 4.28 se aproximaram bem dos valores obtidos na simulação numérica, sendo que os métodos das equações 4.18 e 4.28 se destacam como melhor aproximação. Os métodos do bocal e do micro-manômetro se distanciaram um pouco dos numéricos paras vazões de ar maiores que $301 / \mathrm{s}$

\section{Conclusões.}

O estudo proposto para este trabalho foi à utilização de ferramentas de fluidodinâmica computacional na simulação do escoamento de um aerador de fundo, através da quantificação da concentração de ar, dos picos de pressão sob o jato, com a determinação de seu comprimento e a vazão de ar sob o salto.

Os valores encontrados para os perfis de aeração em ambos os experimentos calculados numericamente foram muito próximos aos experimentais. Mas para obtenção destes bons resultados foi necessária uma adaptação de malha para refinamento na região de superfície 
livre. Os valores do campo de pressão sob os degraus tiveram um comportamento similar, mas os picos tiveram uma boa concordância para a maioria dos ensaios realizados.

Os perfis de velocidades foram determinados e comparados com dados de velocimetria a LASER, com erros máximos de 10\%. A camada limite foi visualizada na simulação numérica e verificou-se que sua espessura é pequena, assim como foi observado experimentalmente.

Seis métodos para determinação da vazão de ar sob o salto, além a utilização do CFD, foram utilizados e comparados com a simulação numérica. Dentre estes métodos, a utilização de medidas em tubo de Pitot em um bocal e a utilização de micro-manômetros para medida da pressão de sucção, não resultaram em boas comparações com dados numéricos, especialmente para os valores maiores de vazão de ar. Dentre os métodos comparados, o que mais se destacou foi o método proposto pelo Prof. Dr.Podalyro Amaral de Souza (equações 4.18 e 4.28), em que se determina a vazão de ar através de uma relação com a vazão de água. Esta equação é interessante, pois a vazão de ar passa a depender, além da pressão sob o salto, do comprimento do jato e da altura da lamina d'água.

\subsection{Proposta de Aerador de Fundo no Início do Vertedouro.}

O risco de cavitação é o principal problema em vertedouros em degraus. Considerando esse fato, limita-se, atualmente, o uso de vertedouros com degraus para vazões específicas da ordem de 10 a $15 \mathrm{~m}^{3} / \mathrm{s} / \mathrm{m}$. Sabe-se ainda que um escoamento com concentração de ar maior que $7 \%$ é suficiente para evitar o risco de cavitação. Para garantia da aeração na região próxima às paredes dos degraus, a construção de um aerador de fundo no início do vertedouro poderia propiciar uma aeração mais eficiente, possibilitando também o uso da calha com degraus em uma faixa maior de condições de escoamento.

A proposta geométrica desenvolvida para o aerador de fundo, constitui-se na construção de uma câmara de aeração, utilizando-se duas curvas do perfil padrão WES deslocadas uma da outra. O escoamento se dá inicialmente na curva padrão WES superior de forma a adquirir velocidade suficiente para a realização do salto sobre o aerador. Posteriormente, após a decolagem da lâmina de água ocorre a aeração da face inferior do escoamento, até o impacto do jato à curva padrão WES inferior, onde o escoamento se desenvolve com a presença de ar incorporado em uma concentração maior do que no vertedouro em degrau convencional.

Nas figuras 4.49 e 4.50 é apresentada a geometria proposta de um vertedouro em degraus, com o detalhamento do deslocamento da curva padrão WES e do aerador de fundo. Na figura 4.49 também são apresentadas as seções de estudo em que foram comparadas as 
condições de escoamento para o cotejo entre os resultados dos escoamentos com e sem o aerador de fundo.

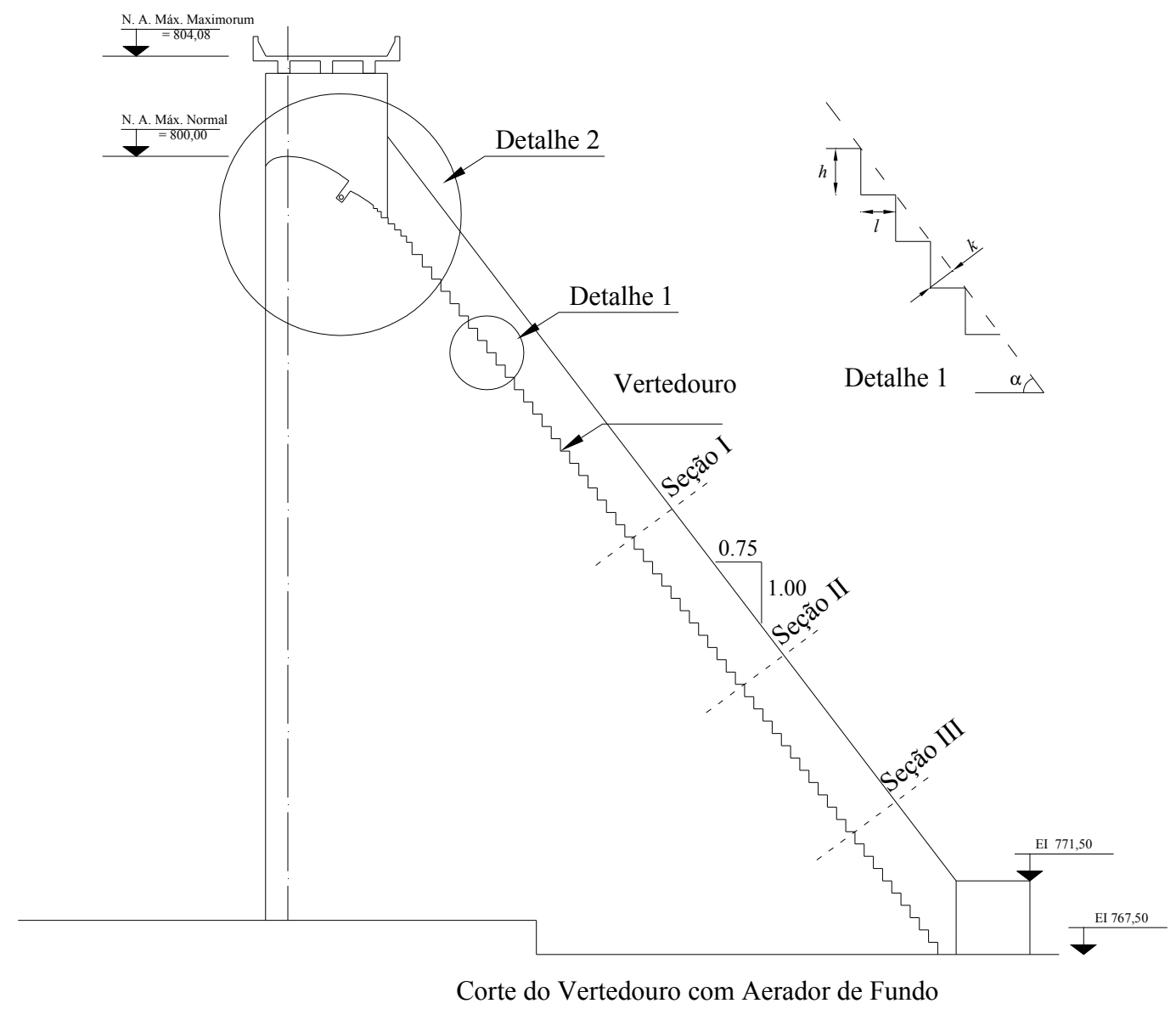

Figura 4.49. Vertedouro com Aerador de Fundo.

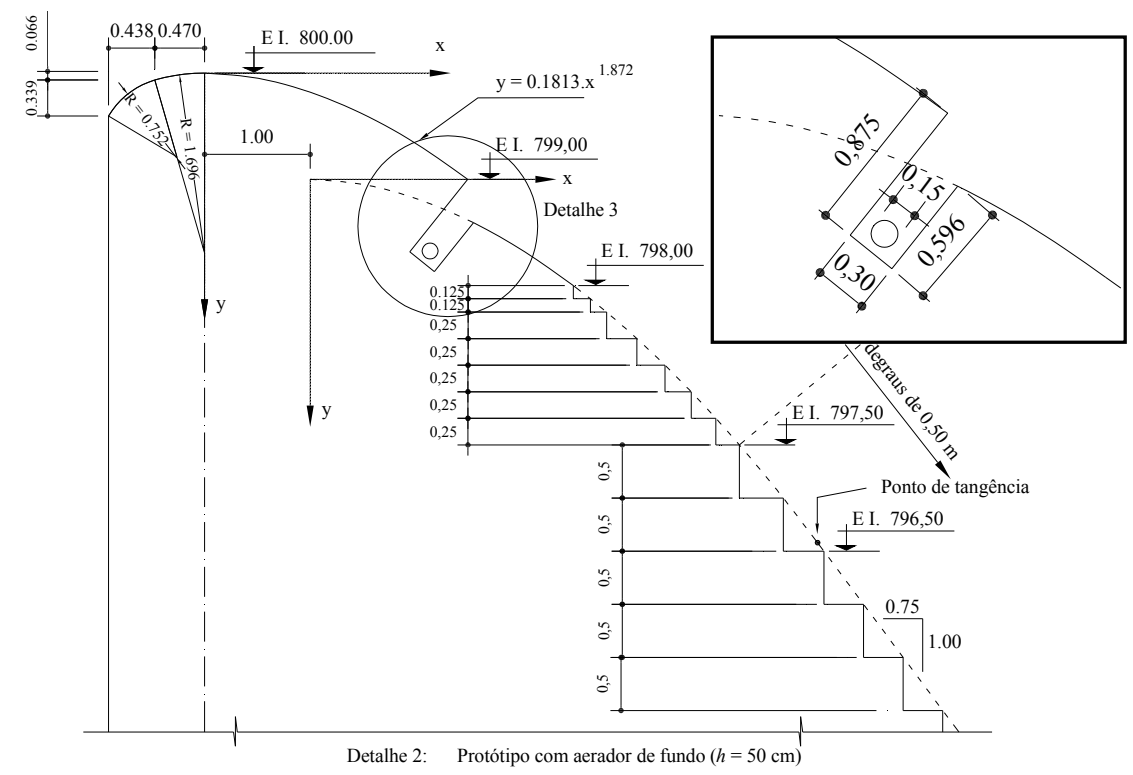

Figura 4.50. Detalhes do Aerador de Fundo Proposto. 
A simulação numérica realizada constituiu na simulação em duas etapas até o estado estacionário, de forma que o erro médio quadrático alcançasse a ordem de $10^{-4}$. A primeira etapa constituiu na simulação na condição de malha variando de $15 \mathrm{~mm}$ a $150 \mathrm{~mm}$ em todo domínio, sendo a malha mais fina próxima às paredes. Na segunda etapa da simulação utilizou-se um refinamento da malha em função do gradiente de concentração de ar, melhorando a condição da interface ar-água. Na figura 4.51 está representada a variação da concentração de ar-água em todo o domínio de escoamento do vertedouro em degraus com aerador de fundo. Visualiza-se no detalhe apresentado nesta mesma figura a incorporação de ar na superfície inferior do jato formado no aerador e o carreamento do ar ao longo do escoamento proporcionando maior aeração nas proximidades das paredes. Esta maior concentração de ar é importante para evitar a cavitação.

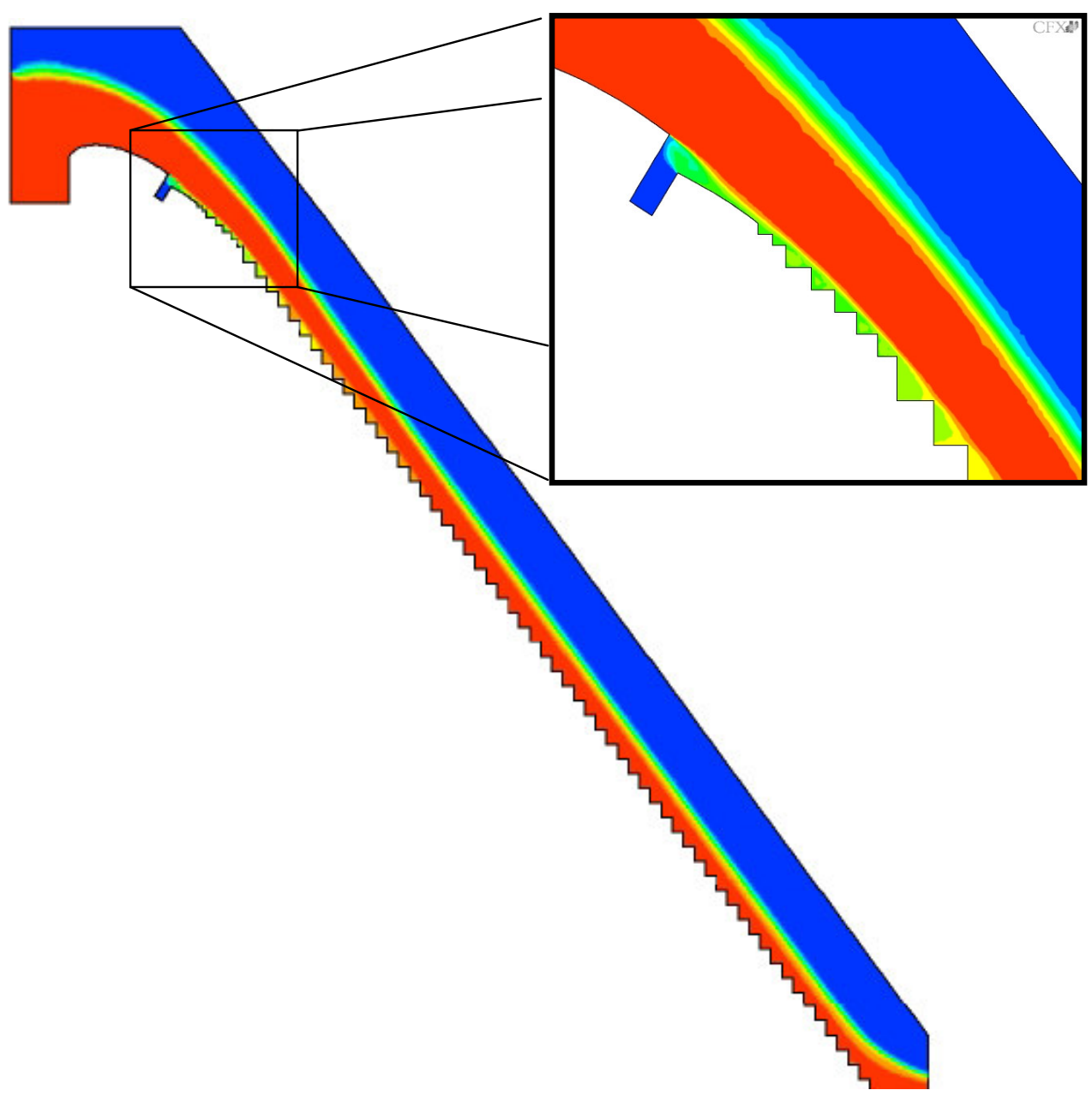

Figura 4.51. Variação da concentração e ar no escoamento do vertedouro em degraus com aerador de fundo. 
Os perfis de velocidades para o escoamento na condição de maior vazão estudada $(11,7$ $\mathrm{m}^{3} / \mathrm{s} / \mathrm{m}$ ) nas três seções de estudos (Seção I, II e III) são apresentados na figura 4.52. Verificase que as velocidades nas seções com mesma altura em relação à crista do vertedouro apresentam-se com perfis maiores para a condição de vertedouro com aerador de fundo, caracterizando a menor dissipação de energia no escoamento aerado.

A diferença de dissipação de energia também pode ser visualizada na figura 4.53 , em que são apresentadas as linhas de energia específica em relação ao pé do vertedouro para as condições de escoamento em vertedouro com e sem aerador e também com os dados do modelo reduzido com a correção de escala (1:15). Nesta comparação verifica-se que diferença entre as energias específicas com e sem o aerador aumenta com o comprimento do vertedouro, chegando a uma porcentagem maior, para a condição aerada, de mais de $13 \%$. Esta menor dissiparação ocorre devido à presença do ar incorporado ao escoamento que diminui o fator de resistência efetivo e a dissipação de energia.

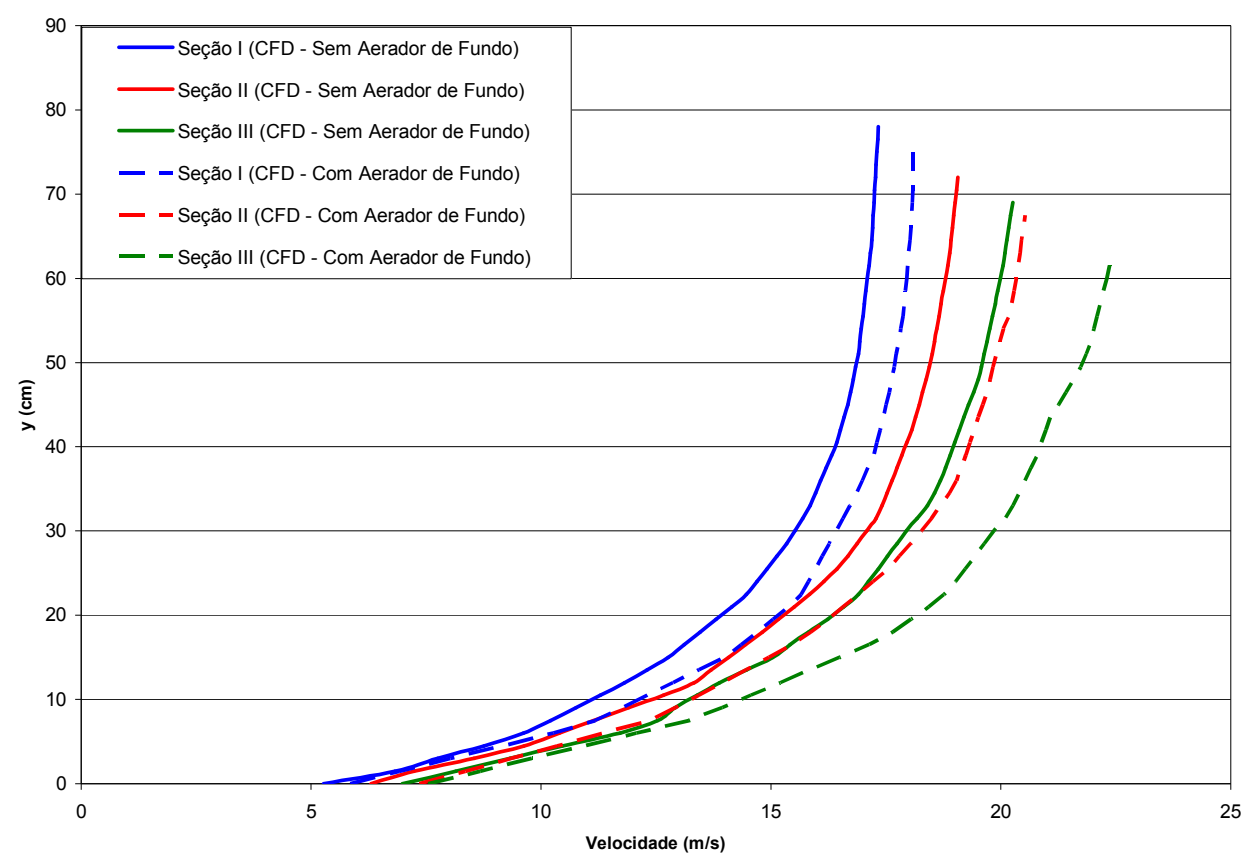

Figura 4.52. Perfis de velocidades nas seções de estudo para os vertedores com e sem o aerador de fundo. 


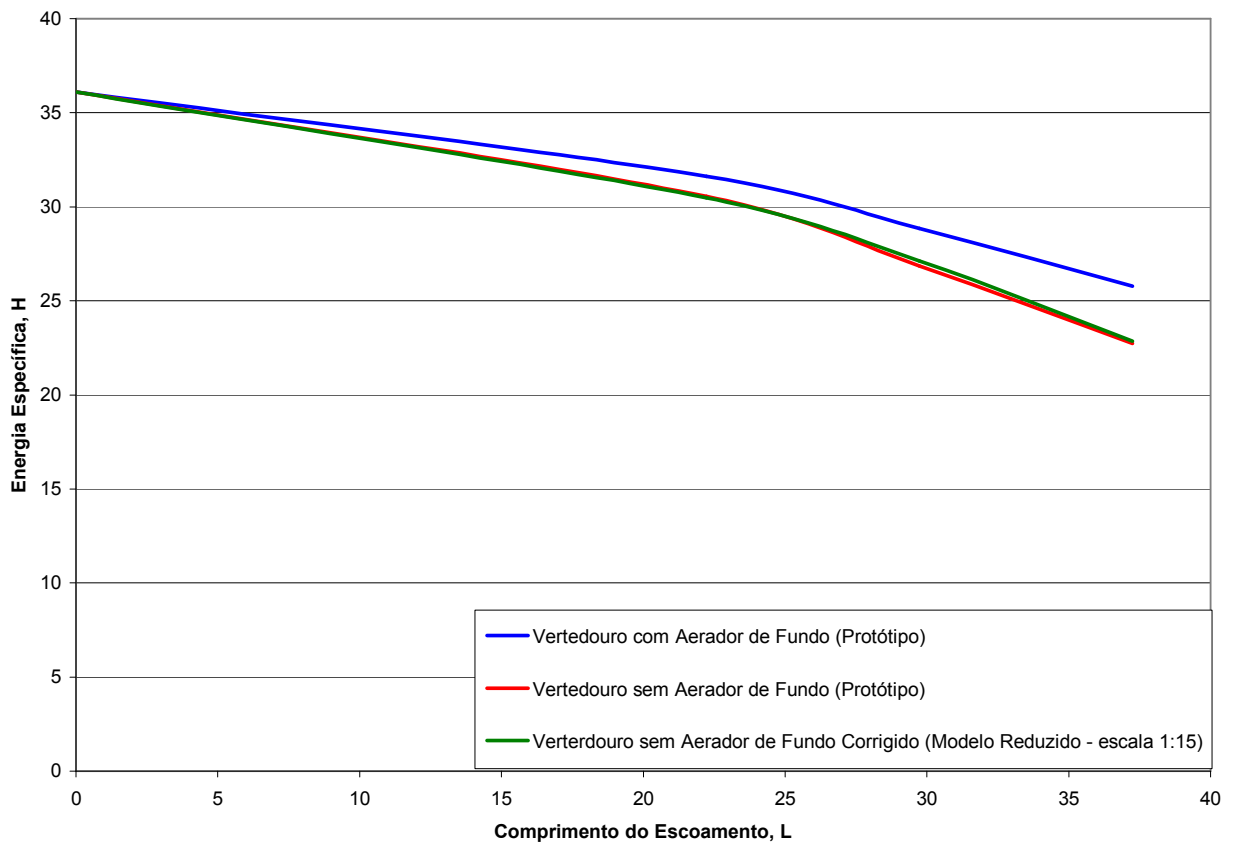

Figura 4.53. Variação da energia específica ao longo do escoamento, com referência ao pé da barragem.

Sabe-se que a presença de ar incorporado, a uma concentração maior que 7\%, diminui a possibilidade de cavitação. Para a visualização dos locais mais propícias à cavitação, é apresentada na figura 4.54, a região em que a concentração de ar varia entre 0 e 7 \%. Verificase que logo após a passagem sobre o aerador de fundo é garantida uma concentração maior que $7 \%$ até o degrau 28. Do degrau 29 ao degrau 43 ocorrem concentrações menores que 7\% próximo às paredes, mas estes valores são ainda maiores que $6 \%$, de forma a dificultar a cavitação nestes locais. Acredita-se que para esta vazão simulada, a aeração existente seja suficiente para diminuir a possibilidade de cavitação. Um estudo mais apurado através modelagem física poderia acrescentar informação para uma análise mais conclusiva quanto a garantia da inexistência da cavitação. 


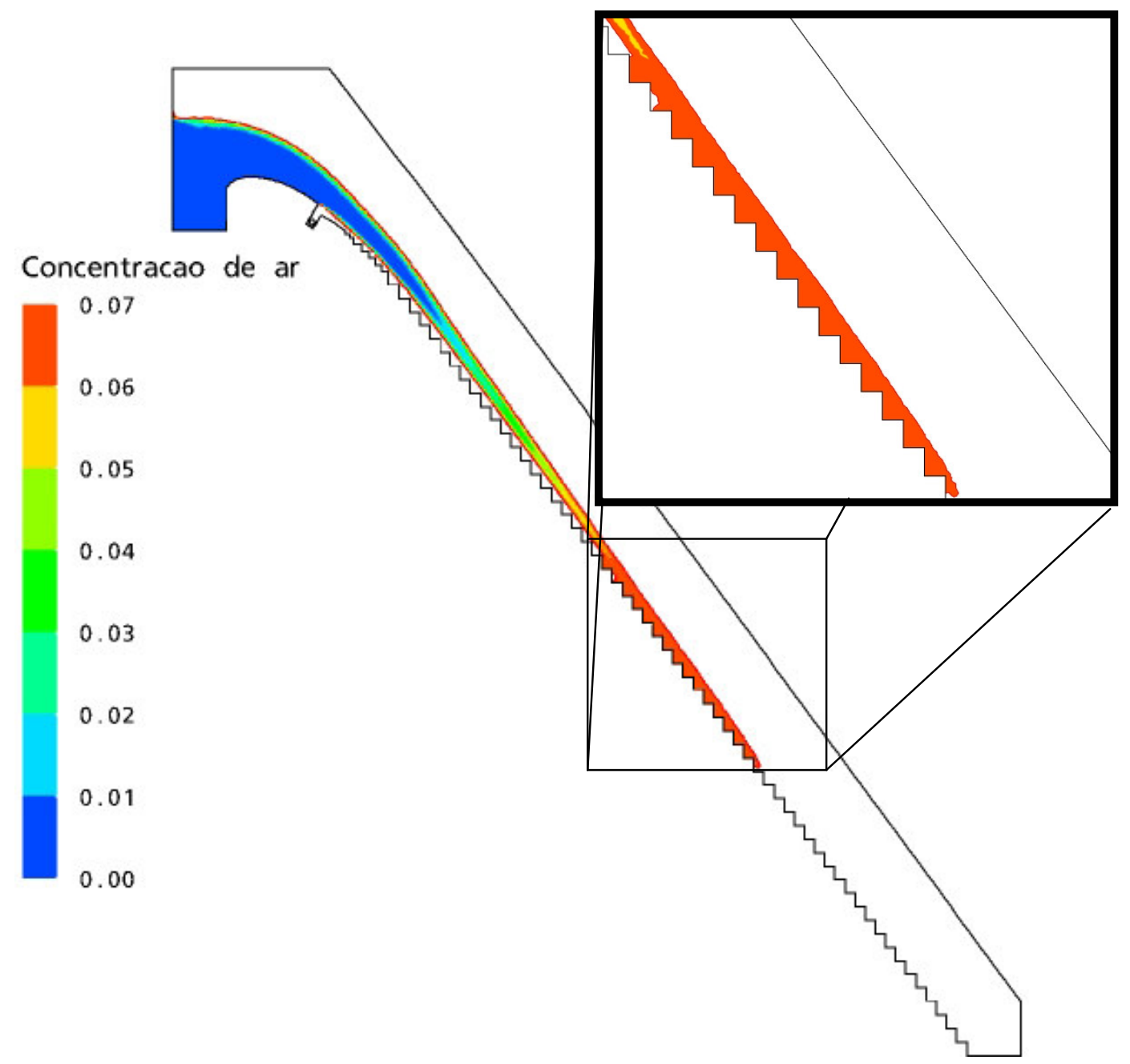

Figura 4.54. Região com concentração de ar variando de 0 a 7\%.

Outra análise que pode ser realizada para o estudo da possibilidade de cavitação é a verificação da grandeza e da localização das pressões negativas em todo o domínio do escoamento. Na figura 4.55, são apresentadas as pressões relativas em um plano para o vertedouro em degraus com aerador de fundo. Esta mesma análise foi realizada para a simulação do vertedouro sem o aerador (Figura 4.33), verificando-se que a menor pressão encontrada para esta condição de escoamento foi de $-31654,5$ Pa, já para o escoamento com aerador de fundo o valor encontrado foi menos vulnerável à cavitação, sendo a menor pressão igual a -7322 Pa. Comparando-se a região onde a pressão é mínima no vertedouro aerado com a região de concentração de ar maior que 7\%, verifica-se que existe uma concentração de ar suficiente neste local de pressão mínima para evitar a cavitação. 


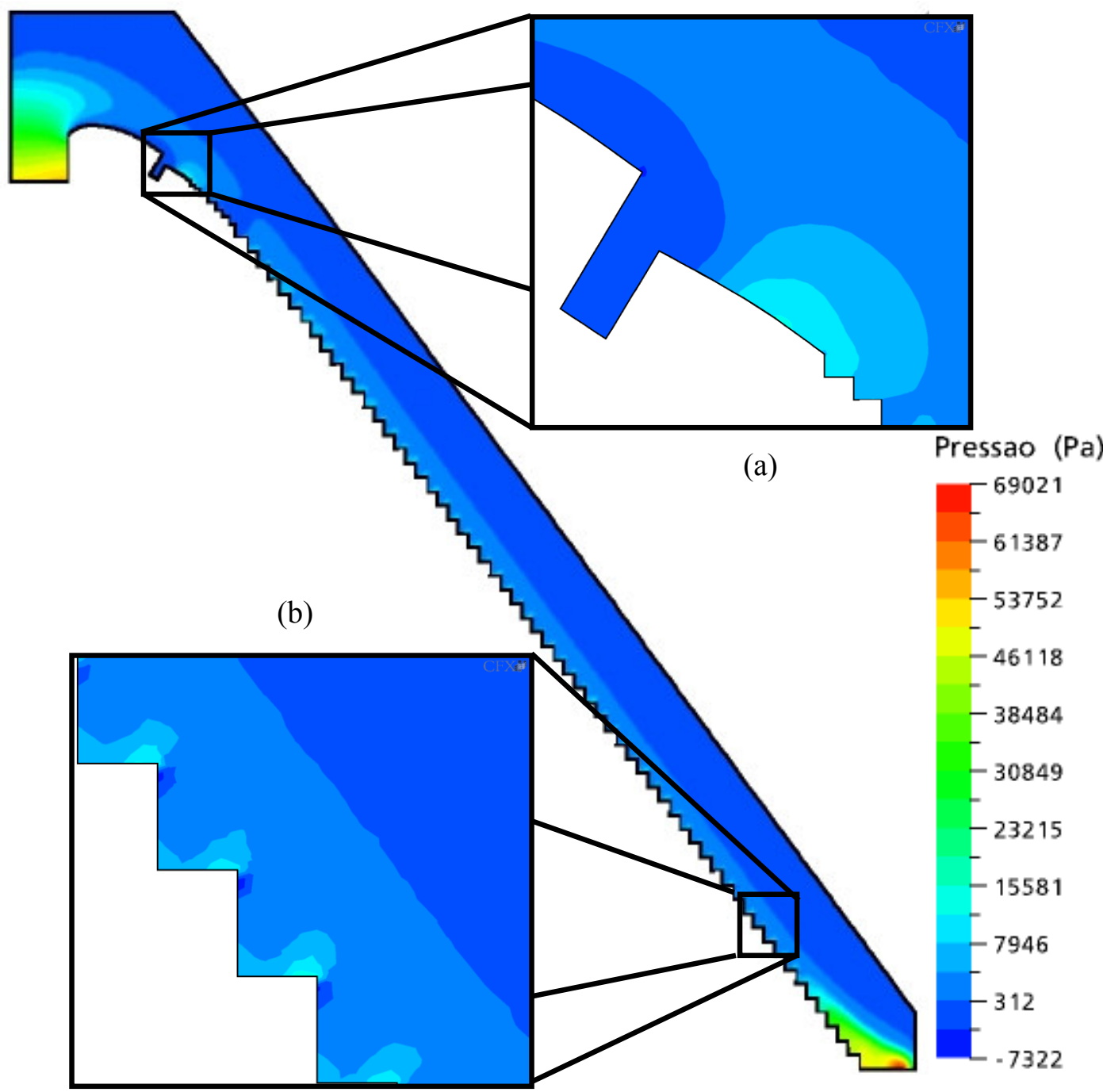

Figure 4.55. Campo de Pressões no vertedouro em degraus com aerador de fundo.

(a) - Na região do aerador de fundo, (b) - Na região próxima ao fim do vertedouro.

\section{Conclusão.}

A simulação de uma proposta geométrica para o vertedouro em degraus, com um dispositivo de aeração de fundo foi realizada para o estudo da dissipação de energia e da incorporação de ar próximo às paredes dos degraus.

Os resultados obtidos permitiram visualizar a distribuição da concentração de ar ao longo do escoamento e identificar as regiões onde as concentrações de ar são maiores que 7\%, condição suficiente para evitar a cavitação. Foram identificadas as regiões com pressão menores que a pressão de vapor de referencia e comparada com as pressões negativas para o escoamento sem o aerador de fundo. A dissipação de energia para o vertedouro em degraus 
com aerador de fundo foi comparada com o vertedouro em degraus sem o aerador de fundo, verificando uma redução da dissipação devido à presença do aerador.

Analisando os resultados verifica-se que o aerador de fundo promove uma aeração nos degraus mais próximos da entrada, suficiente para evitar a cavitação, mas o aerador de fundo também propicia uma diminuição na dissipação de energia de até $13 \%$ no pé do vertedouro. 


\section{CONCLUSÕES E DISCUSSÕES}

Os estudos sobre escoamentos em vertedouros em degraus foram realizados experimentalmente por diversos autores, mas a utilização de ferramentas de computação numérica ainda é muito escassa nesse particular. Assim, propôs-se para esta pesquisa, a utilização de ferramentas de fluidodinâmica computacional, com o intuito de caracterizar o escoamento sobre o vertedouro, estabelecer equacionamento em termos da dissipação de energia e também estudar a ocorrência de cavitação nos degraus.

Utilizou-se um pacote computacional para a simulação numérica dos escoamentos. O software utilizado foi o ANSYS CFX $10^{\circledR}$. Os procedimentos para as simulações numéricas constituíram em: geração da geometria e da malha, estabelecimentos das condições de contorno e iniciais, escolha dos modelos de simulação e dos critérios, resolução e visualização dos resultados.

O modelo de turbulência adotado em todas as simulações foi o SSG Reynolds Stress, que constitui o modelo de Tensões de Reynolds para a condição anisotrópica com a possibilidade de uso da lei da parede. Esse modelo de turbulência foi escolhido devido possibilidade de representar das condições anisotrópicas dos escoamentos e por considerar a maior quantidade de variáveis entre os modelos RANS. O modelo multifásico escolhido foi o homogêneo (Multiphase Homogeneous Model) com o modelo de mistura na interface (Mixture Model) e coeficiente de tensão superficial de 0,0732 N/m. A utilização do modelo homogêneo se deve a dificuldade na realização das simulações com os modelos não homogêneos que necessitam de critérios de convergência e de malha mais apurados, aumentando o tempo de simulação para valores inviáveis para este trabalho.

Para a caracterização do escoamento em vertedouros em degraus que é um dos objetivos principais deste trabalho, foram realizados os estudos com a comparação de resultados experimentais da literatura com os resultados das simulações, sendo abaixo descritos:

- Quatro experimentos realizados por Olinger (2001) foram simulados e comparados. Os resultados da simulação numérica foram analisados, de forma a verificar que os perfís de pressões degraus se apresentaram de forma similar aos experimentais e os perfis de velocidades quantificados numericamente representaram uma boa aproximação ao estudo realizado por Olinger (2001). 
- Um estudo computacional sobre a mudança de regime no escoamento sobre o vertedouro também foi realizado, de forma a tentar visualizar a mudança de regime do tipo nappe para skimming. Devido à dificuldade de visualização do início da mudança de regime, da necessidade de muitas simulações, este estudo não teve uma continuação, mas é interessante comentar que nas simulações realizadas foi possível caracterizar o regime do escoamento. Um estudo mais apurado poderia ser realizado em outros trabalhos, de forma a estabelecer ou comprovar o equacionamento para a mudança de regime.

- Um estudo da perda de energia em vertedouro em degraus por meio da simulação numérica do escoamento, para comparação com os resultados experimentais de Christodoulou (1993) foi realizado para sete condições de vazão. Nestas simulações foi possível visualizar as características do escoamento, como distribuição de velocidades, perfil da superfície livre, etc. Os resultados da perda de energia foram corrigidos com o coeficiente de Coriolis, utilizando-se o perfil de velocidade resultante da simulação numérica. Os resultados da perda de energia encontrados pela simulação foram menores que os experimentais de Christodoulou (1993), devido à não correção pelo coeficiente de Coriolis nos experimentos e também por um possível efeito de escala nas condições de pequenas vazões.

- Uma reedição dos ensaios realizados por Tozzi (1992), utilizando-se as ferramentas de fluidodinâmica computacional, foi realizada para a caracterização do escoamento em vertedouros em degraus. Foram simulados os escoamentos para cinco condições de vazão e três condições de macrorugosidade do degrau. Neste trabalho foram comparados os resultados dos perfis de velocidades, o ponto de início da aeração e os perfis de concentração de ar. Os perfis de velocidades foram também adimensionalisados e comparados com equações teóricas para as condições de escoamento do protótipo e do modelo reduzido. A perda de energia ao longo do vertedouro também foi determinada e comparada com uma equação teórica proposta por Chanson (1994). Um estudo do fator de resistência para as condições de escoamento foi realizado. No estudo para determinação do início da aeração foram determinados os pontos em que o crescimento da camada limite encontra-se com a superfície livre e comparou-se com a curva proposta por Tozzi (1992), para o início da aeração. Para o estudo da aeração do escoamento comparou-se os resultados numéricos com duas equações teóricas em que os parâmetros determinados com base na simulação foram próximos aos encontrados experimentalmente por Straub e Anderson (1958) para calhas alisada. Para finalizar o estudo do escoamento em 
vertedouros em degraus, foi realizado um estudo das condições de pressão nos degraus do vertedouro, nas condições de protótipo e modelo reduzido, para verificar o efeito de escala na pressão e localizar as possíveis regiões de origem da cavitação. Pode-se concluir que a utilização das ferramentas de fluidodinâmica computacional proporcionou a realização de diversas análises do escoamento em vertedouro em degraus, representando de forma adequada às características desse escoamento.

- A caracterização do escoamento em um canal de alta declividade com um aerador de fundo foi proposto para servir como uma calibração na determinação de uma metodologia para quantificar o perfil de aeração do vertedouro em degraus, tendo em vista a existência de dados experimentais confiáveis de aeração do trabalho realizado por Lima (2003). Foram obtidos ótimos resultados em termos de aeração, e bons resultados em termos de campos de pressões e de velocidades. Um estudo da vazão de ar sob o salto foi realizado onde foram comparados seis métodos para a determinação desta vazão com destaque para o resultado de um método proposto pelo Prof. Dr. Podalyro Amaral de Souza, em que se determina a vazão de ar através de uma relação com a vazão de água. Esta equação é interessante, pois a vazão de ar passa a depender, além da pressão sob o salto, do comprimento do jato e da altura da lâmina de água.

- Para finalização deste trabalho foi proposta uma geometria alternativa para minimizar o problema referente à cavitação nas paredes dos degraus. Propõe-se a construção de um aerador de fundo no início do escoamento, antes do primeiro degrau. A simulação realizada com esta nova configuração do vertedouro permitiu observar a presença da aeração na região inferior do escoamento, próximo às paredes dos degraus, com valor de concentração de ar superior a $7 \%$ em quase todos os degraus, é suficiente para evitar a cavitação. A perda de energia específica para as condições de escoamento com e sem o aerador de fundo foram comparadas, verificando-se maior dissipação para a condição sem aerador de até 13\%. Esta diminuição na eficiência da dissipação ocorre devido a diminuição do fator de resistência do escoamento com a presença da aeração.

A utilização da ferramenta de fluido dinâmica computacional se mostrou muito eficaz para quantificação dos fenômenos existentes nos escoamentos em vertedouros em degraus e em canais de alta declividade. Essa ferramenta poderá ser utilizada em projetos de obras hidráulicas de forma a caracterizar o escoamento e para a otimização das características necessárias para a condição de projeto e ou do planejamento do ensaio em modelo reduzido. Não é escopo deste trabalho propor uma substituição da modelagem experimental, ela ainda é 
essencial na caracterização de algumas condições de escoamentos e para dar maior credibilidade aos resultados obtidos. Desta forma acredita-se que as ferramentas numéricas devem ser aplicadas de forma a otimizar o projeto na determinação de uma geometria, por exemplo, para a construção do modelo reduzido utilizado na caracterização do escoamento experimentalmente, para enfim, ser proposta a configuração final para construção.

Para continuação deste trabalho pode-se propor uma análise transiente do escoamento em vertedouro em degraus, na tentativa de determinar a variação da pressão nas paredes dos degraus e ainda uma análise da variação dos perfis de velocidade com possíveis existências de desprendimentos de vórtices e um estudo mais apurado da condição de aeração do escoamento. Propõe-se ainda o estudo de novas configurações de vertedouros, com diferentes inclinações, diferentes regimes de escoamento, com vazões especificas maiores.

A utilização de modelos mais apurados, como os modelos multifásicos não-homogêneos ou o modelos de turbulência de simulação de grandes escalas e emprego de malhas refinadas em todo domínio, poderia gerar resultados com mais representatividade dos fenômenos envolvidos, mas os tempos necessários para obtenção de resultados seriam bem maiores. Dessa forma propõe-se para os trabalhos futuros a utilização desses modelos mais apurados para verificar essa maior eficácia na representatividade dos fenômenos. 


\section{REFERÊNCIAS BIBLIOGRÁFICAS.}

AMADOR, A.; VAN DER GRAAF, G.; SÁNCHEZ-JUNY, M.; DOLZ, J.; SÁNCHEZTEMBLEQUE, F.; PUERTAS, J.. Characterization of the flow field in a stepped spillway by PIV. 12 ${ }^{\text {th }}$ International Symposium on Aplications of LASER Techniques of Fluid Mechanics, Lisboa, Portugal, p. 12-25. Jul. 2004.

BAKER, R. Brushes Clough wedge block spillway: progress report no. 3. SCEL Project Report. No. SJ542-4, University of Salford, Greater Manchester, U.K. 1994.

BAYAT, H. O. Stepped spillway model investigations. Proc., $17^{\text {th }}$ ICOLD Congress, Vienna, Austria, III, v. 66, p. 1809 - 1817. 1991.

BINDO, M.; GAUTIER, J.; LACROIX, F. The stepped spillway of M'Bali Dam. J. Int. Water Power and Dam Construction, v. 45, n. 1, p. 35 - 36. 1993

BRACKBILL, J.U, KOTHE, D.B.; ZEMACH, C. A Continuum Method for Modelling Surface Tension. Journal of Computational Physics. v. 100, p. 335-354. 1992

CARVALHO, P. D. Aeração de escoamento de alta velocidade em canais de forte declividade. Tese (Doutorado em Engenharia Civil), Escola de Engenharia de São Carlos Departamento de Hidráulica e Saneamento, Universidade de São Paulo, São Carlos-SP, 1997.

CFX. CFX 5 Solver Theory. Ansys Canada Ltda, Waterloo, Ontario, Canada. p. 250. 2004.

CHAMANI, M. R.; RAJARATNAM, N. Characteristics of skimming flow over stepped spillways. Journal of Hydraulic Engineering. ASCE, v.125, n. 4 , p. 361 - 368. 1999.

CHANSON, H. Hydraulics of skimming flows over stepped channels and spillways. Journal of Hydraulic. Research. v. 32, n. 3, p. $445-460.1994$ 
CHANSON, H. Measuring Air-Water Interface Area in Supercritical Open Flow. Water Resources. IAWPRC v. 31, n. 6, p. 1414-1420. 1997

CHANSON, H. Prediction of the transition nappe/skimming flow on a stepped channel. Journal of Hydraulic. Research, v. 34, n. 3, p 421-429. 1996.

CHANSON, H.; TOOMBES, L. Stream Reaeration in Nonuniform Flow: Macroroughness Enhancement. Journal of Hydraulic Engineering. p. 222-223. Mar. 2000.

CHANSON, H.; TOOMBES, L. Strong Interactions between Free-Surface aeration and turbulence in an open channel flow. Experimental Thermal and Fluid Science. 27, p 525535. 2003

CHANSON, H.; YASUDA, Y.; OHTSU, I. Flow resistance in skimming flows and its modelling. Canadian Journal of Civil Engineering, 29(6): 809-819. 2002

CHEN, Q.; DAI, G.; LIU, H. Volume of Fluid Model for Turbulence Numerical Simulation of Stepped Overflow. Journal of Hydraulic Engineering, ASCE, 128(7), 683-688. 2002

CHENG, X.; LUO, L; ZHAO, W.; LI, R. Two-phase flow simulation of aeration on stepped spillwasy. Progress in Natural Science, v. 14, n. 7, p. 626-630. 2004.

CHOUDHURY, D. Introduction to the Renormalization Group Method and Turbulence Modeling. Fluent Inc. Technical Memorandum TM-107, 1993.

CHOW, V. T. (1959). Open-Channel Hydraulics. Livro, McGRAW-HILL, p. 680. 1959

CHRISTODOULOU, G. C. Energy dissipation on stepped spillways. Journal of Hydraulic Engineering., ASCE, v. 119, n. 5, p. $644-649.1993$.

DAI-PRÁ, M. Caracterização do Escoamento sobre Vertedouros em Degraus Degraus de declividade 1V:1H. Dissertação (Mestrado), Instituto de Pesquisas Hidráulicas da Universidade Federal do Rio Grande do Sul, Porto Alegre, RS. 2004 
DALY, B.J.; HARLOW, F. H. Transport Equations in Turbulence. Physics and Fluids, v. 13, p. 2634-2649. 1970.

DIEZ-CASCON, J.; BLANCO, J. L.; REVILLA, J.; GARCIA, R. Studies on hydraulic behavior of stepped spillways. Journal International Water Power and Dam Construction, v. 43, n. 9, p. $22-26.1991$.

ELLIS, J. Guide to Analysis of Open-Channel Spillway Flow. CIRIA. Technical Note n. 134, Segunda Edição, London, UK. 1989.

ERVINE, D.A.; FALVEY, H.T.; KAHN A. R. Turbulent Flow Structure and Air Uptake at Aerations. International Journal on Hydropower and Dams, v. 2, n. 5, pp 89-96. Set. 1995.

ELVIRO, V.; MATEOS, C. Spanish research into stepped spillways. International Journal on Hydropower and Dams, v. 2, n. 5. p. 61-65. 1995.

ESSERY, I. T. S.; HORNER, M. W. The hydraulic design of stepped spillways. CIRIA. Rep. 33, U. K. 1978.

FLUENT. Fluent Inc. Product Documentation. 2000.

FORTUNA, A. O. Técnicas Computacionais para Dinâmica dos Fluidos, Livro,p. 432. 2000.

GIBSON, M. M.; LAUNDER, B. E. Ground Effects on Pressure Fluctuations in the Atmospheric Boundary Layer. Journal of Fluid Mechanic, v. 86, p. 491-511. 1978.

GOMES, J. F. Campo de Pressões. Condições de Incipiência à Cavitação em Vertedouros em Degraus com Declividades 1V:0,75H. Tese (Doutorado), Instituto de Pesquisas Hidráulicas da Universidade Federal do Rio Grande do Sul, Porto Alegre, RS. 2006

GULliVER, J. S.; HALVERSON, M. J. Air-Water Gás Transfer in Open Channels. Water Resources Research. v.25, n. 8, p. 1783 - 1793. 1989. 
HOLLINGWORTH, F.; DRUYTS, F. H. W. Rollcrete: Some Applications to Dams in South Africa. International Water Power and Dam Construction. v. 38, n.. 1, p 13-16. Jan. 1986.

HORNER, M. W. An Analysis of Flow on Cascades of Steps. Ph.D. thesis, Univ. of Birmingham, UK. 1969

HOUSTON, K. L. Hydraulic Model Studies of Upper Stillwater Dam and Stepped spillways and outlet Works. Denver: Bureau of Reclamation, p 51 (REC-ERC-87-6). 1987.

INGARD, K. U. Fundamentals of Waves and Oscillations. Cambridge University Press. 1988.

KANASHIRO, W. H. Vertedores em degraus: avaliação de efeitos do escoamento dos degraus na dissipação de energia. Tese (Doutorado), Escola Politécnica da Universidade de São Paulo, São Paulo, SP. 1995

LAUNDER, B. E.; SPALDING, D. B. Lectures in Mathematical Models of Turbulence. Academic Press, London, England. 1972.

LESIEUR, M. Turbulence in Fluids. Kluwer Academic Publishers, Livro. 1996.

LIEN, F. S.; LESCHZINER, M. A. Assessment of Turbulent Transport Models Including Non-Linear RNG Eddy-Viscosity Formulation and Second-Moment Closure. Computers and Fluids, v. 23, n. 8, p. 983-1004. 1994.

LILLY, D. K.(1966). "On the Application of the Eddy Viscosity Concept in the Inertial Subrange of Turbulence”. NCAR Manuscript 123.

LIMA, A. C. M. Caracterização da estrutura turbulenta em escoamentos aerados em canal de forte declividade com auxílio de técnicas de velocimetria a LASER, Tese (Doutorado em Engenharia Civil), Escola de Engenharia de São Carlos - Departamento de Hidráulica e Saneamento, Universidade de São Paulo, São Carlos-SP, v. 1 e 2, 2003. 
MATOS, J. Discussão do artigo: Characteristics of skimming flow over stepped spillways. Journal of Hydraulic Engineering. ASCE. v. 126 n.11, p. 860-873. 2000.

MATOS, J.; FRIZELL, K. H. Air concentration measurements in highly turbulent aerated flow. Proc., 28th IAHR Congr., Theme D, Vol. 1, Sam S. Y. Wang and Torkild Carstens, eds., San Francisco, p. 149-154. 1997

MATOS, J. S. G.; QUINTELA, A. C. Emulsionamento de ar e energia específica residual do escoamento em descarregadores de cheias em degraus. In: Congresso da Água, 3., Lisboa, 1996; Simpósio Luso-Brasileiro de Engenharia Sanitária e Ambiental - SILUBESA, 7., Lisboa, 1996. [Anais] Lisboa: APRH, ABES, v. 2, p. 495-503. 1996

MATOS, J.; SANCHEZ, M.; QUINTELA, A.; DOLZ, J. Characteristic depth and pressure profiles in skimming flow over stepped spillways. In Proceedings of the 28th Biennial Congress of the International Association for Hydraulic Research, Graz, Austria, p. 2227, Session B14. CD-ROM. Ago. 1999.

NOVÁK, P.A.; MOFFAT, I.B.; NALLURI, C.; NARAYANAN, R. Hydraulic structures. Unwin Hyman, London, UK. 1990.

OLINGER, J. C. Contribuição ao Estudo da Distribuição de Pressões nos Vertedouros em Degraus. Tese (Doutorado), Escola Politécnica da Universidade de São Paulo, São Paulo, SP. 2001.

OTA, J. J.; TOZZI, M. J. e PINTO, N. L. S. Estudos Hidráulicos em Modelo Reduzido do Vertedouro em Degraus do Aproveitamento Hidrelétrico de Cubatão. Relatório no 02 Determinação das Características Básicas do Escoamento sobre a Calha do Vertedouro. 1990.

PEGRAM, G. G. S.; OFFICER, A. K.; MOTTRAM, S. R. Hydraulics of skimming flow on modeled stepped spillways. Journal Hydraulic Engineering. ASCE. v. 125, n. 5, p. $500-$ 510. 1999. 
PENNA, J. A. Estudo da influência da mistura hidráulica rápida na floculação de águas de abastecimento. Dissertação de Mestrado da Universidade de São Paulo. Brasil. p.150. 1984.

PETERKA, A. J. The Effect of entrained Air on Cavitation pitting. In: Minnesota International Hydraulics Convention. Minneapolis. Proceeding. Minneapolis: IARH/ASCE, 1953. p. 507-518. 1953.

PEYRAS, L.; ROYET, P.; DEGOUTTE, G. Flow and energy dissipation over gabion weirs. Journal of Hydraulic. Engineering. ASCE. v. 118, n. 5, p. 707-717. 1992.

PORTO, R. M. Hidráulica Básica. Projeto REENGE. p. 519. 2004.

RAJARATNAM, N. Skimming flow in stepped spillways. Journal of Hydraulic Engineering. ASCE, v. 116, n. 4, p. 587 - 591. 1990.

RAJARATNAM, N.; CHAMANI, M. R. Energy loss at drops. Journal of. Hydraulic Research, v. 33, n. 3, p.373-384. 1995.

ROMA, W. Fenômenos de Transporte para Engenharia. Editora Rima. 2006.

RUFF, J.F.; FRIZELL, K.H.. Air concentration measurements in highly-turbulent flow on a steeply-sloping chute. In Proceedings of the ASCE Hydraulic Engineering Conference, Buffalo, N.Y., 1-5. Editado por C.A. Pugh. American Society of Civil Engineers, New York, v. 2, p. 999-1003. Ago. 1994.

SANAGIOTTO, D. G. Caracterização do Escoamento sobre Vertedouros em Degraus Degraus de declividade 1V:0,75H Dissertação (Mestrado), Instituto de Pesquisas Hidráulicas da Universidade Federal do Rio Grande do Sul, Porto Alegre, RS. 2003

SCHUlZ, H. E. Alternativa de Turbulência. (Projeto Reenge) Publicação Escola de Engenharia de São Carlos da Universidade de São Paulo, São Carlos, SP. 2001 
SHIH, T. H.; LIOU, W. W.; SHABBIR, A.; YANG, Z.; ZHU, J. A New $k$ - $\epsilon$ Eddy-Viscosity Model for High Reynolds Number Turbulent Flows - Model Development and Validation”. Computers Fluids, v. 24 n. 3, p. 227-238. 1995.

SMAGORINSKY, J. General Circulation Experiments with the Primitive Equations. I. The Basic Experiment. Monthly Weather Review, v. 91, p. 99-164. 1963.

SORENSEN, R. M. Stepped spillway hydraulic model investigation. Journal of Hydraulic Engineering. ASCE, v. 111.n. 12, p. 1461 - 1472. 1985.

STEPHENSON, D. Energy dissipation down stepped spillways. Water Power and Dam Construction. p. 27-30. Set. 1991.

STRAUB, L. G.; ANDERSON, A. G. (1958). Experiments on self-aerated flow in open channels. Proc. ASCE, v. 87, n. 7, p. 1890-1 - 1890-35. 1958.

TOSCANO, M. Estudo de Dissipadores de Energia para obras hidráulicas de pequeno porte. Dissertação (Mestrado), Escola Politécnica da Universidade de São Paulo, São Paulo, SP. 1999.

TOZZI, M. J. Caracterização/Comportamento de Escoamentos em Vertedouros com Paramento em Degraus. Tese (Doutorado), Escola Politécnica da Universidade de São Paulo, São Paulo, SP. 1992.

TOZZI, M. J. Residual energy in stepped spillways. Journal International Water Power and Dam Construction. v. 46, p. 32 - 34. 1994.

TOZZI, M. J.; TANIGUCHI, E.; OTA, J. J. Air concentration in flows over stepped spillways. Proceedings of FEDSM'98. 1998 ASME Fluids Engineering Division Summer Meeting. Junho de 1998.

VENNARD, J. K; STREET, R. L., Elementos de Mecânica dos Fluidos. Livro. p. 687. 1978. 
WHITE, F. M., Mecânica dos Fluidos, Livro. p. 570. 1999.

WOOD, I. R. Air Entrainment in High Speed Flows. Proc, International Symposium on Scale Effects in Modelling Hydraulic Structures, IAHR, Esslingen, Germany, H. KOBUS editor, artigo 4.1. 1984.

WOOD, I. R.; CAIN, P. Measurements of Self-Aerated Flow on a Spillway. Journal of The Hydraulics Division. v. 107 (HY11). P. 1425-1444. 1989.

YASUDA, Y.; OHTSU, I. Flow resistence of skimming flow in stepped channels, In: Congress IAHR, 28, GRAZ-AUSTRIA. Proceedings: abstract volume, papers on CD-ROM. Graz: IEHR, p. 6. 1999. 


\section{APÊNDICE A}

Rugosidade ( $k_{a}$ ) de $2 \mathrm{~cm}$.

Seção I.
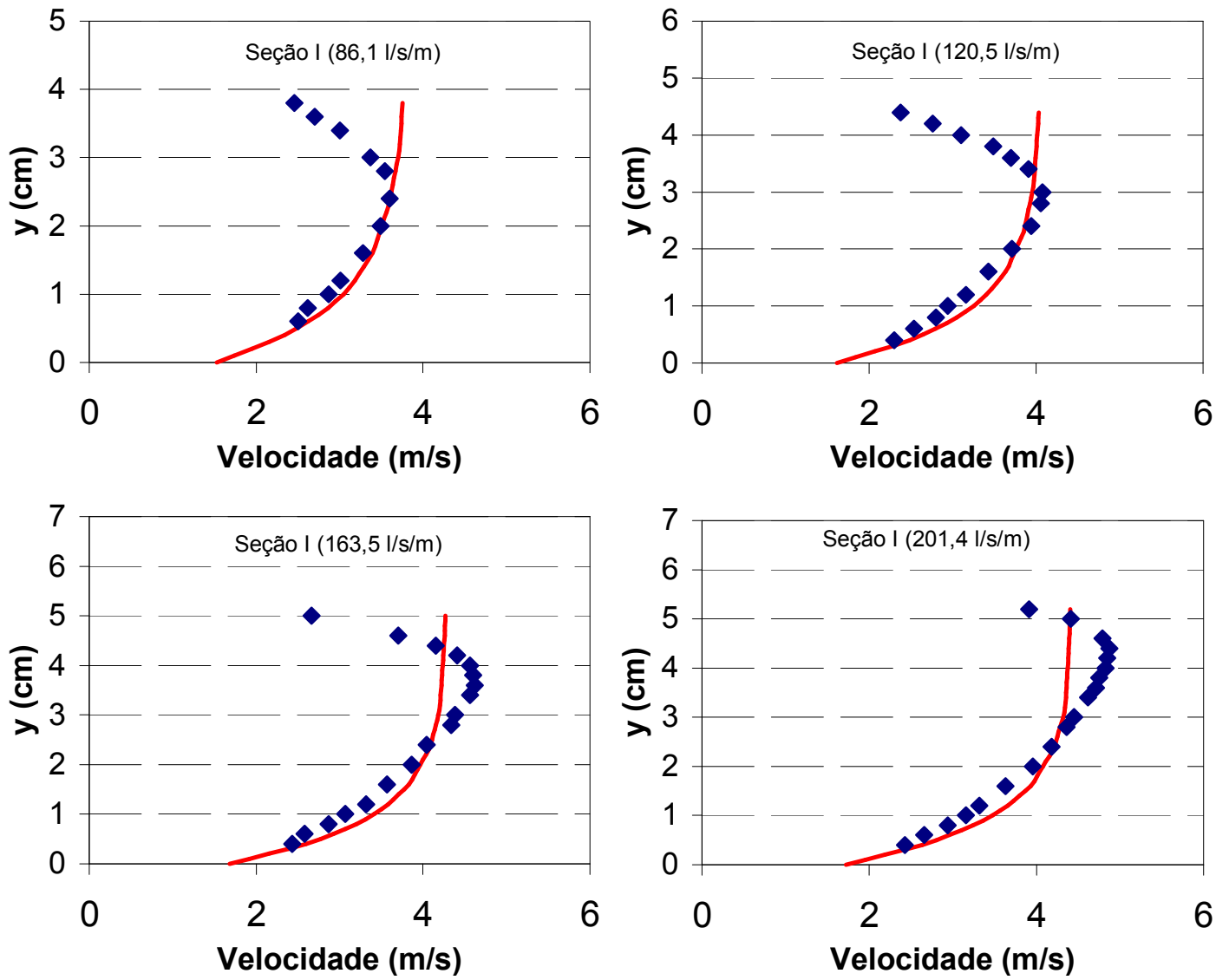

$$
\begin{aligned}
& \text { Experimental (TOZZI, 1992) } \\
& \text { — Numérico - CFD }
\end{aligned}
$$

Figura A.1. Comparação entre os perfis de velocidade experimental (TOZZI,1992) e numérico - Seção I $-k_{a}=2 \mathrm{~cm}$. 
Seção II.
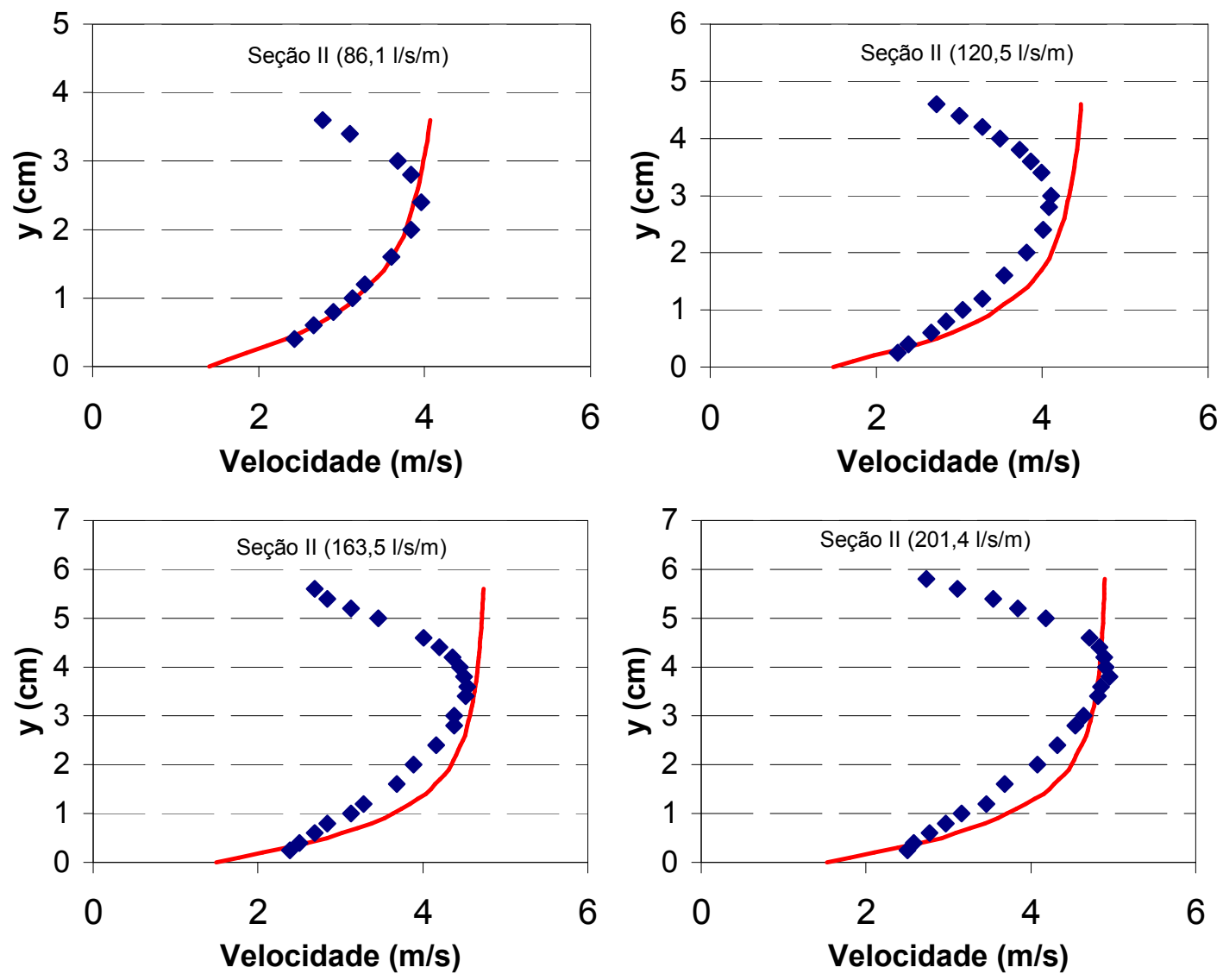

- Experimental (TOZZI, 1992)

- Numérico - CFD

Figura A.2. Comparação entre os perfis de velocidade experimental (TOZZI,1992) e numérico - Seção II $-k_{a}=2 \mathrm{~cm}$. 
Seção III.
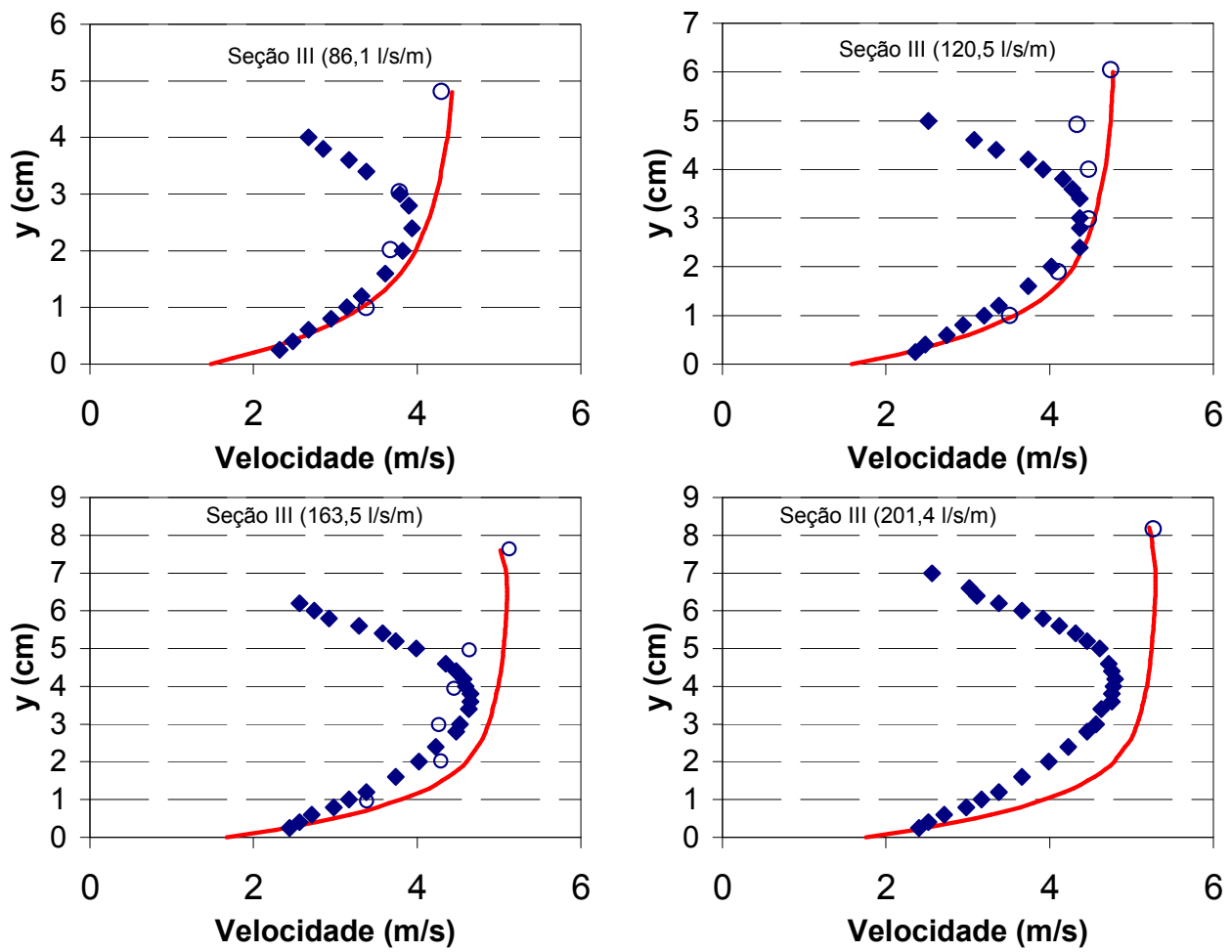

- Tubo de Estagnação (TOZZI, 1992)

○ Eletrodos ou Flutuantes (TOZZI, 1992)

— Numérico - CFD

Figura A.3. Comparação entre os perfis de velocidade experimental (TOZZI,1992) e numérico - Seção III $-k_{a}=2 \mathrm{~cm}$. 
Rugosidade $\left(k_{a}\right)$ de $3 \mathrm{~cm}$.

Seção I.
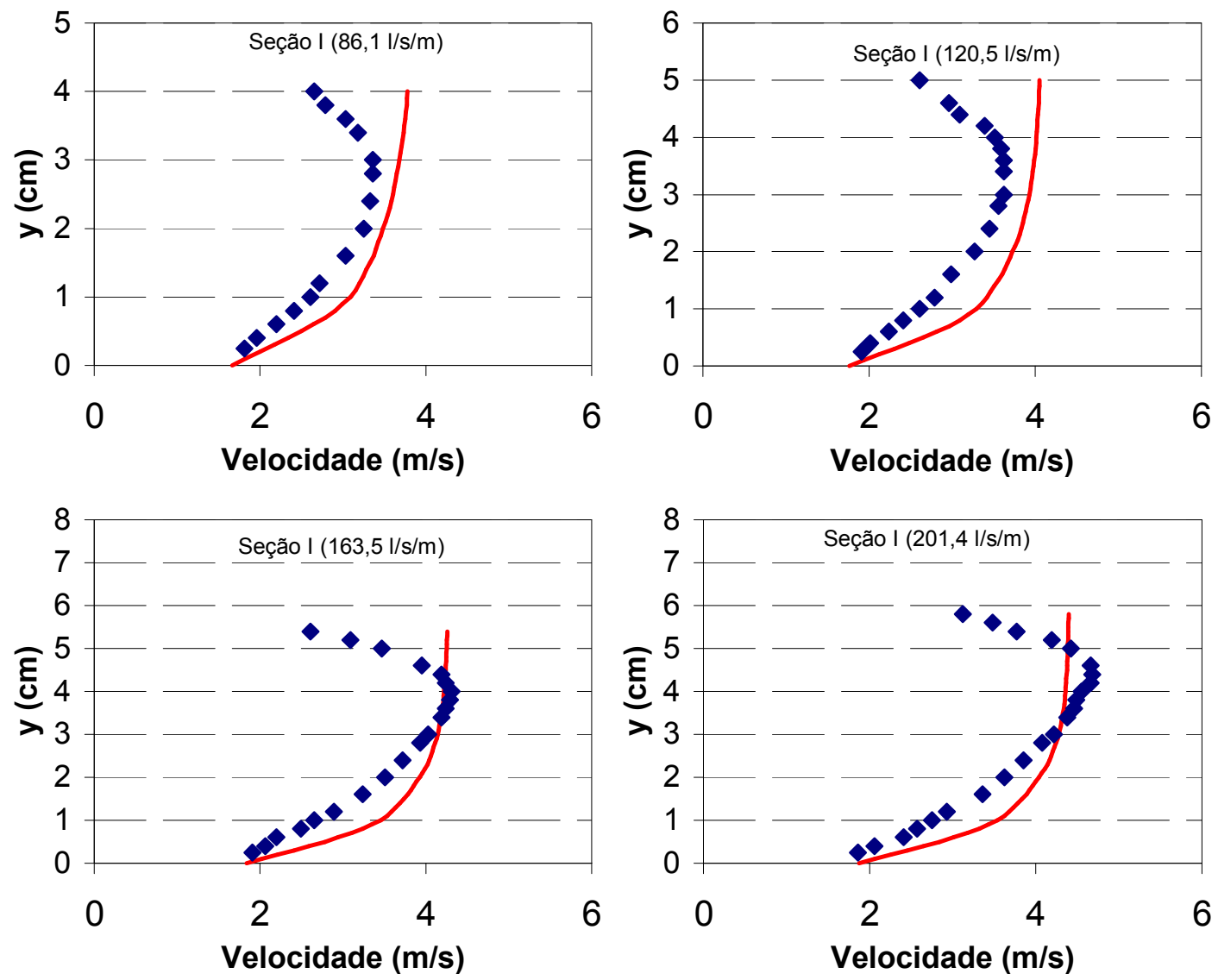

- Experimental (TOZZI, 1992)

— Numérico - CFD

Figura A.4. Comparação entre os perfis de velocidade experimental (TOZZI,1992) e numérico - Seção I $-k_{a}=3 \mathrm{~cm}$. 
Seção II.
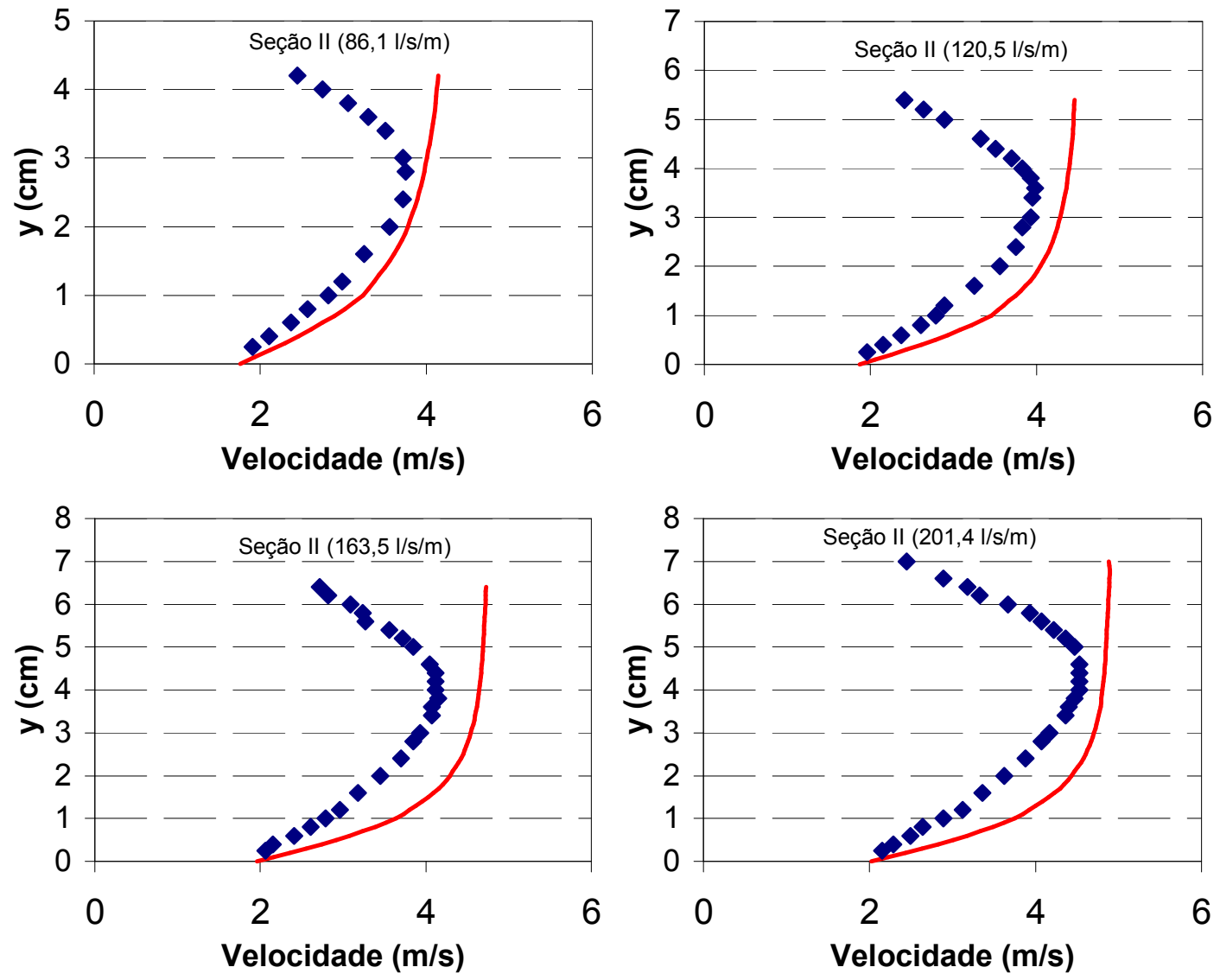

- Experimental (TOZZI, 1992)

_ Numérico - CFD

Figura A.5. Comparação entre os perfis de velocidade experimental (TOZZI,1992) e numérico - Seção II $-k_{a}=3 \mathrm{~cm}$. 
Seção III.
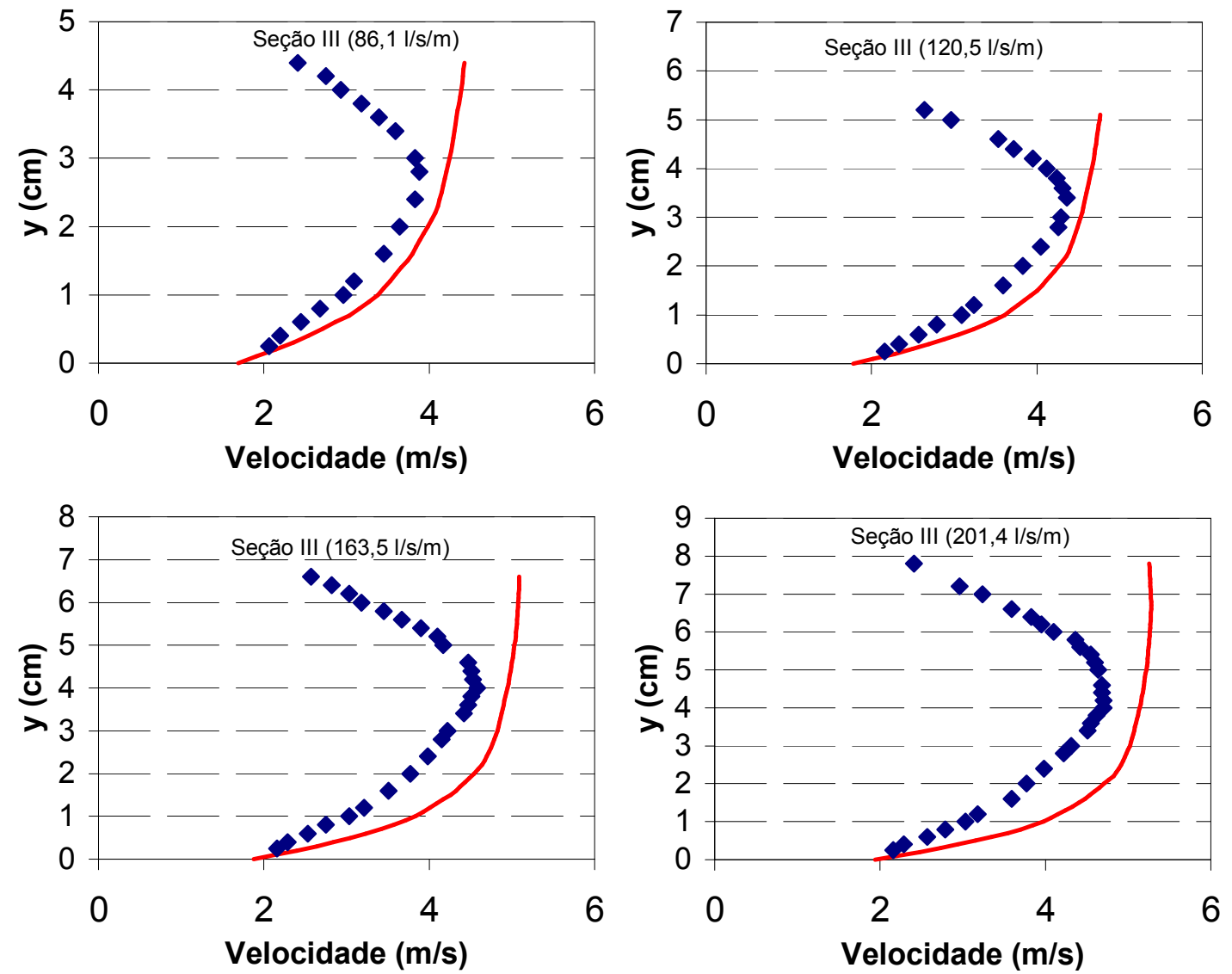

Experimental (TOZZI, 1992)
— Numérico - CFD

Figura A.6. Comparação entre os perfis de velocidade experimental (TOZZI,1992) e numérico - Seção III $-k_{a}=3 \mathrm{~cm}$. 
Rugosidade $\left(k_{a}\right)$ de $6 \mathrm{~cm}$.

Seção I.
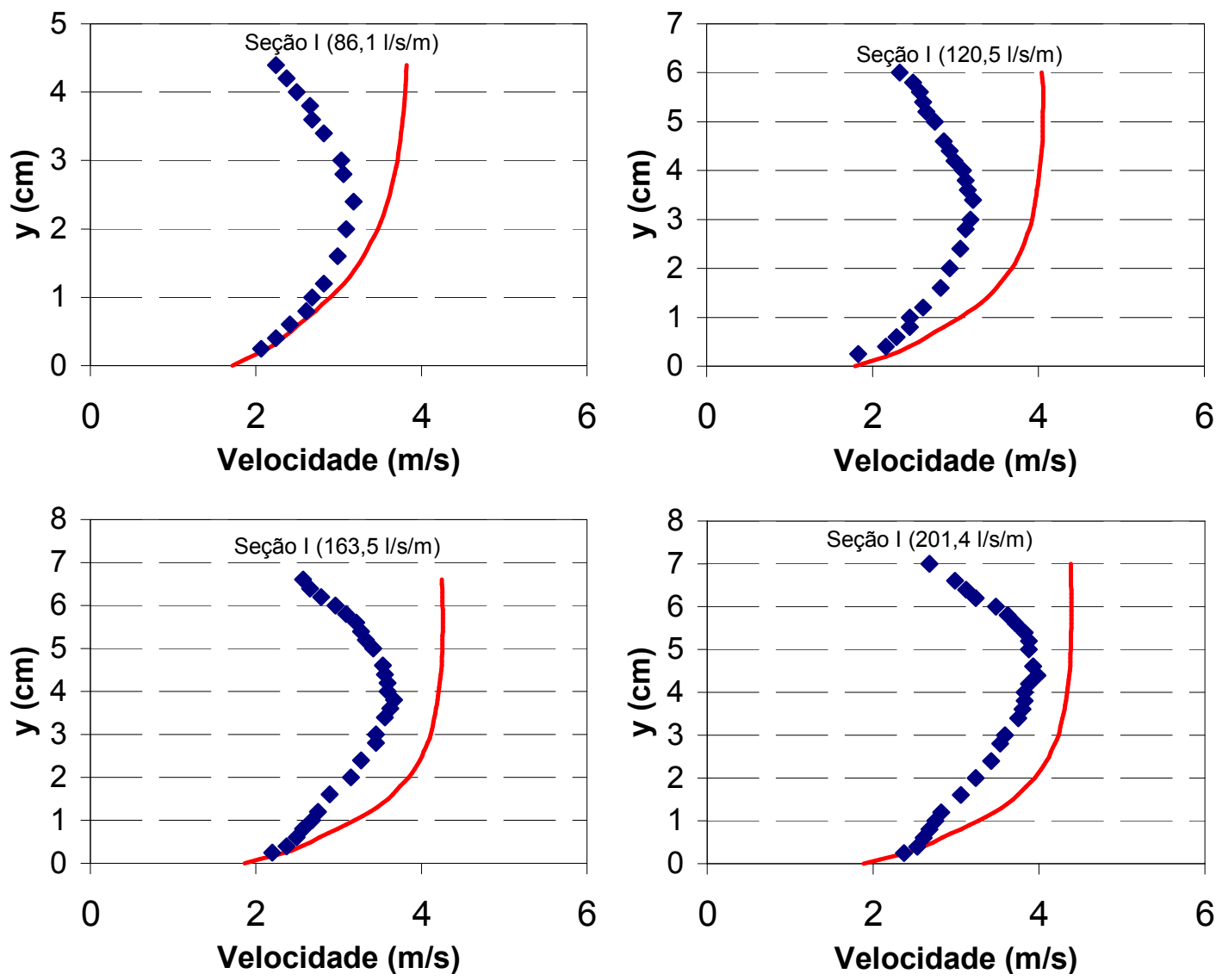

- Experimental (TOZZI, 1992) — Numérico - CFD

Figura A.7. Comparação entre os perfis de velocidade experimental (TOZZI,1992) e numérico - Seção I $-k_{a}=6 \mathrm{~cm}$. 
Seção II.
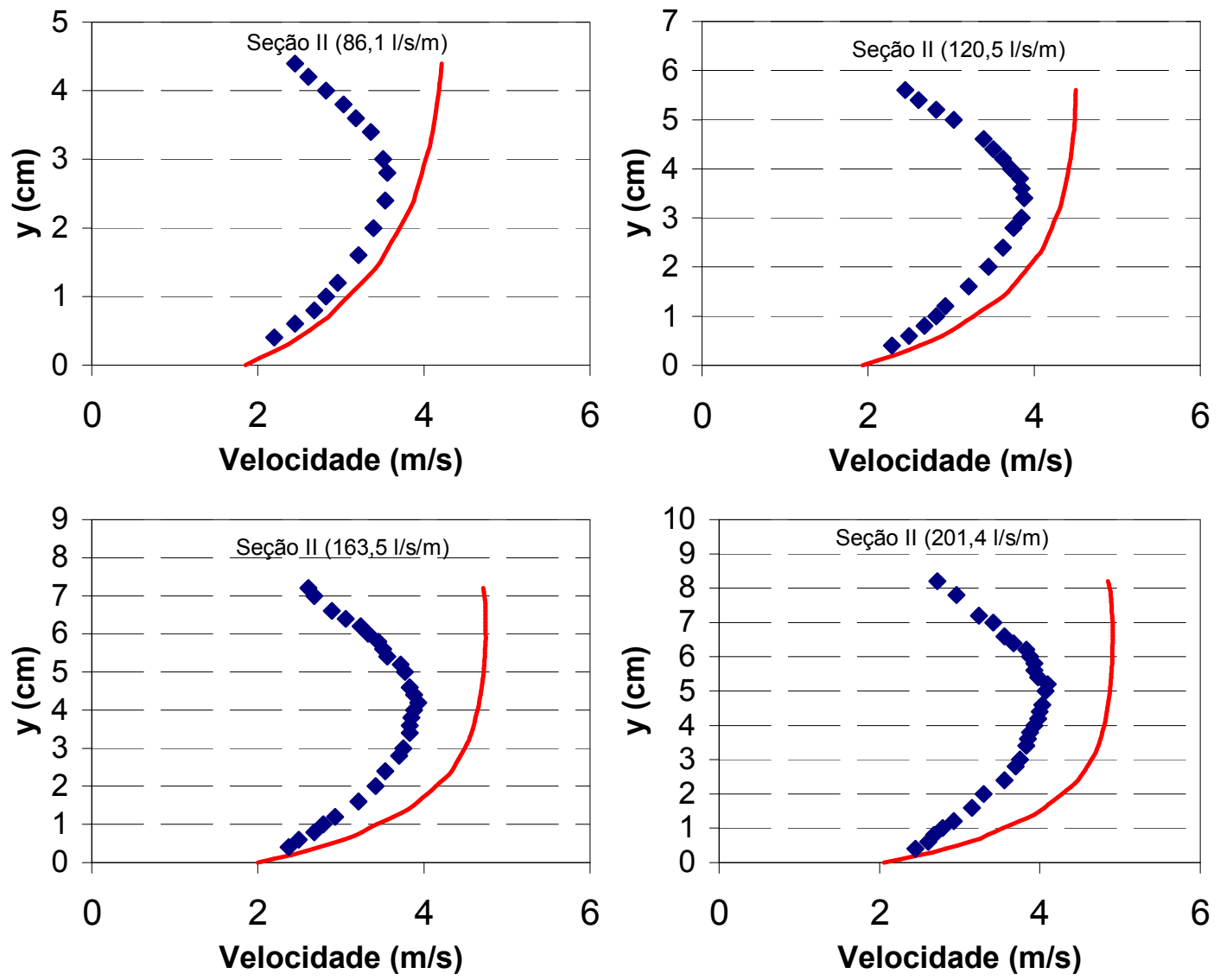

Experimental (TOZZI, 1992)
— Numérico - CFD

Figura A.8. Comparação entre os perfis de velocidade experimental (TOZZI,1992) e numérico - Seção II $-k_{a}=6 \mathrm{~cm}$. 
Seção III.
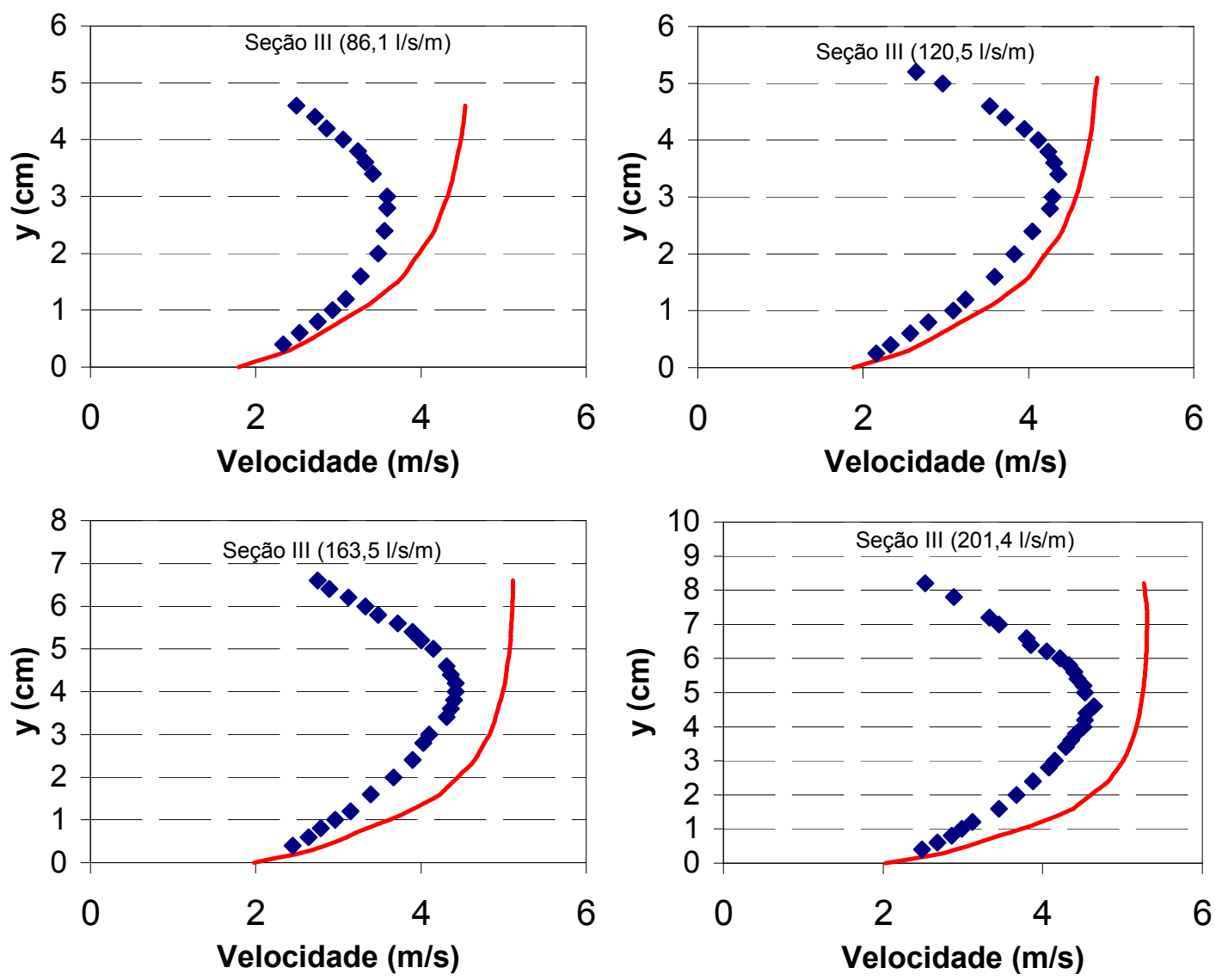

Experimental (TOZZI, 1992)
— Numérico - CFD

Figura A.9. Comparação entre os perfis de velocidade experimental (TOZZI,1992) e numérico - Seção III $-k_{a}=6 \mathrm{~cm}$. 


\section{APÊNDICE B}

Rugosidade ( $k_{a}$ ) de $2 \mathrm{~cm}$.
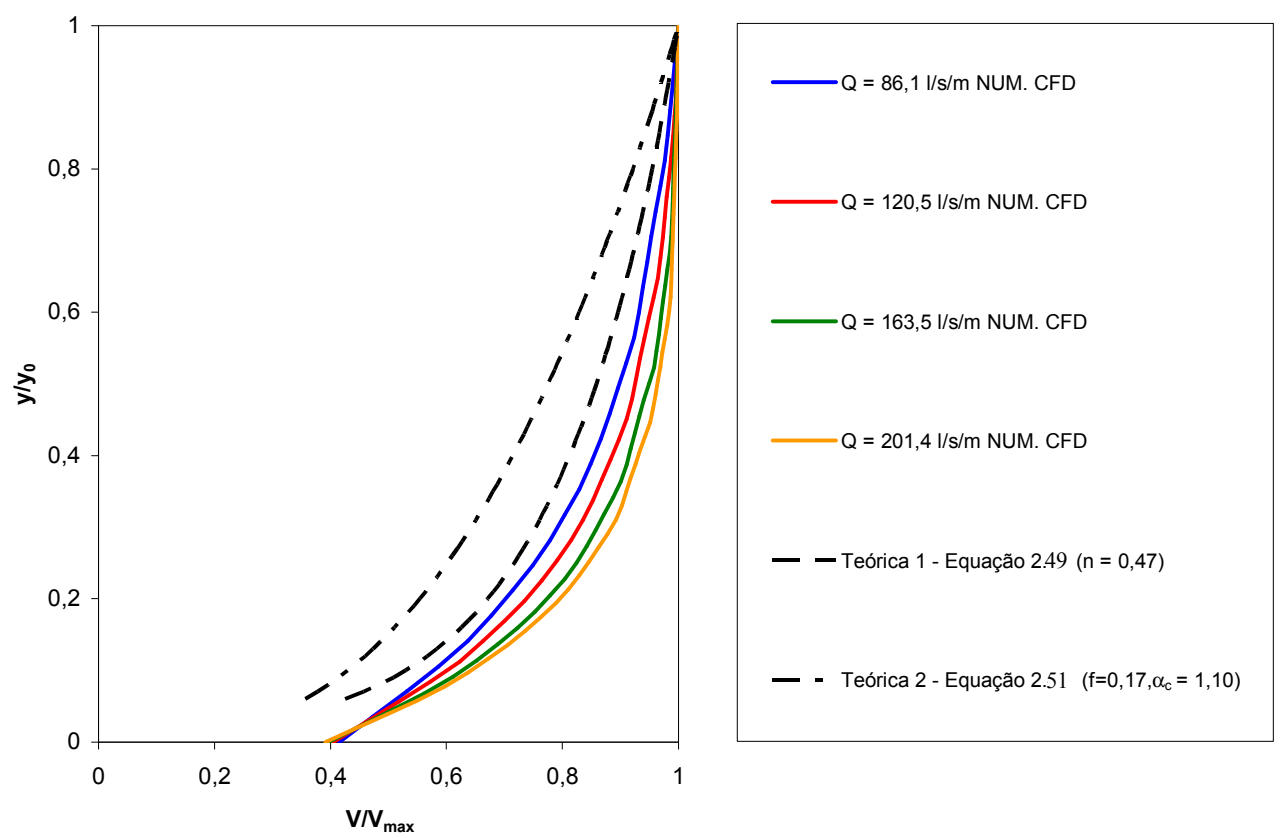

Figura B.1. Perfis de velocidades adimensionalizados para seção I $-k_{a}=2 \mathrm{~cm}$.
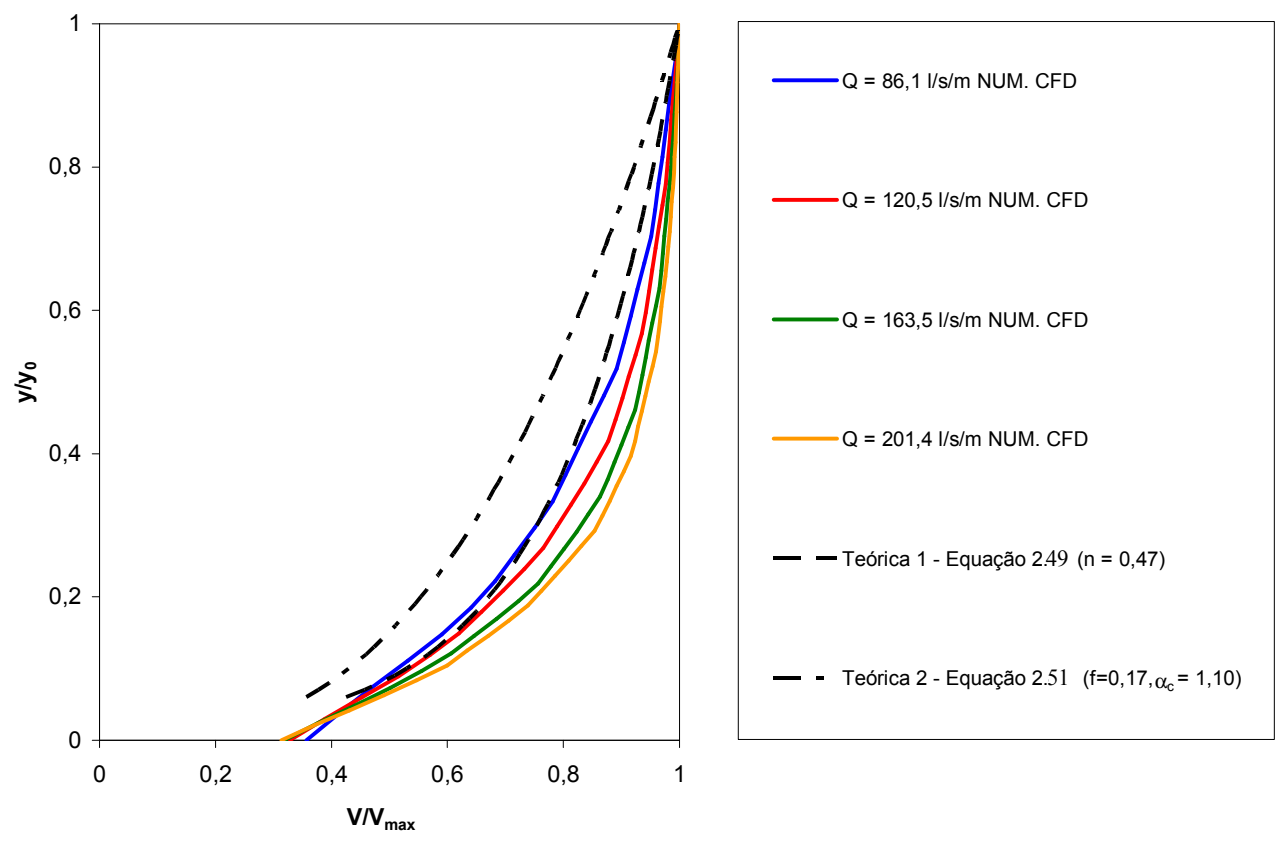

Figura B.2. Perfis de velocidades adimensionalizados para seção II $-k_{a}=2 \mathrm{~cm}$. 

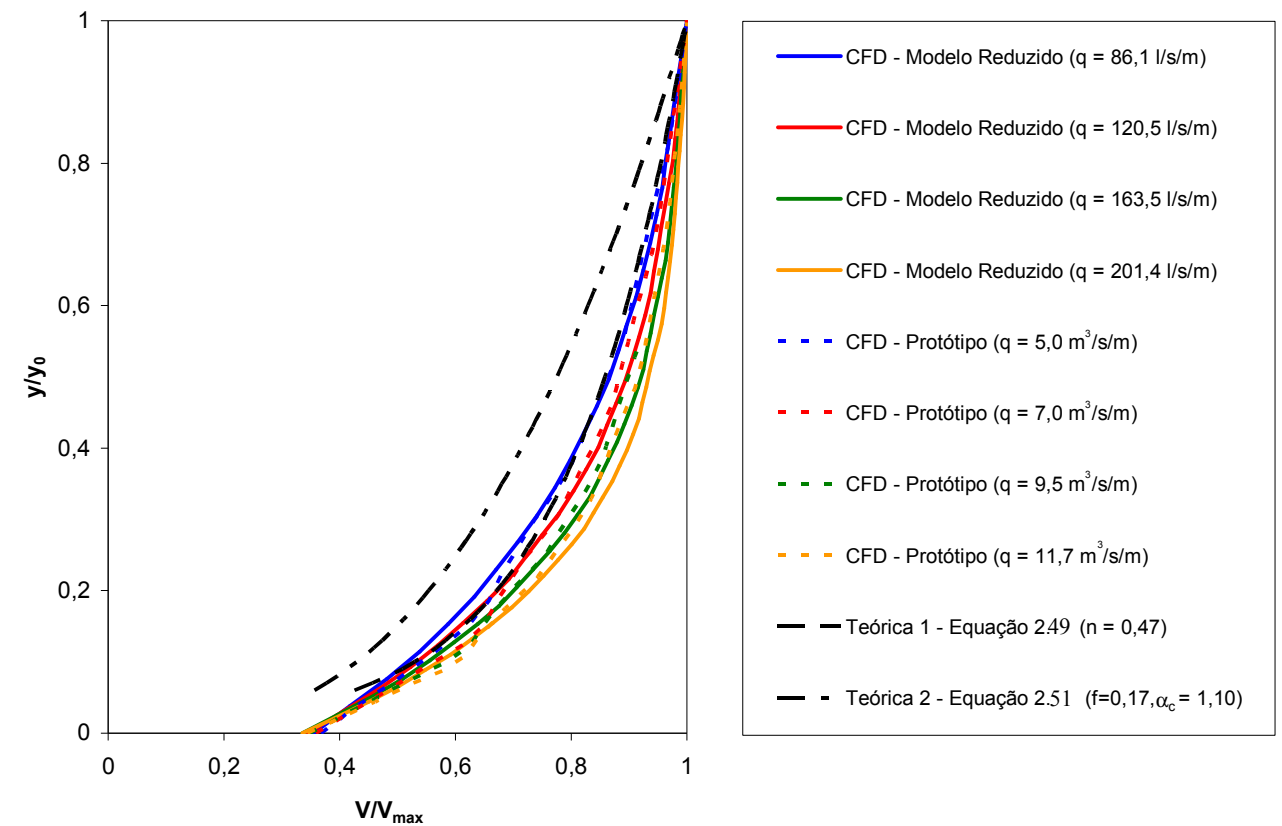

Figura B.3. Perfis de velocidades adimensionalizados para seção III $-k_{a}=2 \mathrm{~cm}$.

Rugosidade $\left(k_{a}\right)$ de $3 \mathrm{~cm}$.
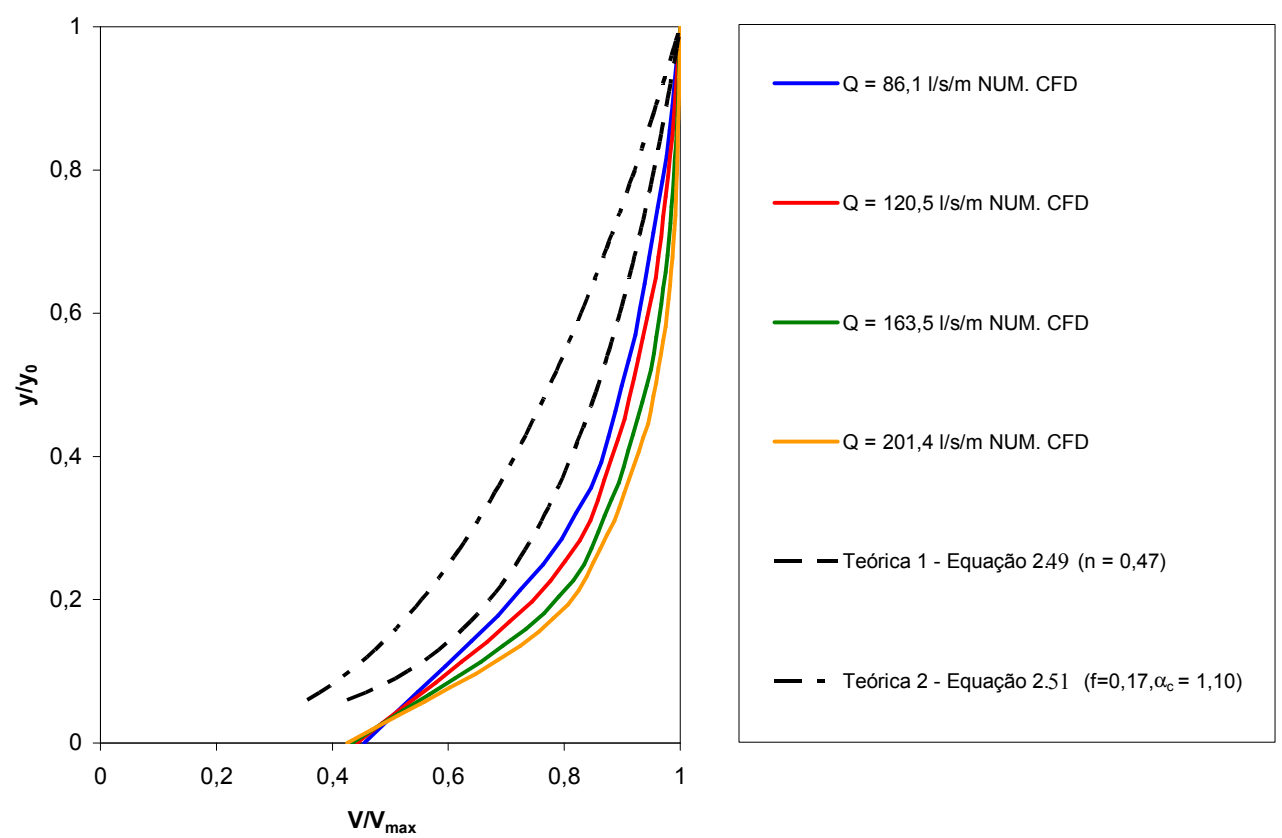

Figura B.4. Perfis de velocidades adimensionalizados para seção I $-k_{a}=3 \mathrm{~cm}$. 


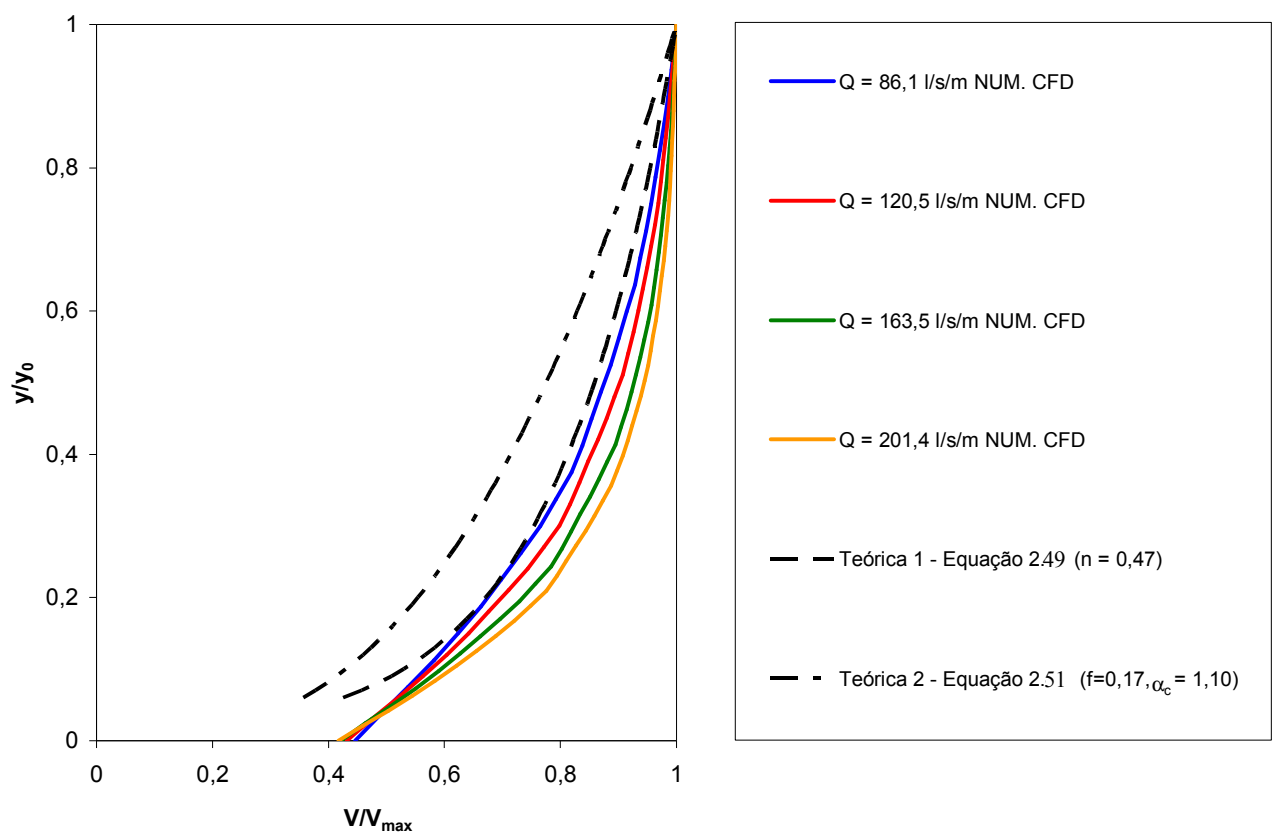

Figura B.5. Perfis de velocidades adimensionalizados para seção II $-k_{a}=3 \mathrm{~cm}$.

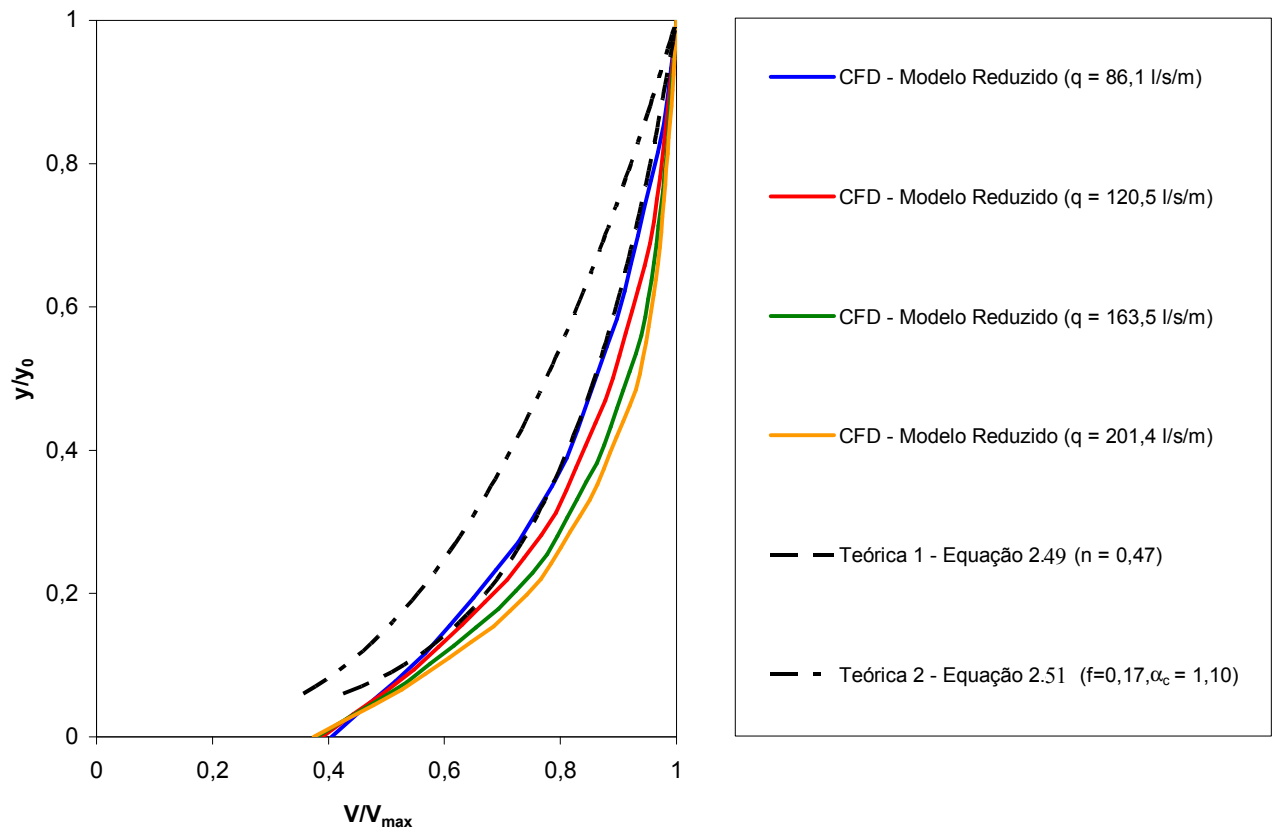

Figura B.6. Perfis de velocidades adimensionalizados para seção III $-k_{a}=3 \mathrm{~cm}$. 
Rugosidade ( $\left.k_{a}\right)$ de $6 \mathrm{~cm}$.

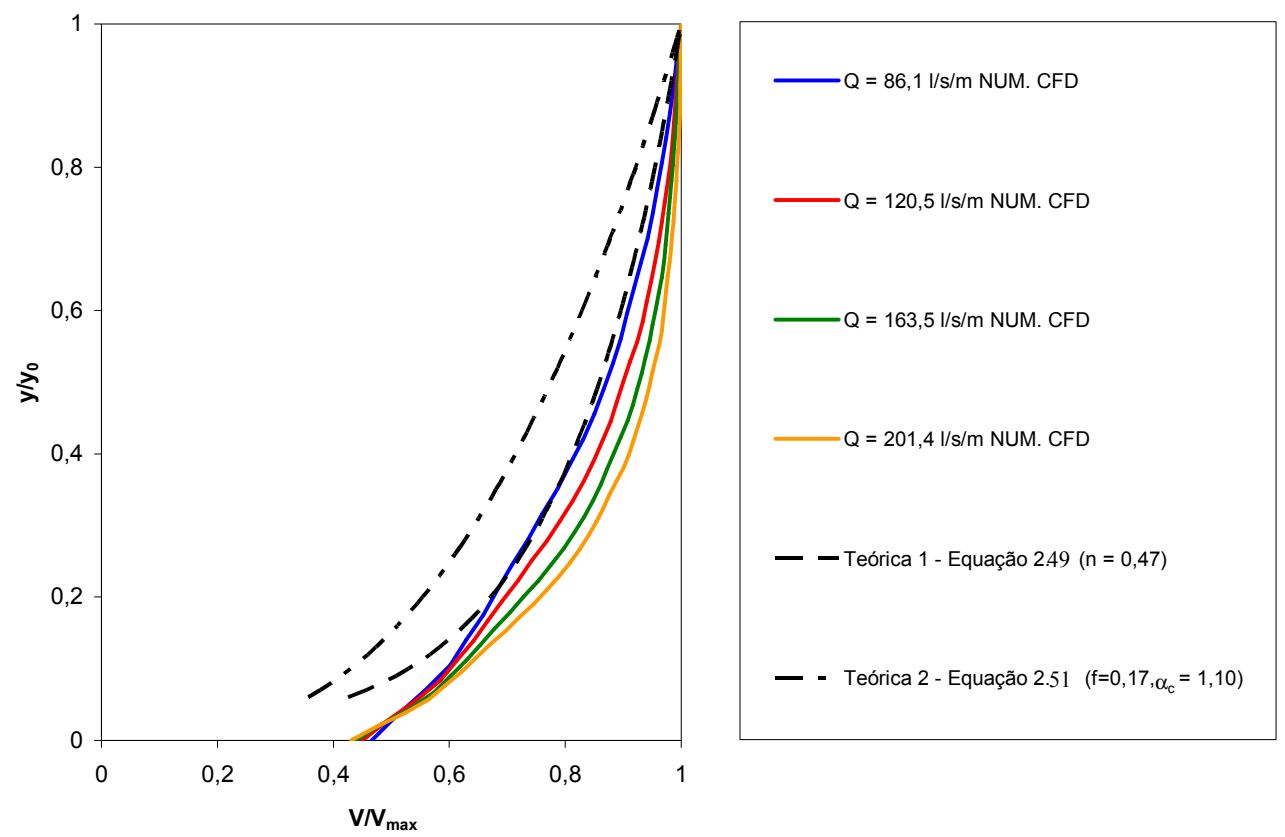

Figura B.7. Perfis de velocidades adimensionalizados para seção I $-k_{a}=6 \mathrm{~cm}$.

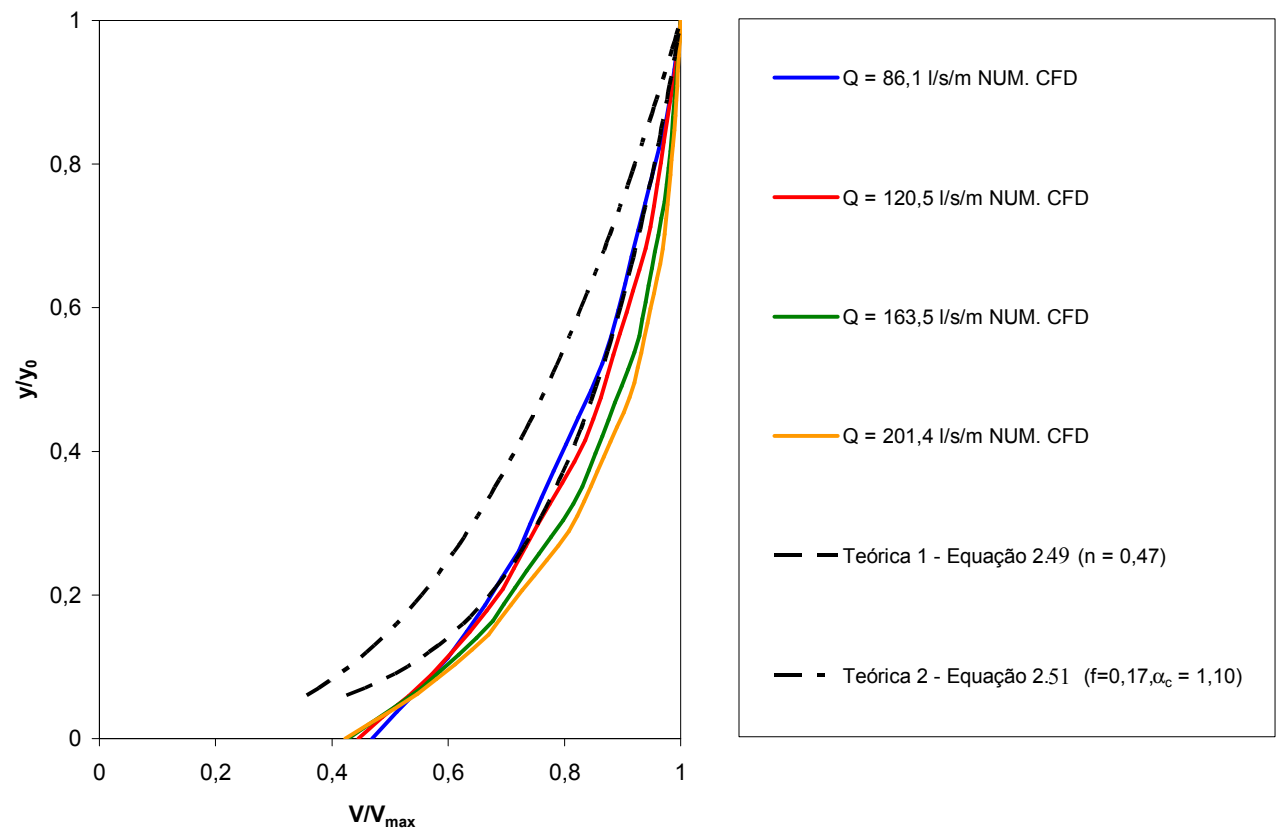

Figura B.8. Perfis de velocidades adimensionalizados para seção II $-k_{a}=6 \mathrm{~cm}$. 


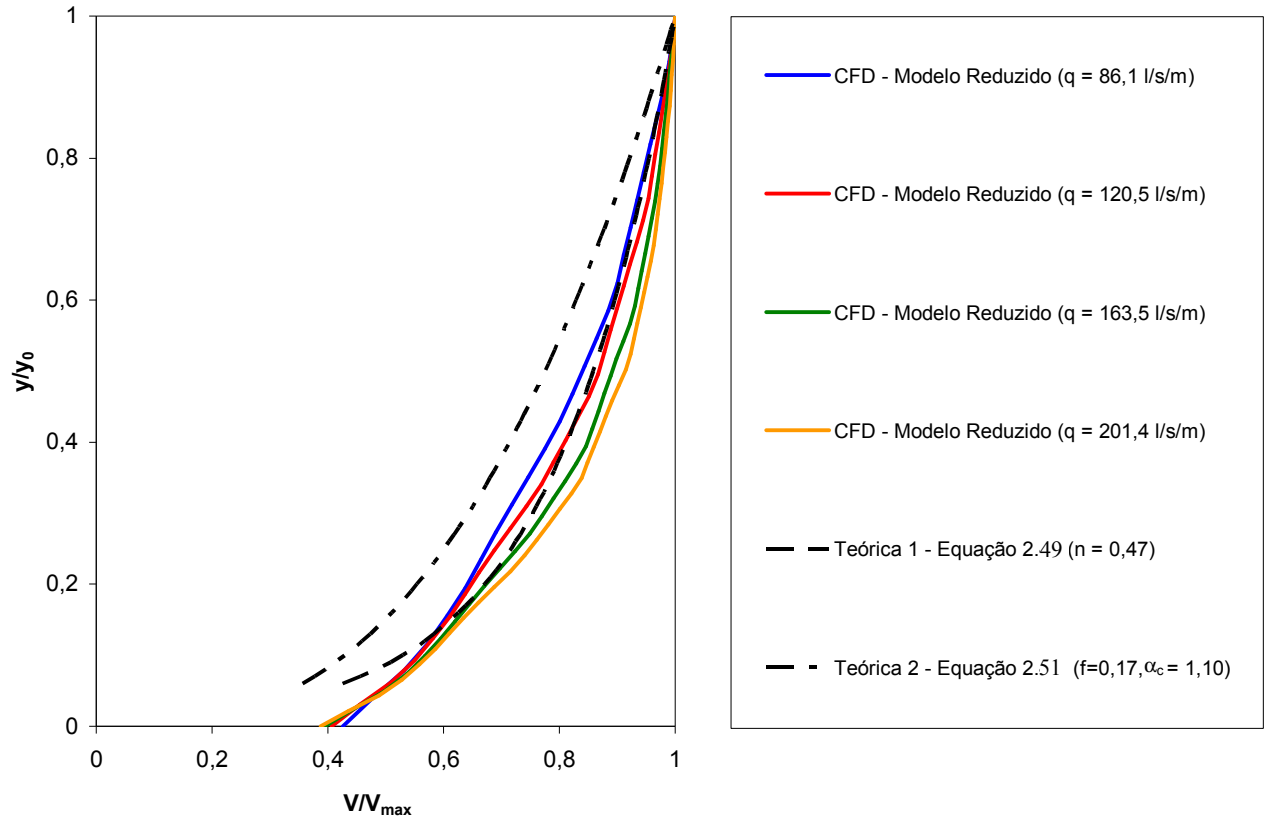

Figura B.9. Perfis de velocidades adimensionalizados para seção III $-k_{a}=6 \mathrm{~cm}$. 


\section{APÉNDICE C}

Tabela C.1. Resultados da Simulação Numérica (CFD) para rugosidade $k_{a}=3 \mathrm{~cm}$.

\begin{tabular}{|c|c|c|c|c|c|c|c|c|c|c|}
\hline Seção & $\begin{array}{c}\mathrm{q} \\
(\mathrm{l} / \mathrm{m} / \mathrm{s})\end{array}$ & $\begin{array}{c}\mathrm{y}_{\mathrm{c}} \\
(\mathrm{cm})\end{array}$ & $\begin{array}{c}\mathrm{V} \\
(\mathrm{m} / \mathrm{s})\end{array}$ & $\begin{array}{c}\mathrm{y}_{\mathrm{o}} \\
(\mathrm{cm})\end{array}$ & $\alpha_{c}$ & $\begin{array}{c}\mathrm{H} \\
(\mathrm{m})\end{array}$ & $\begin{array}{l}\mathrm{H}_{\mathrm{o}} \\
(\mathrm{m})\end{array}$ & $\Delta \mathrm{H} / \mathrm{H}_{\mathrm{o}}$ & $\mathrm{H}_{\mathrm{barr}} / \mathrm{y}_{\mathrm{c}}$ & $f$ \\
\hline \multirow{5}{*}{ I } & 68,8 & 7,84 & 2,87 & 2,40 & 1,105 & 0,487 & 1,151 & 0,577 & 13,17 & 0,183 \\
\hline & 86,1 & 9,11 & 3,07 & 2,81 & 1,135 & 0,573 & 1,170 & 0,511 & 11,34 & 0,187 \\
\hline & 120,5 & 11,40 & 3,41 & 3,54 & 1,111 & 0,692 & 1,204 & 0,425 & 9,07 & 0,192 \\
\hline & 163,5 & 13,97 & 3,71 & 4,41 & 1,105 & 0,818 & 1,243 & 0,341 & 7,40 & 0,201 \\
\hline & 201,4 & 16,05 & 3,90 & 5,16 & 1,108 & 0,888 & 1,274 & 0,303 & 6,44 & 0,213 \\
\hline \multirow{5}{*}{ II } & 68,8 & 7,84 & 3,05 & 2,25 & 1,133 & 0,561 & 1,517 & 0,630 & 18,27 & 0,152 \\
\hline & 86,1 & 9,11 & 3,25 & 2,67 & 1,166 & 0,656 & 1,532 & 0,572 & 15,73 & 0,161 \\
\hline & 120,5 & 11,40 & 3,62 & 3,33 & 1,130 & 0,788 & 1,559 & 0,495 & 12,58 & 0,160 \\
\hline & 163,5 & 13,97 & 3,98 & 4,11 & 1,123 & 0,948 & 1,591 & & 10,26 & 0,163 \\
\hline & 201,4 & 16,05 & 4,22 & 4,78 & 1,119 & 1,063 & 1,618 & 0,343 & 8,93 & 0,169 \\
\hline \multirow{5}{*}{ III } & 68,8 & 7,84 & 3,17 & 2,17 & 1,145 & 0,606 & 1,951 & 0,689 & 23,37 & 0,136 \\
\hline & 86,1 & 9,11 & 3,37 & 2,57 & 1,184 & 0,713 & 1,970 & 0,638 & 20,13 & 0,144 \\
\hline & 120,5 & 11,40 & 3,77 & 3,20 & 1,158 & 0,872 & 2,004 & 0,565 & 16,09 & 0,141 \\
\hline & 163,5 & 13,97 & 4,16 & 3,93 & 1,131 & 1,041 & 2,043 & 0,490 & 13,12 & 0,142 \\
\hline & 201,4 & 16,05 & 4,43 & 4,54 & 1,118 & 1,166 & 2,074 & 0,438 & 11,42 & 0,145 \\
\hline
\end{tabular}


Tabela C.2. Resultados da Simulação Numérica (CFD) para rugosidade $\mathrm{k}_{\mathrm{a}}=6 \mathrm{~cm}$.

\begin{tabular}{ccccccccccc}
\hline Seção & $\begin{array}{c}\mathrm{q} \\
(\mathrm{l} / \mathrm{m} / \mathrm{s})\end{array}$ & $\begin{array}{c}\mathrm{y}_{\mathrm{c}} \\
(\mathrm{cm})\end{array}$ & $\begin{array}{c}\mathrm{V} \\
(\mathrm{m} / \mathrm{s})\end{array}$ & $\begin{array}{c}\mathrm{y}_{\mathrm{o}} \\
(\mathrm{cm})\end{array}$ & $\alpha_{\mathrm{c}}$ & $\begin{array}{c}\mathrm{H} \\
(\mathrm{m})\end{array}$ & $\begin{array}{c}\mathrm{H}_{\mathrm{o}} \\
(\mathrm{m})\end{array}$ & $\Delta \mathrm{H} / \mathrm{H}_{\mathrm{o}}$ & $\mathrm{H}_{\mathrm{barr}} / \mathrm{y}_{\mathrm{c}}$ & $f$ \\
\hline & 68,8 & 7,84 & 2,81 & 2,45 & 1,077 & 0,459 & 1,151 & 0,601 & 13,17 & 0,194 \\
$\mathrm{I}$ & 86,1 & 9,11 & 3,02 & 2,85 & 1,121 & 0,549 & 1,170 & 0,531 & 11,34 & 0,197 \\
& 120,5 & 11,40 & 3,35 & 3,59 & 1,131 & 0,684 & 1,204 & 0,432 & 9,07 & 0,201 \\
& 163,5 & 13,97 & 3,65 & 4,49 & 1,183 & 0,803 & 1,243 & 0,354 & 7,40 & 0,212 \\
& 201,4 & 16,05 & 3,84 & 5,25 & 1,088 & 0,870 & 1,274 & 0,317 & 6,44 & 0,224 \\
\hline \multirow{4}{*}{ II } & 68,8 & 7,84 & 2,97 & 2,31 & 1,094 & 0,518 & 1,517 & 0,658 & 18,27 & 0,163 \\
& 86,1 & 9,11 & 3,21 & 2,68 & 1,152 & 0,632 & 1,532 & 0,587 & 15,73 & 0,163 \\
& 120,5 & 11,40 & 3,57 & 3,37 & 1,094 & 0,747 & 1,559 & 0,521 & 12,58 & 0,165 \\
& 163,5 & 13,97 & 3,94 & 4,28 & 1,130 & 0,937 & 1,591 & 0,411 & 10,26 & 0,184 \\
& 201,4 & 16,05 & 4,16 & 4,84 & 1,097 & 1,017 & 1,618 & 0,373 & 8,93 & 0,176 \\
\hline \multirow{4}{*}{ III } & 68,8 & 7,84 & 3,10 & 2,21 & 1,114 & 0,569 & 1,951 & 0,708 & 23,37 & 0,144 \\
& 86,1 & 9,11 & 3,36 & 2,56 & 1,187 & 0,708 & 1,970 & 0,640 & 20,13 & 0,143 \\
& 120,5 & 11,40 & 3,73 & 3,23 & 1,151 & 0,850 & 2,004 & 0,575 & 16,09 & 0,145 \\
& 163,5 & 13,97 & 4,15 & 4,06 & 1,155 & 1,057 & 2,043 & 0,482 & 13,12 & 0,157 \\
& 201,4 & 16,05 & 4,37 & 4,58 & 1,141 & 1,171 & 2,074 & 0,436 & 11,42 & 0,149 \\
& & & & & & & & & &
\end{tabular}




\section{APÊNDICE D}

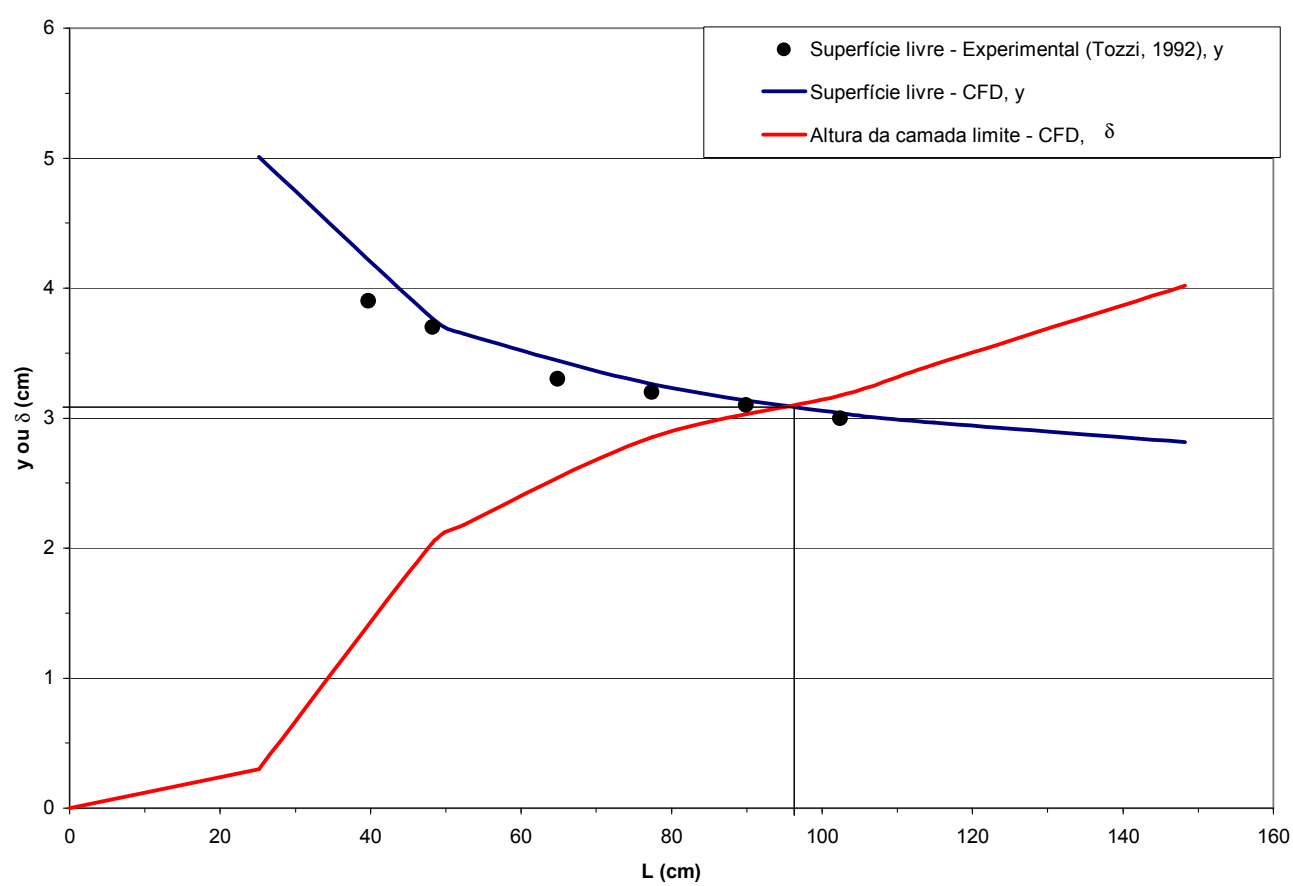

Figura D.1. Crescimento da camada limite e altura da superfície livre (início a aeração) para vazão de $86,11 / \mathrm{s} \cdot \mathrm{m}\left(k_{a}=2 \mathrm{~cm}\right)$.

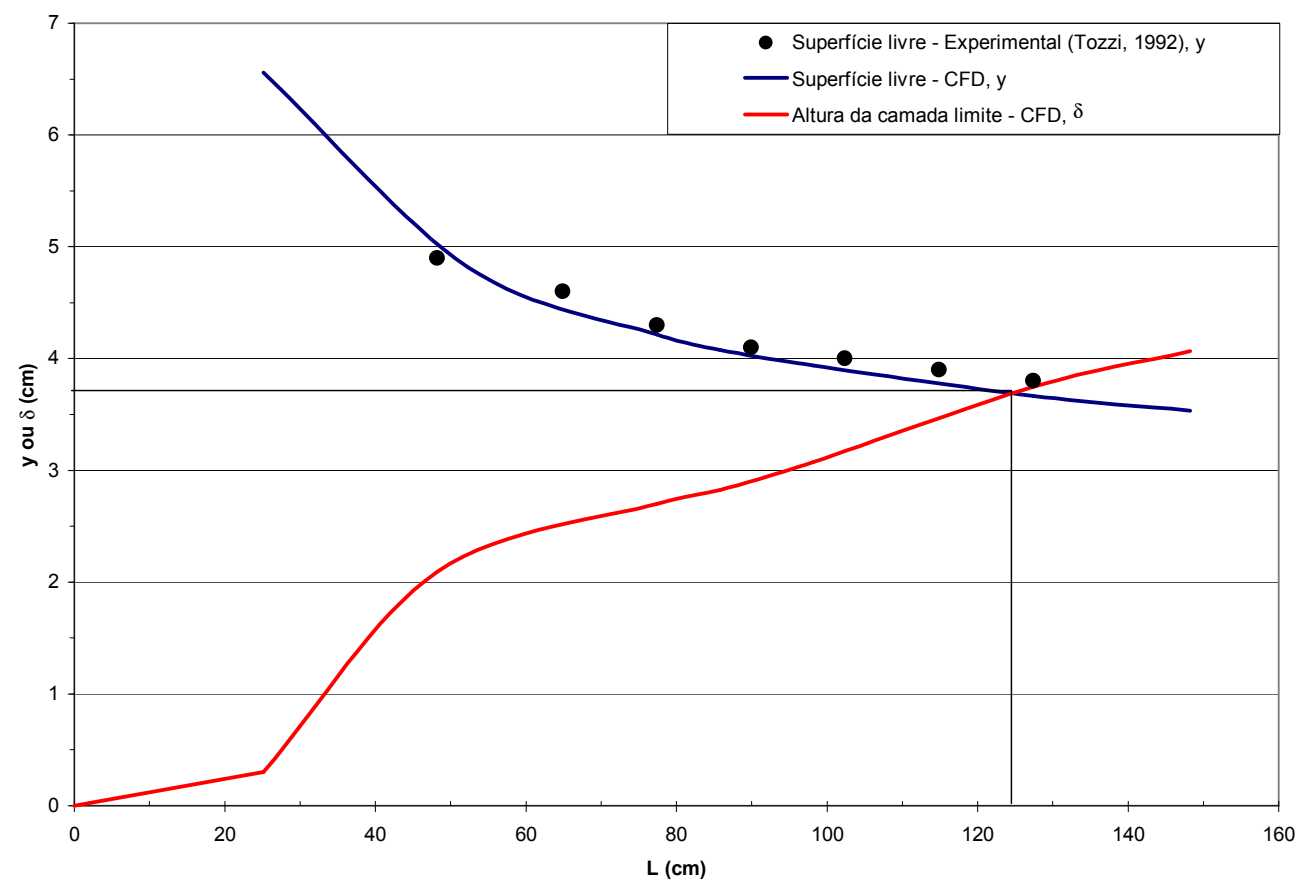

Figura D.2. Crescimento da camada limite e altura da superfície livre (início a aeração) para vazão de 120,5 1/s.m $\left(k_{a}=2 \mathrm{~cm}\right)$. 


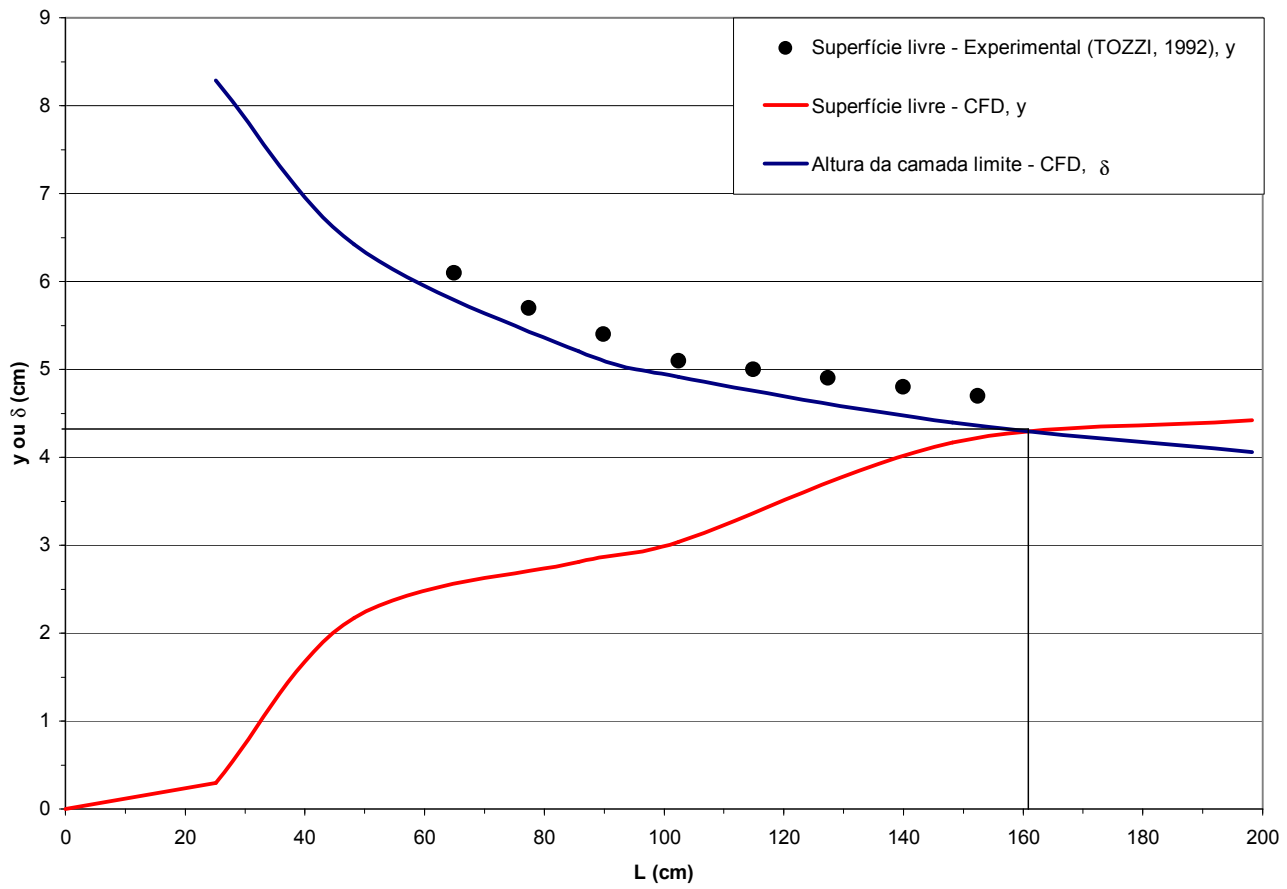

Figura D.3. Crescimento da camada limite e altura da superfície livre (início a aeração) para vazão de 163,5 1/s.m $\left(k_{a}=2 \mathrm{~cm}\right)$.

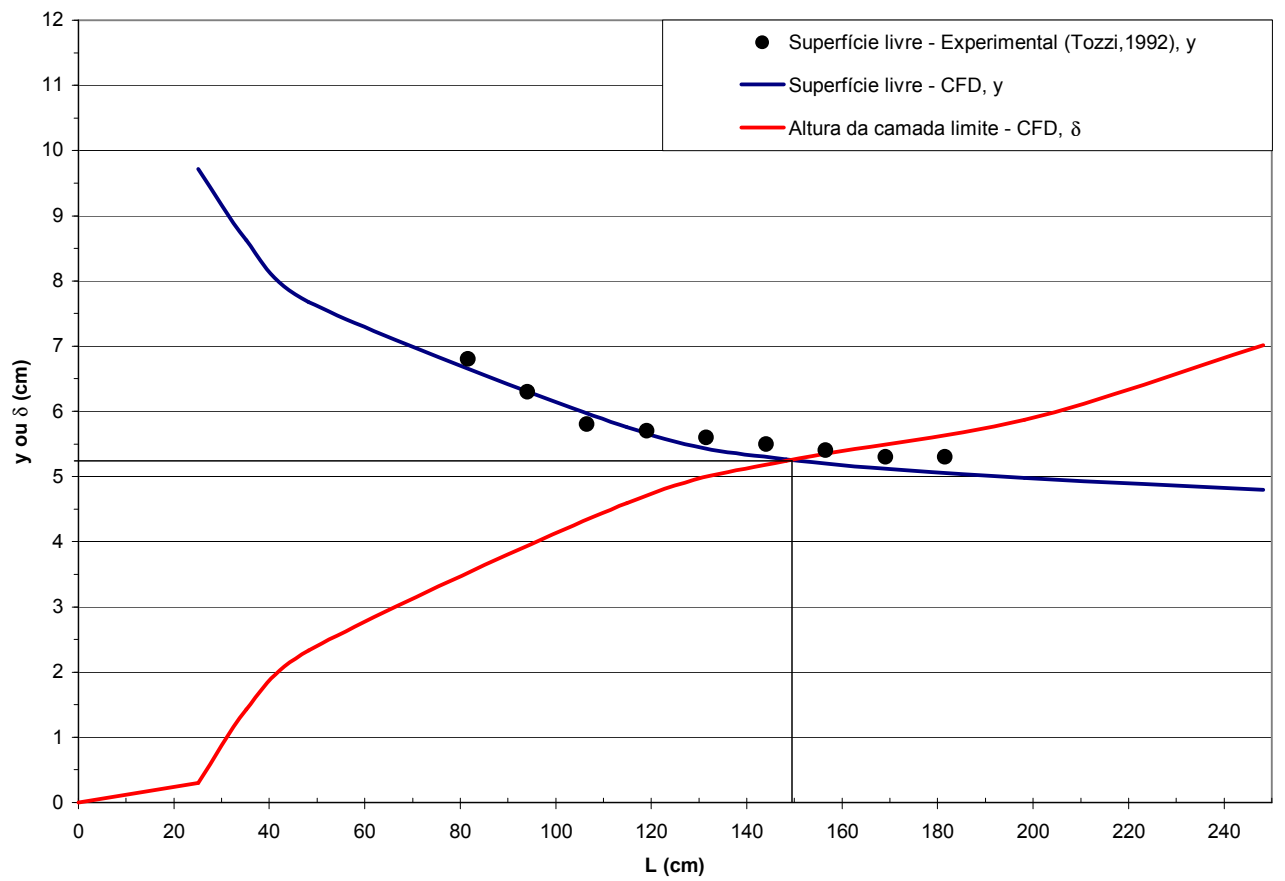

Figura D.4. Crescimento da camada limite e altura da superfície livre (início a aeração) para vazão de 201,4 1/s.m $\left(k_{a}=2 \mathrm{~cm}\right)$. 


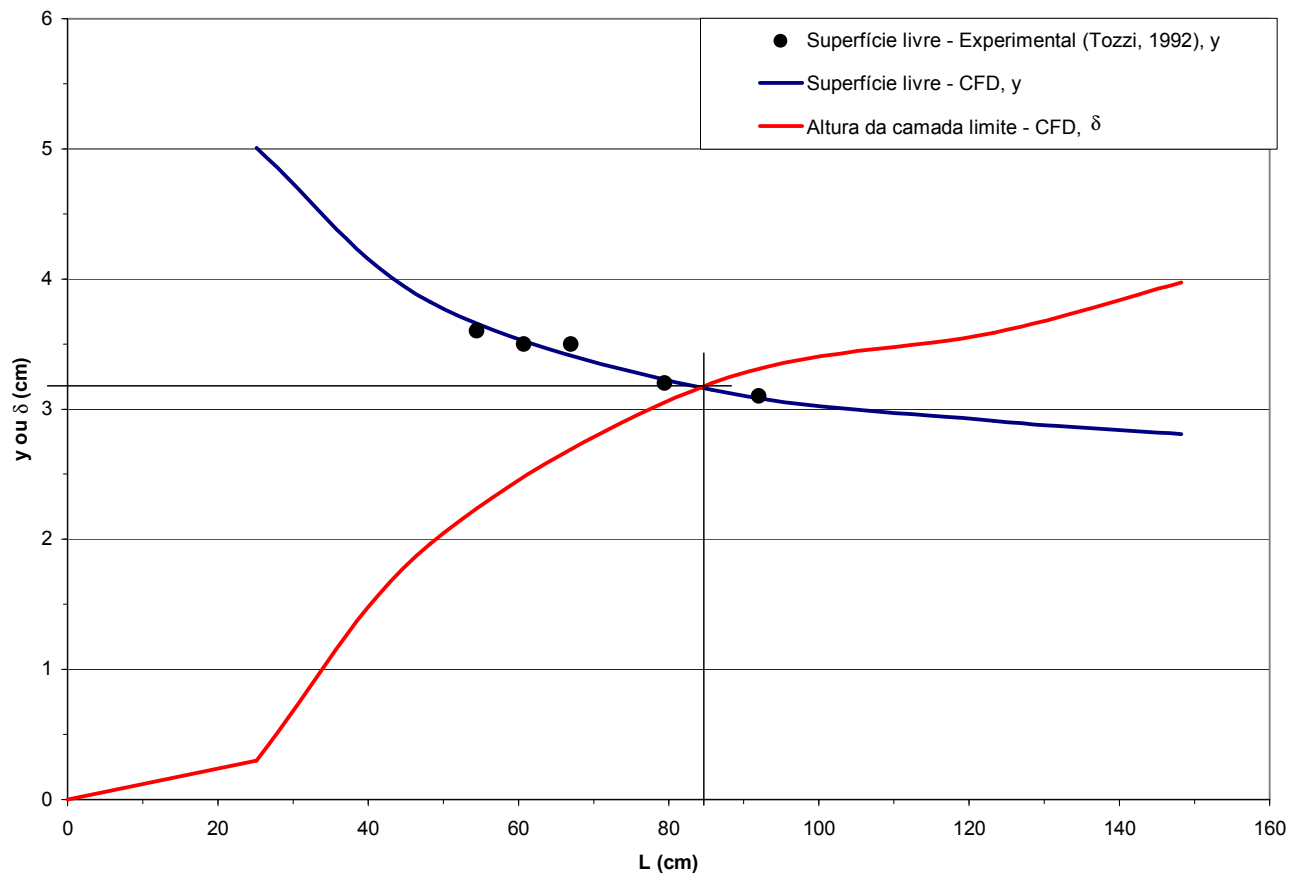

Figura D.5. Crescimento da camada limite e altura da superfície livre (início a aeração) para vazão de $86,11 / \mathrm{s} \cdot \mathrm{m}\left(k_{a}=3 \mathrm{~cm}\right)$.

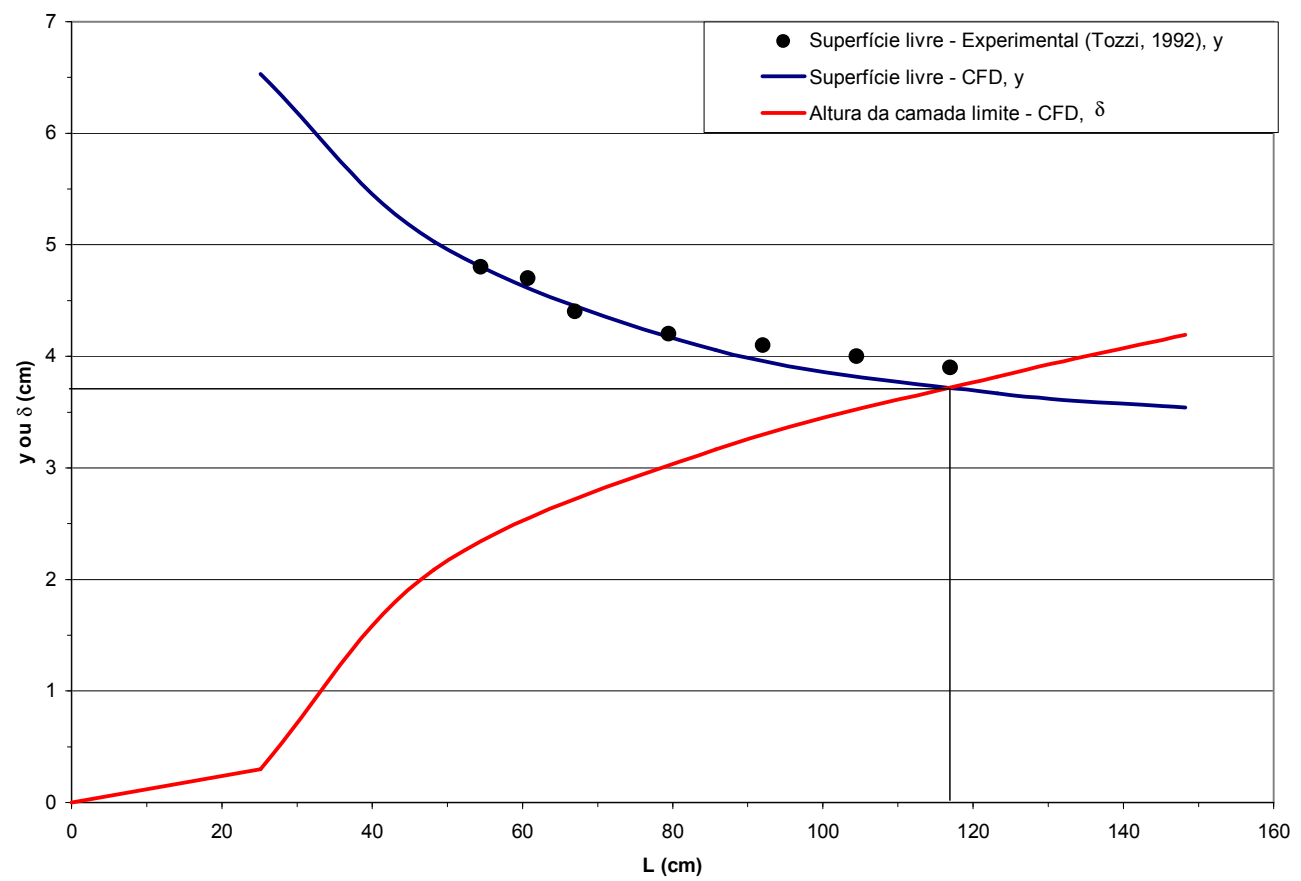

Figura D.6. Crescimento da camada limite e altura da superfície livre (início a aeração) para vazão de $120,51 / \mathrm{s} . \mathrm{m}\left(k_{a}=3 \mathrm{~cm}\right)$. 


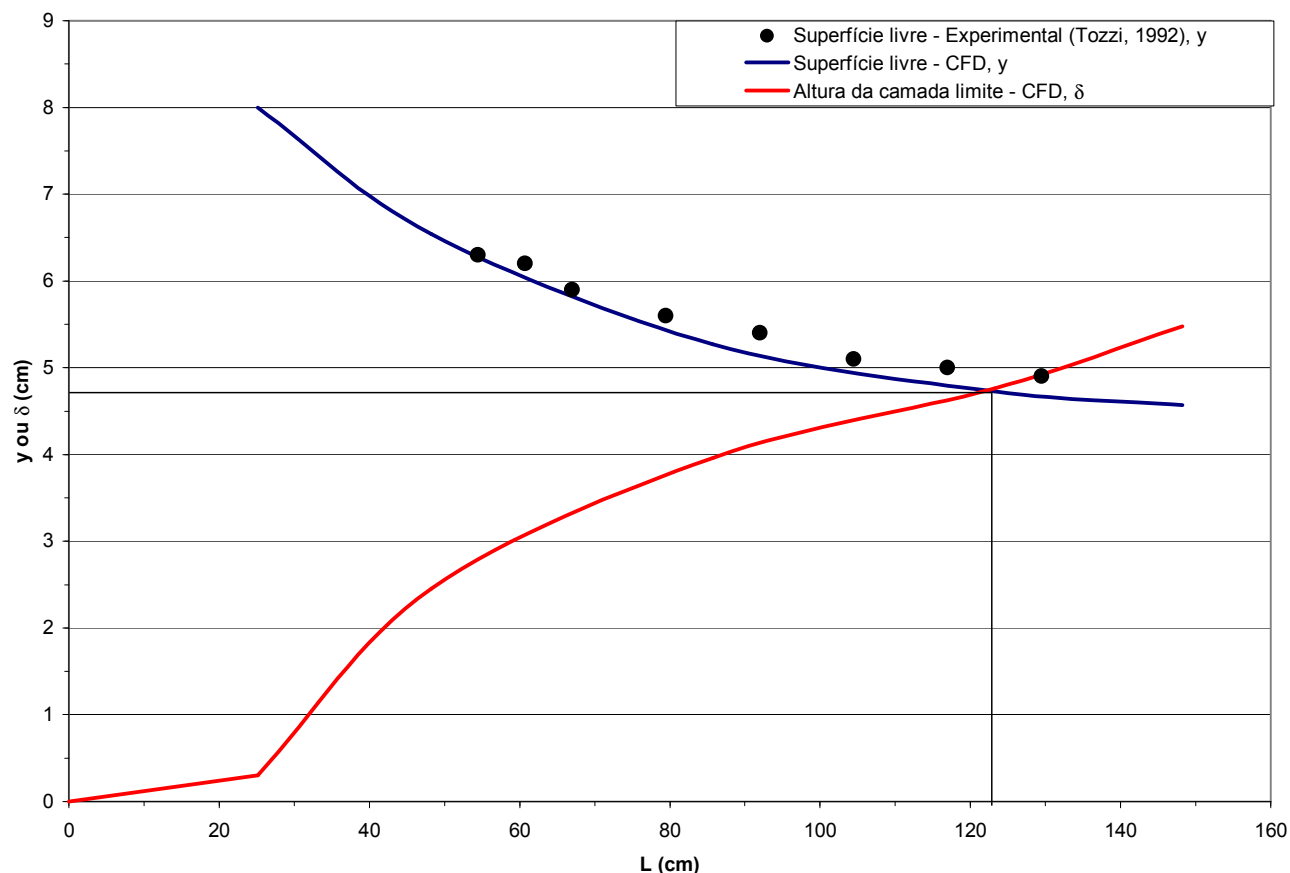

Figura D.7. Crescimento da camada limite e altura da superfície livre (início a aeração) para vazão de 163,5 1/s.m $\left(k_{a}=3 \mathrm{~cm}\right)$.

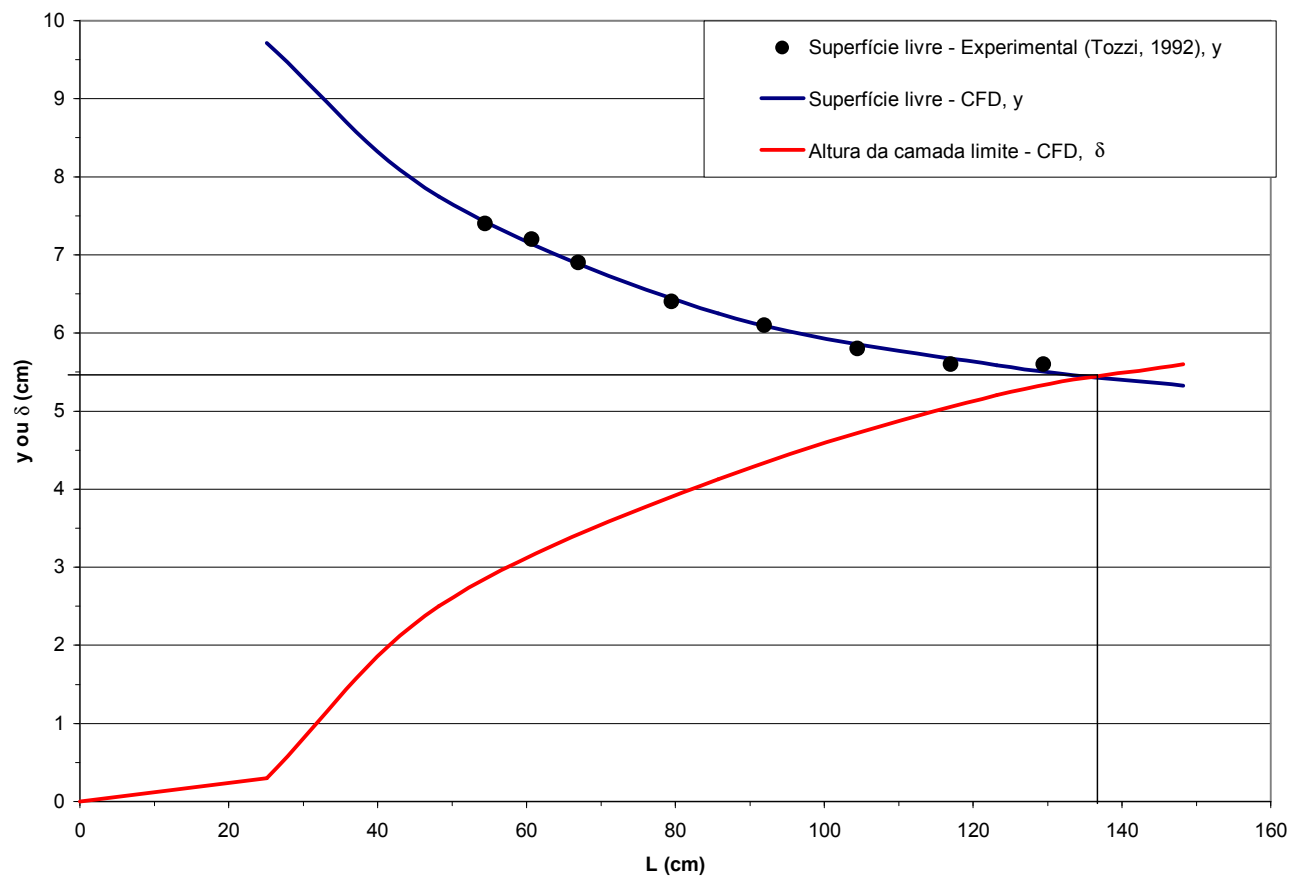

Figura D.8. Crescimento da camada limite e altura da superfície livre (início a aeração) para vazão de $201,41 / \mathrm{s} . \mathrm{m}\left(k_{a}=3 \mathrm{~cm}\right)$. 


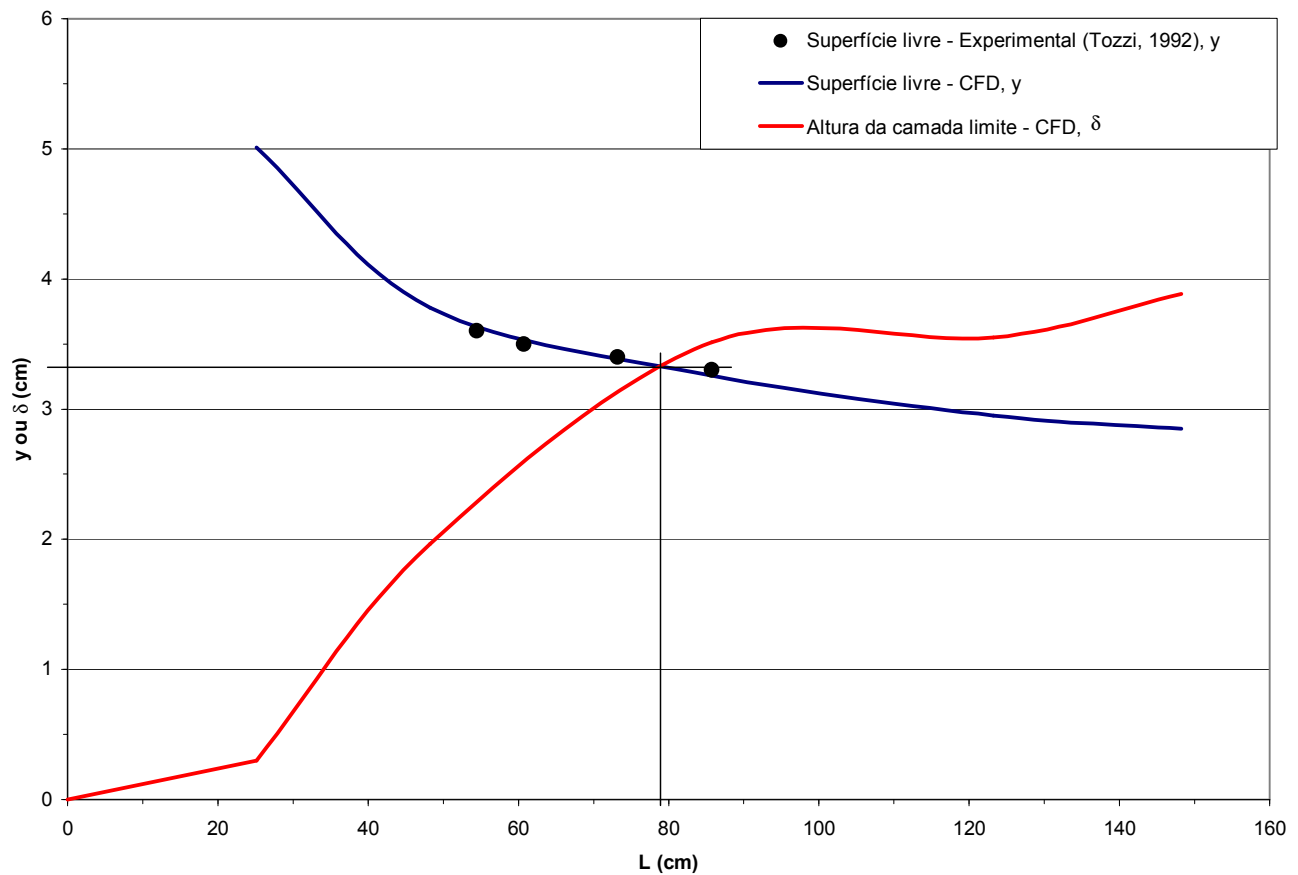

Figura D.9. Crescimento da camada limite e altura da superfície livre (início a aeração) para vazão de $86,11 / \mathrm{s} \cdot \mathrm{m}\left(k_{a}=6 \mathrm{~cm}\right)$.

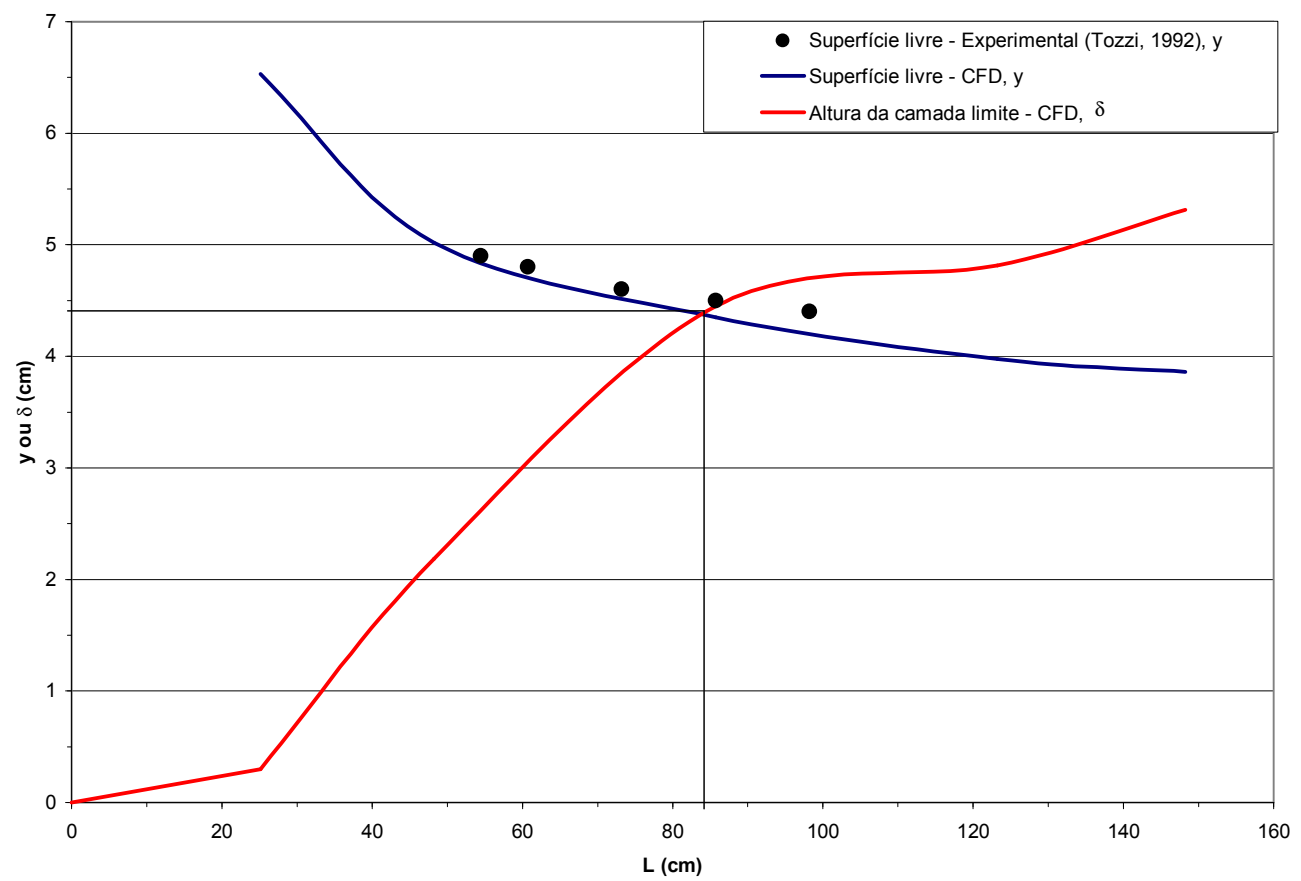

Figura D.10. Crescimento da camada limite e altura da superfície livre (início a aeração) para vazão de 120,5 1/s.m $\left(k_{a}=6 \mathrm{~cm}\right)$. 


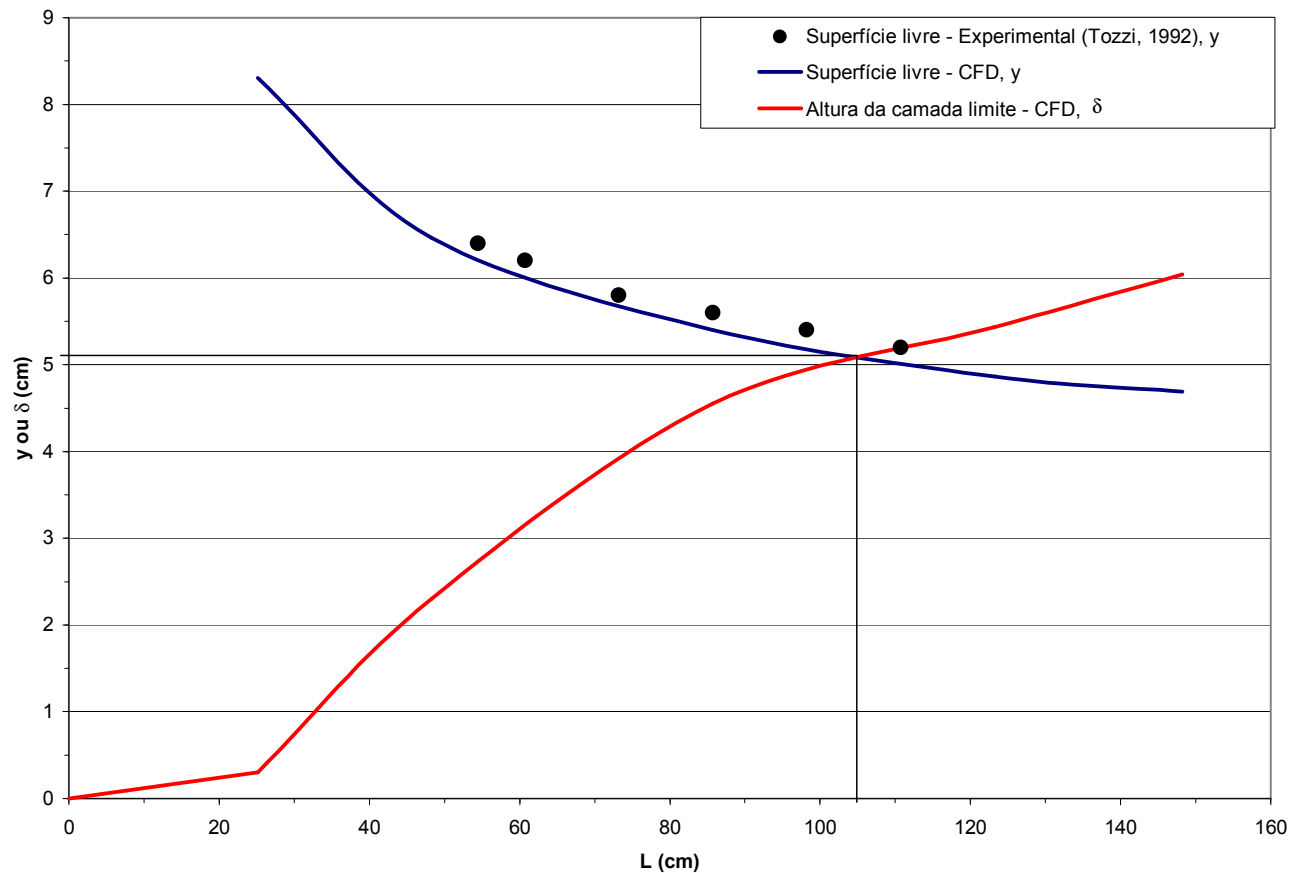

Figura D.11. Crescimento da camada limite e altura da superfície livre (início a aeração) para vazão de 163,5 1/s.m $\left(k_{a}=6 \mathrm{~cm}\right)$.

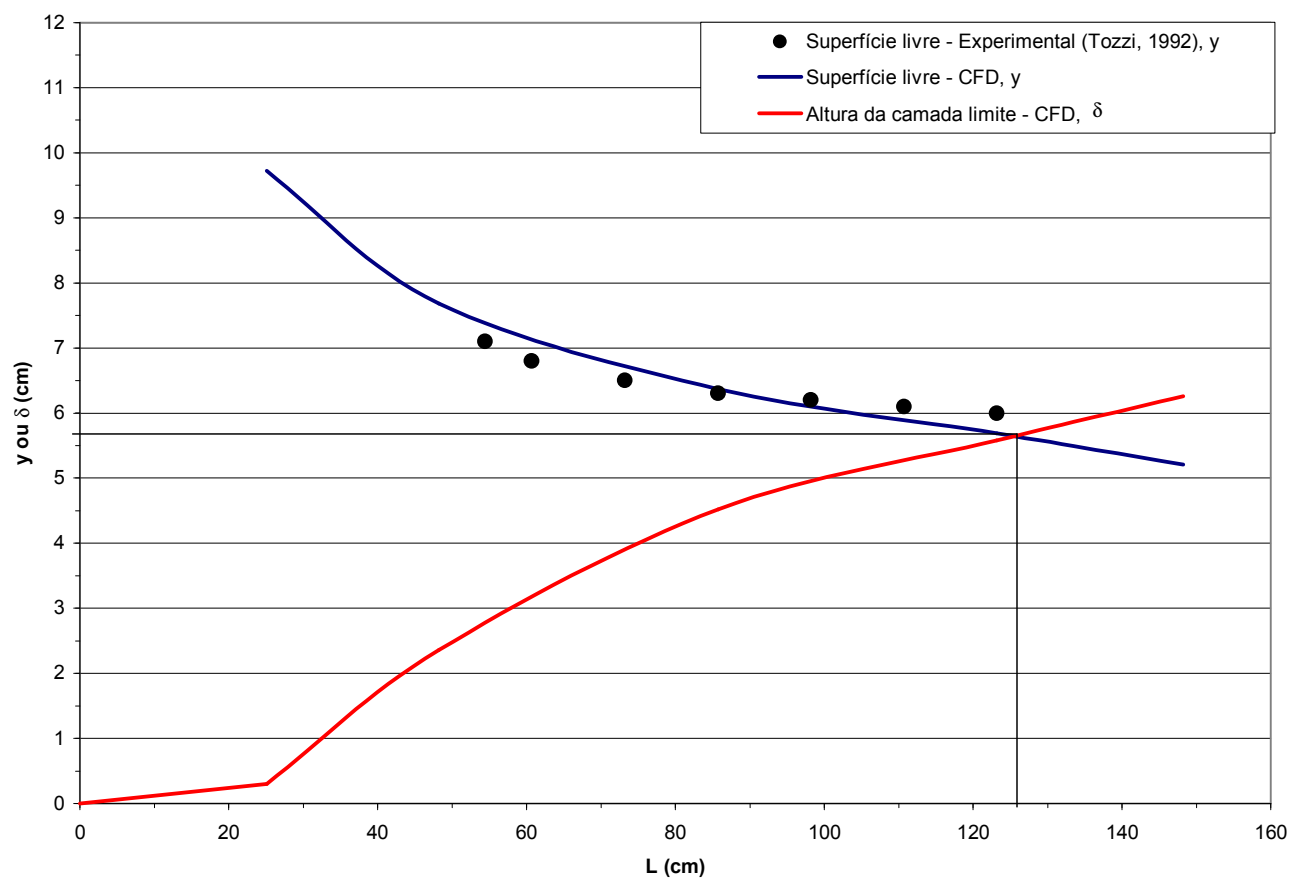

Figura D.12. Crescimento da camada limite e altura da superfície livre (início a aeração) para vazão de 201,4 1/s.m $\left(k_{a}=6\right.$ cm). 


\section{APÊNDICE E}

Rugosidade: $k_{a}=2 \mathrm{~cm}$.

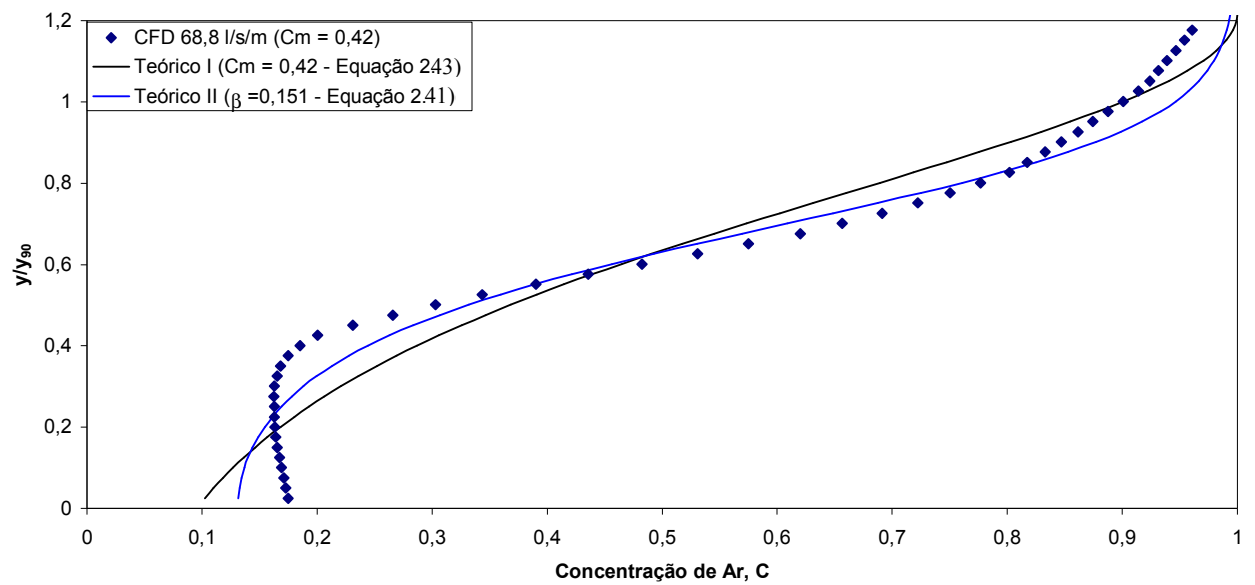

Figura E.1. Perfil de aeração do escoamento na seção III $(68,8$ 1/s/m).

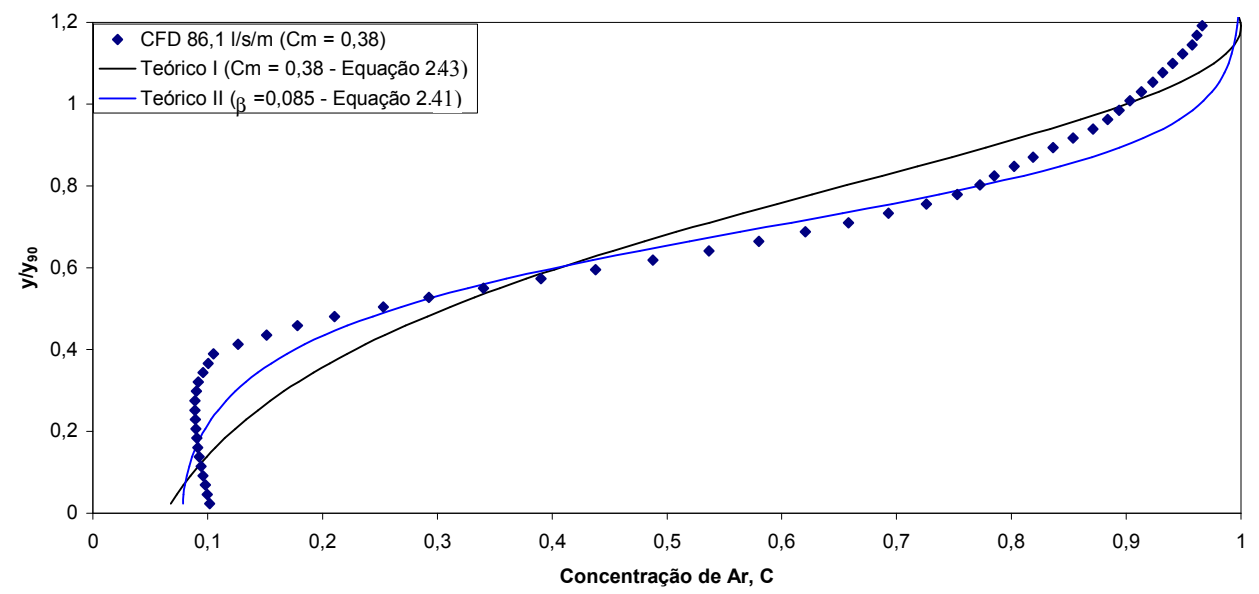

Figura E.2. Perfil de aeração do escoamento na seção III $(68,1$ 1/s/m).

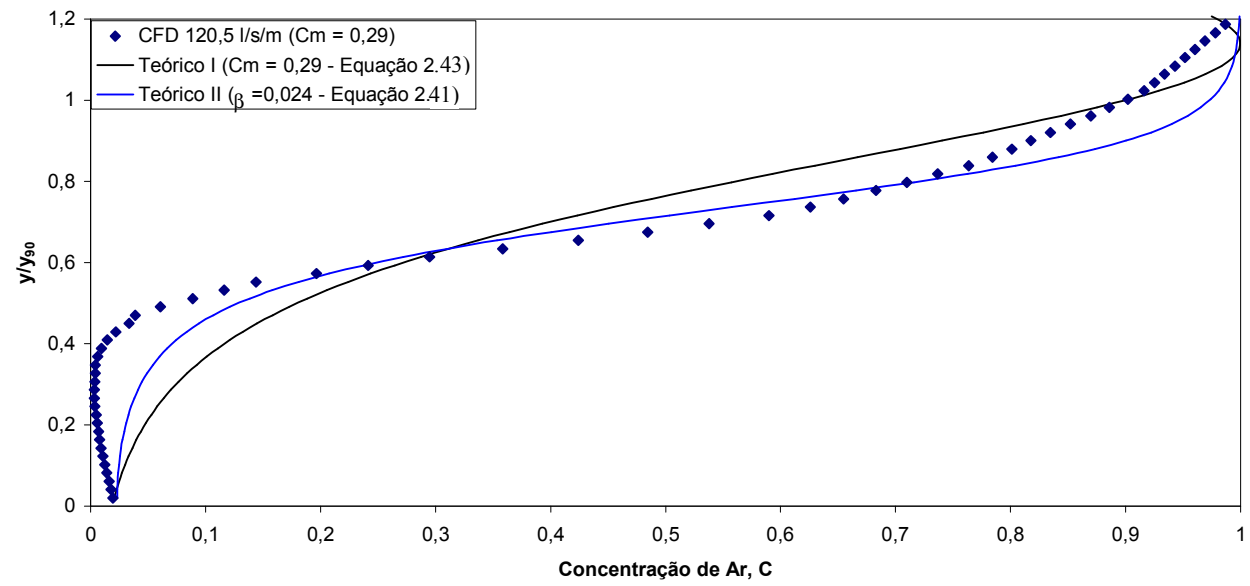

Figura E.3. Perfil de aeração do escoamento na seção III (120,5 1/s/m). 


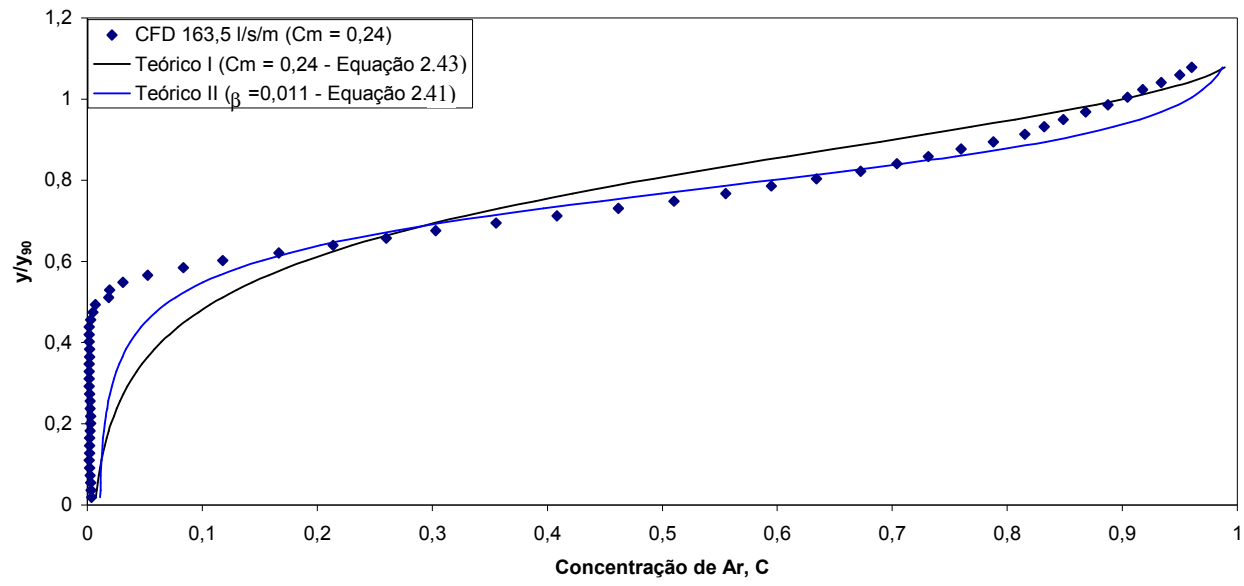

Figura E.4. Perfil de aeração do escoamento na seção III $(163,5$ 1/s/m).

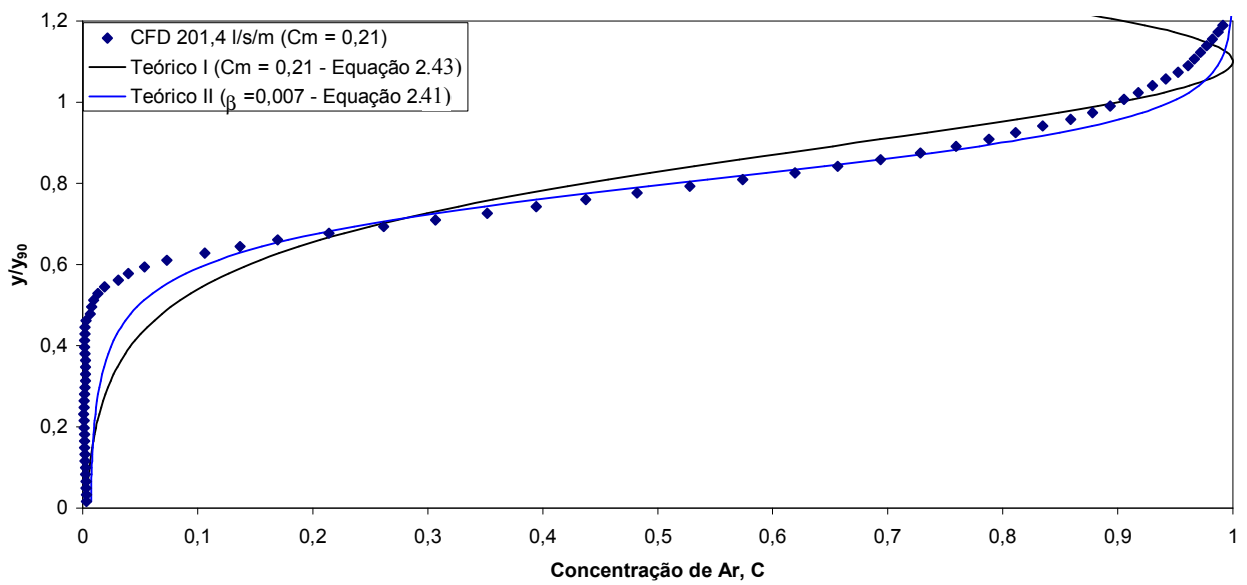

Figura E.5. Perfil de aeração do escoamento na seção III $(201,4$ 1/s/m).

Rugosidade: $k_{a}=3 \mathrm{~cm}$.

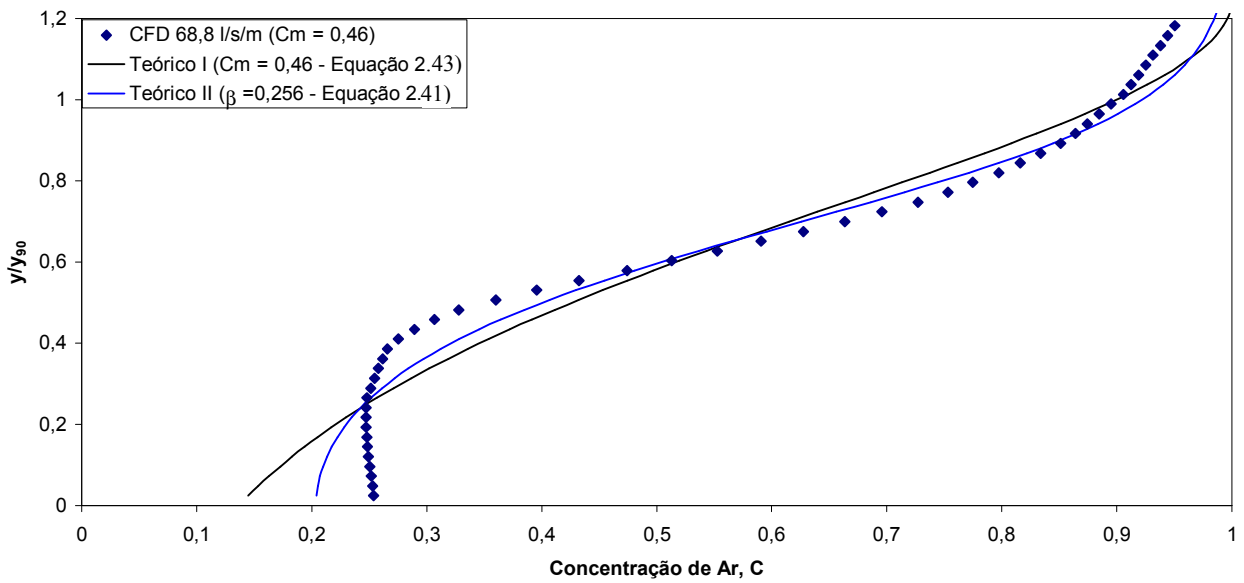

Figura E.6. Perfil de aeração do escoamento na seção III (68,8 1/s/m). 


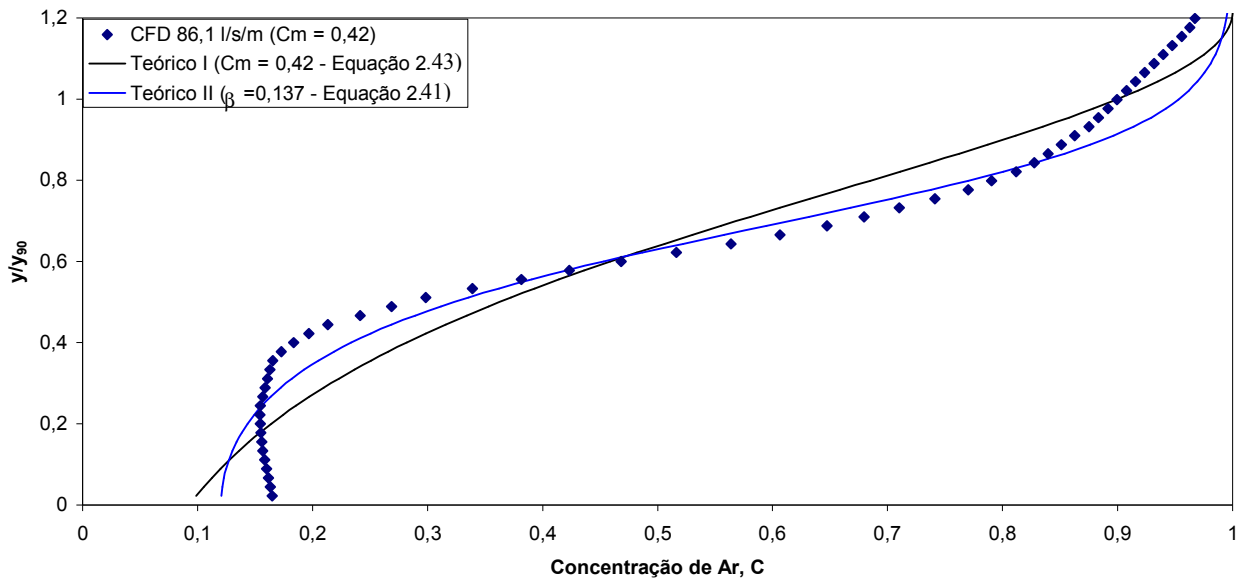

Figura E.7. Perfil de aeração do escoamento na seção III (86,1 1/s/m).

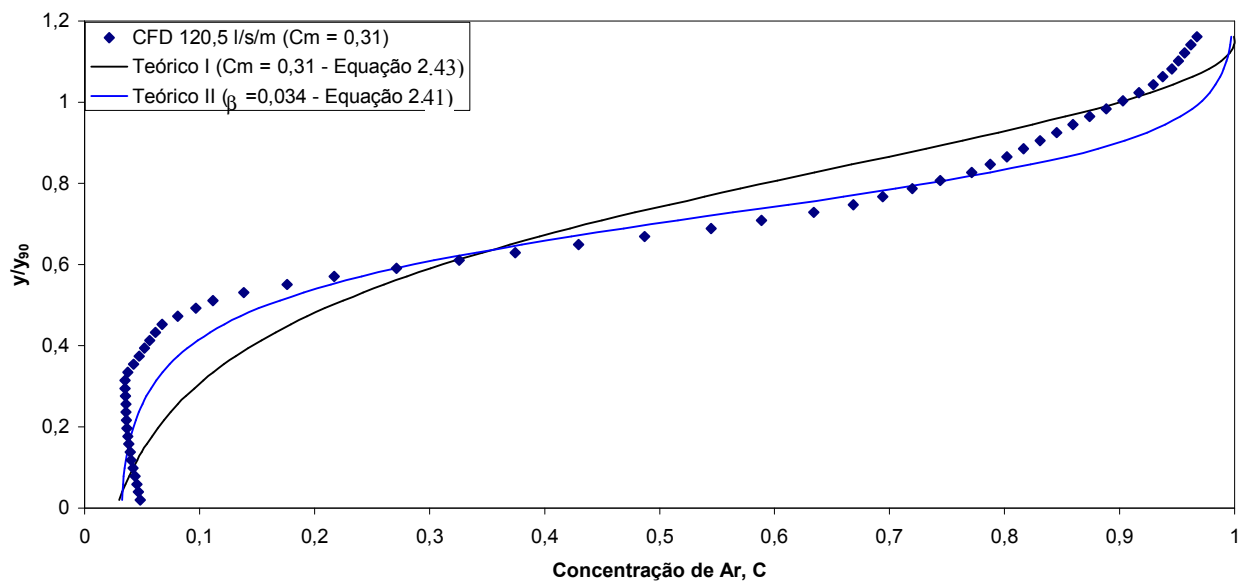

Figura E.8. Perfil de aeração do escoamento na seção III (120,5 1/s/m).

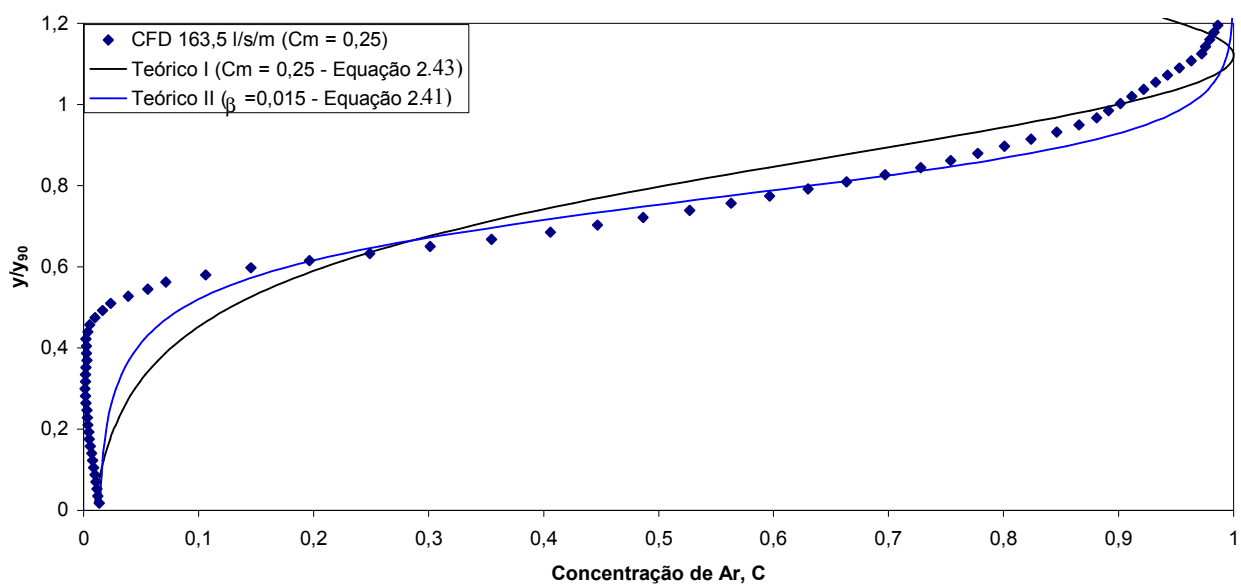

Figura E.9. Perfil de aeração do escoamento na seção III (163,5 1/s/m). 


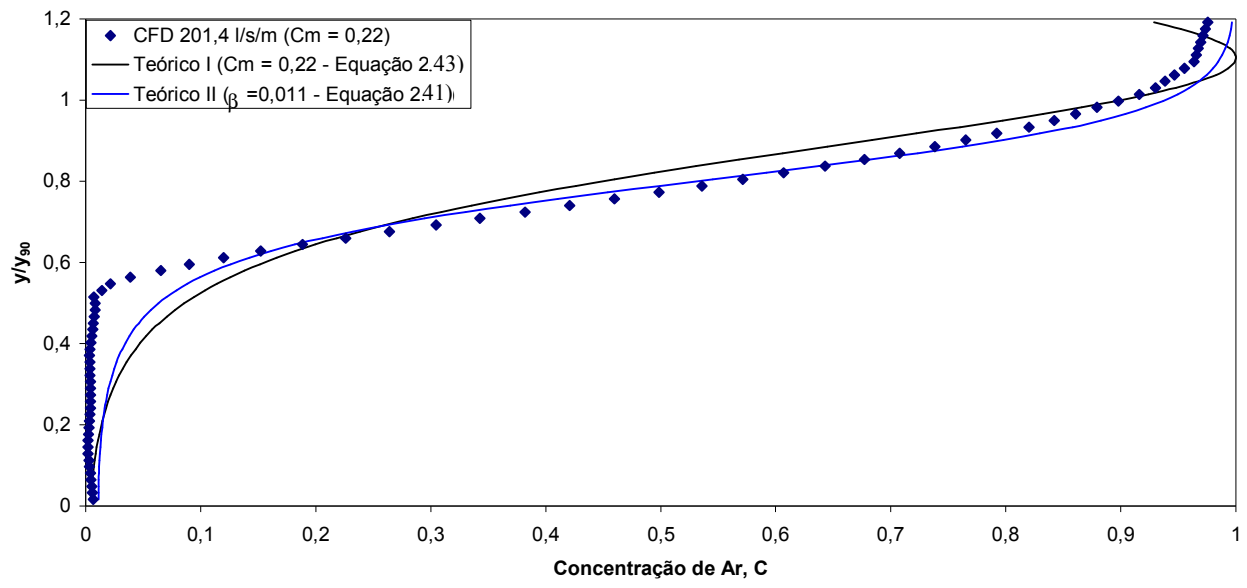

Figura E.10. Perfil de aeração do escoamento na seção III (201,4 1/s/m).

Rugosidade: $k_{a}=6 \mathrm{~cm}$.

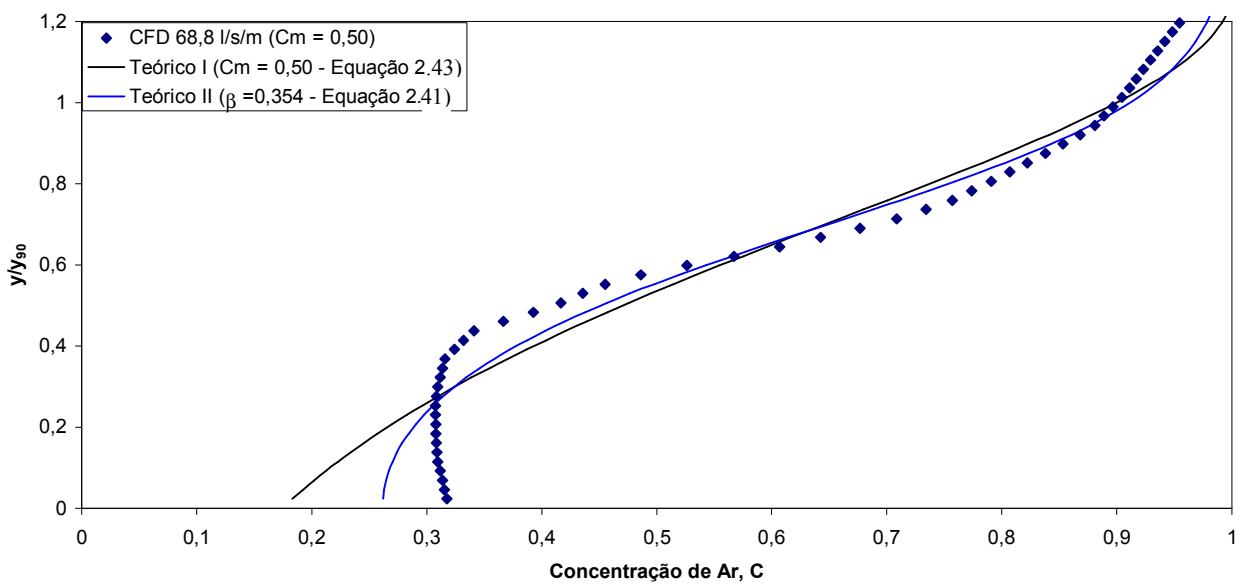

Figura E.11. Perfil de aeração do escoamento na seção III $(68,8$ 1/s/m).

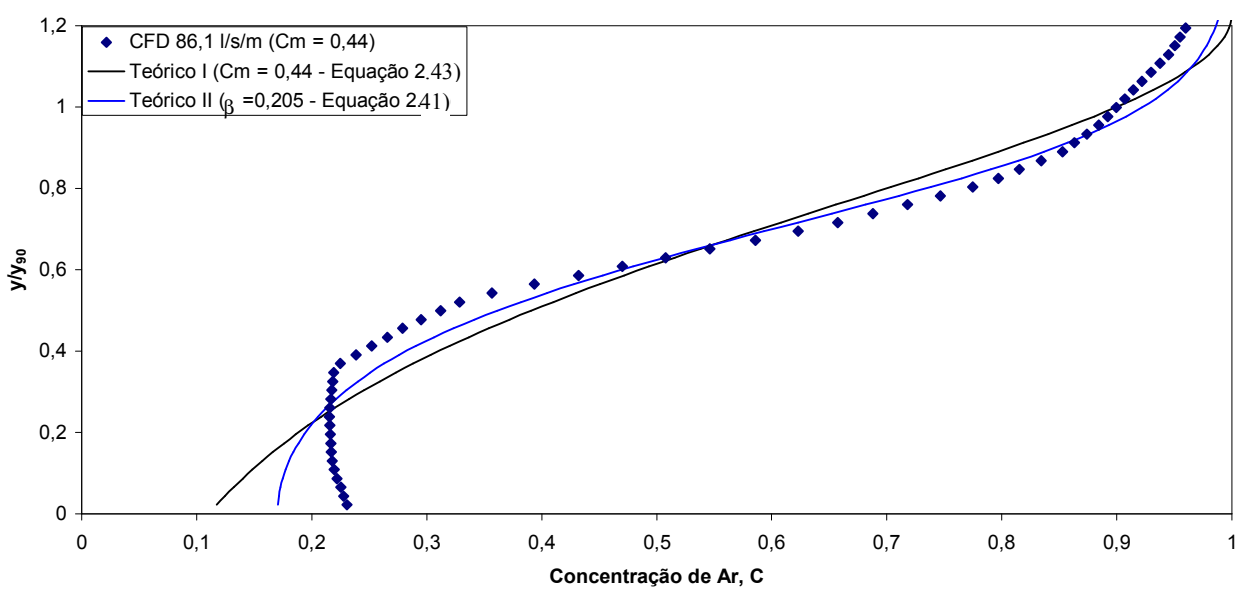

Figura E.12. Perfil de aeração do escoamento na seção III $(86,1$ 1/s/m). 


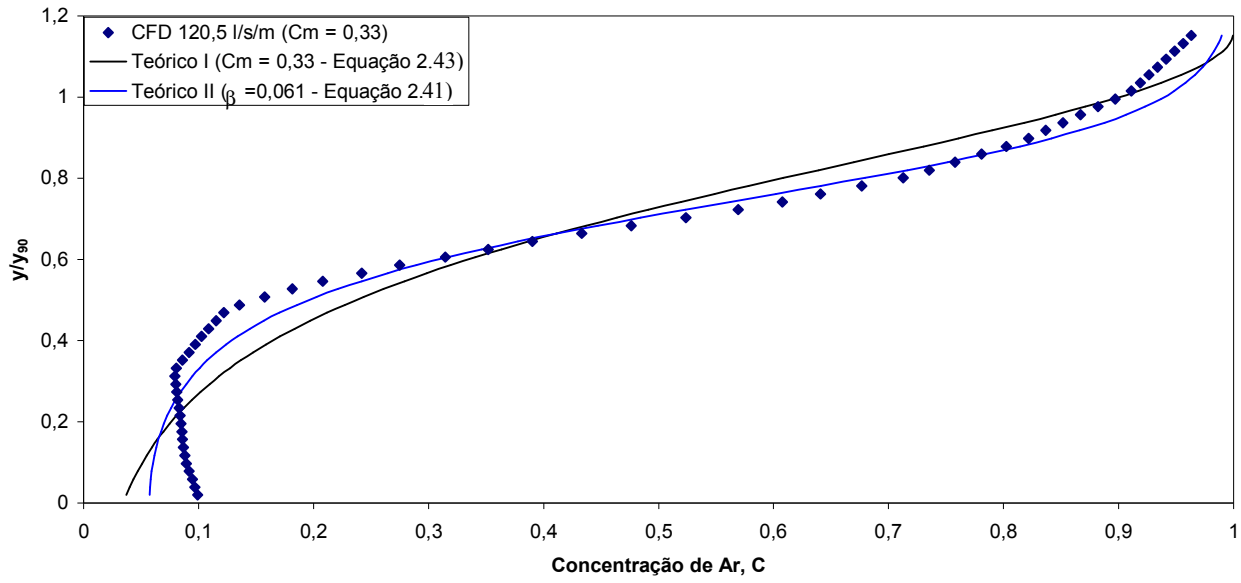

Figura E.13. Perfil de aeração do escoamento na seção III $(120,5$ 1/s/m).

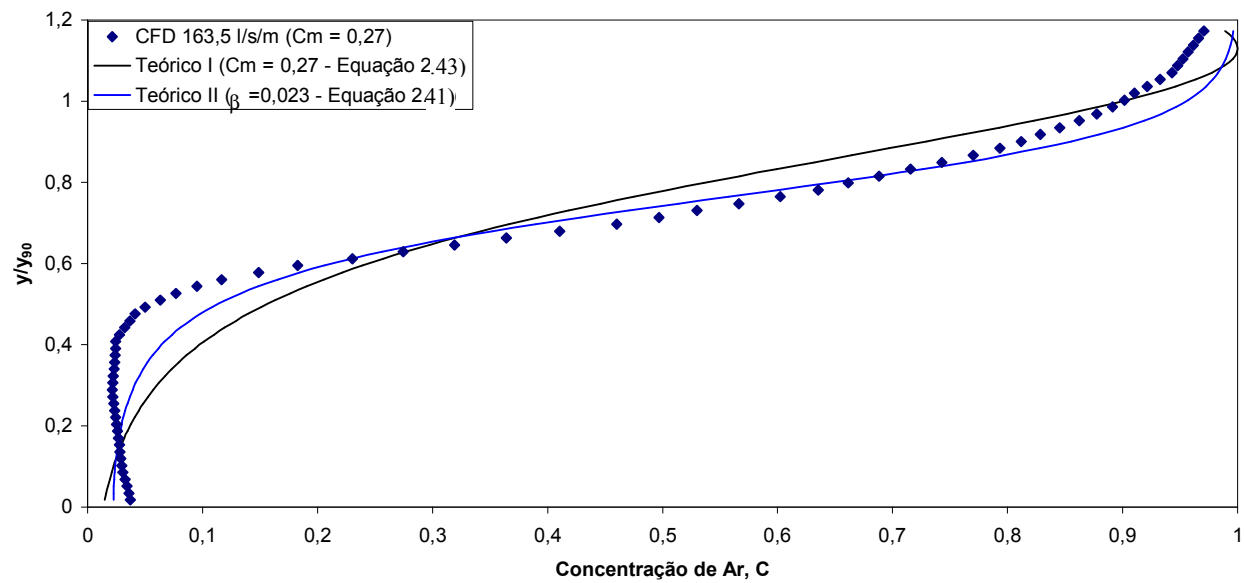

Figura E.14. Perfil de aeração do escoamento na seção III $(163,5$ 1/s/m).

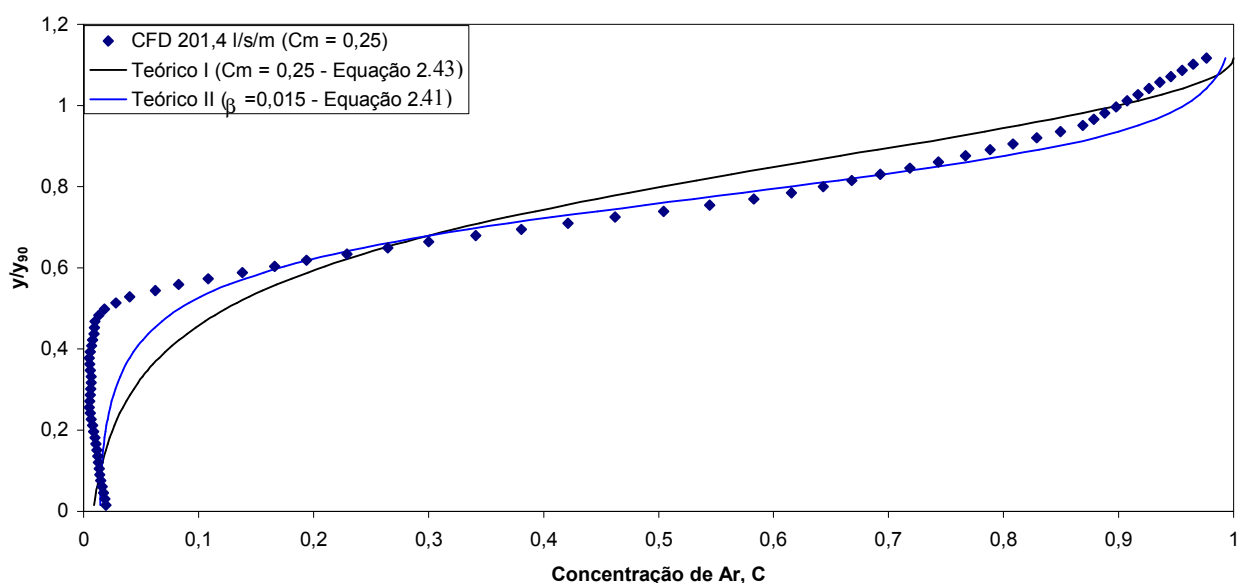

Figura E.15. Perfil de aeração do escoamento na seção III (201,4 1/s/m). 


\section{APÊNDICE F}
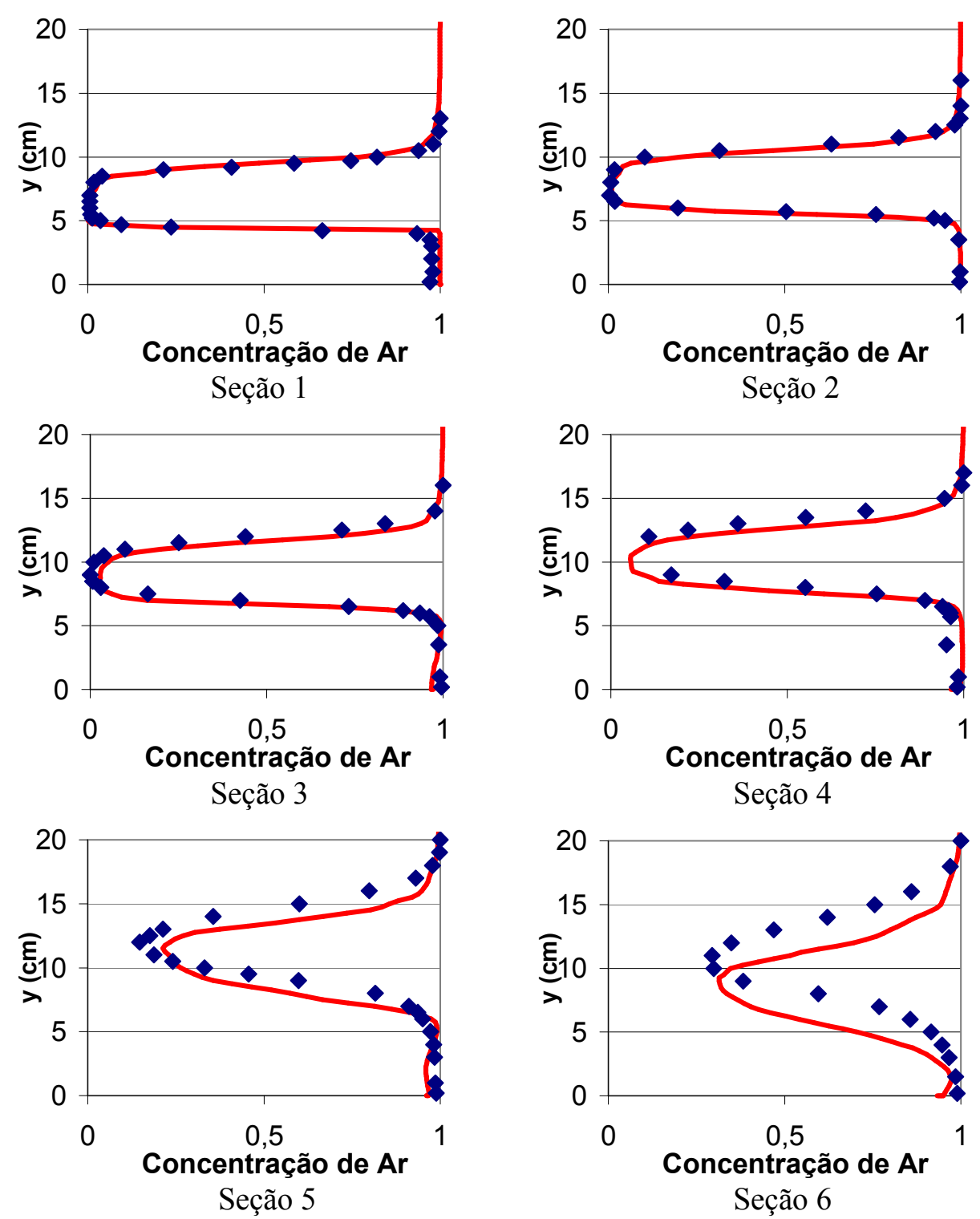

Seção 5

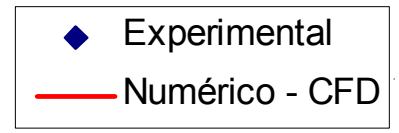

Figura F.1. Concentração de Ar para o Experimento 4. 


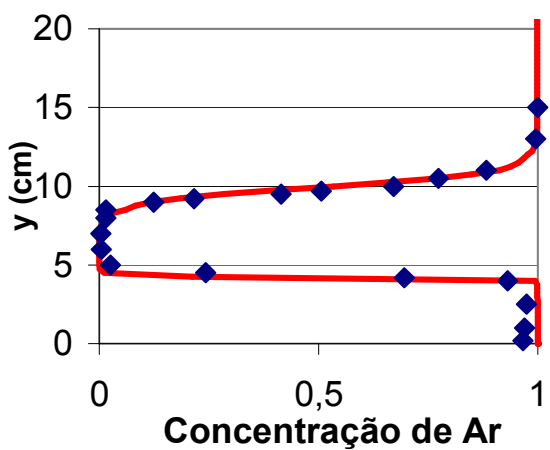

Seção 1

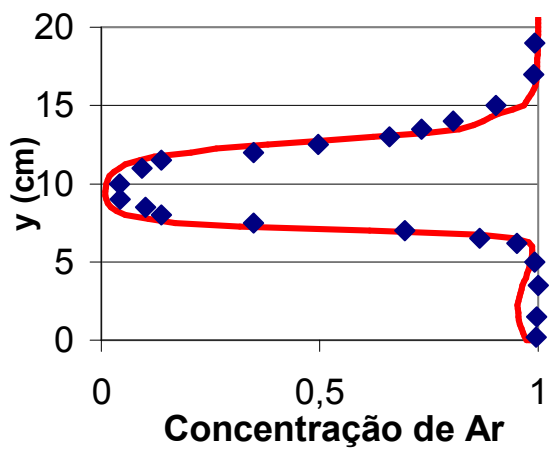

Seção 3

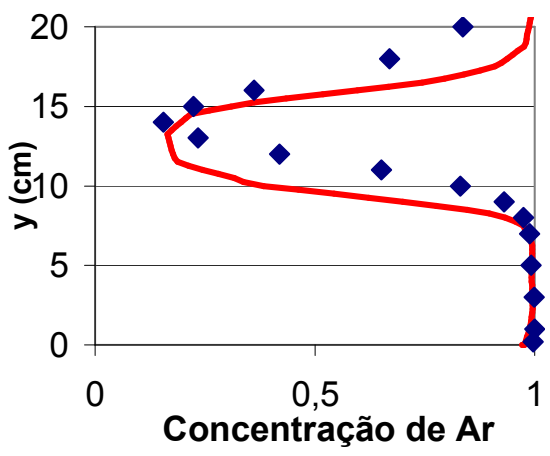

Seção 5

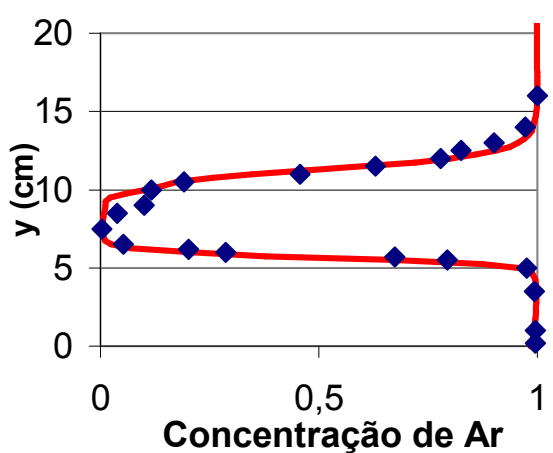

Seção 2

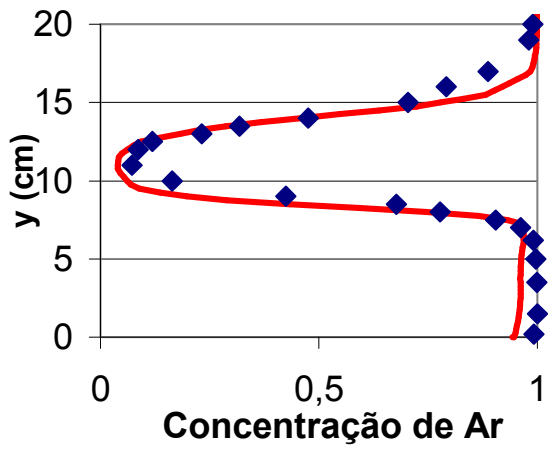

Seção 4

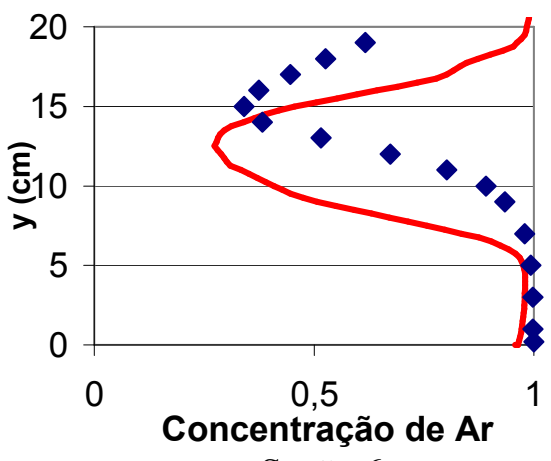

Seção 6

\section{- Experimental Numérico - CFD}

Figura F.2. Concentração de Ar para o Experimento 5. 


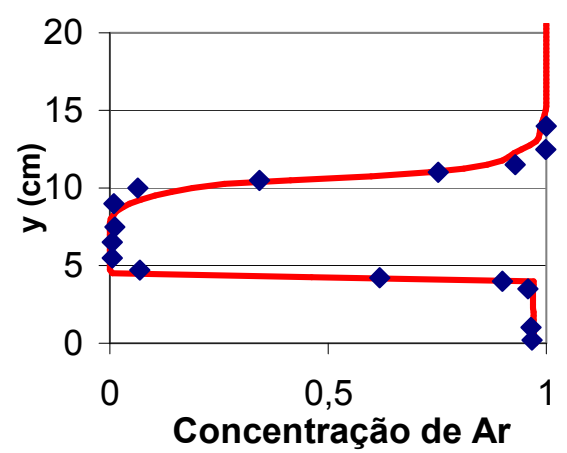

Seção 1

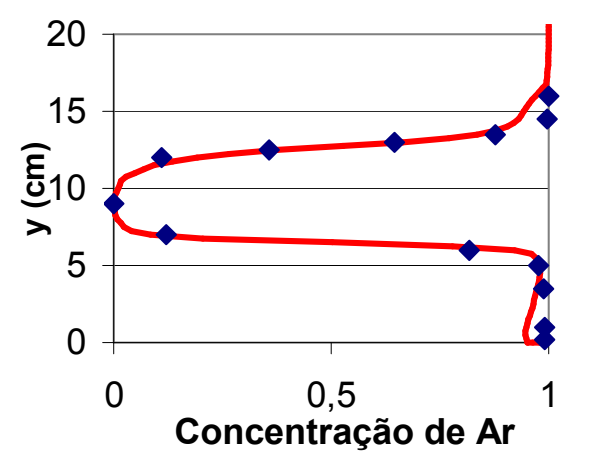

Seção 3

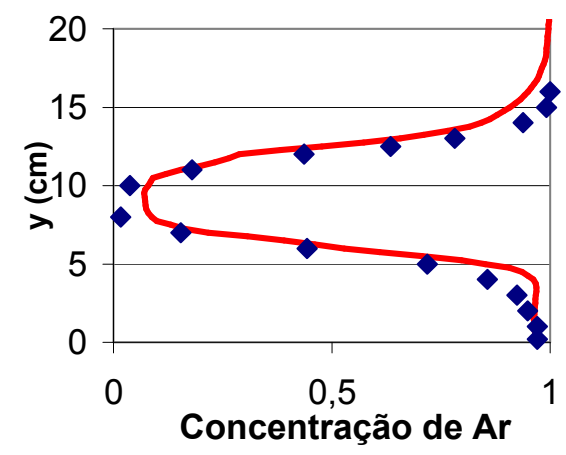

Seção 5

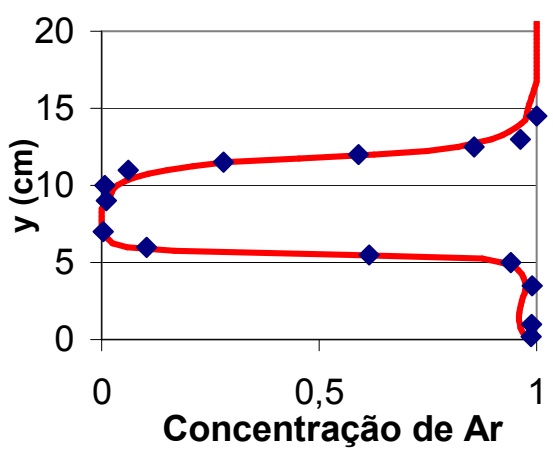

Seção 2

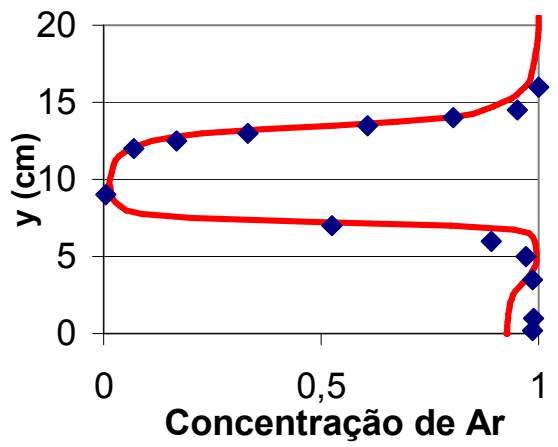

Seção 4

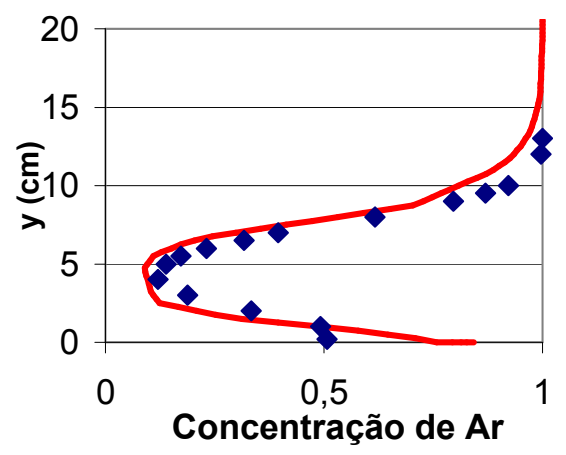

Seção 6

\section{- Experimental Numérico - CFD}

Figura F.3. Concentração de Ar para o Experimento 6. 


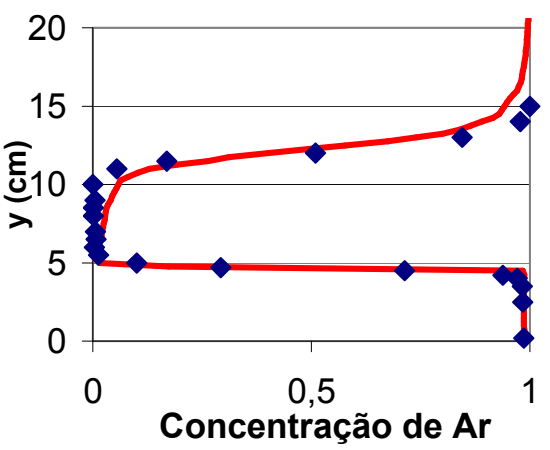

Seção 1

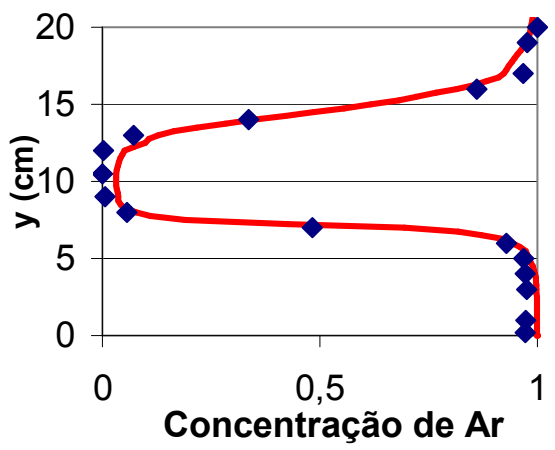

Seção 3

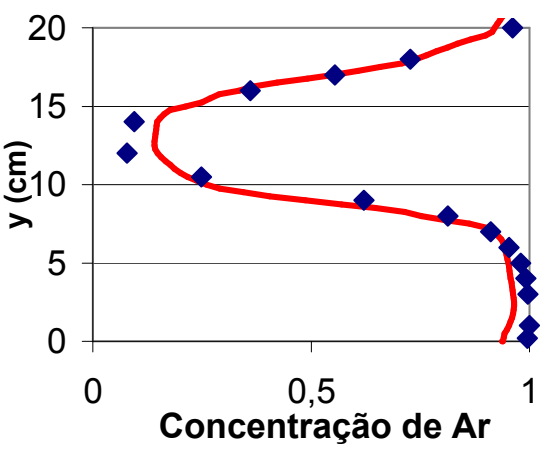

Seção 5

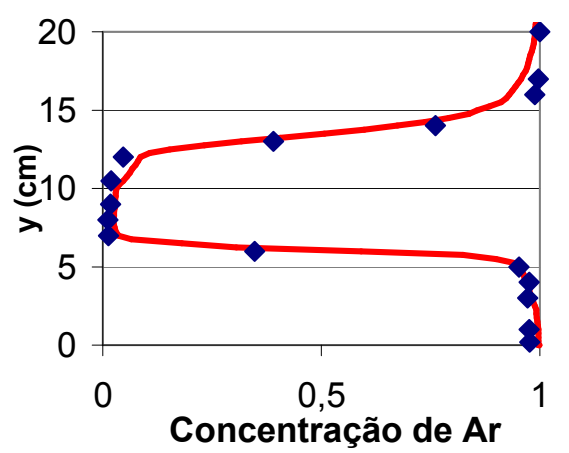

Seção 2

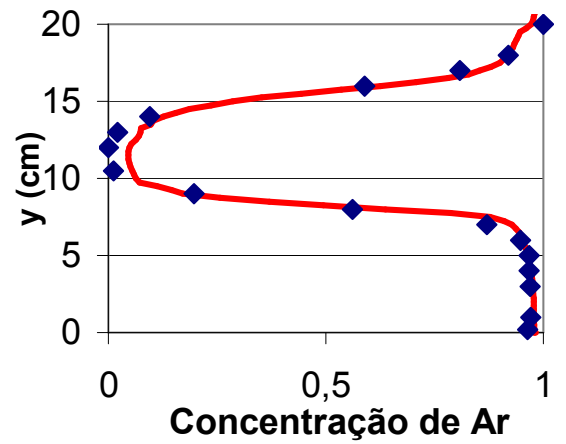

Seção 4

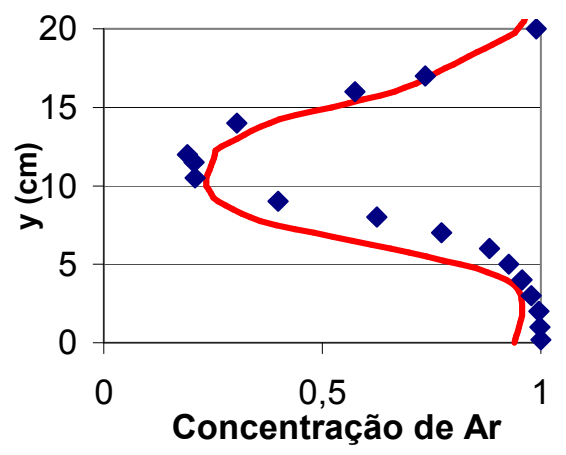

Seção 6

\section{- Experimental Numérico - CFD}

Figura F.4. Concentração de Ar para o Experimento 7. 


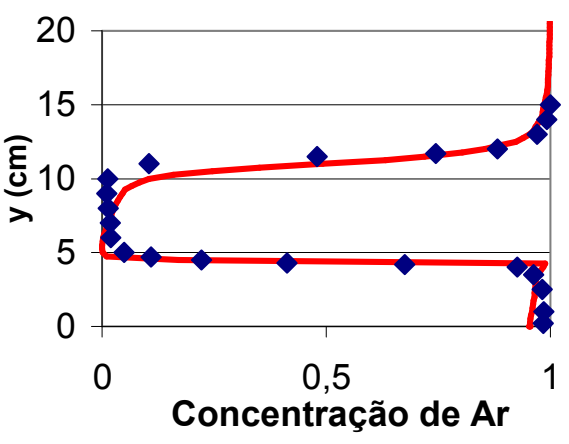

Seção 1

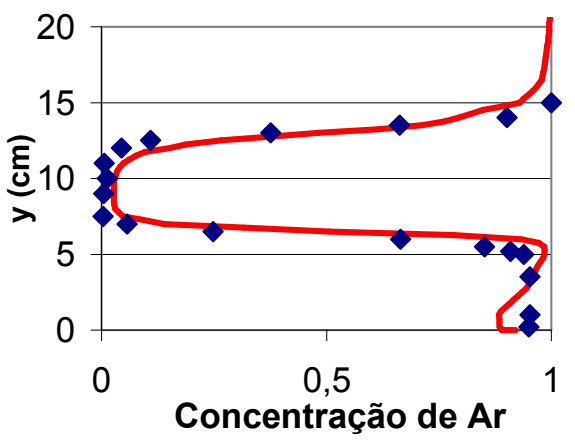

Seção 3

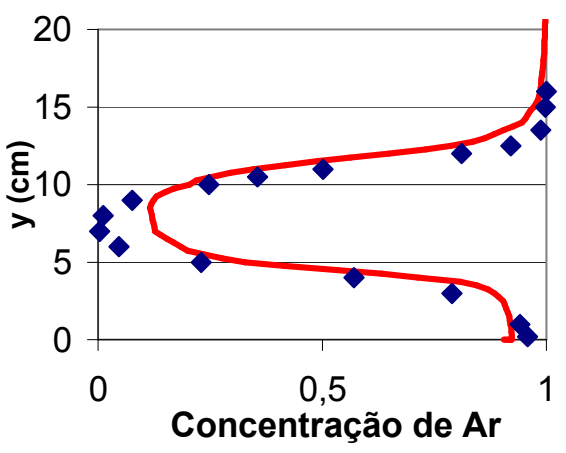

Seção 5

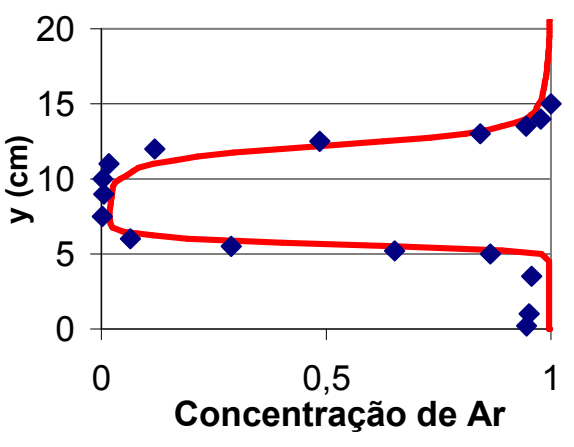

Seção 2

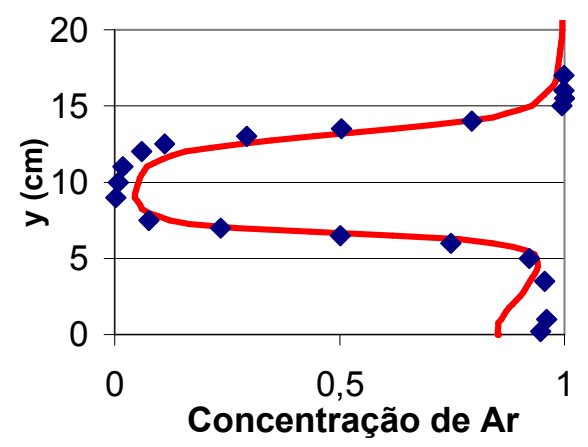

Seção 4

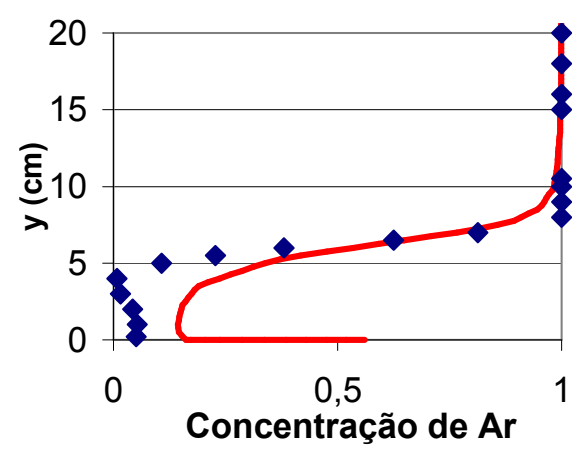

Seção 6

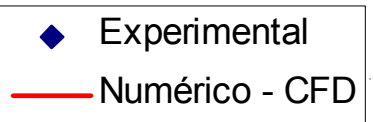

Figura F.5. Concentração de Ar para o Experimento 8. 


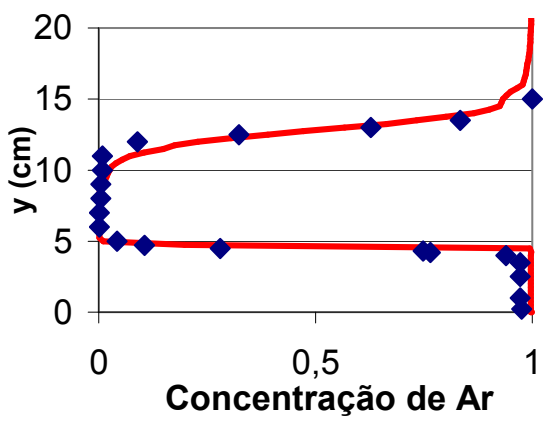

Seção 1

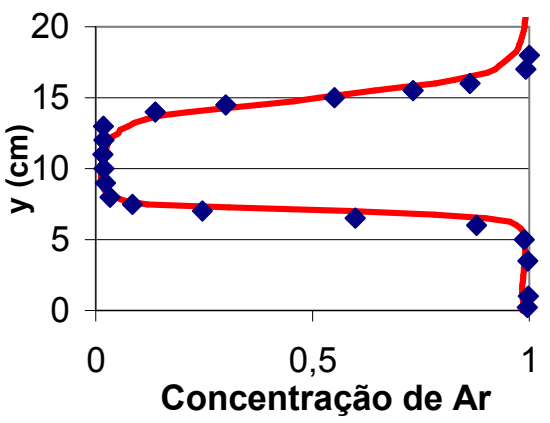

Seção 3

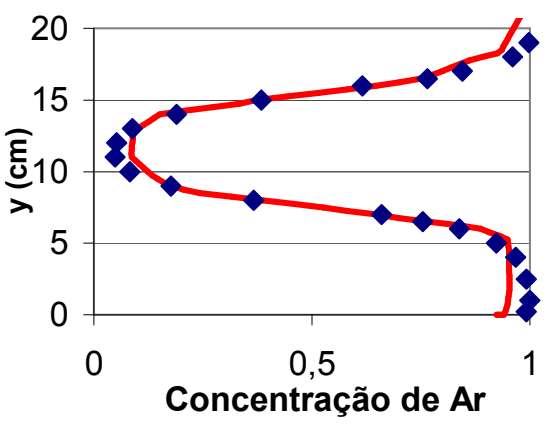

Seção 5

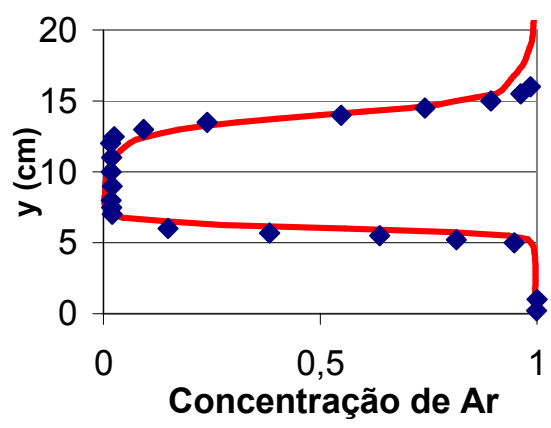

Seção 2

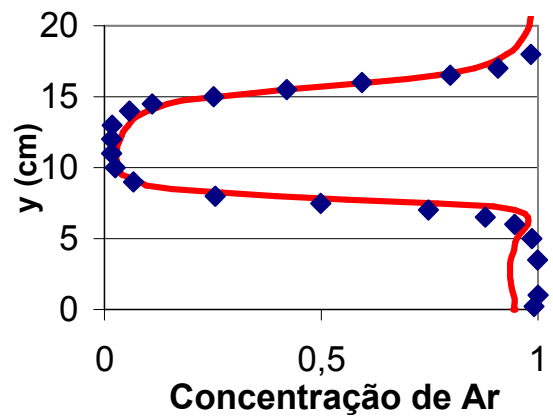

Seção 4

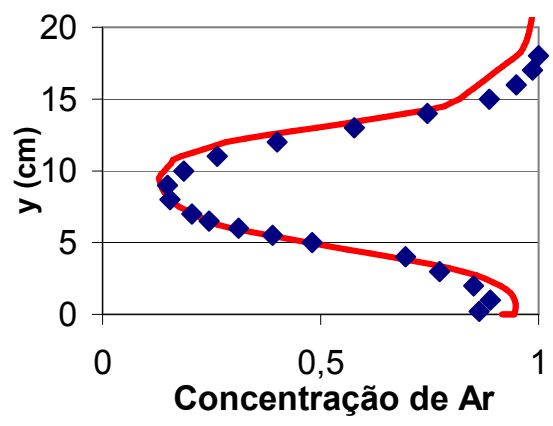

Seção 6

\section{- Experimental Numérico - CFD}

Figura F.6. Concentração de Ar para o Experimento 9. 


\section{APÊNDICE G}

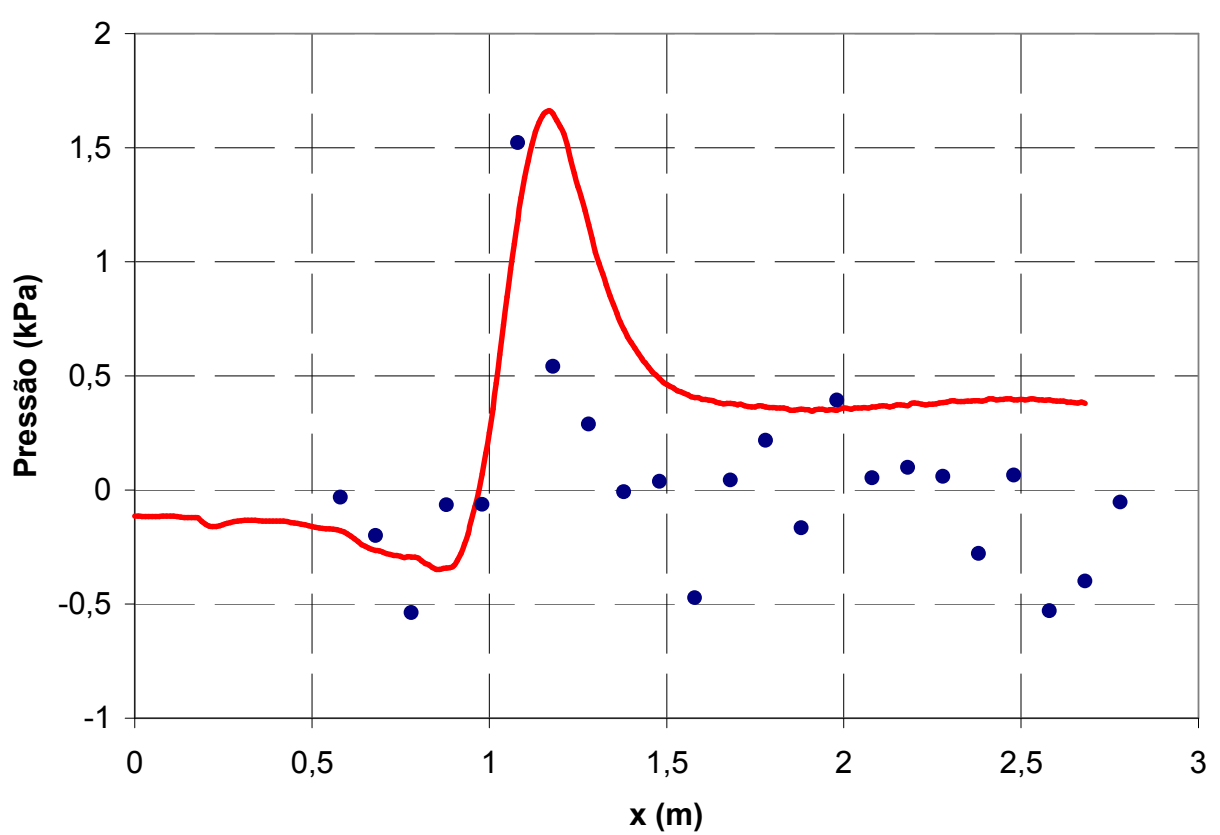

Figura G.1. Pressão Sob o Jato para o Experimento 3.

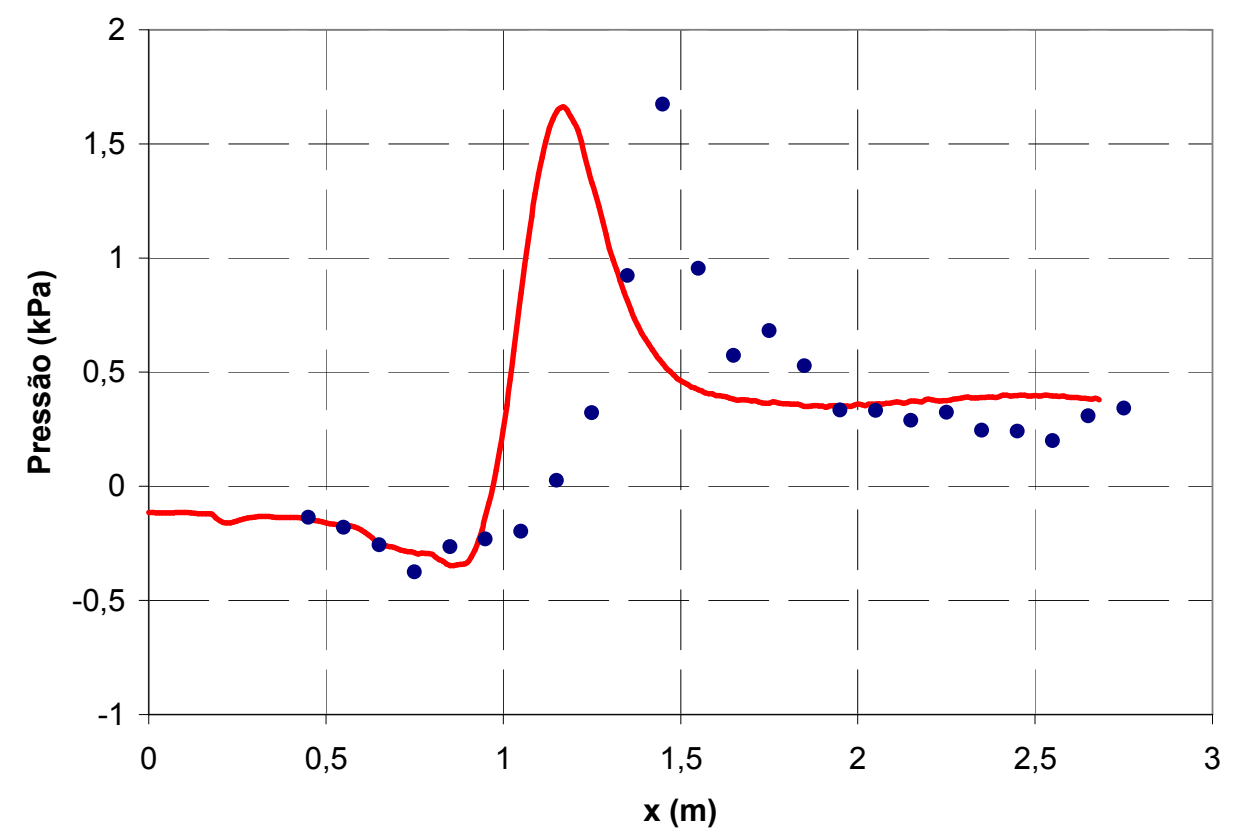

Figura G.2. Pressão Sob o Jato para o Experimento 4. 


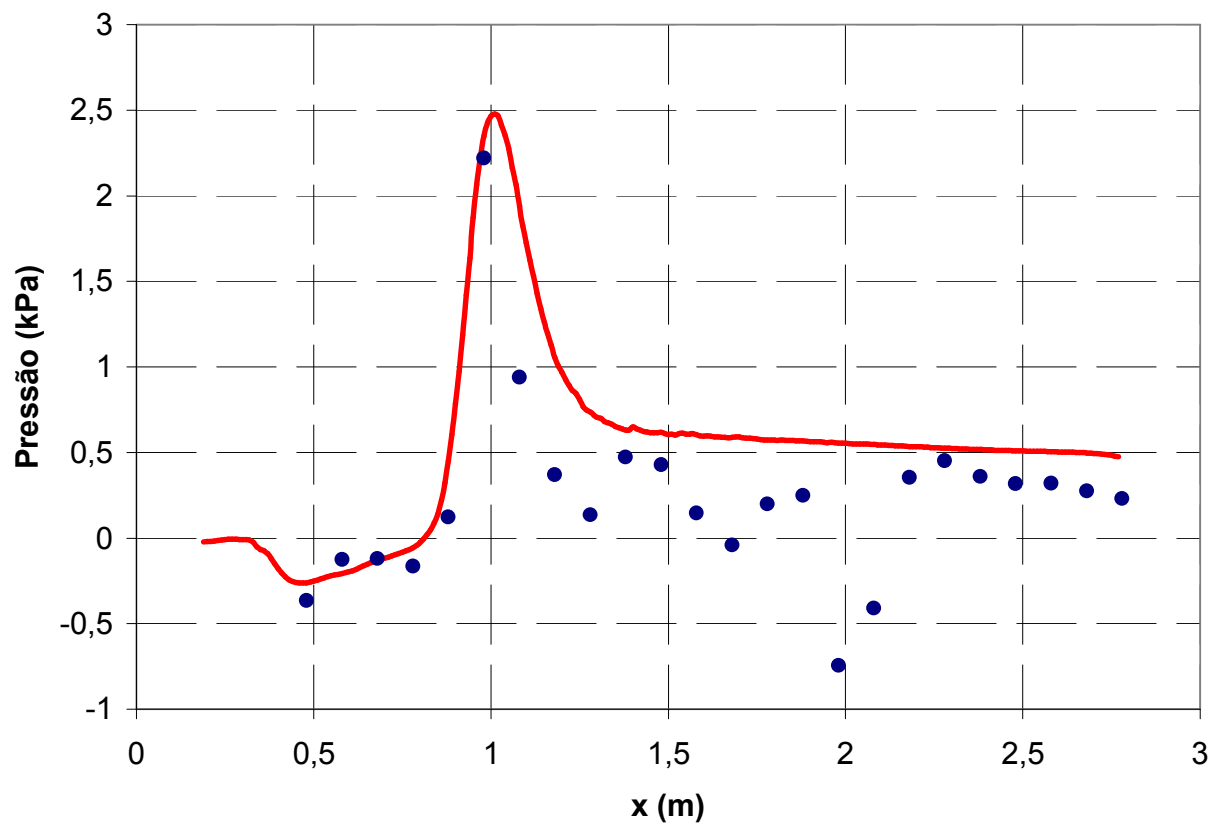

Figura G.3. Pressão Sob o Jato para o Experimento 6.

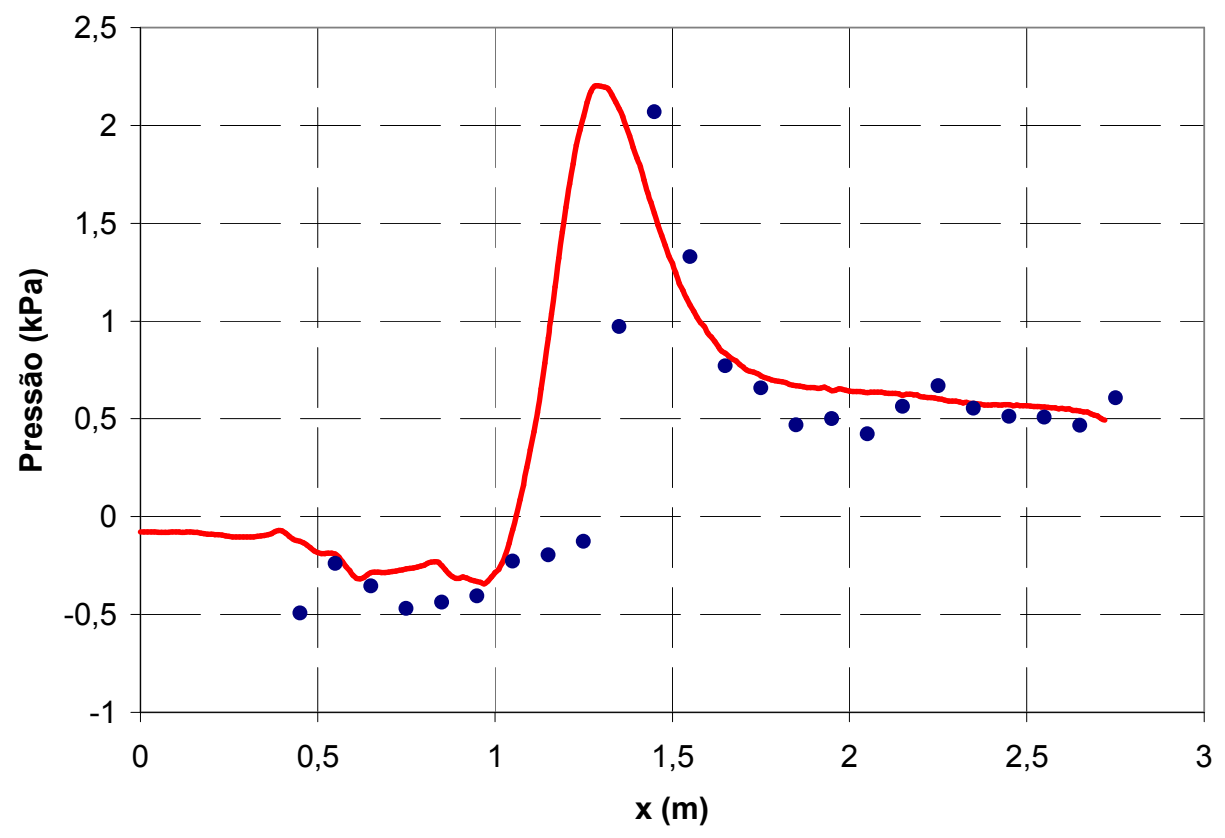

Figura G.4. Pressão Sob o Jato para o Experimento 7. 


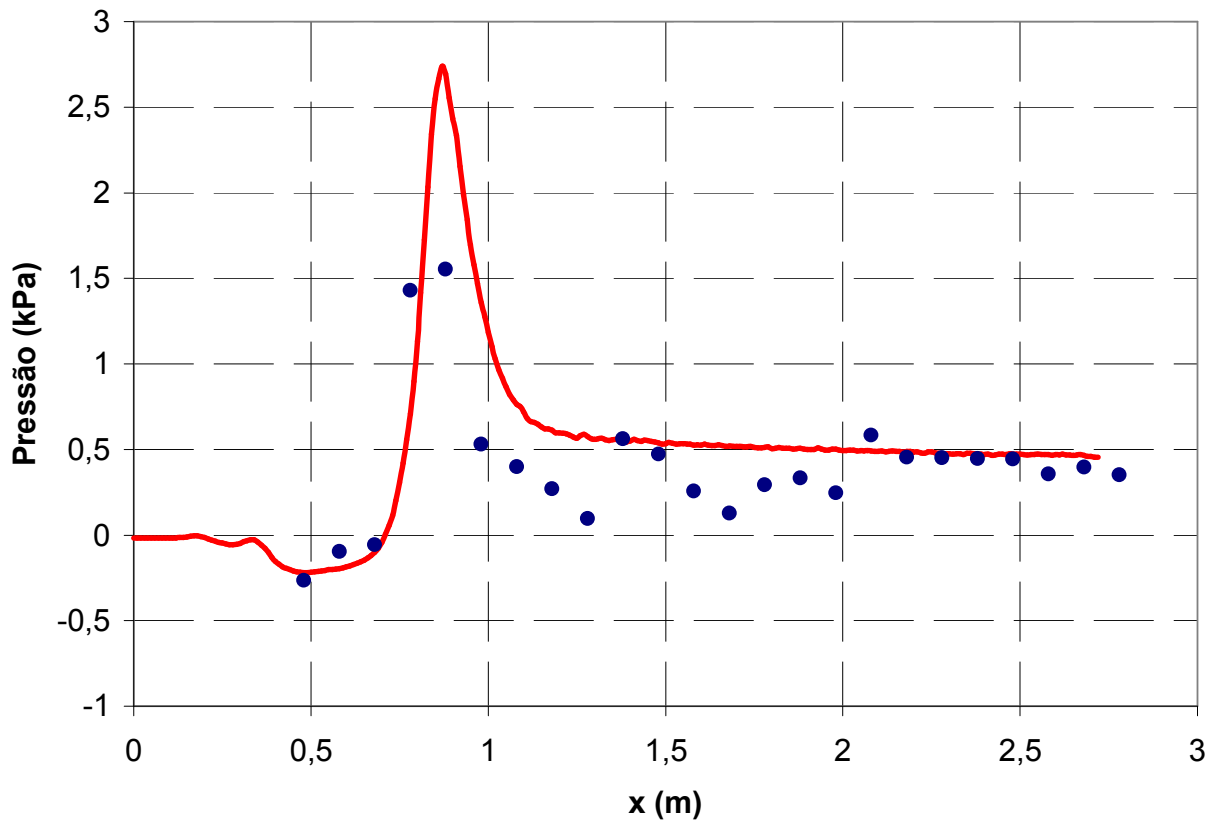

Figura G.5. Pressão Sob o Jato para o Experimento 8.

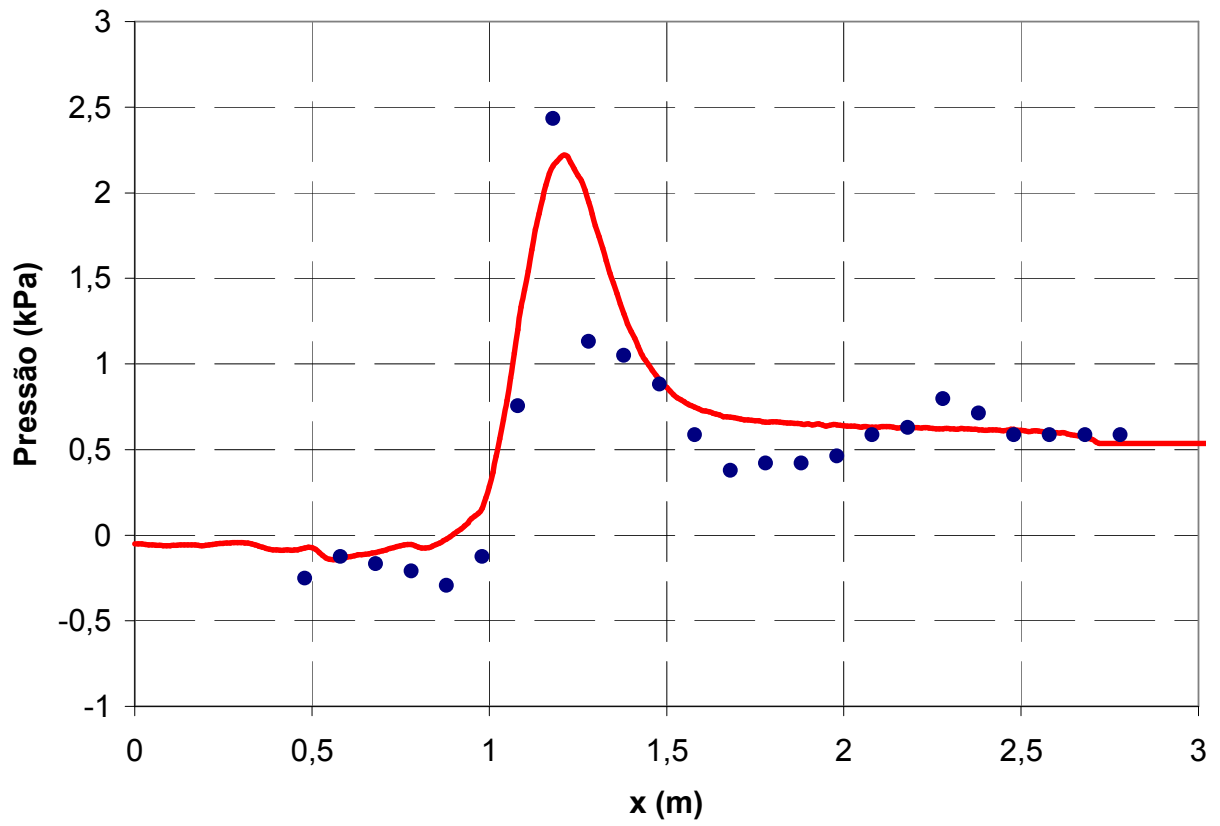

Figura G.6. Pressão Sob o Jato para o Experimento 9. 